ANDREIWID SHEFFER CORREAA

Uma arquitetura de referência colaborativa para estruturação de dados abertos governamentais 


\title{
Uma arquitetura de referência colaborativa para estruturação de dados abertos governamentais
}

\author{
Versão Corrigida \\ (Versão original encontra-se na unidade que aloja \\ o Programa de Pós-graduação)
}

Tese apresentada à Escola Politécnica da Universidade de São Paulo para obtenção do título de Doutor em Ciências.

Área de Concentração: Engenharia de Computação

Orientador: Prof. Dr. Pedro Luiz Pizzigatti Corrêa

Coorientador: Prof. Dr. Flávio Soares Corrêa da Silva 
Este exemplar foi revisado e corrigido em relação à versão original, sob responsabilidade única do autor e com a anuência de seu orientador.

São Paulo, de de

Assinatura do autor:

Assinatura do orientador:

\section{Catalogação-na-publicação}

\section{Corrêa, Andreiwid Sheffer}

Uma arquitetura de referência colaborativa para estruturação de dados abertos governamentais / A. S. Corrêa -- versão corr. -- São Paulo, 2017. $222 \mathrm{p}$.

Tese (Doutorado) - Escola Politécnica da Universidade de São Paulo. Departamento de Engenharia de Computação e Sistemas Digitais.

1.Arquitetura de software 2.Arquitetura de informação 3.Governo eletrônico I.Universidade de São Paulo. Escola Politécnica. Departamento de Engenharia de Computação e Sistemas Digitais II.t. 
Nome: CORRÊA, Andreiwid Sheffer

Título: Uma arquitetura de referência colaborativa para estruturação de dados abertos governamentais

Tese apresentada à Escola Politécnica da Universidade de São Paulo para obtenção do título de Doutor em Ciências.

Aprovado em: 14/02/2017

\section{Banca Examinadora}

Prof. Dr. Pedro Luiz Pizzigatti Corrêa

Instituição: Escola Politécnica da Universidade de São Paulo (EP-USP)

Julgamento: Aprovado

Prof. Dr. Nicolau Reinhard

Instituição: Faculdade de Economia, Administração e Contabilidade da Universidade de São Paulo (FEA-USP)

Julgamento: Aprovado

Prof. Dr. Edison Spina

Instituição: Escola Politécnica da Universidade de São Paulo (EP-USP)

Julgamento: Aprovado

Profa. Dra. Maria Alexandra Viegas Cortez da Cunha

Instituição: Fundação Getúlio Vargas (FGV-SP)

Julgamento: Aprovado

Prof. Dr. Arlindo Flávio da Conceição

Instituição: Universidade Federal de São Paulo (UNIFESP)

Julgamento: Aprovado 
Dedico este trabalho ao meu filho, Felipe, a minha esposa, Matilde, e a minha mãe, Laudina. 


\section{AGRADECIMENTOS}

Agradeço a Deus por me permitir fazer parte deste contexto, onde tenho a oportunidade de avançar na minha instrução.

Agradeço à minha esposa, Matilde, ao meu filho, Felipe, e à minha mãe, Laudina, por me apoiarem. Somente os mais próximos sabem quantos desafios temos que enfrentar para conduzir um trabalho deste porte.

Agradeço aos meus orientadores Prof. Dr. Pedro Luiz Pizzigatti Corrêa e Prof. Dr. Flávio Soares Corrêa da Silva a parceria de sempre.

Agradeço ao meu ex-aluno Evandro de Paula a ajuda na coleta de dados para esta pesquisa. Aos outros meus ex-alunos a participação nos projetos de iniciação científica que conduzi durante $o$ doutorado e cujas as atividades também contribuíram com este trabalho.

Agradeço ao Instituto Federal de Educação, Ciência e Tecnologia de São Paulo (IFSP) por viabilizar diversos mecanismos que contribuem com a qualificação do docente que deseja avançar em seus estudos.

Agradeço à Capes o apoio financeiro parcial que recebi para concluir este projeto de pesquisa.

Agradeço aos colegas, aos professores e aos funcionários do Departamento de Engenharia de Computação (PCS) da Escola Politécnica da USP a atenção prestada durante minha passagem por esta instituição.

Agradeço a todos que não me referi nominalmente aqui a contribuição direta ou indireta para com este trabalho.

Por fim, agradeço a mim mesmo a conclusão de um projeto iniciado há cinco anos atrás, com muito esforço, disciplina e honestidade. 
"Não são as espécies mais fortes que sobrevivem, nem as mais inteligentes, e sim as mais sensíveis à mudança."

Charles Darwin (1809-1882) 


\section{RESUMO}

CORRÊA, Andreiwid Sheffer. Uma arquitetura de referência colaborativa para estruturação de dados abertos governamentais. 2017. 222 f. Tese (Doutorado em Sistemas Digitais) - Escola Politécnica, Universidade de São Paulo, São Paulo, 2017.

O grande número de websites heterogêneos e sem padronização para divulgar informações sobre transparência pública é uma evidência do despreparo das instituições públicas frente ao movimento denominado Open Government Data ou Dados Abertos Governamentais. Este cenário é encontrado no mundo todo, porém com evidência nas instituições onde os princípios de dados abertos ainda são novidade, sobretudo os governos locais. Esta pesquisa objetiva definir uma arquitetura de referência para estruturação de dados a partir dos repositórios distribuídos caracterizados pelos websites de transparência. Os requisitos de qualidade da arquitetura foram identificados a partir dos problemas de disponibilização de dados em uma amostra de 561 websites mantidos por municípios brasileiros. Uma vez definida, a arquitetura passou por um processo de validação para verificar sua viabilidade e seu potencial de utilidade pela percepção dos usuários externos ao seu desenvolvimento e por meio da implementação em um protótipo de software. Com a arquitetura, e seu aspecto colaborativo envolvido, será possível implementar sistemas de software que disponibilizam ferramentas aos usuários para facilmente abrir os dados de qualquer instituição que utilize a internet para disseminar informações de transparência.

Palavras-chave: Transparência. Dados abertos governamentais. OGD. Arquitetura de software. 


\begin{abstract}
CORRÊA, Andreiwid Sheffer. A reference collaborative-oriented architecture for structuring information to open government data. 2017. $222 \mathrm{f}$. Tese (Doutorado em Sistemas Digitais) - Escola Politécnica, Universidade de São Paulo, São Paulo, 2017.

The large number of heterogeneous and non-standardized websites to disseminate information about public transparency is an evidence of the lack of preparation of public institutions in relation to the Open Government Data movement. This scenario is found all over the world, but with more frequency in institutions where open data principles are still new, especially local governments. This research aims to define a reference architecture for structuring data from distributed repositories characterized by transparency websites. The quality requirements of the architecture were identified from the problems of data availability in a sample of 561 websites maintained by Brazilian municipalities. Once defined, the architecture underwent a validation process to verify its viability and its potential of utility by the perception of external users to its development and by the implementation of a software prototype. With the architecture, and its collaborative aspect involved, it will be possible to implement software systems that provide users with tools to easily open data from any institution that uses the internet to disseminate transparency information.
\end{abstract}

Keywords: Transparency. Open Government Data. OGD. Software architecture. 


\section{LISTA DE FIGURAS}

Figura 1 - Escopo e dimensões

Figura 2 - Procedimento metodológico. 28

Figura 4 - Estrutura básica da LAI com seus principais componentes e requisitos...38

Figura 5 - Sistema de cinco estrelas para dados abertos de Tim Berners-Lee .42

Figura 6 - Diagrama de atividade do processo de desenvolvimento da arquitetura ..51

Figura 7 - Camada semântica e suas subcamadas de extração, transformação e carga, persistência e manipulação de dados

Figura 8 - Formato preferencial para divulgação dos dados 65

Figura 9 - Atendimento dos seis itens mínimos de divulgação 66

Figura 10 - Atendimento dos requisitos técnicos estabelecidos na LAI

Figura 11 - (a) Número de websites avaliados e presença de convenção para nomeação de domínios governamentais. (b) Número de websites que tiveram a acessibilidade verificada

Figura 12 - Formatos preferenciais para a divulgação dos documentos de transparência

Figura 13 - Atendimento dos itens mínimos de divulgação para transparência ativa, conforme $\S 1^{\circ}$ do Art. $8^{\circ}$ da LAI

Figura 14 - Atendimento e índice de acessibilidade pelo total de itens mínimos de divulgação

Figura 15 - Atendimento dos requisitos técnicos que os websites precisam atender, conforme $\S 3^{\circ}$ do Art. $8^{\circ}$ da LAl (mapeados na Tabela 5) .80

Figura 16 - Atendimento e índice de acessibilidade pelo total de requisitos técnicos 
Figura 17 - Atendimento e índice de acessibilidade de todos os itens de divulgação avaliados - agrupamento por região

Figura 18 - Atendimento e índice de acessibilidade de todos os requisitos técnicos avaliados - agrupamento por região

Figura 19 - llustração do aspecto colaborativo e seus principais elementos .92

Figura 21 - Diagrama de casos de uso gerais do sistema .95

Figura 22 - Diagrama de expansão do caso de uso UC-1: Consumir dados .97

Figura 23 - Diagrama de expansão do caso de uso UC-2: Fazer estruturação .98

Figura 24 - Diagrama de expansão do caso de uso UC-3: Avaliar estruturação ........99

Figura 25 - Passos e artefatos do Método ADD 101

Figura 26 - Digrama de associações dos balizadores pela meta da iteração colaboração 109

Figura 27 - Elementos - colaboração 110

Figura 28 - Principais classes e relacionamentos - colaboração.

Figura 29 - Sequenciamento dos eventos - colaboração

Figura 30 - Diagrama de associações de seleção dos balizadores pela meta da iteração - estruturação

Figura 31 - Elementos - estruturação

Figura 32 - Modelo lógico de dados do SGBD - estruturação

Figura 33 - Sequenciamento dos eventos do componente Gerenciamento de usuários - estruturação

Figura 34 - Sequenciamento dos eventos do componente Extração - estruturação

Figura 35 - Sequenciamento dos eventos do componente Carregamento e catalogação - estruturação 
Figura 36 - Sequenciamento dos eventos do componente Servidor colaborativo estruturação.

Figura 37 - Diagrama de associações de seleção dos balizadores pela meta da iteração - apresentação

Figura 38 - Elementos - apresentação

Figura 39 - Organização hierárquica do CKAN

Figura 40 - Visão geral da arquitetura expondo a organização de suas camadas, as principais funções e o fluxo de informação.

Figura 41 - Diagrama de sequência expondo a interação no contexto da arquitetura

Figura 42 - Fluxo conceitual do ATAM mapeado com os passos do roteiro do Lightweight Architecture Evaluation 152

Figura 43 - Modelo da Ficha de Análise Arquitetural 154

Figura 44 - Fotografia tirada durante o processo de validação 156

Figura 45 - Identificação de conteúdo tabular dentro de um arquivo PDF utilizando o Tabula

Figura 46 - Quadro-resumo dos componentes utilizados e artefatos produzidos no contexto do protótipo do sistema

Figura 47 - Instância configurada do CKAN com a organização OGD USP Brazil..173

Figura 48 - Protótipo do Portal Colaborativo externado aos usuários 174

Figura 49 - Interface do usuário expondo o processo de estruturação por meio do navegador web com a extensão instalada. (a) Dados tabulares dento de uma página HTML. (b) Dados tabulares dentro de um documento PDF 175 


\section{LISTA DE TABELAS}

Tabela 1 - Mapeamento dos requisitos técnicos definidos no $\S 3^{\circ}$ do Art. $8^{\circ}$ da LAI com os princípios de OGD

Tabela 2 - Benefícios da publicação e consumo de dados abertos por nível do sistema de cinco estrelas de Tim Berners-Lee (ISOTANI; BITTENCOURT, 2015).

Tabela 3 - Sumarização dos problemas em potencial dos formatos PDF e HTML segundo o sistema de cinco estrelas e os princípios de OGD

Tabela 4 - Itens mínimos de divulgação para transparência ativa definidos pela LAI no $\S 1^{\circ}$ do Art. $8^{\circ}$

Tabela 5 - Requisitos técnicos mapeados e definição da descrição sucinta 60

Tabela 6 - Critérios de avaliação para cada requisito técnico 62

Tabela 7 - Municípios pesquisados com a data de levantamento dos dados. Adaptado de Adaptado de Corrêa; Corrêa e da Silva (2014)

Tabela 8 - Resumo dos achados na literatura a respeito da abertura de dados em websites de transparência

Tabela 9 - Total de municípios, universo de interesse e cálculo da amostra por unidade de federação. Base: IBGE (2013). Extraído de Corrêa et al. (2017)

Tabela 10 - Síntese dos principais problemas mapeados na caracterização dos dados abertos nos municípios brasileiros

Tabela 11 - Descrição dos casos de uso gerais do sistema. .95

Tabela 12 - Atributos de qualidade da arquitetura 104

Tabela 13 - Interesses arquiteturais 106

Tabela 14 - Restrições aplicadas à arquitetura 
Tabela 15 - Decisões sobre conceitos de projeto para satisfação dos balizadores colaboração

Tabela 16 - Elementos, responsabilidades e interfaces - colaboração.

Tabela 17 - Análise da meta da iteração - colaboração

Tabela 18 - Decisões sobre conceitos de projeto para satisfação dos balizadores estruturação

Tabela 19 - Elementos, responsabilidades e interfaces - estruturação 122

Tabela 20 - Detalhamento das interfaces - estruturação 123

Tabela 21 - Análise da meta da iteração - estruturação 130

Tabela 22 - Decisões sobre conceitos de projeto para satisfação dos balizadores apresentação

Tabela 23 - Elementos, responsabilidades e interfaces - apresentação 134

Tabela 24 - Detalhamento das interfaces - apresentação 135

Tabela 25 - Análise da meta da iteração - apresentação 137

Tabela 26 - Análise das metas de todas as iterações 138

Tabela 27 - Interações do usuário no contexto da arquitetura 143

Tabela 28 - Roteiro do processo de validação pelo método ATAM do Lightweight Architecture Evaluation. Adaptado de Bass; Clements e Kazman (2012)

Tabela 29 - Definição dos perfis para composição do time de validação. 153

Tabela 30 - Atributos de qualidade da arquitetura priorizados para as fichas de análise arquitetural

Tabela 31 - Decisões arquiteturais levantadas e a categorização após a análise para o cenário \#A1 referente ao atributo QA-2 - Operação colaborativa........158 
Tabela 32 - Decisões arquiteturais levantadas e a categorização após a análise para o cenário \#A2 referente ao atributo QA-3 - Moderação hierarquizada ..159

Tabela 33 - Decisões arquiteturais levantadas e a categorização após a análise para o cenário \#A3 referente ao atributo QA-4 - Avaliação mútua 160

Tabela 34 - Decisões arquiteturais levantadas e a categorização após a análise para o cenário \#A4 referente ao atributo QA-5 - Operação baseada no navegador 161

Tabela 35 - Decisões arquiteturais levantadas e a categorização após a análise para o cenário \#A5 referente ao atributo QA-6 - Autenticação do usuário ....162

Tabela 36 - Decisões arquiteturais levantadas e a categorização após a análise para o cenário \#A6 referente ao atributo QA-7 - Acesso autoconcedido 163

Tabela 37 - Decisões arquiteturais levantadas e a categorização após a análise para o cenário \#A7 referente ao atributo QA-9 - Acesso manual 163

Tabela 38 - Decisões arquiteturais levantadas e a categorização após a análise para o cenário \#A8 referente ao atributo QA-10 - Acesso automatizado ......164

Tabela 39 - Quadro-resumo de pontos identificados no processo de validação .....165

Tabela 40 - Desmembramento dos pontos identificados por usuário 166 


\section{LISTA DE ABREVIATURAS E SIGLAS}

ADD Attribute-Driven Design

API Application Programming Interface

ASC Architectural Separation of Concerns

ASES Avaliador e Simulador de Acessibilidade em Sítios

ATAM Architecture Tradeoff Analysis Method

BAPO Business Architecture Process and Organization

CGU Controladoria Geral da União

CKAN Comprehensive Knowledge Archive Network

CSV Comma-separated values

eMAG Modelo de Acessibilidade em Governo Eletrônico

GPL Affero General Public License

HAP HTML Agility Pack

HTML HyperText Markup Language

HTTP HyperText Transfer Protocol

IBGE Instituto Brasileiro de Geografia e Estatística

JPEG Joint Photographic Experts Group

JSON JavaScript Object Notation

LAI Lei de Acesso à Informação

MIT Massachusetts Institute of Technology

ODS Open Document Spreadsheet

OECD Organisation for Economic Co-operation and Development

OGD Open Government Data

OGP Open Government Partnership

PDF Portable Document Format

PNG Portable Network Graphics

RDF Resource Description Framework

RTF Rich Text Format

RUP4+1 Rational Unified Process $4+1$ views

S4V Siemens' 4 Views

SDK Software Development Kit

SEI Software Engineering Institute 
SGBD Sistema de Gerenciamento de Banco de Dados

SHA Secure Hash Algorithm

TIC Tecnologias e da Informação e Comunicação

UML Unified Modeling Language

URL Uniform Resource Locator

W3C World Wide Web Consortium

WCAG Web Content Accessibility Guidelines

XLS Microsoft Excel Spreasheet

XML Extensible Markup Language

XPath XML Path Language 


\section{SUMÁRIO}

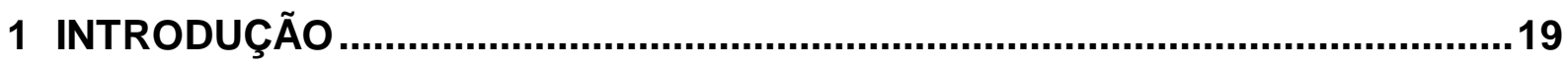

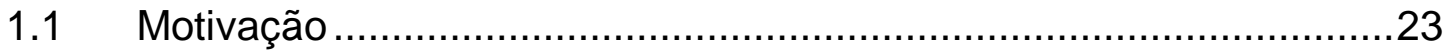

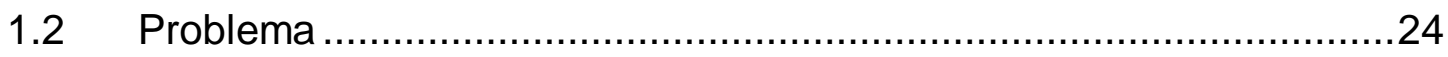

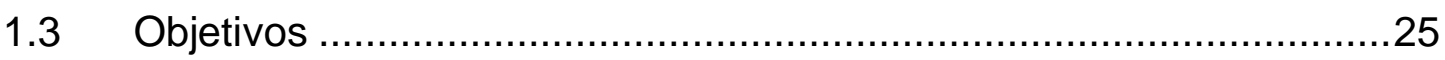

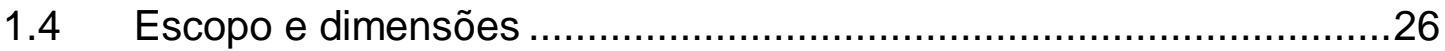

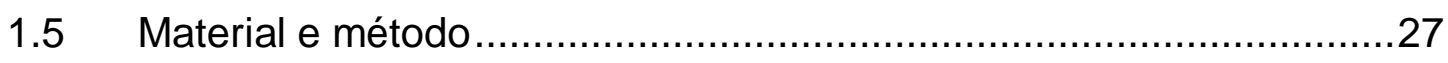

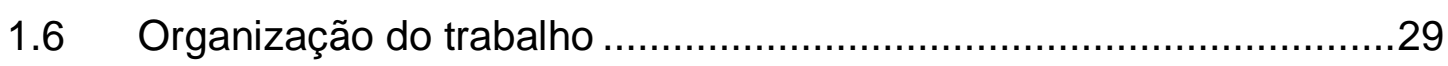

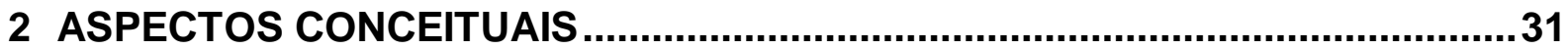

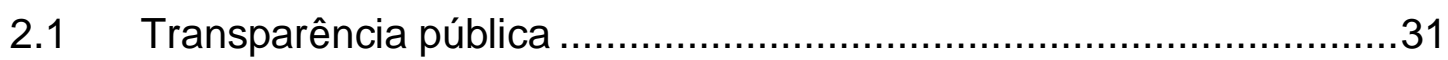

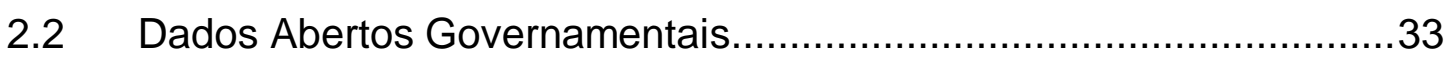

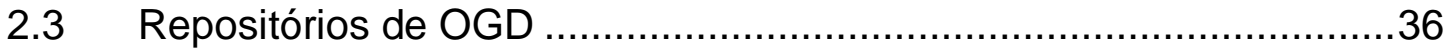

2.4 Direito de acesso à informação .....................................................

2.5 O formato no contexto de dados abertos, dados estruturados $\mathrm{e}$

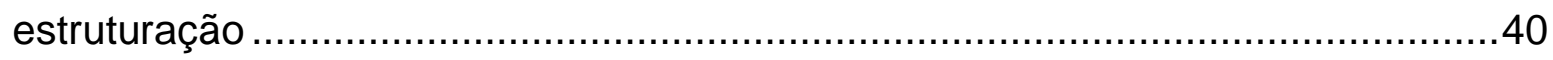

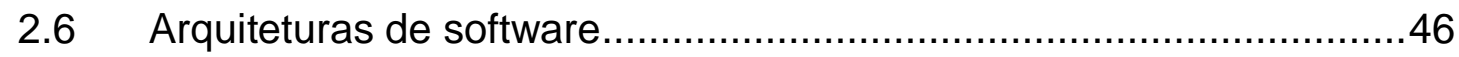

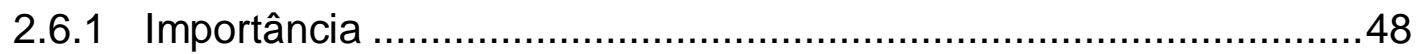

2.6.2 Arquiteturas de referência e arquiteturas concretas.......................50

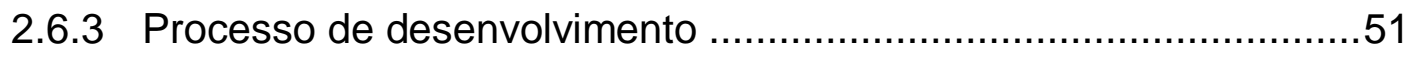

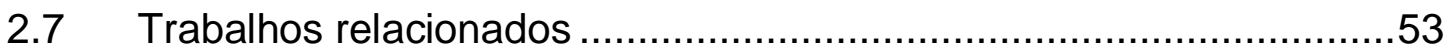




\section{CARACTERIZAÇÃO DOS DADOS ABERTOS NOS MUNICÍPIOS}

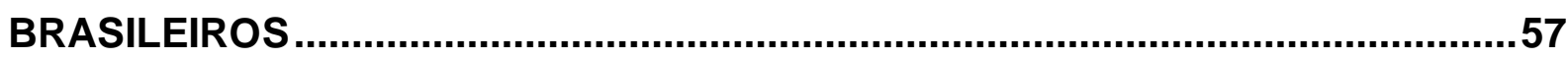

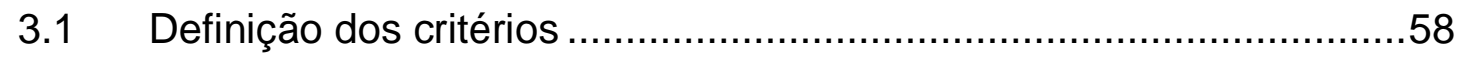

3.2 Levantamento preliminar .........................................................63

3.3 Levantamentos relacionados na bibliografia ................................68

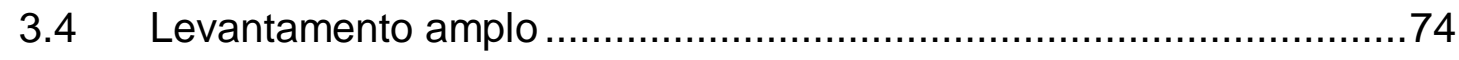

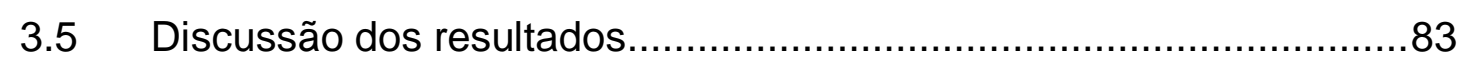

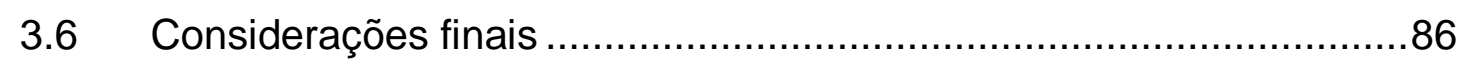

\section{DEFINIÇÃO DA ARQUITETURA DE REFERÊNCIA COLABORATIVA ..............89}

4.1 Modelo de negócio: 0 aspecto colaborativo …................................90

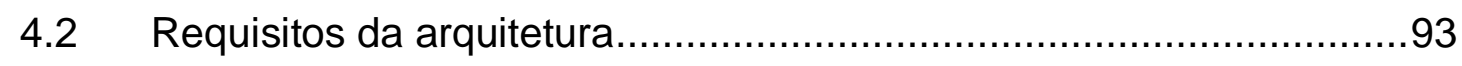

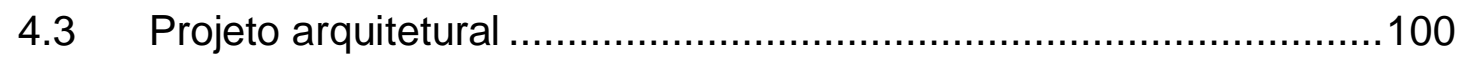

4.3.1 ADD - Passo 1: Revisão das entradas ........................................102

4.3.2 Iteração 1: Estrutura de suporte à colaboração ...........................107

4.3.3 Iteração 2: Estrutura de suporte à estruturação ............................116

4.3.4 Iteração 3: Estrutura de suporte à apresentação dos dados ..........130

4.3.5 Análise das metas das iterações..............................................137

4.4 Documentação da arquitetura ................................................... 139

4.4.1 Visão geral da arquitetura ....................................................139

4.4.2 Camada Apresentação............................................................ 144

4.4.3 Camada Estruturação .......................................................... 144

4.4.4 Camada Colaborativa .........................................................146

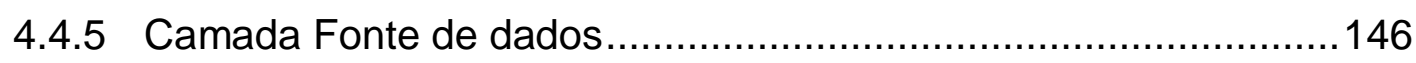




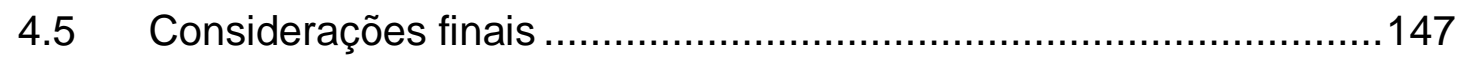

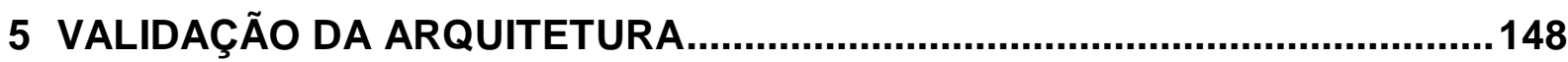

5.1 Método de validação .............................................................149

5.2 Procedimento de validação .......................................................152

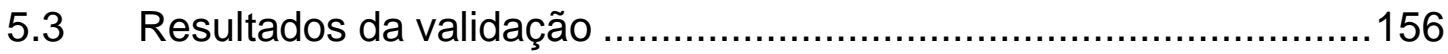

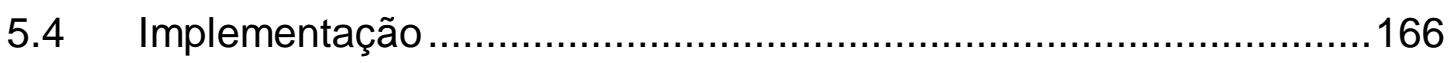

5.4.1 Middleware, Web services e APls .........................................167

5.4.2 Ferramentas de extração de conteúdo tabular............................168

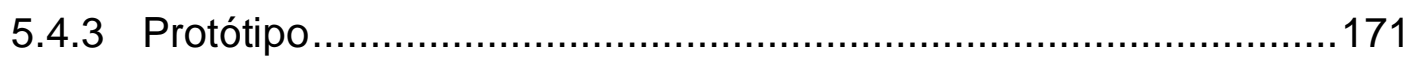

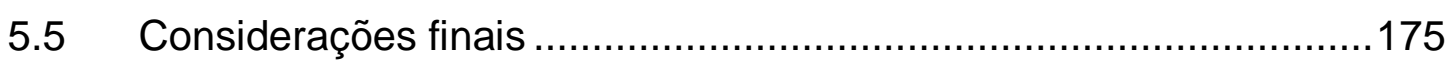

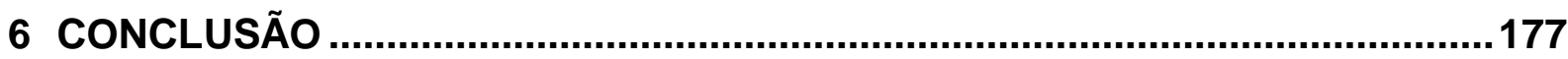

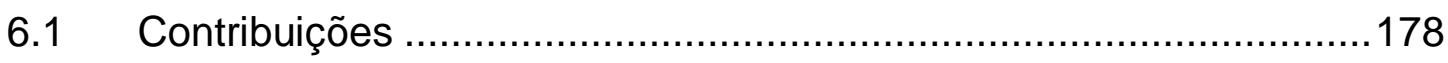

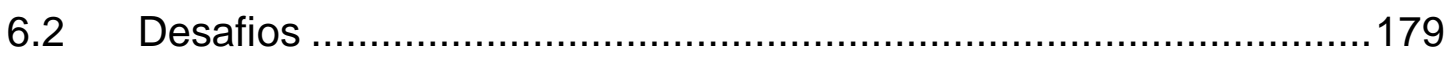

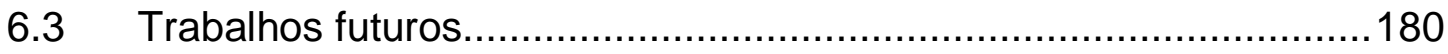

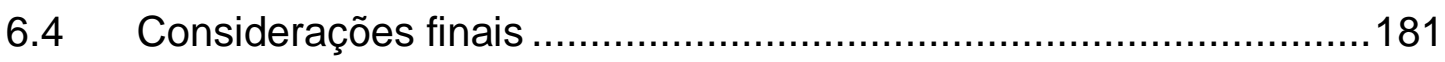

REFERÊNCIAS

APÊNDICE A - Detalhamento da amostra do levantamento amplo..................191

APÊNDICE B - Disponibilidade dos dados do levantamento amplo .................206

APÊNDICE C - Fichas de análise arquitetural geradas no processo de validação

APÊNDICE D - Quadro comparativo de serviços, ferramentas e bibliotecas para extração de dados tabulares 


\section{INTRODUÇÃO}

O uso das Tecnologias da Informação e Comunicação (TICs) vem revolucionando a forma de como a sociedade interage com os governos e participa de suas decisões. Uma corrente que vem à tona e ganha importância na última década é o acesso irrestrito a qualquer tipo de informação pública, viabilizado por infraestrutura específica de dados.

O surgimento de legislações, que visam garantir o processo de acesso às informações desde sua geração até a distribuição irrestrita dos dados, ganha espaço nas democracias modernas e introduz uma diversidade de páginas web ou portais de transparência dedicados ao assunto. (RELLY; SABHARWAL, 2009).

A partir desse contexto, a Internet contribuiu por possibilitar o uso das TICs para, de um lado, disponibilizar eficientemente informação à sociedade e, por outro lado, materializar o interesse dos governos em se tornar mais abertos e dialogar com seus administrados (BERTOT; JAEGER; GRIMES, 2010; OECD, 2003a; PEW RESEARCH CENTER'S INTERNET \& AMERICAN LIFE PROJECT, 2010).

Consequentemente, o movimento denominado Open Government Data (OGD) ou dados abertos governamentais emergiu e estabeleceu uma série de princípios conceituais e técnicos que visam guiar a abertura de registros públicos por intermédio do uso das TICs. Para uma iniciativa ser considerada de acordo com OGD, esta deve seguir certos requisitos para que os dados (provenientes das ações de transparência pública) possam ser livremente usados, reutilizados e redistribuídos por qualquer um, para qualquer propósito (OPEN KNOWLEDGE FOUNDATION, 2012; TAUBERER, 2014).

A disponibilização de dados de acordo com os princípios de OGD aumenta a possibilidade de análise dos registros públicos por permitir o seu acesso sem restrições. Isso tem o potencial para aumentar a participação da sociedade, normalmente representada por críticos na figura de jornalistas, economistas, cientistas políticos e outros especialistas. Desse modo, o desafio desses profissionais estaria direcionado à tarefa de análise dos dados para extrair valor pela 
sua interpretação, e não o tratamento ou processamento técnico para possibilitar a análise.

Por este motivo, Barack Obama, em seu primeiro dia como Presidente dos Estados Unidos, emitiu um memorando intitulado "Transparency and Open Government" (OBAMA, 2009), no qual expressou sua intenção e compromisso em administrar seu governo com nível sem precedentes de transparência. Este compromisso anunciou a implementação de OGD no governo norte americano com o uso extensivo das TICs para sua consecução e, de certo modo, foi um propulsor para demais governos fazerem o mesmo.

Em 2011 houve outro importante passo em direção à abertura dos registros públicos com a Open Government Partnership (OGP). A OGP é um acordo multilateral onde países são convidados a estabelecer ambiciosas reformas em favor da abertura dos governos e transparência pública. O Brasil foi um dos oito países fundadores do acordo. Em 2016, esse número cresceu para 70 países que fazem parte da parceria.

O principal desdobramento da participação do Brasil na OGP foi o desenvolvimento e implementação da Lei de Acesso à Informação (LAI) - Lei Federal n 12.527/2011, sancionada em novembro de 2011 (BRASIL, 2011). Esta lei estabeleceu um marco legal para regular e garantir o acesso à informação pela sociedade, que inclui a transparência pela disponibilização de dados e uso da internet. A LAI é aplicada em todas as esferas de governo e poderes definidos na constituição brasileira.

Além do Brasil, um estudo proposto por Relly e Sabharwal (2009) apresenta uma pesquisa com 122 países, dos quais 48\% adotam leis de transparência e acesso à informação. A adesão de vários países à OGP e a adoção de leis de transparência ao redor do mundo mostram uma tendência em prol da abertura de registros públicos como marca das democracias modernas.

Mesmo considerando estes importantes avanços, ainda há muito que se fazer para materializar os acordos e legislações existentes em benefícios para a sociedade. No Brasil, por exemplo, tendo em vista suas dimensões continentais e sua organização política, a adaptação à LAI ainda é um desafio que está na pauta 
das administrações. Um de seus principais requisitos é a denominada transparência ativa, a qual determina a divulgação regular de certos itens de transparência e seguindo requisitos técnicos que envolvem os princípios OGD.

Nesse sentido, um dos principais problemas que se coloca para o efetivo atendimento da legislação de transparência, e como consequência os princípios de OGD, são as limitações técnicas impostas pelos atuais mecanismos de disponibilização de dados. Isto se acentua no âmbito dos governos locais, pois a existência de mais de 5.570 municípios (IBGE, 2016) autônomos é um indicativo de que as ações relacionadas à transparência e disponibilização de dados são implementadas de forma independente e heterogênea, sem padronização e completo entendimento do que deve ser feito, principalmente em termos técnicos para o uso das TICs. Ademais, faz-se necessário colocar em prática a cultura da informação (CGU, 2011) com vários potenciais benefícios para a sociedade.

Como resultado, presencia-se a proliferação de websites dedicados à transparência que são repositórios de documentos semelhantes a relatórios impressos, normalmente viabilizados por meio do Portable Document Format (PDF) e do HyperText Markup Language (HTML) (CORRÊA; CORRÊA; SILVA, 2014). Enquanto a bibliografia aponta que as TICs são cruciais para aumentar a transparência de um governo, percebe-se que há grandes desafios, maiores ainda nos governos locais (COELHO et al., 2015). Um estudo da Fundação Getúlio Vargas revela que a publicação de dados governamentais em formato aberto no Brasil ainda é pouco efetiva. Apenas 29,6\% das unidades federativas brasileiras disponibilizam dados em formato aberto de forma estruturada. Este número é menor ainda quando a esfera de análise é a municipal. Considerando as capitais brasileiras e os municípios acima de 400 mil habitantes, apenas 14,75\% possuem dados abertos em portais próprios ou sistematizados em portais de transparência, sendo que a grande maioria $(77,8 \%)$ é referente às capitais nacionais, melhor equipadas com recursos e corpo técnico (CUNHA et al., 2015).

Assim, o acesso irrestrito aos dados fica comprometido, tendo em vista as limitações técnicas impostas pelos formatos não abertos ou com conteúdo desestruturado, principalmente o processamento automatizado por máquina. 
A partir desse cenário, o objetivo desta pesquisa foi a definição de uma arquitetura de referência para possibilitar a estruturação de documentos dispostos nos repositórios de transparência existentes, com intuito de torná-los irrestritamente acessíveis para a crítica especializada sem as barreiras técnicas que impõem o tratamento e o processamento de formatos. Parte-se do princípio que as informações de transparência continuarão sendo divulgadas da forma que estão, pois a maturidade dos governos frente aos princípios de OGD demandará tempo de seus administradores e será pautada pela evolução natural determinada pela própria sociedade. Uma arquitetura de referência viabilizará a implementação de sistemas para a consistência dos dados de transparência e seu funcionamento não interferirá na geração da informação, mas tão somente na disponibilização segundo os princípios de OGD para acesso irrestrito por qualquer um e para qualquer finalidade.

A arquitetura pauta-se na atuação colaborativa dos interessados e entusiastas da comunidade de dados abertos, de modo especial jornalistas, analistas políticos e economistas. Isso significa que sua ampla utilização terá como catalisador a atuação de pessoas fora da administração para contribuir com a estruturação distribuída dos dados, sem excluir a possibilidade da própria administração obter seus benefícios. Uma vez estruturados, os dados serão disponibilizados em repositório compatível com os princípios de OGD para consumo de outros interessados. A característica colaborativa da arquitetura viabiliza mecanismos de avaliação e classificação, com intuito de formar uma rede de mediação das contribuições realizadas pelos próprios contribuidores.

Esta pesquisa leva em consideração os problemas enfrentados nos municípios brasileiros como base de análise para definição da arquitetura. Para isso, também faz parte deste trabalho a caracterização dos dados abertos nos municípios brasileiros obtida de uma amostra de 561 websites municipais, com intuito de levantar os formatos adotados e os principais problemas acerca do acesso e disponibilização do ponto de vista de dados abertos. 


\subsection{Motivação}

A motivação deste trabalho está pautada na afirmativa de que a informação empodera a sociedade para a construção de melhores governos. Assim, a sociedade, na figura de representada, possa cobrar melhores resultados de seus representantes.

Considerando que no atual contexto nossa sociedade é nutrida com informações viabilizadas pela transparência pública, fazê-la em consonância com os princípios de OGD e atendendo a todos os seus requisitos técnicos traz possibilidades para o acompanhamento, a participação e a fiscalização das contas públicas.

Mais especificamente, outros pontos motivadores desta pesquisa são:

- O potencial de uso dos repositórios de OGD para disponibilização dos dados em múltiplos formatos, de forma automatizada e sem qualquer restrição de reuso;

- A comunidade que necessita de informações sobre transparência pública como jornalistas, cientistas políticos, especialistas em administração pública e demais profissionais contribuem mais quando focam no trabalho de análise de dados, em vez de se preocupar com seu processamento, conversão e organização;

- A atuação colaborativa e o poder das contribuições distribuídas para estruturação de dados ampliam 0 acesso às informações de transparência;

- A estruturação e abertura dos dados realizada pela sociedade, antes mesmo dos governos, ajuda a impulsionar mudanças estruturais na administração pública para que esta considere os princípios de OGD desde a geração do dado nos sistemas e processos de trabalho;

- O potencial de uso de OGD para gerar negócios; 
- O potencial de OGD para contribuir para a melhoria da administração pública em estabelecer reuso e compartilhamento de dados entre o governo e o setor produtivo.

\subsection{Problema}

A transparência pública, apenas pela disponibilização indiscriminada de documentos na internet, não torna a iniciativa eficaz a ponto de inserir o cidadão como verdadeiro partícipe dos governos e, assim, extrair o ganho social esperado.

Significa que o acesso, a interpretação e o aproveitamento do conteúdo dos documentos dependem (1) da forma como é gerado e (2) da capacidade de seus destinatários em manipulá-lo. A geração de documentos em formatos fechados, de difícil manipulação, sem padronização e que não consideram seu reaproveitamento, compromete a interoperabilidade. $O$ consumo das informações, por conseguinte, fica prejudicado quando o conteúdo do documento é direcionado somente a humanos, pois limita os mecanismos de análise automatizada fornecidos pelos sistemas da informação modernos (CGI.BR, 2011a, 2011b).

Nessa problemática, insere-se a administração pública e seus meios de transparência que impõem limitações técnicas para o livre uso e reuso dos dados por qualquer um e para qualquer propósito. No Brasil, por exemplo, a complexidade organizacional e sua divisão política são desafios para ações orquestradas para o efetivo atendimento dos princípios de OGD. Apenas para ilustrar, segundo o Instituto Brasileiro de Geografia e Estatística - IBGE (IBGE, 2016), existem 5.570 municípios divididos nas 26 unidades de federação. A Constituição Brasileira coloca os municípios e estados como entes independentes e autônomos, podendo suas administrações empregar os meios que desejarem na adoção de sistemas da informação. Assim, quando da publicação de dados com fins de transparência pública, opta-se por uma diversidade de sistemas e formatos, que vão desde repositórios de documentos desestruturados do ponto de vista da automatização, como PDFs e HTMLs, até páginas com anotações semânticas indicadas para disponibilização avançada de dados abertos. A preferência por documentos 
desestruturados é dominante e motivada pela simplicidade e semelhança ao relatório impresso.

Além da complexidade organizacional, há também questões culturais que influenciam na disponibilização das informações públicas. A cultura do segredo (CGU, 2011), em oposição à cultura do acesso, ainda encontra espaço na administração pública. Esta cultura baseia-se no princípio que a circulação de informações representa riscos, pois quanto mais se sabe mais vulnerável fica por possibilitar o questionamento das ações. Em oposição, a cultura do acesso está pautada na premissa que a informação pública pertence ao cidadão, que o estado tem o dever de provê-la para atender os anseios da sociedade. Com o avanço das legislações que regem a transparência pública e a disponibilização de dados, o livre acesso à informação pública passou a ser regra. Já seu ocultamente, a exceção (CGU, 2011).

É de se notar que os problemas atualmente enfrentados para viabilizar a transparência pública contrastam com o interesse do cidadão neste tipo de informação. Uma pesquisa conduzida no final de 2009 nos Estados Unidos, com 2.258 adultos com mais de 18 anos, revelou que $40 \%$ das pessoas buscam e acessam dados de transparência pública pela internet (PEW RESEARCH CENTER'S INTERNET \& AMERICAN LIFE PROJECT, 2010). Este número mostra que o interesse do cidadão é significativo frente às atitudes positivas dos governos em prol da disponibilização de dados sobre transparência pública.

\subsection{Objetivos}

O objetivo desta pesquisa é definir uma arquitetura de referência colaborativa para estruturação de informações de transparência pública, à luz dos dados abertos governamentais.

Para alcançar o objetivo proposto nesta pesquisa, estão sendo considerados os seguintes objetivos específicos:

- Definir método para levantamento e identificação dos problemas de acesso e disponibilização de dados abertos; 
- Construir projeto arquitetural como referência para um sistema de estruturação de dados;

- Validar os atributos de qualidade da arquitetura pela percepção de utilidade dos potenciais usuários.

\subsection{Escopo e dimensões}

Esta pesquisa se insere no escopo de arquiteturas de referência, especificamente no domínio de dados abertos governamentais, cuja principal contribuição é a definição de uma arquitetura para estruturação de dados.

Faz-se necessário ressaltar que a contribuição deste trabalho se desdobra em três diferentes dimensões a partir de seu escopo, conforme ilustrado na Figura 1 a seguir.

Figura 1 - Escopo e dimensões

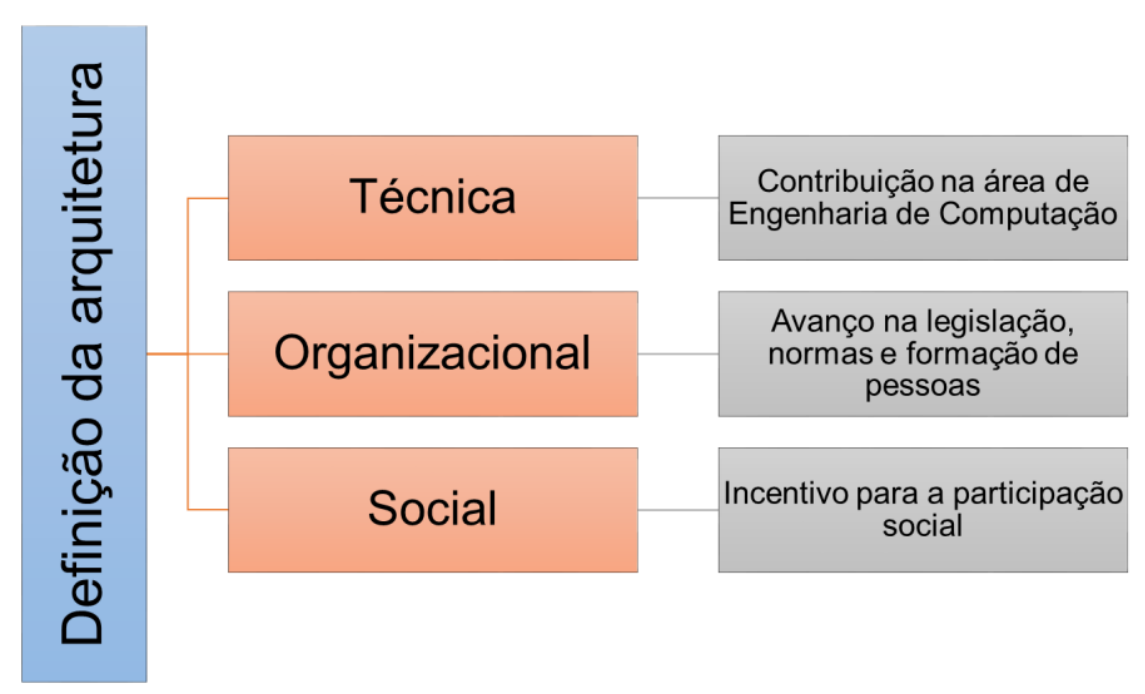

Fonte: Elaborado pelo autor.

Na dimensão Técnica, tem-se a principal contribuição deste trabalho dentro da área de conhecimento Engenharia de Computação. A definição da arquitetura avança no estado da arte por desenvolver um modelo de solução para a problemática de disponibilização de dados, mesmo quando as fontes ainda não se encontram adequadas segundo os princípios de OGD. Este trabalho produz e 
evidencia, por meio da formalização de artefatos, os elementos necessários para o desenvolvimento de um sistema com base na arquitetura.

$\mathrm{Na}$ dimensão Organizacional, este trabalho propõe modelos de trabalho contendo regras, elementos e relações que subsidiam a elaboração, o aprimoramento e a aplicação da legislação e normas relacionadas a dados abertos. Ademais, tem-se um meio de comunicação com seus destinatários para promover a formação de pessoas no âmbito dos governos, pois estes podem ser subsidiados pelo conhecimento produzido por esta pesquisa.

Na dimensão Social, este trabalho incentiva a participação da sociedade por meio das ferramentas que podem ser implementadas pela instanciação da arquitetura definida nesta pesquisa. O público interessado na temática de dados abertos tem em mãos mecanismos para fiscalizar os registros públicos e assim verificar se o retorno social esperado está sendo atingido.

\subsection{Material e método}

O procedimento metodológico utilizado neste trabalho foi composto pelas atividades sumarizadas na Figura 2. 
Figura 2 - Procedimento metodológico

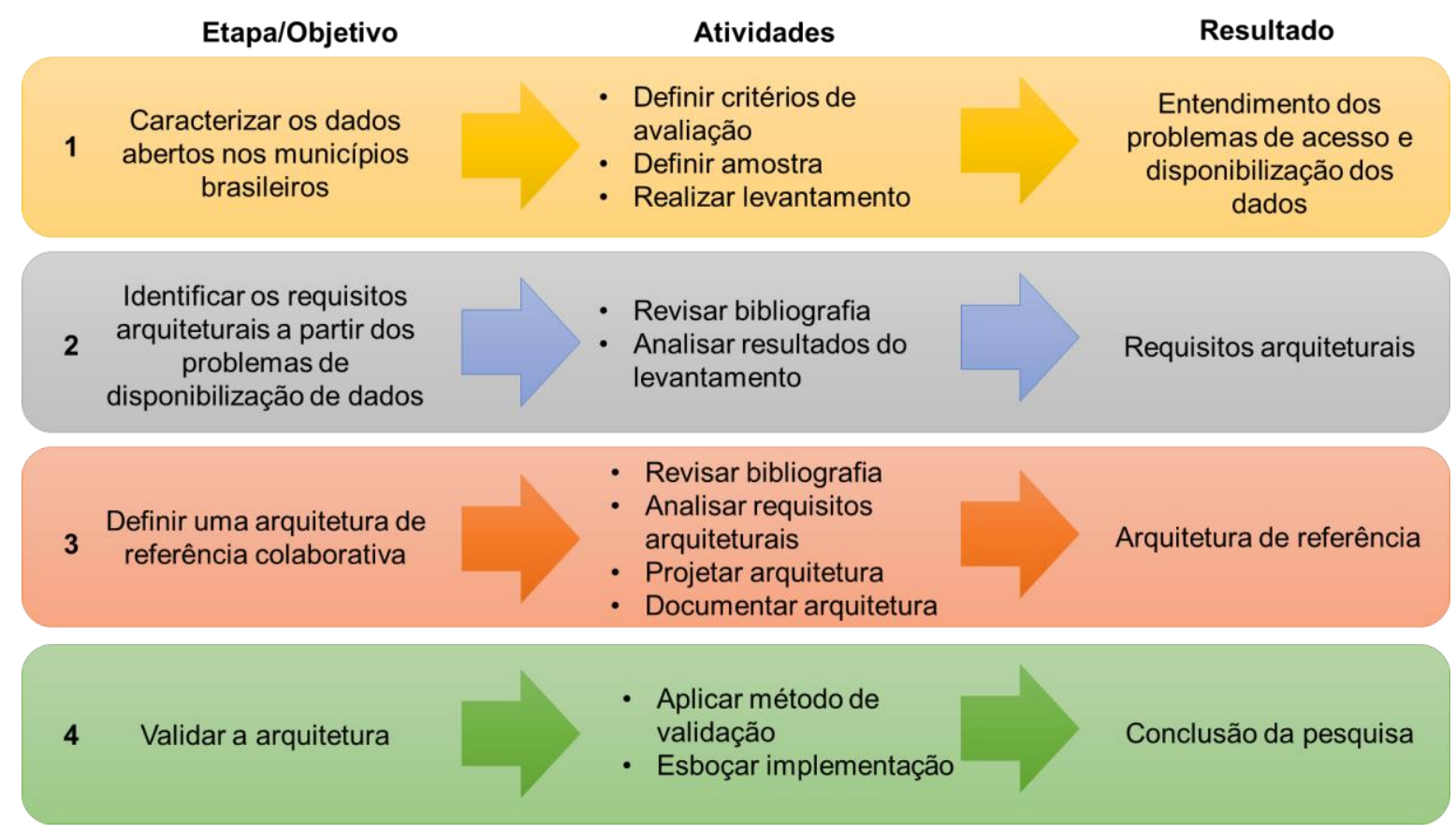

Fonte: Elaborado pelo autor.

Primeiramente, conduziu-se a caracterização dos dados abertos nos websites de transparência mantidos pelos municípios brasileiros por meio de um levantamento amostral. Dentre as atividades, foi definido o método de levantamento com o estabelecimento dos critérios de avaliação e a definição da amostra a ser considerada. Por conseguinte, foi realizado o levantamento que consistiu de visitas manuais aos websites dos municípios. As visitas ocorreram entre o período de 25/04/2014 a 09/12/2014, assim os resultados obtidos têm como base um instantâneo da disponibilidade dos registros durante o momento do levantamento. Esta etapa resultou no entendimento dos problemas de acesso e disponibilização dos dados.

A partir dos achados obtidos com o levantamento, conduziu-se a identificação dos requisitos arquiteturais a partir dos problemas de acesso e disponibilização dos dados. Dentre as atividades, foi realizada a revisão da literatura sobre OGD, trabalhos relacionados, legislação de transparência e sistemas baseados na colaboração. 
A etapa seguinte consistiu da definição da arquitetura de referência compreendendo os elementos de software e as relações entre eles, assim como suas propriedades e tendo como modelo de negócio a atuação colaborativa da sociedade. Dentre as atividades, foi realizada a revisão da bibliografia sobre o Método Attribute-Driven Design (ADD) para desenvolvimento de arquiteturas. Com isso, procedeu-se o projeto arquitetural e a documentação da arquitetura.

A última etapa consistiu da validação da arquitetura com base em seus requisitos de qualidade. Dentre as atividades, foi realizada a revisão da bibliografia sobre o Método Architecture Tradeoff Analysis Method (ATAM) para validação de arquiteturas de software por meio de sessões de avaliação com os potenciais stakeholders ${ }^{1}$, além de proposto um protótipo com base na arquitetura definida.

\subsection{Organização do trabalho}

Este documento possui seis capítulos que organizam e detalham o desenvolvimento da pesquisa.

O Capítulo 2 apresenta os aspectos conceituais que introduzem a temática da pesquisa relacionada a OGD e seu impacto frente às ações de transparência pública operados no Brasil e no mundo. São abordados conceitos de arquitetura de software e sua relevância dentro da engenharia de computação.

O Capítulo 3 descreve a caracterização dos dados abertos nos municípios brasileiros essencialmente a partir da avaliação de uma amostra ampla de websites, além de incluir revisão bibliográfica para identificar avaliações semelhantes no cenário nacional e internacional a respeito do uso de dados abertos pelas instituições governamentais.

O Capítulo 4 apresenta o processo de definição da arquitetura como principal contribuição deste trabalho. São desenvolvidos e detalhados o modelo de negócio baseado na colaboração, os requisitos que retratam a realidade do negócio, o projeto arquitetural e a documentação da arquitetura.

\footnotetext{
${ }^{1}$ Neste trabalho, stakeholder é traduzido como "partes interessadas" em um determinado projeto. Este termo é utilizado em diversas áreas como gestão de projetos, administração e engenharia de software. https://pt.wikipedia.org/wiki/Stakeholder. Acesso em: 03/04/2016.
} 
O Capítulo 5 discute o processo de validação da arquitetura definida neste trabalho e o protótipo de implementação que é parte do processo de instanciação com base na arquitetura.

O Capítulo 6 destaca as contribuições deste trabalho, os desafios enfrentados ao longo da pesquisa e os trabalhos futuros visualizados.

Por fim, relacionam-se as referências utilizadas neste trabalho e os apêndices que são parte integrante desta pesquisa. 


\section{ASPECTOS CONCEITUAIS}

Neste capítulo são apresentados os principais conceitos que embasaram o desenvolvimento deste trabalho, assim como a relação entre os tópicos e a área de aplicação da pesquisa.

\subsection{Transparência pública}

Iniciativas de transparência pública emergiram nos últimos anos como um caminho para possibilitar a participação da sociedade na administração dos governos e acompanhamento das políticas públicas. Muitos países têm adotado leis de acesso à informação para uniformizar a divulgação dos registros públicos e seus mecanismos de acesso, normalmente por intermédio da internet como principal meio de disseminação (RELLY; SABHARWAL, 2009).

A instituição Organisation for Economic Co-operation and Development-OECD (OECD, 2003a) considera a transparência o principal elemento para construir um governo aberto, definindo-a como "confiável, relevante e com informações atualizadas sobre as atividades dos governos que são disponibilizadas ao público".

Exemplos de transparência pelos governos não são recentes. Tem-se registros de publicação em 1953 com relatórios compreensivos evidenciando leis e decisões judiciais a respeito do direito ao acesso à informação (BOTEIN; CROSS, 1954). A definição do termo transparência, no entanto, não é unânime na literatura (RELLY; SABHARWAL, 2009). Prefere-se a definição de transparência como o grau no qual a informação é colocada à disposição de pessoas de fora da administração pública, com o objetivo de que essas pessoas possam influenciar em suas decisões (FLORINI, 2007).

A transparência pública é normalmente associada a leis de acesso à informação que disciplinam sua implementação e operacionalização. Uma pesquisa conduzida por Relly e Sabharwal (2009) faz uma digressão dos países que possuem as mais antigas leis que mencionam a transparência, como Suécia (1766), Finlândia (1951), Dinamarca (1964) e Estados Unidos (1966). O mesmo estudo também 
identificou que $48 \%$ dos 122 países pesquisados adotaram leis de transparência, sendo que $46 \%$ deles as adotaram após o ano 2000.

Esse crescimento na legislação sobre acesso à informação apoia-se na popularização da internet e na consolidação das ações de governo eletrônico, as quais são caracterizadas pela entrega de serviços governamentais por meio das TICs (OECD, 2003b). As leis de acesso à informação direcionam o uso das TICs como meio primário para atingir a transparência, normalmente pela disponibilização de portais ou sites dedicados à divulgação de registros públicos (BERTOT; JAEGER; GRIMES, 2010). Assim, a Internet revolucionou a maneira como os governos e sociedade interagem, trazendo novas perspectivas e recursos para a eficiência governamental. Percebe-se, como uma sistemática, que quanto mais informação é disponibilizada, mais a sociedade tende a confiar nos seus representantes, o que gera uma grande demanda pela informação (JETZEK; AVITAL; BJORN-ANDERSEN, 2014; O'HARA, 2012; REINHARD; GERMANO, 2016).

A demanda da sociedade pela transparência e a tendência dos governos em disponibilizar seus registros também trouxeram uma nova preocupação: os governos optaram por implantar seus próprios silos de dados e disseminá-los pela internet por meio de websites heterogêneos. Esta abordagem faz com que a integração e o acesso universal fiquem comprometidos, pois cada ente governamental é responsável pelo desenvolvimento de seus próprios mecanismos de disseminação da informação. O problema é acentuado no contexto dos governos locais, dado que a diversidade e autonomia dos entes contrastam com a padronização tecnológica (ARMSTRONG, 2011).

Neste contexto, portanto, soluções para o possibilitar a transparência de modo colaborativo, eficiente e integrado surgiram no horizonte, as quais são construídas nos avanços impulsionados pela Web 2.0 e dados abertos governamentais (BONSÓN et al., 2012; MENDOZA, 2013).

No entanto, cabe ponderar alguns efeitos negativos da disponibilização de informações principalmente quando afetam a segurança nacional e os direitos individuais. 
Em maio de 2013 foi divulgado por Edward Snowden a exposição de 1,7 milhão de documentos contendo programas secretos conduzidos pelo governo norte americano contra seus próprios cidadãos, outros países e vários líderes mundiais (VERBLE, 2014). Apesar de ter sido um vazamento não autorizado de informações sensíveis, o episódio trouxe à tona a preocupação com a divulgação indiscriminada de dados de posse de entidades governamentais.

Mais especificamente sobre dados abertos, Zuiderwijk e Janssen (2014) discutem os efeitos negativos de OGD a partir dos achados de uma pesquisa com representantes do setor público. A pesquisa resultou em uma lista com 16 potenciais fatores que impactam negativamente quando da disponibilização de dados pelos governos. Entre eles, cabe destacar a dificuldade de se estabelecer a propriedade sobre os dados, sua má interpretação ou mau uso, a desvantagem em tomar decisões com base em informação de baixa qualidade e o desperdício de recursos com a disponibilização de dados sem necessidade.

\subsection{Dados Abertos Governamentais}

Seguindo o raciocínio proposto pela OECD (2003a), a transparência é o principal elemento para caracterizar um governo aberto. O substrato primário da transparência são os dados (ou informações) por ele produzidos. Assim, as iniciativas de transparência podem ser consideradas o motor propulsor para a popularização de dados abertos governamentais (TAUBERER, 2014).

Em termos formais, para formatar e conceituar OGD, um grupo de trabalho de 30 pessoas promoveu um encontro em 2007 na Califórnia para desenvolver o que foi chamado de Oito Princípios de Dados Abertos Governamentais, os quais se tornaram um parâmetro para avaliar as iniciativas de OGD (TAUBERER, 2014). Esses princípios são historicamente resgatados e disseminados pelo site opengovdata.org (OPENGOVDATA, 2007) e são reproduzidos a seguir:

1. Completos - Os dados devem ser completos (Data must be Complete). Todos os dados públicos devem estar disponíveis. Dados públicos não podem estar sujeitos a limitações de privacidade, segurança ou controle de acesso. 
2. Primários - Os dados devem ser primários (Data must be Primary). Os dados são apresentados como coletados na fonte com o maior nível de granulidade possível, sem agregação ou modificação.

3. Atuais - Os dados devem ser atuais (Data must be Timely). Os dados devem ser disponibilizados tão logo quanto necessário para preservar seu valor.

4. Acessíveis - Os dados devem ser acessíveis (Data must be Acessible). Os dados devem ser disponibilizados ao maior público possível para as mais diversas finalidades.

5. Processáveis por máquina - Os dados devem ser processáveis por máquina (Data must be Machine Processable). Os dados são razoavelmente estruturados para permitir o processamento automatizado.

6. Não discriminatórios - Os dados devem ser de acesso não discriminatório (Access must be Non-Discriminatory). Os dados devem ser disponíveis a todos, sem que seja necessário identificação ou registro.

7. Não proprietários - Os dados devem ser não proprietários (Data formats must be Non-Proprietary). Os dados devem estar disponíveis em um formato sobre o qual nenhum ente tenha controle exclusivo.

8. Livres de licença - Os dados devem ser livres de licença (Data must be License-free). Os dados não devem estar sujeitos a regulações de direitos autorais, marcas, patentes ou segredo industrial. Restrições razoáveis de privacidade, segurança e controle de acesso podem ser permitidas na forma regulada por estatutos.

Adicionalmente, a bibliografia indica a existência de três leis que regem OGD. Estas leis foram propostas pelo ativista em governo aberto Eaves (EAVES, 2009) e, de algum modo, incorporam os princípios de OGD:

1. Se o dado não pode ser encontrado e indexado na web, ele não existe.

2. Se não estiver aberto e disponível em formato compreensível por máquina, ele não pode ser reaproveitado. 
3. Se algum dispositivo legal não permitir sua replicação, ele não é útil.

Sob uma análise mais cuidadosa, as três leis de Eaves compreendem, de certo modo, os oito princípios de OGD definidos em 2007. Como boa parte da bibliografia aponta ambas as construções, faz-se necessário deixar esta informação aqui registrada.

A partir de então, surgiram experiências no sentido de atender aos princípios e leis norteadoras de OGD. Ao mesmo tempo, o mundo tecnológico vivenciava o desenvolvimento da web semântica cuja ideia seminal datava de 2001 (BERNERSLEE; HENDLER; LASSILA, 2001). A web semântica descreve um framework que permite que dados sejam compartilhados e reusados entre aplicações. Seu objetivo é transformar a web clássica, dominada por documentos semiestruturados ou mesmo desestruturados, na web dos dados, onde o significado desses dados seja entendido por computadores em vez de somente humanos. Para isso, a web semântica faz uso de ontologias para estabelecer classes de significado e suas relações. Os padrões da web semântica são mantidos pelo World Wide Web Consortium (W3C) por meio da descrição do Resource Description Framework (RDF) (BRICKLEY; GUHA, 2014).

O uso da web semântica em OGD foi introduzido por meio de projeto piloto no âmbito do governo britânico (SHADBOLT et al., 2012). As ações, os achados e as lições aprendidas com o projeto foram relatados por Alani et al. (2007).

Com o desenvolvimento da web semântica e sua aplicação em OGD, surgiu também um outro conceito que permeia a disponibilização de dados abertos, o denominado Linked data (BERNERS-LEE, 2010; BIZER; HEATH; BERNERS-LEE, 2009). Em resumo, na descrição de seus precursores, Linked data diz respeito ao uso da web para criar formas de ligação de dados entre diversas fontes. Estas fontes podem estar geograficamente distribuídas e possuírem seus próprios mecanismos de geração de dados, podendo ser mantidas por sistemas heterogêneos, desde que publicadas em formatos específicos. De forma mais pragmática, o conceito de Linked data refere-se à publicação de dados na web de modo que sejam legíveis por máquinas, com semântica explicitamente definida e ligados ou acessíveis por fontes de dados externas (BIZER; HEATH; BERNERSLEE, 2009). 


\subsection{Repositórios de OGD}

A materialização da web semântica e o uso de Linked data levaram ao desenvolvimento de uma série de repositórios de OGD para a divulgação de conjunto de dados ou datasets. Como exemplo, cita-se os quatro maiores repositórios de dados abertos governamentais existentes (HENDLER et al., 2012): Estados Unidos (www.data.gov), Reino Unido (www.data.gov.uk), França (www.data.gouv.fr) e Singapura (www.data.gov.sg). O Brasil também possui o portal www.dados.gov.br para divulgação dos dados abertos de interesse nacional.

Os repositórios dos Estados Unidos (BOLYCHEVSKY, 2013), Reino Unido e Brasil têm em comum a utilização de uma plataforma de softwares web para gerenciamento dos dados abertos, denominado Comprehensive Knowledge Archive Network (CKAN).

O CKAN foi desenvolvido e é mantido pela Open Knowledge, uma organização sem fins lucrativos fundada em 2004 e dedicada à promoção do conhecimento aberto. A Open Knowledge possui grupos de trabalho locais em mais de uma dúzia de países, entre eles o Brasil. Segundo a entidade, o CKAN é atualmente a plataforma líder mundial em gerenciamento de dados abertos e está implantada em cerca de 150 instâncias ao redor do mundo, nos âmbitos de governo nacional, regional e local (OPEN KNOWLEDGE FOUNDATION, 2016).

O CKAN é um software livre e de código aberto que permite o completo gerenciamento de dados abertos. Disponibiliza uma série de ferramentas para publicar, compartilhar, descobrir e usar os dados por meio do gerenciamento de datasets. A plataforma é indicada a governos e entidades que desejam ampliar a utilização de dados abertos pela sociedade.

Uma das premissas do CKAN é aproveitar os repositórios e processos de disponibilização de dados já existentes e bem estabelecidos nas entidades. Desse modo, os dados podem ser simplesmente importados para dentro do CKAN na forma de datasets. Arquivos em texto puro, Comma-separated values (CSV), Extensible Markup Language (XML), Microsoft Excel Spreasheet (XLS), PDF ou mesmo RDF são alguns dos recursos possíveis de serem levados para dentro do 
CKAN e assim publicados em um repositório central com vários recursos de gerenciamento de dados, cujo principal benefício refere-se ao uso de Application Programming Interface (API) para integração com a plataforma.

O CKAN está disponível para baixar, compartilhar e implementar, como qualquer software livre. A Open Knowledge mantém o serviço Datahub² como uma implementação on-line do CKAN disponível para quem queira publicar datasets. Outro recurso importante mantido pela mesma entidade é o Openspending ${ }^{3}$, que basicamente é uma plataforma direcionada a armazenar dados financeiros governamentais. Disponibiliza várias ferramentas de análise e filtros, com a visualização de gráficos bem elaborados para incentivar a participação da sociedade no acompanhamento dos gastos governamentais. O Openspending trabalha integrado ao Datahub para acesso aos datasets importados e publicados na plataforma.

Convém citar que além do CKAN existem no mercado o Socrata e o OASIS OData Protocol (OASIS, 2012). Socrata é um produto comercial desenvolvido e mantido pela Socrata Inc. que tem funcionalidades e objetivos semelhantes aqueles encontrados no CKAN. O OData não é considerado genuinamente uma plataforma OGD, mas sim um padrão que define boas práticas para construção e consumo de APIs.

\subsection{Direito de acesso à informação}

Em seu primeiro dia de trabalho como presidente dos Estados Unidos, Barack Obama assinou um importante memorando intitulado "Transparency and Open Government" (OBAMA, 2009). Sua iniciativa mostrou ao país a importância da transparência pública por meio da abertura dos registros governamentais. Desde então, outros governos ao redor do mundo foram encorajados a fazer o mesmo, trazendo novas formas de participação para a sociedade.

\footnotetext{
2 http://datahub.io

${ }^{3}$ http://openspending.org
} 
Em 2011, outro importante passo foi dado em direção à consolidação de governos abertos com a OGP. Foi estabelecida uma parceria entre África do Sul, Brasil, Estados Unidos, Filipinas, Indonésia, México, Noruega e Reino Unido. A OGP é um acordo multilateral no qual países são convidados a desenvolver e implementar ambiciosas reformas para prover governos mais abertos. No momento de redação deste texto a OGP tinha crescido de oito países fundadores para 70 países que faziam parte do acordo.

O marco regulatório de acesso à informação no Brasil foi introduzido com a Lei Federal nº. 12.527 de 2011, denominada Lei de Acesso à Informação - LAI (BRASIL, 2011). Considerada elemento principal para cumprir com os compromissos assumidos pelo Brasil perante a OGP (COELHO; WAISBICH, 2013), a LAl é uma lei nacional aplicável aos níveis nacional, estadual, municipal e do Distrito Federal. Isso significa que órgãos e entidades da administração pública direta e indireta de todo o país são submetidos às regras da lei, independentemente da autonomia e do nível de governo que a Constituição Brasileira confere.

A Figura 3 ilustra a estrutura básica da LAl, expondo como seus principais componentes (transparência passiva e ativa) funcionam e as definições que a lei impõe.

Figura 3 - Estrutura básica da LAI com seus principais componentes e requisitos

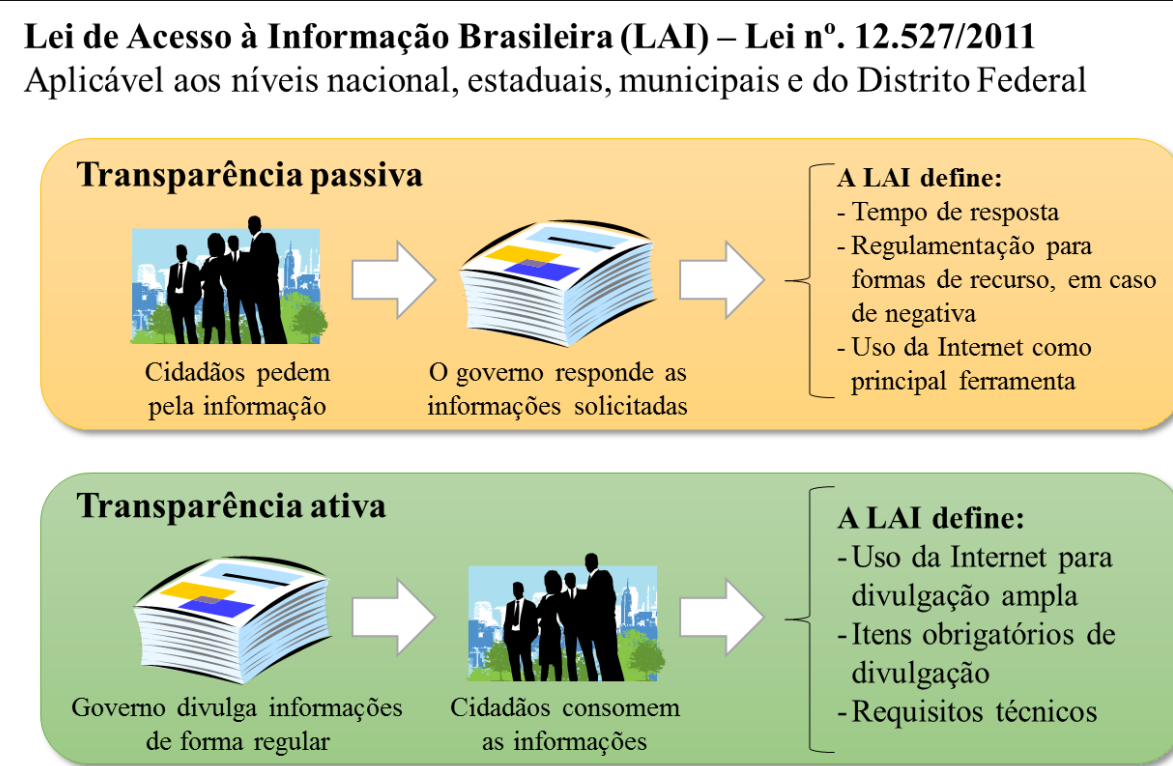

Fonte: Elaborado pelo autor. 
A transparência passiva regula o direito de qualquer cidadão obter, sem justificativa, informações de seu interesse. No âmbito federal, define os procedimentos, prazos e meios de recurso em caso de negativa por parte dos governos; já nos governos estaduais e municipais exige-se a regulamentação desses procedimentos. Um dos pontos mais inovadores que a LAI trouxe foi que os órgãos e entidades da administração pública são obrigados a prover a informação solicitada que, por padrão, é passível de fornecimento. A confidencialidade, por outro lado, é definida como uma exceção. As regras que definem a confidencialidade estão exaustivamente definidas na lei, evitando assim que as instituições públicas, sob o pretexto da autonomia, criem novas formas de segredo para não fornecer a informação.

Já a transparência ativa regula o mínimo de informação que deve ser publicada periodicamente pelas instituições, sem a necessidade de qualquer requisição. Neste ponto são definidos os requisitos técnicos que precisam ser atendidos e que compreendem os princípios de OGD. Pelo fato desta pesquisa ter como foco de estudo a transparência ativa, ou seja, os dados que são disponibilizados pelos entes para divulgação à sociedade, faz-se necessário primeiramente entender como os requisitos técnicos definidos na LAI (em jargão jurídico) refletem os oito princípios de OGD. A Tabela 1 a seguir expõe esta reflexão com o mapeamento dos requisitos técnicos da LAI com os princípios de OGD.

Tabela 1 - Mapeamento dos requisitos técnicos definidos no $\S 3^{\circ}$ do Art. $8^{\circ}$ da LAl com os princípios de OGD

\begin{tabular}{|c|c|}
\hline $\begin{array}{l}\text { Requisitos técnicos } \\
\text { (Art. } 8 \text { } 3^{\circ} \mathrm{da} \mathrm{LAl} \text { ) }\end{array}$ & Princípios de OGD \\
\hline $\begin{array}{l}\text { I - conter ferramenta de pesquisa de conteúdo que permita o } \\
\text { acesso à informação de forma objetiva, transparente, clara e } \\
\text { em linguagem de fácil compreensão }\end{array}$ & $\begin{array}{l}\text { 4. Acessível } \\
\text { 6. Não discriminatório }\end{array}$ \\
\hline $\begin{array}{l}\text { II - possibilitar a gravação de relatórios em diversos formatos } \\
\text { eletrônicos, inclusive abertos e não proprietários, tais como } \\
\text { planilhas e texto, de modo a facilitar a análise das informações }\end{array}$ & $\begin{array}{l}\text { 5. Processável por máquina } \\
\text { 7. Não proprietário }\end{array}$ \\
\hline $\begin{array}{l}\text { III - possibilitar o acesso automatizado por sistemas externos } \\
\text { em formatos abertos, estruturados e legíveis por máquina }\end{array}$ & 5. Processável por máquina \\
\hline $\begin{array}{l}\text { IV - divulgar em detalhes os formatos utilizados para } \\
\text { estruturação da informação }\end{array}$ & $\begin{array}{l}\text { 1. Completo } \\
\text { 2. Primário }\end{array}$ \\
\hline V - garantir a autenticidade e a integridade das informações & Sem mapeamento direto \\
\hline
\end{tabular}




\begin{tabular}{l|l}
\hline disponíveis para acesso & \\
\hline VI - manter atualizadas as informações disponíveis para acesso & 3. Atual \\
\hline $\begin{array}{l}\text { VII - indicar local e instruções que permitam ao interessado } \\
\text { comunicar-se, por via eletrônica ou telefônica, com o órgão ou } \\
\text { entidade detentora do sítio }\end{array}$ & $\begin{array}{l}\text { 1. Completo } \\
\text { 4. Acessível }\end{array}$ \\
\hline $\begin{array}{l}\text { VIII - adotar as medidas necessárias para garantir a } \\
\text { acessibilidade de conteúdo para pessoas com deficiência }\end{array}$ & 6. Não discriminatório \\
\hline
\end{tabular}

Fonte: Elaborado pelo autor.

Dos requisitos técnicos contidos na lei, o único que não encontra correspondência direta é o item $\underline{\mathrm{V} \text {-garantir a autenticidade e a integridade das }}$ informações disponíveis para acesso, pois os princípios de OGD não explicitam esta característica.

Já o princípio de OGD $\underline{8}$. Livre de licença não é mencionado na LAI. A questão dos direitos autorais sobre os dados públicos é controversa na legislação brasileira pois sua principal lei de direitos autorais levanta algumas dúvidas em relação a este ponto. Várias ações estão em curso para atualizar a lei de direitos autorais brasileira e definir o conceito de licença livre aos dados públicos (MIZUKAMI et al., 2008). Porém, acredita-se que o legislador ao mencionar na LAl o termo aberto quis também se referir ao licenciamento. A pacificação desta questão, no entanto, será tratada por regulamentação nos âmbitos específicos ou então de forma geral pela atualização da lei.

\subsection{O formato no contexto de dados abertos, dados estruturados e estruturação}

Introduzida por governos de todo o mundo, a abertura de registros públicos com o uso da internet encontrou nas páginas HTML e arquivos PDF um meio amigável de disseminar para a sociedade documentos semelhantes a relatórios. Mesmo governos com resultados favoráveis na disponibilização de dados abertos, ainda encontram problemas na disponibilização segundo os princípios de OGD (BUNYAKIATI; VORAVITTAYATHORN, 2012; COELHO et al., 2015; CORRÊA; CORRÊA; SILVA, 2014; CUNHA et al., 2015; DAVIES; FRANK, 2013; HELBIG et al., 
2012; MACHADO; OLIVEIRA, 2011; RIBEIRO; MATHEUS; VAZ, 2011; SANTANA; RODRIGUES, 2013; VELJKOVIĆ; BOGDANOVIĆ-DINIĆ; STOIMENOV, 2014).

Uma avaliação preliminar conduzida em alguns municípios brasileiros (CORRÊA; CORRÊA; SILVA, 2014) mostrou que 90\% dos documentos estão disponíveis nos formatos HTML e PDF. Um estudo de caso (VELJKOVIĆ; BOGDANOVIĆ-DINIĆ; STOIMENOV, 2014) no principal repositório norte americano data.gov, conduzido em outubro de 2012, revelou que o indicador de resultado referente a dado processável por máquina obteve a menor pontuação no estudo, parcialmente por causa dos documentos serem em formato PDF. Outro estudo de caso (DAVIES; FRANK, 2013) focado na estratégia digital do governo do Reino Unido identificou a disseminação de planilhas PDF em detrimento da presença de dados de texto puro legíveis por máquina. Uma pesquisa (BUNYAKIATI; VORAVITTAYATHORN, 2012) sobre formatos de dados em países e instituições do Sudeste Asiático encontrou a predominância de HTML e PDF. Por fim, Santana e Rodrigues (2013) apontam o uso do PDF em atividades legislativas do Senado Federal Brasileiro, o que compromete o acesso aos dados.

Apesar dos aparentes benefícios encontrados nos formatos HTML e PDF, estes formatos não são totalmente compatíveis com os princípios de OGD por violarem essencialmente o princípio Processável por máquina (HELBIG et al., 2012; OPENGOVDATA, 2007; TAUBERER, 2014). Para apoiar este entendimento, remete-se também a um outro sistema de classificação proposto por Tim BernersLee onde o autor define um método de avaliação denominado sistema de cinco estrelas para estabelecer o nível de abertura dos dados (BERNERS-LEE, 2010). Quanto mais aberto, maior é a quantidade de estrelas atribuídas aos dados e maior também são os benefícios em potencial. A Figura 4 ilustra o sistema de cinco estrelas para dados abertos de Tim Berners-Lee e exemplifica com alguns formatos mencionados cada nível do sistema. 
Figura 4 - Sistema de cinco estrelas para dados abertos de Tim Berners-Lee
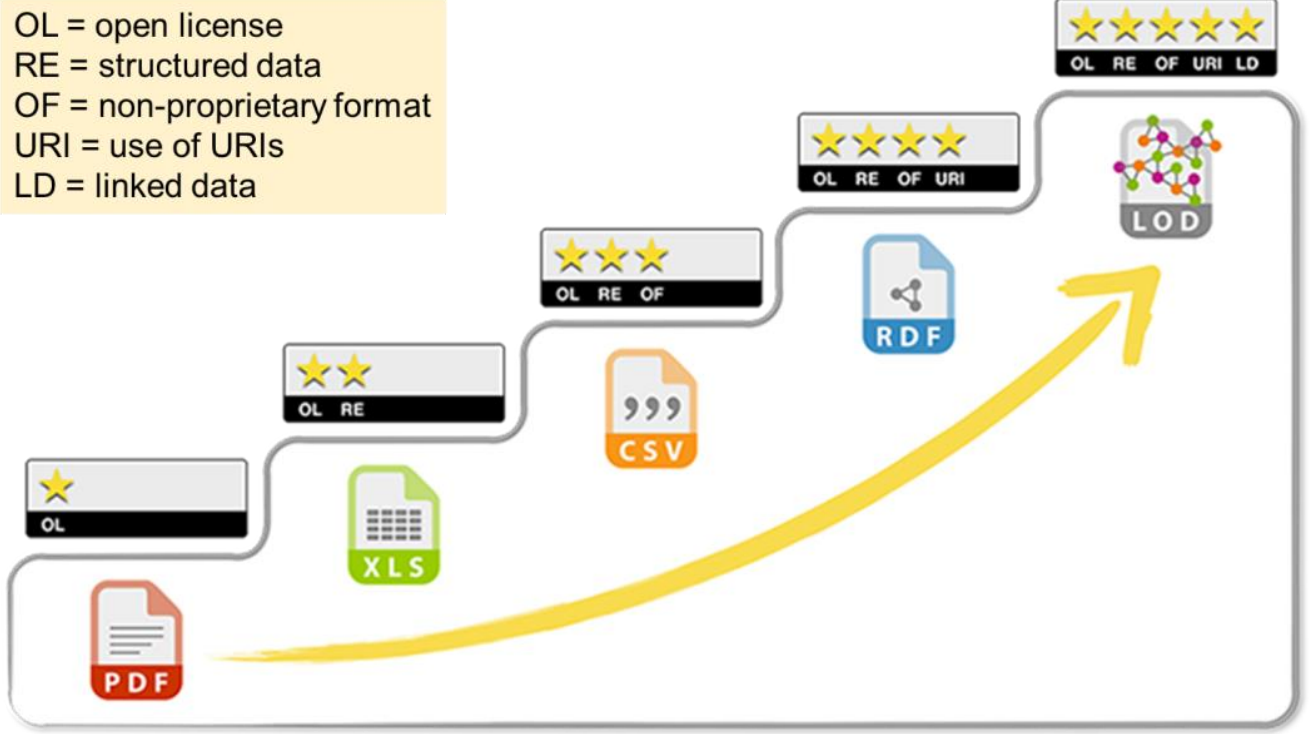

Fonte: Adaptado de Berners-Lee (2016).

A Tabela 2 a seguir foi extraída de Isotani e Bittencourt (2015) e evidencia os potenciais benefícios da publicação e consumo de dados abertos por nível do sistema de cinco estrelas definido por Tim Berners-Lee.

Tabela 2 - Benefícios da publicação e consumo de dados abertos por nível do sistema de cinco estrelas de Tim Berners-Lee

\begin{tabular}{|c|c|c|}
\hline Estrelas & Quem consome & Quem Publica \\
\hline \multirow{6}{*}{$\star$} & Ver os dados & É simples de publicar \\
\hline & Imprimi-los & $\begin{array}{l}\text { Não precisa explicar repetitivamente } \\
\text { que as pessoas podem fazer uso dos } \\
\text { dados }\end{array}$ \\
\hline & $\begin{array}{l}\text { Guardá-los (no disco rígido ou num pen- } \\
\text { drive, por exemplo) }\end{array}$ & \\
\hline & Modificar os dados como queira & \\
\hline & Acessar o dado de qualquer sistema & \\
\hline & Compartilhar o dado com qualquer pessoa & \\
\hline \multirow{3}{*}{$\star \star$} & $\begin{array}{l}\text { Os mesmos benefícios de quem usa uma } \\
\text { estrela }\end{array}$ & É fácil publicar \\
\hline & $\begin{array}{l}\text { Usar softwares proprietários para } \\
\text { processar, agregar, calcular e visualizar os } \\
\text { dados }\end{array}$ & \\
\hline & $\begin{array}{l}\text { Exportá-los em qualquer formato } \\
\text { estruturado }\end{array}$ & \\
\hline
\end{tabular}




\begin{tabular}{|c|c|c|}
\hline \multirow[b]{2}{*}{$\star \star \star$} & $\begin{array}{l}\text { Os mesmos benefícios de quem usa duas } \\
\text { estrelas }\end{array}$ & É ainda mais fácil de publicar \\
\hline & $\begin{array}{l}\text { Manipular os dados da forma que lhe } \\
\text { agrada, sem estar refém de algum software } \\
\text { em particular }\end{array}$ & $\begin{array}{l}\text { Obs.: Pode ser necessário conversores } \\
\text { ou plugins para exportar os dados do } \\
\text { formato proprietário }\end{array}$ \\
\hline \multirow{5}{*}{$\star \star \star \star$} & $\begin{array}{l}\text { Os mesmos benefícios de quem usa três } \\
\text { estrelas }\end{array}$ & $\begin{array}{l}\text { Há controle dos itens dos dados e pode } \\
\text { melhorar seu acesso }\end{array}$ \\
\hline & Fazer marcações & $\begin{array}{l}\text { Outros publicadores podem conectar } \\
\text { seus dados, promovendo-os às cinco } \\
\text { estrelas }\end{array}$ \\
\hline & Reutilizar parte dos dados & \\
\hline & $\begin{array}{l}\text { Reutilizar ferramentas e bibliotecas de } \\
\text { dados existentes, mesmo que elas } \\
\text { entendam apenas parte dos padrões } \\
\text { usados por quem publicou }\end{array}$ & \\
\hline & Combinar os dados com outros & \\
\hline \multirow{3}{*}{$\star \star \star \star \star$} & $\begin{array}{l}\text { Descobrir mais dados vinculados enquanto } \\
\text { consome dados }\end{array}$ & $\begin{array}{l}\text { Torna o dado mais fácil de ser } \\
\text { descoberto }\end{array}$ \\
\hline & $\begin{array}{l}\text { Aprender sobre a classificação das cinco } \\
\text { estrelas }\end{array}$ & Aumenta o valor do dado \\
\hline & & $\begin{array}{l}\text { A organização ganha os mesmos } \\
\text { benefícios com a vinculação de dados } \\
\text { que os consumidores }\end{array}$ \\
\hline
\end{tabular}

Fonte: Isotani e Bittencourt (2015).

O PDF é um formato utilizado para distribuição de documentos pela internet e a especificação do formato está padronizada pela norma ISO 32000-1:2008 (INTERNATIONAL ORGANIZATION FOR STANDARDIZATION, 2008), mas que não apresenta a característica para processamento automatizado por máquina. Ou seja, os dados em um PDF estão fechados e sua extração demanda técnicas e ferramentais não triviais para a maioria das pessoas. Na classificação do sistema de estrelas de Tim Berners-Lee o formato PDF recebe apenas uma estrela e também viola os princípios de OGD Acessível e Processável por máquina.

Já as páginas HTML são documentos semiestruturados que disponibilizam meios para processar e estruturar seu conteúdo (BIZER; HEATH; BERNERS-LEE, 2009). Porém, o conteúdo tabular em HTML é normalmente gerado após seleção/definição de filtros e parâmetros que são parte da programação dinâmica das páginas web, os quais dificultam o processamento automatizado que não seja aquele direcionado para o navegador de internet. O HTML recebe três estrelas pela 
classificação de Tim Berners-Lee, porém entende-se que o formato também viola os princípios de OGD Acessível e Processável por máquina.

A Tabela 3 a seguir sumariza os problemas em potencial dos formatos PDF e HTML segundo o sistema de cinco estrelas de Tim Berners-Lee (BERNERS-LEE, 2010) e os princípios de OGD (OPENGOVDATA, 2007).

Tabela 3 - Sumarização dos problemas em potencial dos formatos PDF e HTML segundo o sistema de cinco estrelas e os princípios de OGD

\begin{tabular}{c|l|l|l}
\hline $\begin{array}{c}\text { Formato de } \\
\text { divulgação }\end{array}$ & $\begin{array}{l}\text { Sistema de cinco } \\
\text { estrelas } \\
\text { (BERNERS-LEE, } \\
\text { 2010) }\end{array}$ & $\begin{array}{c}\text { Princípios de OGD } \\
\text { (OPENGOVDATA, 2007) }\end{array}$ & Problemas em potencial \\
\hline PDF & $\begin{array}{l}\text { Classificado com } \\
\text { (uma estrela) }\end{array}$ & $\begin{array}{l}\text { Viola os princípios } \\
\text { Acessível e Processável por } \\
\text { máquina. }\end{array}$ & $\begin{array}{l}\text { Extração dos dados } \\
\text { demanda técnicas e } \\
\text { ferramentais não triviais } \\
\text { para a maioria das } \\
\text { pessoas }\end{array}$ \\
\hline HTML & $\begin{array}{l}\text { Classificado com } \\
\star \star \star \text { (três } \\
\text { estrelas) }\end{array}$ & $\begin{array}{l}\text { Viola os princípios } \\
\text { Acessível e Processável por } \\
\text { máquina. }\end{array}$ & $\begin{array}{l}\text { Conteúdo tabular é } \\
\text { normalmente gerado após } \\
\text { seleção/definição de } \\
\text { filtros e parâmetros no } \\
\text { contexto das páginas } \\
\text { dinâmicas }\end{array}$ \\
\hline
\end{tabular}

Fonte: Elaborado pelo autor.

Apesar da ampla disseminação de iniciativas OGD e o conhecimento acerca do impacto do formato na disponibilização de dados governamentais (MATHEUS; RIBEIRO; VAZ, 2012; SHADBOLT et al., 2012; SHADBOLT; O'HARA, 2013), o conceito de dados abertos para a efetiva transparência ainda é uma preocupação.

Assim, faz-se necessário estimular a disponibilização de dados por meio de um formato comum e não proprietário, em texto puro, como o CSV, e externá-lo utilizando catálogos de OGD que implementam uma série de mecanismo para automatização com o uso de APIs.

Uma vez disponibilizados em CSV, as dados podem ser convertidos para atingir a estruturação semântica e a interligação por meio de RDF (BRICKLEY; GUHA, 2014), que é um formato cinco estrelas segundo a classificação de Tim Berners-Lee. Nesse sentido, um trabalho proposto por Ermilov; Auer e Stadler (2013) explora uma coleção de ferramentas e reporta resultados de sua contribuição 
usando uma abordagem específica dos autores para esta tarefa. Sustenta-se que ter dados disponibilizados em CSV é o primeiro passo rumo à abertura dos dados (THORSBY et al., 2016), tendo em vista que as características licença aberta, conteúdo estruturado e formato não proprietário são passos fundamentais para atingir níveis mais altos de abertura e dados.

Depois de analisadas as principais questões sobre o formato dos dados, faz-se necessário diferenciar os conceitos de dados abertos, dados estruturados e o processo de estruturação, termos utilizados ao longo deste trabalho.

Dados abertos são os dados compatíveis com os oito princípios de OGD, conforme visto em sessão anterior neste capítulo. Neste sentido, sua conceituação vai além do formato do dado em si, tendo em vista que questões como acesso, granulidade, temporariedade e licenciamento estão envolvidos em sua definição.

Já dados estruturados, para efeito deste trabalho, são considerados os dados que atendam à segunda estrela da classificação de Tim Berners-Lee e adicionalmente estejam sob um formato não proprietário, característica dada pela terceira estrela. Assim, compatibiliza-se o conceito de dados estruturados no contexto deste trabalho com as características da terceira estrela da classificação de Tim Berners-Lee, as quais são (BERNERS-LEE, 2010):

1. Licença aberta. Permite o acesso, a impressão, o armazenamento, a introdução do conteúdo em qualquer outro sistema, a alteração e o compartilhamento dos dados por qualquer um e para qualquer propósito;

2. Conteúdo estruturado. Permite processar diretamente o conteúdo para realizar agregações, cálculos, visualizações, agrupamentos, filtros e qualquer outro tipo de manipulação a partir da granularidade disponibilizada;

3. Formatos não proprietário. Permite qualquer manipulação sem restrições impostas por softwares específicos e que exijam licenciamento de uso.

Por conseguinte, também para entendimento deste trabalho, a estruturação de dados é o processo compreendendo as seguintes etapas:

1. Identificação de conteúdo tabular; 
2. Extração de dados a partir de informações dispostas em formatos desestruturados;

3. Catalogação com descrição de metadados; e,

4. Carregamento em datasets.

Desse modo, entende-se que a estruturação possibilita a abertura dos dados com o objetivo de torna-los acessíveis por qualquer um e para qualquer propósito, sem as barreiras técnicas para o processamento dos formatos. Mas para que isso seja possível, são necessários outros mecanismos de apoio para que os dados resultantes da estruturação sejam considerados dados abertos. Estes mecanismos são implementados, por exemplo, por meio das funcionalidades do catálogo CKAN.

Uma vez abertos os dados, tem-se vários potenciais benefícios. Como exemplos concretos, Pires (2015) menciona o aplicativo Citymapper ${ }^{4}$ que reúne informações em tempo real das linhas de transporte público para milhões de usuários ao redor do mundo e o portal QEdu ${ }^{5}$ que reúne dados governamentais sobre a educação brasileira como subsídio para pesquisadores e formuladores de políticas públicas na área de educação.

\subsection{Arquiteturas de software}

Para entender o que são arquiteturas de software, faz-se necessário primeiramente compreender sua definição. A este respeito, muito já foi escrito nesta área do conhecimento e não há uma definição universal aceita pela bibliografia ou de praticantes mundo afora, visto que o Software Engineering Institute ${ }^{6}$ (SEI) já identificou mais de 150 definições nesta disciplina (CLEMENTS et al., 2010).

Uma definição bastante aceita diz que "the software architecture of a system is the set of structures needed to reason about the system, which comprise software

\footnotetext{
${ }^{4} \mathrm{https}: / / \mathrm{citymapper} . c o m /$

${ }^{5} \mathrm{http}: / /$ www.qedu.org.br/

${ }^{6}$ O Software Engineering Institute (SEI) é uma conceituada instituição norte americana fundada para a pesquisa e desenvolvimento na área de Engenharia de Software. O SEI é patrocinado pela Departamento de Defesa e é operado pela Carnegie Mellon University.
} 
elements, relations among them, and properties of both"7 (BASS; CLEMENTS; KAZMAN, 2012).

Estrutura é um conjunto de elementos mantidos por relações entre eles. Software é composto por muitas estruturas, porém nem todas estas estruturas são arquiteturais. Uma estrutura é arquitetural quando suporta o raciocínio sobre o sistema e suas propriedades, o que dá embasamento aos stakeholders para a tomada de decisão sobre suas funcionalidades, disponibilidade, dificuldades de manutenção, respostas às requisições dos usuários e outras genericamente chamados de atributos de qualidade (BASS; CLEMENTS; KAZMAN, 2012).

Conceitualmente, as arquiteturas omitem certas informações que não essenciais para o raciocínio sobre o sistema. Os componentes de software dispostos em uma arquitetura existem como "blocos opacos", ou seja, os detalhes internos não são expostos. Do mesmo modo, omitem detalhes que não tenham ramificações além de um elemento único dentro da arquitetura. Diz-se, então, que a arquitetura é uma abstração onde se enfatiza certos detalhes e suprime outros de modo a tratar a complexidade para o correto entendimento de um sistema para além de suas partes individuais (BASS; CLEMENTS; KAZMAN, 2012; MITRA, 2015).

Para que uma arquitetura de software cumpra seu papel, deve possibilitar uma visão de alto nível do sistema que está sendo construído e cobrir os seguintes aspectos (HANMER, 2013):

- Objetivos e filosofia do sistema: a arquitetura declara seus objetivos e descreve seu propósito para com o sistema, assim como quem usará o sistema e qual problema pretende resolver;

- Premissas e dependências da arquitetura: a arquitetura exprime as premissas sobre o ambiente e sobre si mesma. As premissas são as situações dadas como certas dentro de seu contexto. As dependências da arquitetura são definidas como as relações envolvidas com outros sistemas;

\footnotetext{
7 Tradução literal produzida pelo autor deste trabalho e utilizada ao longo dos textos que se seguem: "a arquitetura de software é um conjunto de estruturas necessárias para raciocinar sobre o sistema, os quais compreendem elementos de software, as relações entre eles e suas propriedades".
} 
- Requisitos arquiteturais significantes: a arquitetura exprime os pontos mais significantes que a moldaram;

- Instruções de empacotamento para subsistemas e componentes: a arquitetura explica como as partes do sistema serão implementadas nas plataformas computacionais e como elas são combinadas para funcionar corretamente. Os subsistemas e componentes envolvidos são considerados blocos envolvidos na construção da arquitetura;

- Subsistemas e camadas críticas: a arquitetura exprime as diferentes visões e partes do sistema e como elas se relacionam;

- Referência aos elementos de projeto significantes: a arquitetura evidencia as mais importantes e significativas partes envolvidas em seu projeto;

- Interfaces críticas do sistema: a arquitetura descreve as interfaces do sistema com especial atenção às interfaces críticas que são parte dos requisitos de qualidade do sistema;

- Principais cenários que descrevem os comportamentos do sistema: a arquitetura exprime os cenários mais importantes que ilustram e explicam com o sistema será utilizado.

Uma arquitetura, quando bem projetada, traz incontáveis potenciais benefícios para o sistema e aos stakeholders, pois podem visualizar o sistema sendo construído evitando assim desperdício de recursos com o retrabalho no desenvolvimento ou manutenção do software. A seção a seguir relaciona a importância de uma arquitetura e seus potenciais benefícios.

\subsubsection{Importância}

De modo geral, investir na definição de arquiteturas é essencialmente importante para reduzir o retrabalho proveniente da implementação direta do software sem considerar suficientemente os detalhes de sua complexidade e os riscos envolvidos (BASS; CLEMENTS; KAZMAN, 2012; BELL, 2016; DASHOFY; MEDVIDOVIC; TAYLOR, 2009; KAZMAN; CERVANTES, 2016; MITRA, 2015; 
SANGWAN, 2015). Estes, por sua vez, são obtidos pelo levantamento dos requisitos extraídos do objetivo do negócio e das expectativas dos stakeholders para com o sistema.

A importância das arquiteturas de software para um sistema pode ser expressa em uma variedade de razões para sua existência. Conforme pode-se observar pelas anotações de Kazman e Cervantes (2016) sobre estas razões, alguns pontos que merecem atenção e são de interesse desta pesquisa são:

- O processo de desenvolvimento e definição de uma arquitetura leva ao raciocínio sobre o sistema e o provisionamento de seus requisitos de qualidade almejados;

- Uma arquitetura definida e documentada melhora a comunicação entre os stakeholders e consequentemente define um idioma comum para refletir sobre o sistema a ser desenvolvido;

- No contexto de uma arquitetura são tomadas as decisões mais críticas em um sistema pois retrata sua concepção e estruturas mais fundamentais de funcionamento;

- A arquitetura fornece uma base para o processo evolucionário de software e sua prototipação como formas de refinamento dos requisitos e consequente melhoria da qualidade do produto pretendido (PRESSMAN, 2011; SOMMERVILLE, 2007);

- O desenvolvimento de software baseado em arquitetura permite focar a atenção na montagem dos componentes e sua interligação, ou seja, o reuso em vez do redesenvolvimento;

- Ao restringir as mais diversas alternativas de projeto com a proposta de uma arquitetura, tem-se uma forma de reduzir a complexidade inerente ao software.

A não definição de arquiteturas previamente ao desenvolvimento do sistema pode levar a situações de riscos para o processo de engenharia de software, mesmo em projetos menores de desenvolvimento (KAZMAN; CERVANTES, 2016). Por isso, 
a definição da arquitetura e seu contínuo refinamento torna-se uma atividade essencial no contexto do ciclo de vida do software.

\subsubsection{Arquiteturas de referência e arquiteturas concretas}

Os sistemas de software são construídos para satisfazer os objetivos de negócio de uma organização. Assim, os objetivos de negócio são considerados muitas vezes artefatos abstratos dentro de uma arquitetura e o resultado final - 0 software funcionando - é o artefato concreto. A arquitetura é a ponte entre esses artefatos (BASS; CLEMENTS; KAZMAN, 2012).

A diferença fundamental entre os dois tipos de arquitetura está na essência genérica da arquitetura de referência. Ela é projetada para servir de funcionalidades e qualidades para todos os stakeholders nos seus contextos específicos, em um alto nível de abstração (ANGELOV; TRIENEKENS; GREFEN, 2008).

Uma arquitetura concreta estabelece claramente os produtos e tecnologias envolvidos em seu projeto, especificando inclusive as versões dos componentes que são por ela projetados. Já a arquitetura de referência se preocupa mais em estabelecer os componentes pelas suas funcionalidades e as relações que existem entre eles.

$\mathrm{Na}$ área de conhecimento sobre arquiteturas de software, diz-se que uma arquitetura de referência pode ser instanciada para se tornar concreta. O termo instanciação, utilizado em linguagens de programação orientadas a objetos, significa dizer que o objeto instanciado compartilha dos mesmos atributos do objeto de referência. Especificamente para arquiteturas de software, a instanciação de uma arquitetura a partir da referência dará linhas base para composição da arquitetura concreta para fins de implementação do arcabouço de tecnologias, produtos e padrões envolvidos. A implementação é uma das formas de validação da arquitetura de referência, pois materializa a intenção do projetista para com a construção de um sistema que será testado em um ambiente real de operação.

Esta pesquisa trata da definição de uma arquitetura de referência. No Capítulo 5 está sendo proposto um protótipo com base na arquitetura de referência definida como parte de sua validação. 
2.6.3 Processo de desenvolvimento

Assim como no processo de desenvolvimento do software, a arquitetura também possui um processo para seu desenvolvimento caracterizado por uma série de atividades. A Figura 5 expressa este processo com cinco atividades fundamentais que estão sendo consideradas nesta pesquisa e anota o procedimento metodológico seguido.

Figura 5 - Diagrama de atividade do processo de desenvolvimento da arquitetura

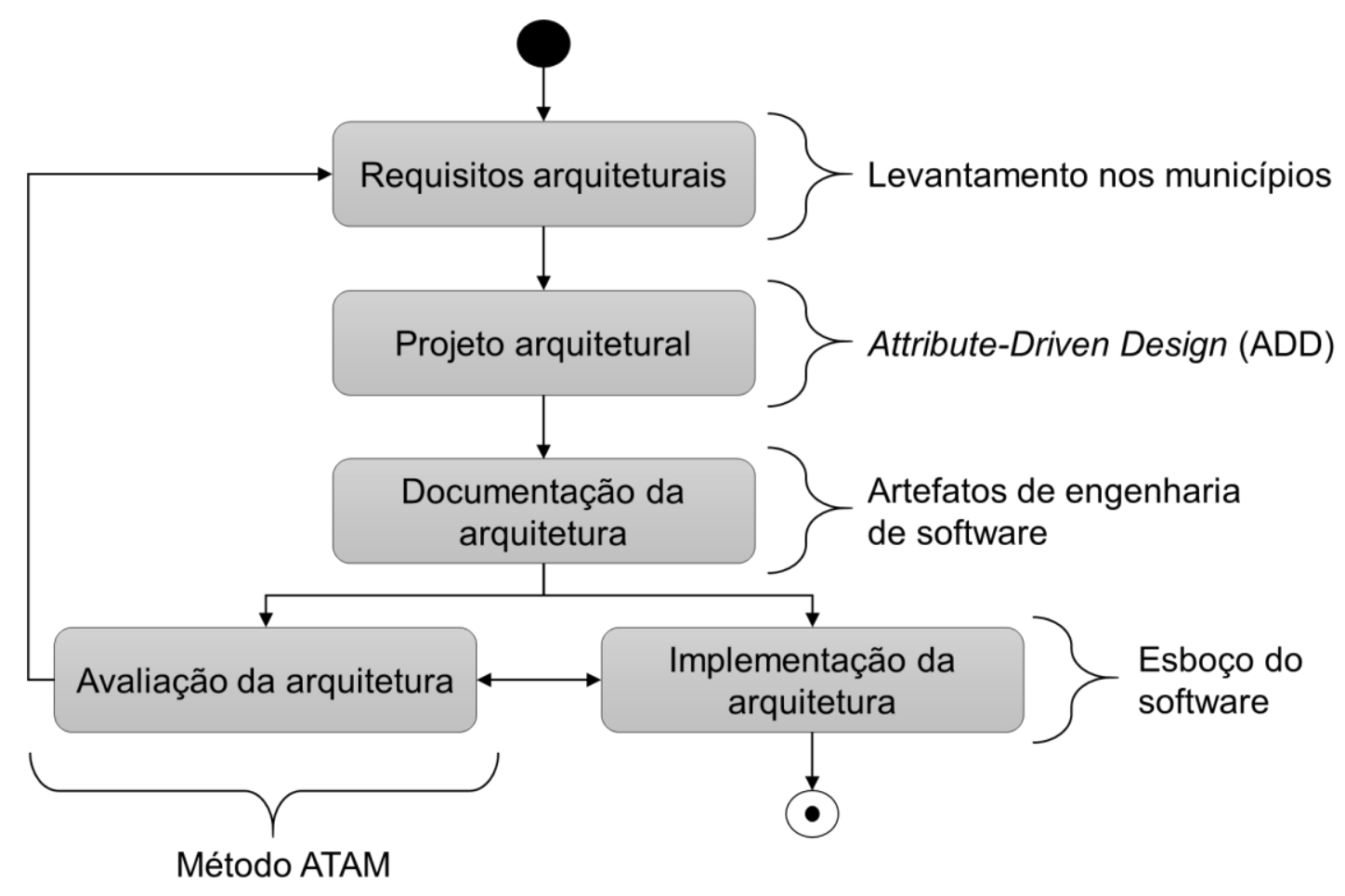

Fonte: Adaptado de Kazman e Cervantes (2016).

- Requisitos arquiteturais compreende o levantamento dos requisitos de qualidade que detalham a realidade do negócio sendo considerado.

- Projeto arquitetural é a tradução dos requisitos levantados na atividade anterior para definição da estrutura, dos componentes e suas relações.

- Documentação da arquitetura refere-se à criação de algum nível documental para descrever a arquitetura utilizando recursos textuais e visuais de fácil compreensão. 
- Avaliação da arquitetura busca validar a arquitetura do ponto de vista dos stakeholders para assegurar que os requisitos críticos de qualidade foram incluídos.

- Implementação da arquitetura visa criar uma instância concreta para ser operada em ambiente real e materializar a intenção para com arquitetura.

Esta pesquisa segue o processo de desenvolvimento da arquitetura exposto na Figura 5 a partir da proposta de Kazman e Cervantes (2016). As atividades do processo foram adaptadas para esta pesquisa com a adoção do procedimento metodológico da seguinte forma:

1. Atividade Requisitos arquiteturais: realizado o levantamento dos requisitos da arquitetura a partir da caracterização do cenário de disponibilização de dados nos municípios brasileiros e do modelo de negócio colaborativo.

2. Atividade Projeto arquitetural: aplicado o método ADD, considerado como o mais usado e compreensivo para projetar arquiteturas (BASS; CLEMENTS; KAZMAN, 2012; KAZMAN; CERVANTES, 2016).

3. Atividade Documentação da arquitetura: utilizados recursos da linguagem textual e gráfica convencionais, assim como recursos da Unified Modeling Language - UML (BOOCH; RUMBAUGH; JACOBSON, 2005).

4. Atividade Avaliação da arquitetura: utilizado o método ATAM (BASS; CLEMENTS; KAZMAN, 2012; GALLAGHER, 2000).

5. Atividade Implementação da arquitetura: realizado o desenvolvimento de um protótipo compreendendo os principais componentes e bibliotecas mais importantes para instanciação da arquitetura.

No Capítulo 4 deste trabalho é detalhado todo o processo de desenvolvimento da arquitetura compreendendo todas as atividades envolvidas. 


\subsection{Trabalhos relacionados}

Até a presente seção foram discutidos os principais pontos dos aspectos conceituais que nortearam o desenvolvimento deste trabalho. Entre eles, destacamse os conceitos sobre dados abertos governamentais, a importância do formato de disponibilização dos dados e a área de conhecimento sobre engenharia de arquiteturas.

Adicionalmente, procedeu-se com uma extensa pesquisa bibliográfica para identificar trabalhos diretamente relacionados à contribuição principal desta pesquisa, que é a definição de uma arquitetura. A este respeito, foram identificados trabalhos com algumas semelhanças, porém ainda distantes da proposta pretendida por esta pesquisa.

Primeiramente, menciona-se o Modelo de Maturidade em Dados Abertos promovido pelo governo britânico (DODDS; NEWMAN, 2015). Apesar de ser definido conceitualmente por um modelo de maturidade pretendido para avaliação institucional, e não uma arquitetura de referência, o trabalho prioriza comportamentos generalizados que uma organização deve ter e os processos que deve adotar. Esses processos se assemelham com prescrições de como modelar uma infraestrutura de dados abertos, apesar de não ser prescritivo. Selecionou-se este exemplo britânico para enfatizar que existem modelos que podem também servir de referência para as instituições construírem e avaliarem suas ações para dados abertos. Porém, o modelo britânico não propõe uma solução para as fontes de dados desestruturadas que existem nas instituições, apenas fornece um meio para identifica-las e avalia-las.

Um estudo mais próximo desta pesquisa é proposto por Kong (2015). O autor propõe uma solução para abertura de dados voltada à interoperabilidade, definindo uma arquitetura orientada a serviço seguindo padrões abertos. A arquitetura assemelha-se por ser base para desenvolvimento de software, mas não considera em momento algum a situação atual das instituições com relação à presença de fontes de dados desestruturadas. O autor direciona seu trabalho para a proposição de uma arquitetura que servirá de base para os sistemas serem desenvolvidos ou adaptados e segundo as prescrições da arquitetura. 
Pires (2015) se refere às recomendações técnicas do Banco Mundial8 para retratar modelos de implementação de infraestrutura para manter bases de dados acessíveis e atualizadas. Apesar de não ser uma arquitetura de software propriamente dita, as soluções técnicas recomendadas pelo Banco Mundial consideram explicitamente a coexistência de bases de dados inclusive de fontes desestruturadas. As recomendações abarcam três modelos de soluções com referência ao número de bases de dados pré-existentes, assim esta semelhança faz com que o trabalho dos autores seja citado por esta pesquisa. Ressalta-se, no entanto, que as recomendações do Banco Mundial são sucintas e não endossam qualquer software ou solução tecnológica, focando apenas em diagramas simplificados contemplando os elementos recomendados para promover a abertura dos dados. Ademais, as propostas do Banco Mundial não levam em consideração o cenário de limitação técnica das instituições destinatárias.

Outro estudo conduzido por Machado e Oliveira (2011) tem como foco definir um padrão de arquitetura para portais de governo e assim estabelecer um acordo semântico entre fontes de dados heterogêneas para permitir a fusão de dados no âmbito dos dados abertos conectados (Linked data). A arquitetura é definida em camadas, sendo que em uma das camadas há a menção explícita de extração de dados semiestruturados e não estruturados. A Figura 6 reproduz a ilustração da camada semântica e o arranjo de suas subcamadas proposta por Machado e Oliveira (2011). A proposta dos autores parte de uma subcamada de extração de dados desestruturados que são transformados e carregados por outra subcamada. A persistência é realizada em uma subcamada específica e por sua vez manipulados pela última subcamada da solução.

8 O Banco Mundial mantém um repositório compreensivo de materiais e ferramentas para apoiar e sustentar a adoção de OGD pelas instituições governamentais. O repositório é encontrado no endereço http://opendatatoolkit.worldbank.org/en/. Acesso em: 10/10/2016. 
Figura 6 - Camada semântica e suas subcamadas de extração, transformação e carga, persistência e manipulação de dados

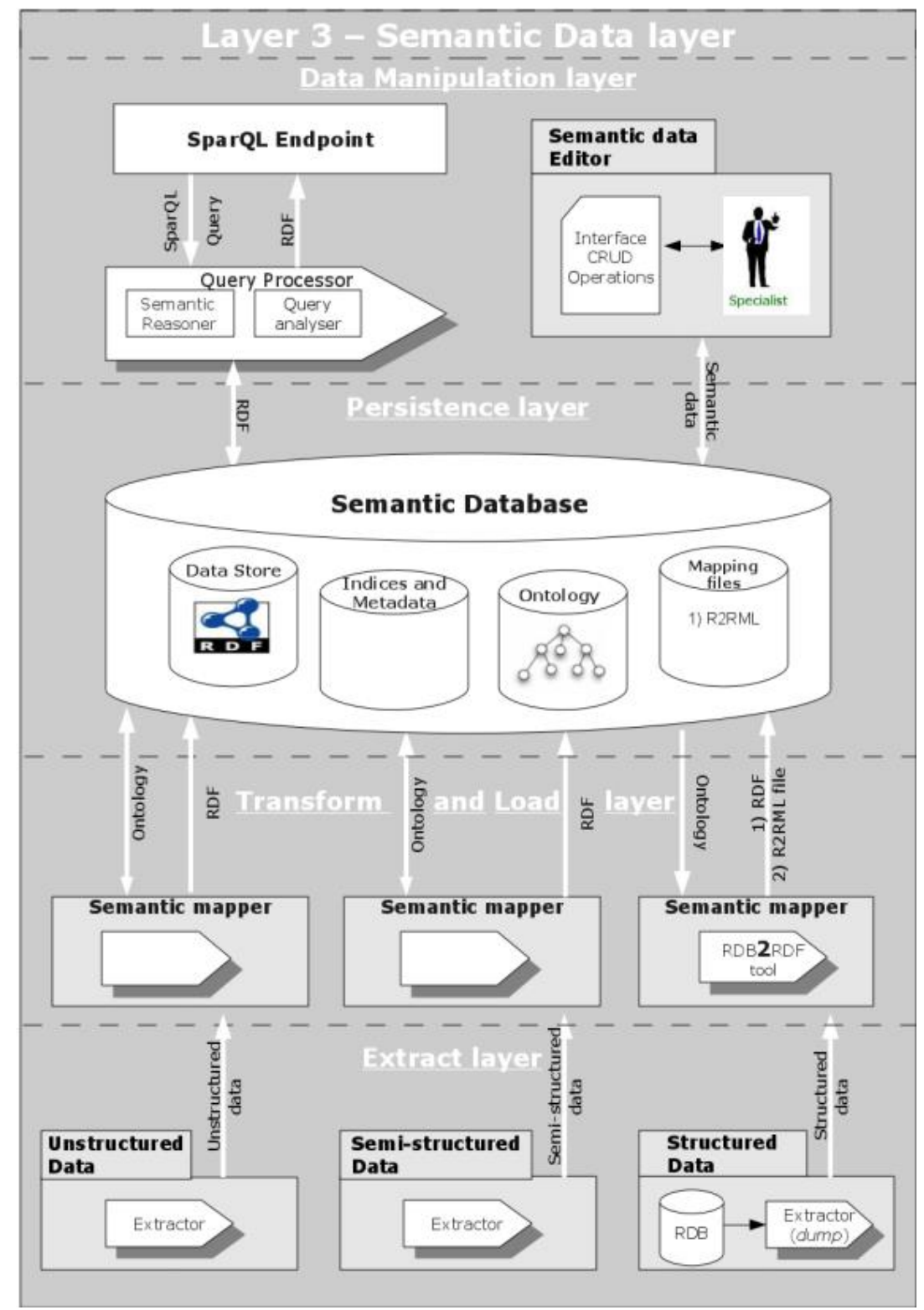

Fonte: Adaptado de Machado e Oliveira (2011).

Não obstante a menção explícita do processo de extração de dados semiestruturados e não estruturados no contexto de uma arquitetura, o que se assemelha com esta pesquisa, o trabalho de Machado e Oliveira (2011) tem como principal abordagem o mapeamento semântico com base em ontologias para mapear os dados em triplas RDF e assim persisti-las em um banco de dados semântico contido no contexto da mesma camada. Este aspecto se distancia da 
presente pesquisa por avançar além da terceira estrela da classificação de Tim Berners-Lee (BERNERS-LEE, 2010), conforme já discutido em seção específica neste capítulo. Adicionalmente, buscou-se na bibliografia versões mais recentes da proposta dos autores, porém sem resultados satisfatórios. 


\section{CARACTERIZAÇÃO DOS DADOS ABERTOS NOS MUNICÍPIOS BRASILEIROS}

Como um fenômeno global no contexto de OGD, uma das principais preocupações em todos os níveis de governo é com a relação à efetiva transparência e especialmente como divulgar informações considerando dados abertos desde os processos iniciais de produção do dado (CONRADIE; CHOENNI, 2014; LOURENÇO et al., 2013; YAVUZ; WELCH, 2014). Apesar da existência de legislações específicas neste sentido e a consolidação do tema na bibliografia, os governos tendem a disponibilizar dados sem observar integralmente os princípios de OGD (BUNYAKIATI; VORAVITTAYATHORN, 2012; COELHO et al., 2015; CORRÊA; CORRÊA; SILVA, 2014; CUNHA et al., 2015; DAVIES; FRANK, 2013; HELBIG et al., 2012; MACHADO; OLIVEIRA, 2011; RIBEIRO; MATHEUS; VAZ, 2011; SANTANA; RODRIGUES, 2013; VELJKOVIĆ; BOGDANOVIĆ-DINIĆ; STOIMENOV, 2014). Assim, identificar e compreender como os governos direcionam seus esforços para a transparência pública e como implementam suas infraestruturas de dados abertos é essencial para promover melhorias no cenário atual.

Dessa forma, este capítulo tem como objetivo caracterizar a situação dos dados abertos nos municípios brasileiros essencialmente a partir da avaliação de uma amostra com 561 websites de governos locais (CORRÊA et al., 2017). Previamente a esta ampla avaliação, procedeu-se com um levantamento preliminar com 20 municípios onde também se definiu o método de levantamento e os respectivos critérios de avaliação. Adicionalmente, foi realizada revisão bibliográfica para identificar avaliações semelhantes no cenário nacional e internacional a respeito do uso de dados abertos pelas instituições governamentais.

A caracterização contida neste capítulo não pretende disponibilizar mais um índice ou ranking de transparência, apesar de ser possível derivar os dados para este tipo de análise. Busca-se identificar e entender como as ações correntes de operacionalização de dados abertos e a transparência estão relacionadas com OGD no contexto dos municípios, e assim mapear os problemas existentes para levantar os requisitos da arquitetura sendo definida nesta pesquisa. 
Primeiramente, são evidenciados os critérios de avaliação definidos para a consecução dos levantamentos. Posteriormente, são apresentados os resultados obtidos com o levantamento preliminar com 20 munícipios e em seguida a apresentação da pesquisa bibliográfica sobre trabalhos semelhantes. Por conseguinte, são apresentados os resultados com a amostra de 561 websites e finalmente as discussões sobre os resultados que embasam os requisitos da arquitetura a serem discutidos no próximo capítulo.

\subsection{Definição dos critérios}

Como parte do método empregado nos levantamentos, definiu-se os critérios de avaliação a partir da checagem dos itens mínimos necessários definidos pela LAI (BRASIL, 2011) para a transparência ativa ( $\left(1^{\circ}\right.$ Art. $\left.8^{\circ}\right)$ e os seus requisitos técnicos (§ $3^{\circ}$ Art. $\left.8^{\circ}\right)$, os quais incorporam os princípios de OGD.

Com isso, além de obter os resultados para subsidiar esta pesquisa, foi possível disseminar os critérios empregados para que estes pudessem ser aplicados e aprimorados em outros estudos.

Primeiramente, faz-se necessário evidenciar os itens mínimos necessários definidos pela LAI e como se deu o processo de avaliação. A Tabela 4 expõe os itens conforme especificados na LAI.

Tabela 4 - Itens mínimos de divulgação para transparência ativa definidos pela LAI no $\S 1^{\circ}$ do Art. $8^{\circ}$

\begin{tabular}{l|l}
\hline Referência & \multicolumn{1}{c}{ Descrição } \\
\hline (a) & $\begin{array}{l}\text { Registro das competências e estrutura organizacional, endereços e telefones das } \\
\text { respectivas unidades e horários de atendimento ao público }\end{array}$ \\
\hline (b) & Registros de quaisquer repasses ou transferências de recursos financeiros \\
\hline (c) & Registros das despesas \\
\hline (d) & $\begin{array}{l}\text { Informações concernentes a procedimentos licitatórios, inclusive os respectivos } \\
\text { editais e resultados, bem como a todos os contratos celebrados }\end{array}$ \\
\hline (e) & $\begin{array}{l}\text { Dados gerais para o acompanhamento de programas, ações, projetos e obras de } \\
\text { órgãos e entidades }\end{array}$ \\
\hline (f) & Respostas a perguntas mais frequentes da sociedade \\
\hline
\end{tabular}

Fonte: Adaptado de Brasil (2011). 
O processo de avaliação consistiu na verificação da existência de cada item necessário apresentados na Tabela 4. Neste ponto, optou-se por não utilizar critérios binários e então definiu-se critérios compostos por três tipos de avaliação para cada item, expressos por Sim, Parcial e ãao. Por um lado, os municípios que divulgam corretamente o item obtêm a avaliação Sim (atende); por outro lado, Não representa a ausência total do item (não atende); o termo Parcial indica que o item não atende inteiramente o requerido pela LAI ou são fornecidas informações incompletas (atende parcialmente).

Com relação aos requisitos técnicos ( $\S 3^{\circ}$ Art. $8^{\circ}$ ), a LAl os define como necessários para atender a divulgação das informações pelos websites. Apesar deste parágrafo da LAl pressupor a regulamentação pelas respectivas leis ou decretos municipais, as diretrizes básicas são elencadas na lei nacional pelos seus incisos e trazem consigo a essência da maioria dos princípios de OGD. Neste sentido, considera-se como pertinente revisitar o mapeamento realizado na Tabela 1 do Capítulo 2, o qual considera a linguagem jurídica dos requisitos técnicos contidos na lei e os princípios de OGD. A Tabela 5 reproduz esse mapeamento e introduz uma descrição sucinta utilizada partir de agora para se referir aos requisitos técnicos. 
Tabela 5 - Requisitos técnicos mapeados e definição da descrição sucinta

\begin{tabular}{|c|c|c|}
\hline Requisitos técnicos da LAI (§ $3^{\circ}$ Art. 8) & Princípios de OGD & Descrição sucinta \\
\hline $\begin{array}{l}\text { I - conter ferramenta de pesquisa de conteúdo que } \\
\text { permita o acesso à informação de forma objetiva, } \\
\text { transparente, clara e em linguagem de fácil } \\
\text { compreensão }\end{array}$ & $\begin{array}{l}\text { 4. Acessível } \\
\text { 6. Não } \\
\text { discriminatório }\end{array}$ & I - Busca e acesso \\
\hline $\begin{array}{l}\text { II - possibilitar a gravação de relatórios em diversos } \\
\text { formatos eletrônicos, inclusive abertos e não } \\
\text { proprietários, tais como planilhas e texto, de modo a } \\
\text { facilitar a análise das informações }\end{array}$ & $\begin{array}{l}\text { 5. Processável por } \\
\text { máquina } \\
\text { 7. Não proprietário }\end{array}$ & II - Multi-formato \\
\hline $\begin{array}{l}\text { III - possibilitar o acesso automatizado por sistemas } \\
\text { externos em formatos abertos, estruturados e legíveis } \\
\text { por máquina }\end{array}$ & $\begin{array}{l}\text { 5. Processável por } \\
\text { máquina }\end{array}$ & $\begin{array}{l}\text { III - Legível por } \\
\text { máquina }\end{array}$ \\
\hline $\begin{array}{l}\text { IV - divulgar em detalhes os formatos utilizados para } \\
\text { estruturação da informação }\end{array}$ & $\begin{array}{l}\text { 1. Completo } \\
\text { 2. Primário }\end{array}$ & $\begin{array}{l}\text { IV - Estrutura dos } \\
\text { dados }\end{array}$ \\
\hline $\begin{array}{l}\mathrm{V} \text { - garantir a autenticidade e a integridade das } \\
\text { informações disponíveis para acesso }\end{array}$ & $\begin{array}{l}\text { Sem mapeamento } \\
\text { direto }\end{array}$ & $\begin{array}{l}\text { V - Autenticidade } \\
\text { e integridade }\end{array}$ \\
\hline $\begin{array}{l}\mathrm{VI} \text { - manter atualizadas as informações disponíveis } \\
\text { para acesso }\end{array}$ & 3. Atual & $\begin{array}{l}\mathrm{VI}-\text { Dados } \\
\text { atualizados }\end{array}$ \\
\hline $\begin{array}{l}\text { VII - indicar local e instruções que permitam ao } \\
\text { interessado comunicar-se, por via eletrônica ou } \\
\text { telefônica, com o órgão ou entidade detentora do sítio }\end{array}$ & $\begin{array}{l}\text { 1. Completos } \\
\text { 4. Accessíveis }\end{array}$ & $\begin{array}{l}\text { VII - Informações } \\
\text { de contato }\end{array}$ \\
\hline $\begin{array}{l}\text { VIII - adotar as medidas necessárias para garantir a } \\
\text { acessibilidade de conteúdo para pessoas com } \\
\text { deficiência }\end{array}$ & $\begin{array}{l}\text { 6. Não } \\
\text { discriminatório }\end{array}$ & $\begin{array}{l}\text { VIII - } \\
\text { Acessibilidade }\end{array}$ \\
\hline Não especificado na LAI & 8. Livre de licença & - \\
\hline
\end{tabular}

Fonte: Elaborado pelo autor.

A partir desse mapeamento, pode-se inferir que a lei brasileira incorpora os princípios de OGD, embora este entendimento decorra do jargão jurídico possivelmente não usual para parte dos entusiastas de OGD. Esta análise é relevante para entender que a política nacional já prevê os princípios de OGD em seu cenário e define as diretrizes para todos os níveis de governos em matéria de dados abertos. Ressalta-se, também, que existem outros indicadores de OGD especificados no decorrer de toda a LAI. 
Isso posto, para cada requisito técnico foram definidos critérios para orientar a avaliação dos websites. Os critérios são expressos por Sim (atende) e Não (não atende), de acordo com a presença de cada requisito, exceto o requisito VIII Acessibilidade que tem uma avaliação gradual específica. A este respeito, a acessibilidade é considerada de forma global para todo website. Acredita-se que se um website atenda ao requisito técnico, mesmo que parcialmente, seus criadores estão conscientes da necessidade e podem ser capazes de fazer melhorias para atingir níveis mais altos de acessibilidade. A Tabela 6 detalha os critérios de avaliação para cada requisito fornecendo uma descrição técnica que orientou o processo de avaliação. 
Tabela 6 - Critérios de avaliação para cada requisito técnico

\begin{tabular}{|c|c|c|}
\hline $\begin{array}{l}\text { Requisito } \\
\text { técnico }\end{array}$ & Critérios & Descrição \\
\hline \multirow{2}{*}{$\begin{array}{l}\text { I - Busca e } \\
\text { acesso }\end{array}$} & Sim & $\begin{array}{l}\text { Busca pelo termo despesa mostra a informação relacionada } \\
\text { corretamente }\end{array}$ \\
\hline & Não & Não há mecanismo de busca ou este não funciona corretamente \\
\hline \multirow[t]{2}{*}{ II - Multi-formato } & Sim & $\begin{array}{l}\text { Oferece ao menos um formato adicional além do formato adotado } \\
\text { por padrão pelo website. O formato adicional pode ser aberto e não } \\
\text { proprietário, porém não necessariamente }\end{array}$ \\
\hline & Não & $\begin{array}{l}\text { A informação é divulgada em apenas um formato de } \\
\text { disponibilização }\end{array}$ \\
\hline \multirow{2}{*}{$\begin{array}{l}\text { III - Legível por } \\
\text { máquina }\end{array}$} & Sim & $\begin{array}{l}\text { Divulga os dados nos formatos legíveis por máquina, como CSV, } \\
\text { JavaScript Object Notation (JSON), XML ou XLS (pode ser } \\
\text { proprietário) }\end{array}$ \\
\hline & Não & $\begin{array}{l}\text { Os dados são divulgados em outros formatos não considerados } \\
\text { como legíveis por máquina }\end{array}$ \\
\hline \multirow{2}{*}{$\begin{array}{l}\text { IV - Estrutura dos } \\
\text { dados }\end{array}$} & Sim & Fornece detalhes sobre como os dados são estruturados \\
\hline & Não & Não fornece detalhes sobre como os dados são estruturados \\
\hline $\begin{array}{l}\text { V - Autenticidade } \\
\text { e integridade }\end{array}$ & \multicolumn{2}{|c|}{ Não avaliado } \\
\hline \multirow{2}{*}{$\begin{array}{l}\text { VI - Dados } \\
\text { atualizados }\end{array}$} & Sim & $\begin{array}{l}\text { Dados sensíveis ao tempo são atualizados dentro de dois meses. A } \\
\text { checagem se deu pela localização de informações de data nos } \\
\text { cabeçalhos dos documentos ou nos registros }\end{array}$ \\
\hline & Não & $\begin{array}{l}\text { Dados sensíveis ao tempo não são atualizados ou são mais } \\
\text { antigos do que dois meses }\end{array}$ \\
\hline \multirow{2}{*}{$\begin{array}{l}\text { VII - Informações } \\
\text { de contato }\end{array}$} & Sim & Informações de contato são fornecidas \\
\hline & Não & Informações de contato não são fornecidas \\
\hline $\begin{array}{c}\text { VIII - } \\
\text { Acessibilidade }\end{array}$ & $1 \ldots 10$ & $\begin{array}{l}\text { Resultado de um índice que sumariza e quantifica as práticas de } \\
\text { acessibilidade adotadas pelas páginas web baseado nos níveis de } \\
\text { prioridade definidas pelo Web Content Accessibility Guidelines } 2.0 \\
\text { (WCAG), uma recomendação do W3C para desenvolvimento de } \\
\text { websites acessíveis (CALDWELL et al., 2008) }\end{array}$ \\
\hline
\end{tabular}

Fonte: Elaborado pelo autor. 


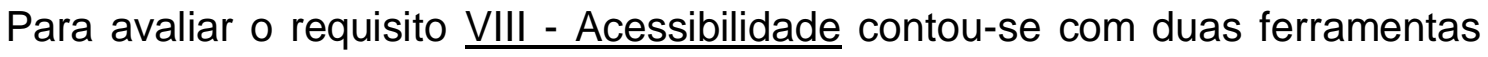
automatizadas especificamente desenvolvidas para esta finalidade. No levantamento preliminar, com 20 munícipios, foi utilizada a ferramenta Avaliador e Simulador de Acessibilidade em Sítios - ASES (SOFTWARE PÚBLICO BRASILEIRO, 2016) cujo funcionamento proporciona a avaliação de acessibilidade de páginas web de acordo com as recomendações do Modelo de Acessibilidade em Governo Eletrônico eMAG (GOVERNO ELETRÔNICO, 2016). O eMAG é uma versão brasileira baseada nas recomendações do W3C referentes ao WCAG (CALDWELL et al., 2008).

Já no levantamento amplo, com amostra de 561 websites municipais, contouse com a ferramenta AccessMonitor (FUNDAÇÃO PARA A CIÊNCIA E TECNOLOGIA, 2015) fornecida pela Fundação para a Ciência e Tecnologia do governo Português. Esta ferramenta faz uma avaliação automática de páginas web por meio de um simples índice quantificado de um a dez, onde valores mais altos indicam níveis mais elevados de acessibilidade com base nas recomendações do WCAG (CALDWELL et al., 2008). O AccessMonitor emprega um método específico para compor o índice e visa proporcionar um indicador simples e intuitivo para avaliar o cumprimento de acessibilidade.

\subsection{Levantamento preliminar}

Nas fases iniciais desta pesquisa conduziu-se uma avaliação preliminar (CORRÊA; CORRÊA; SILVA, 2014) com 20 websites municipais brasileiros para verificar o cumprimento da legislação de acesso à informação pelos governos locais e principalmente verificar qual o formato utilizado para disponibilização dos dados. Os dados foram coletados no período entre 16/09/2013 a 20/10/2013. Os municípios e as respectivas datas exatas de visita aos websites estão relacionados na Tabela 7 a seguir. 
Tabela 7 - Municípios pesquisados com a data de levantamento dos dados

\begin{tabular}{l|l|l}
\hline \multicolumn{1}{c|}{ Município } & \multicolumn{1}{c}{ População } & \multicolumn{1}{c}{ Data da visita } \\
\hline Americana & 210.638 & $16 / 09 / 2013$ \\
\hline Arthur Nogueira & 44.177 & $16 / 09 / 2013$ \\
\hline Campinas & 1.080 .113 & $19 / 09 / 2013$ \\
\hline Engenheiro Coelho & 15.721 & $01 / 10 / 2013$ \\
\hline Holambra & 11.299 & $25 / 09 / 2013$ \\
\hline Hortolândia & 192.692 & $25 / 09 / 2013$ \\
\hline Indaiatuba & 201.619 & $01 / 10 / 2013$ \\
\hline Itatiba & 101.471 & $01 / 10 / 2013$ \\
\hline Jaguariúna & 44.311 & $03 / 10 / 2013$ \\
\hline Monte Mor & 48.949 & $03 / 10 / 2013$ \\
\hline Nova Odessa & 51.242 & $15 / 10 / 2013$ \\
\hline Paulínia & 82.146 & $04 / 10 / 2013$ \\
\hline Pedreira & 41.558 & $04 / 10 / 2013$ \\
\hline Piracicaba & 364.571 & $20 / 10 / 2013$ \\
\hline Santa Bárbara d'Oeste & 180.009 & $27 / 09 / 2013$ \\
\hline Santo Antônio de Posse & 20.650 & $29 / 09 / 2013$ \\
\hline São José dos Campos & 629.921 & $20 / 10 / 2013$ \\
\hline Sumaré & 241.311 & $10 / 09 / 2013$ \\
\hline Valinhos & 106.793 & $10 / 09 / 2013$ \\
\hline Vinhedo & 63.611 & $10 / 09 / 2013$ \\
\hline
\end{tabular}

Fonte: Adaptado de Corrêa, Corrêa e Silva (2014).

A maioria dos municípios envolvidos neste levantamento preliminar estão localizados na Região Metropolitana de Campinas, cuja característica principal é o alto desenvolvimento tecnológico devido à concentração de indústrias de alta tecnologia, centros de pesquisa e serviços relacionados à tecnologia da informação e comunicação (LAMBAIS, 2009).

Este levantamento deu-se a partir da avaliação da existência dos itens de mínimos de divulgação e os requisitos técnicos empregados pelos websites, os quais foram definidos pelos critérios de avaliação detalhados na Seção 3.1 Definição dos critérios. Para cada item de divulgação atendido, checou-se também o formato de disponibilização adotado. 
O levantamento identificou que os princípios de OGD não estavam sendo considerados nas práticas de transparência e os governos locais têm preferido construir websites heterogêneos e utilizar predominantemente os formatos PDF e HTML como meios primários para divulgação dos dados. A Figura 7 apresenta um dos principais resultados obtidos sobre os formatos preferenciais utilizados para divulgação dos documentos.

Figura 7 - Formato preferencial para divulgação dos dados

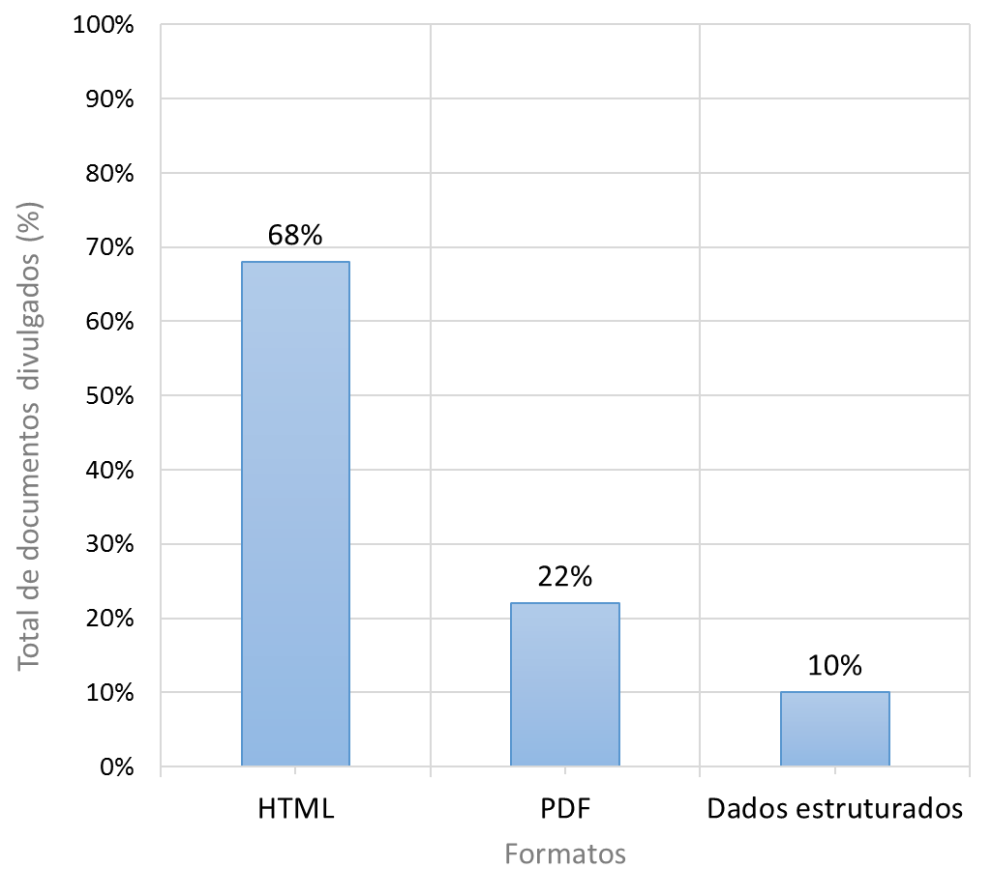

Fonte: Adaptado de Corrêa, Corrêa e Silva (2014).

Pelos resultados do levantamento preliminar, 68\% dos documentos de transparência divulgados estavam no formato HTML e 33\% no formato PDF; apenas $10 \%$ eram disponibilizados como dados estruturados, ou seja, que apresentavam as características da terceira estrela da classificação de Tim Berners-Lee (BERNERSLEE, 2010).

A Figura 8 apresenta os resultados do atendimento aos itens mínimos de divulgação estabelecidos no $\S 1^{\circ}$ do Art. 8ำ da LAI. Foram analisados os seis itens mínimos a partir dos critérios de avaliação definidos no método de levantamento. Com isso, verificou-se que apenas $24 \%$ dos seis itens são inteiramente atendidos, $32 \%$ são atendidos parcialmente e $44 \%$ não são atendidos, considerando o total dos 20 municípios avaliados. 
Figura 8 - Atendimento dos seis itens mínimos de divulgação

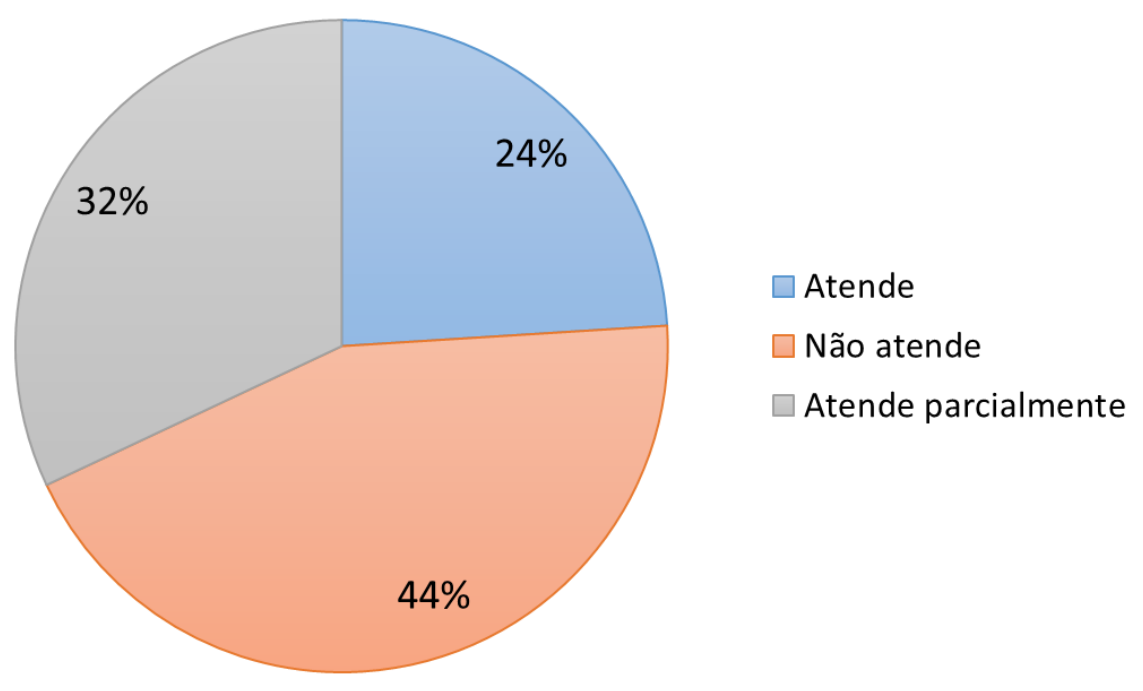

Fonte: Adaptado de Corrêa, Corrêa e Silva (2014).

A Figura 9 apresenta os resultados da avaliação dos requisitos técnicos estabelecidos no $\S 3^{\circ}$ do Art. $8^{\circ}$ da LAI. Os requisitos técnicos foram avaliados conforme os critérios definidos neste capítulo na Seção 3.1 - Definição dos critérios. 
Figura 9 - Atendimento dos requisitos técnicos estabelecidos na LAI

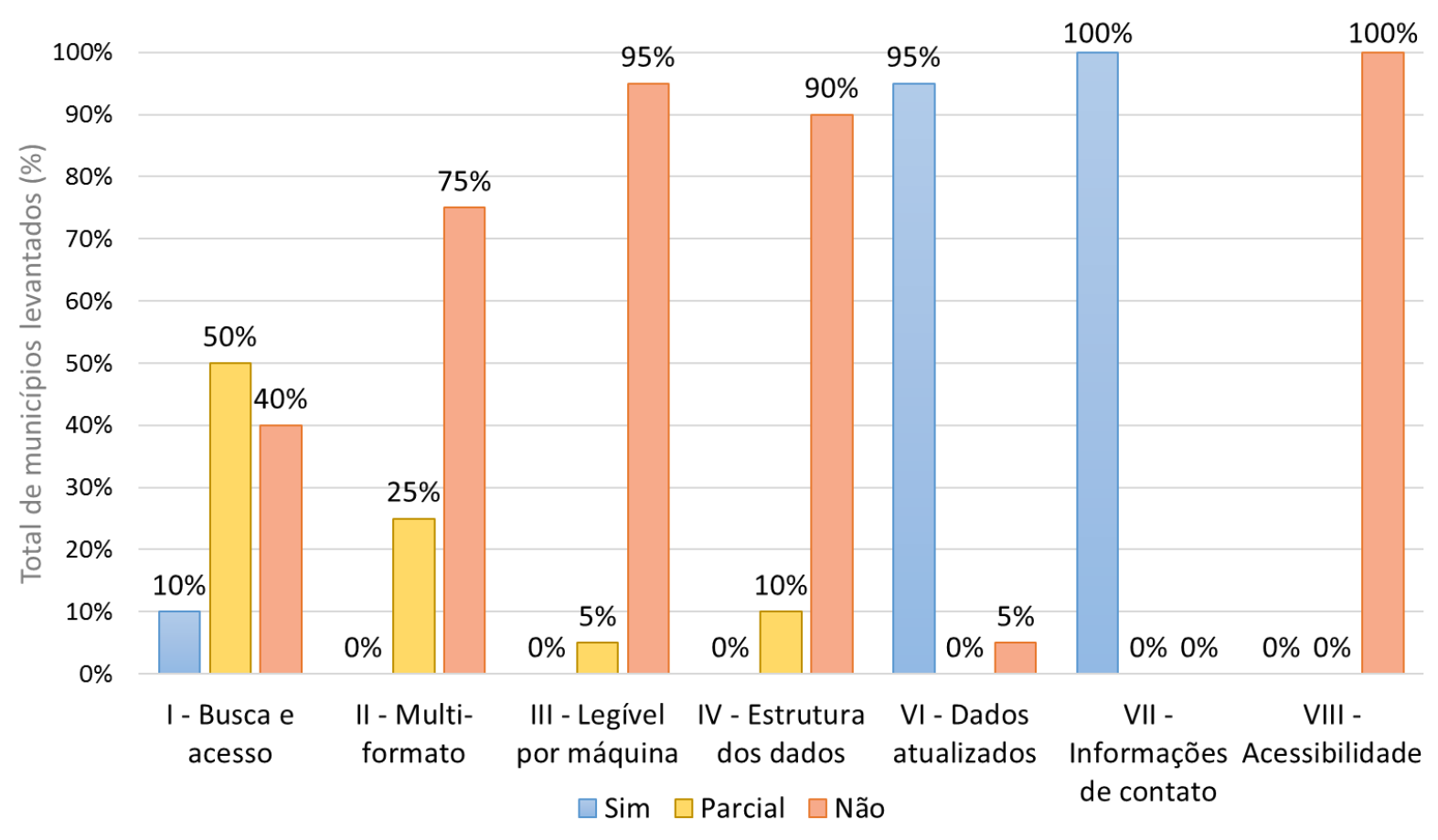

Fonte: Adaptado de Corrêa, Corrêa e Silva (2014).

Pelos resultados, percebe-se que a maioria dos requisitos técnicos (4/7) não são atendidos por $50 \%$ ou mais dos municípios avaliados. Os três piores resultados ficaram com os requisitos VIII - Acessibilidade, IV - Estrutura dos dados e III Legível por máquina, todos com percentual igual ou maior de $90 \%$ dos municípios que não os atendem.

A partir desses achados preliminares, foi realizada também pesquisa bibliográfica para identificar avaliações semelhantes no cenário nacional e internacional a respeito do uso de dados abertos pelas instituições governamentais. Conduziu-se, também, outro levantamento no cenário brasileiro com amostra ampliada a partir dos critérios aqui estabelecidos. As seções seguintes apresentam os resultados obtidos. 


\subsection{Levantamentos relacionados na bibliografia}

Considerando que OGD é uma área de estudo recente, há poucas pesquisas explorando o nível de divulgação de dados a partir da perspectiva de dados abertos. No contexto internacional, a Open Knowledge criou o Global Open Data Index ${ }^{9}$ para avaliar a situação dos dados abertos governamentais nos países. Esta iniciativa tem como objetivo avaliar a abertura em repositórios distribuídos de dados, mesmo que eles não dependam de uma infraestrutura específica de dados abertos. Anualmente, colaboradores ao redor do mundo coletam dados detalhados de países em dez áreas específicas de interesse na forma de datasets individuais. Cada dataset é avaliado com base em nove características semelhantes aos princípios de OGD. A edição de 2014 compara 97 lugares em todo o mundo com 970 entradas de datasets coletadas. Embora uma iniciativa útil, o índice global foi criado para servir de referência para o país em questão e pretende ser um índice global de dados abertos.

Voltado ao nível local de governo (municípios), Yavuz e Welch (2014) apresentam um estudo recente sobre websites governamentais e sua relação com dados abertos por meio de uma pesquisa nacional com 850 gestores governamentais em 500 cidades. Os autores desenvolveram um modelo conceitual de dados abertos para websites e testaram este modelo usando os dados da pesquisa. Os resultados foram comparados em três dimensões diferentes em termos de desenvolvimento da comunidade, finanças e segurança pública. As principais conclusões confirmam as hipóteses dos autores que maior abertura de dados nos websites é influenciada principalmente pela participação da sociedade e a capacidade técnica dos funcionários do governo.

Lourenço et al. (2013) avaliaram 94 municípios de Portugal e Itália. Os autores constataram que apesar da legislação sobre transparência, estes municípios não divulgam os dados corretamente de acordo com OGD, principalmente com problemas de visibilidade, formato adequado e estrutura de dados.

INESC (2014) apresenta uma avaliação de 29 websites brasileiros com base na análise estrita dos oito princípios de OGD para classificar os sites. A principal

\footnotetext{
${ }^{9} \mathrm{http}: / /$ index.okfn.org
} 
constatação indica problemas com a maioria dos princípios, a não ser os princípios Completo (presença de receitas e despesas) e Não discriminatório (não requer acesso especial) que estão sendo cumpridos pela maioria dos websites de transparência.

A Controladoria Geral da União (CGU) publicou a Escala Brasil Transparente, uma avaliação com amostra de 519 entes federativos entre municípios com até 50 mil habitantes, todas as capitais, estados e o Distrito Federal (CGU, 2015). Apesar de recente e com amostra significativa, o estudo não avaliou os itens mínimos de transparência ativa ( $\left(1^{\circ}\right.$ do Art. $\left.8^{\circ} \mathrm{da}\right)$ e, principalmente, os formatos dos dados de transparência não foram pesquisados, item imprescindível para análise sob o ponto de vista de OGD.

Cunha et al. (2015) analisaram 125 websites governamentais e 18 portais de dados abertos no contexto nacional. Segundo os autores, dados financeiros são mais disponibilizados do que outros, porém dados abertos ainda são incipientes nas capitais brasileiras e nos municípios acima de 400 mil habitantes, pois apenas $14,75 \%$ possuem dados abertos em portais próprios ou sistematizados em portais da transparência, sendo que a grande maioria $(77,8 \%)$ é referente às capitais nacionais.

Coelho et al. (2015) visitaram 85 websites de capitais e municípios e constataram que há espaço para avanços na abertura dos dados sobretudo nos governos locais. Os autores estabeleceram um índice de transparência com pontuação máxima de 70 pontos, sendo que o índice obtido foi de 45,8 para os estados e 43,3 para os municípios.

Na Tabela 8 estão resumidos todos os 17 trabalhos pesquisados na bibliografia e divulgados entre os anos de 2011 e 2015 os quais exploram a avaliação de websites ou repositórios para disponibilização de dados abertos. Relaciona-se a base análise, o método empregado e os principais achados de cada trabalho. 
Tabela 8 - Resumo dos achados na literatura a respeito da abertura de dados em websites de transparência

\begin{tabular}{|c|c|c|}
\hline Fonte & Base de análise e método & Principais achados \\
\hline $\begin{array}{l}\text { Coelho et al. } \\
(2015)\end{array}$ & $\begin{array}{l}\text { Avaliação de } 26 \text { capitais } \\
\text { estaduais e } 59 \text { grandes } \\
\text { municípios. } \\
\text { Estabelecimento de índice } \\
\text { de transparência com } \\
\text { pontuação máxima de } 70 \\
\text { pontos }\end{array}$ & $\begin{array}{l}\text { - } \quad \text { 45,8 pontos para os estados } \\
\text { - } 43,3 \text { para os municípios, onde há mais espaço } \\
\text { para avanços na temática de dados abertos }\end{array}$ \\
\hline $\begin{array}{l}\text { Cunha et al. } \\
\text { (2015) }\end{array}$ & $\begin{array}{l}\text { Avaliação de } 125 \text { websites } \\
\text { governamentais e } 18 \text { portais } \\
\text { de dados abertos }\end{array}$ & $\begin{array}{l}\text { - } 29,6 \% \text { das Unidades Federativas brasileiras } \\
\text { disponibilizam dados em formato aberto de } \\
\text { forma estruturada } \\
\text { - Nas capitais brasileiras e os municípios acima } \\
\text { de } 400 \text { mil habitantes, apenas } 14,75 \% \text { possuem } \\
\text { dados abertos em portais próprios ou } \\
\text { sistematizados em portais da transparência, } \\
\text { sendo que a grande maioria ( } 77,8 \%) \text { é referente } \\
\text { às capitais nacionais }\end{array}$ \\
\hline $\begin{array}{l}\text { Escala Brasil } \\
\text { Transparent } \\
\text { e - CGU } \\
(2015)\end{array}$ & $\begin{array}{l}\text { Avaliação de } 519 \text { entes } \\
\text { (municípios, capitais, } \\
\text { estados e Distrito Federal). } \\
\text { Análise de } 12 \text { quesitos que } \\
\text { dizem respeito à } \\
\text { regulamentação da LAl e à } \\
\text { transparência passiva }\end{array}$ & $\begin{array}{l}\text { - Resultados com base em ranking de estados e } \\
\text { municípios } \\
\text { - Cerca de } 66 \% \text { dos estados obtiveram nota maior } \\
\text { que 5,0 em uma escala de 0-10 } \\
\text { - Cerca de } 90 \% \text { dos munícipios obtiveram nota } \\
\text { menor do que 5,0 em uma escala de 0-10 }\end{array}$ \\
\hline $\begin{array}{l}\text { Open Data } \\
\text { Barometer } \\
(2015)\end{array}$ & $\begin{array}{l}\text { Terceira edição de um } \\
\text { levantamento de dados com } \\
92 \text { países para avaliar a } \\
\text { operacionalização de dados } \\
\text { abertos em termos de } \\
\text { preparação, implementação } \\
\text { e impacto }\end{array}$ & $\begin{array}{l}\text { - } 55 \% \text { dos países pesquisados têm iniciativas com } \\
\text { - Nados abertos } \\
\text { - } \text { comparação com as edições anteriores } \\
\text { - Os indicadores de implementação estagnaram } \\
\text { em comparação com as edições anteriores } \\
26 \text { dos } 30 \text { países no topo do ranking de dados } \\
\text { abertos são países ricos }\end{array}$ \\
\hline
\end{tabular}




\begin{tabular}{|c|c|c|}
\hline $\begin{array}{l}\text { Yavuz e } \\
\text { Welch } \\
(2014)\end{array}$ & $\begin{array}{l}\text { Pesquisa com } 850 \text { gestores } \\
\text { de governo em } 500 \text { cidades } \\
\text { norte americanas com } \\
\text { população entre } 25.000 \text { e } \\
250.000 \text { habitantes, cobrindo } \\
\text { as áreas de desenvolvimento } \\
\text { da comunidade, segurança } \\
\text { pública e finanças. } \\
\text { Considera } 12 \text { variáveis } \\
\text { independentes }\end{array}$ & $\begin{array}{l}\text { - Os autores testaram suas cinco hipóteses (H1- } \\
\text { - Au) construídas da bibliografia } \\
\text { (H4), influência da sociedade civil (H3), aumento } \\
\text { da capacidade técnica (H1) e aumento da } \\
\text { utilidade percebida da tecnologia (website) são } \\
\text { positiva e significantemente relacionados à } \\
\text { abertura dos dados nos websites } \\
\text { - O controle organizacional (H2) está relacionado } \\
\text { com baixa abertura dos dados nos websites }\end{array}$ \\
\hline $\begin{array}{l}\text { INESC } \\
(2014)\end{array}$ & $\begin{array}{l}\text { Avaliação com } 29 \text { websites } \\
\text { brasileiros, sendo } 27 \text { de } \\
\text { capitais, um do Governo } \\
\text { Federal e um do Senado } \\
\text { Federal. Os oito princípios de } \\
\text { OGD foram levados em } \\
\text { consideração na análise }\end{array}$ & $\begin{array}{l}\text { - A maioria dos websites atendem aos princípios } \\
\text { - Completo e Não discriminatório } \\
\text { representado pela presença de informações de } \\
\text { receitas e despesas, as quais são providas por } \\
\text { 96,55\% dos websites } \\
\text { - Não discriminatório indica acesso aos dados } \\
\text { sem qualquer restrição (usuário, senha, sistema, } \\
\text { etc.) } \\
\text { - O problema mais contundente reside nos } \\
\text { princípios Primário, Atual, Acessível e Livre de } \\
\text { licenças }\end{array}$ \\
\hline $\begin{array}{l}\text { Conradie e } \\
\text { Choenni } \\
(2014)\end{array}$ & $\begin{array}{l}\text { Avaliação da divulgação de } \\
\text { dados em seis locais do } \\
\text { setor público localizados nos } \\
\text { Países Baixos, através de } \\
\text { workshops, entrevistas, } \\
\text { questionários e pesquisa de } \\
\text { dados secundários }\end{array}$ & $\begin{array}{l}\text { - Uma visão diferenciada é necessária para } \\
\text { desenhar estratégia de divulgação de dados no } \\
\text { nível local, que envolve um cenário complexo de } \\
\text { diversidade } \\
\text { - Evitar a divulgação de dados guiada apenas pelo } \\
\text { entusiasmo: a motivação deveria ser dirigida } \\
\text { para a necessidade de um governo transparente } \\
\text { e aumento da participação pública } \\
\text { - Implementações de dados abertos em grande } \\
\text { escala requer atenção especial. Implementações } \\
\text { parciais são adequadas para reduzir a } \\
\text { complexidade }\end{array}$ \\
\hline
\end{tabular}




\begin{tabular}{|c|c|c|}
\hline $\begin{array}{l}\text { Open } \\
\text { Knowledge } \\
\text { Global Open } \\
\text { Data Index, } \\
\text { edição de } \\
2014\end{array}$ & $\begin{array}{l}\text { Comparação internacional de } \\
\text { países com } 97 \text { locais e } 970 \\
\text { entradas de datasets em dez } \\
\text { campos específicos de } \\
\text { interesse. Cada dataset é } \\
\text { avaliado com base em nove } \\
\text { características }\end{array}$ & $\begin{array}{l}\text { - Brasil está colocado na } 26^{\circ} \text { posição com } 56 \% \text { de } \\
\text { seus dados considerados abertos } \\
\text { - Os três países melhores colocados são Reino } \\
\text { Unido, Dinamarca e França }\end{array}$ \\
\hline $\begin{array}{l}\text { Veljković et } \\
\text { al. (2014) }\end{array}$ & $\begin{array}{l}\text { Proposto um modelo de } \\
\text { benchmark testado no } \\
\text { principal repositório norte } \\
\text { americano data.gov, em } \\
\text { outubro de } 2012 \\
\end{array}$ & $\begin{array}{l}\text { - O indicador de resultado referente a dado } \\
\text { processável por máquina obteve a menor } \\
\text { pontuação no estudo, parcialmente por causa } \\
\text { dos documentos serem em formato PDF }\end{array}$ \\
\hline $\begin{array}{l}\text { Lourenço et } \\
\text { al. (2013) }\end{array}$ & $\begin{array}{l}\text { Avaliação de } 45 \text { municípios } \\
\text { em Portugal e } 49 \text { na ltália, } \\
\text { analisando um total de } 13 \\
\text { itens de divulgação de dados } \\
\text { em três critérios (visibilidade, } \\
\text { formato e entrega) para } \\
\text { compor o que os autores } \\
\text { chamaram de Índice de } \\
\text { Transparência }\end{array}$ & $\begin{array}{l}\text { - Nenhum dos dois países tem divulgação } \\
\text { suficiente para o processo de prestação de } \\
\text { contas (accountability) } \\
\text { - Principalmente prescindem de visibilidade, } \\
\text { formato definido e apresentação autônoma para } \\
\text { atingir OGD } \\
\text { - Países precisam adotam legislação efetiva para } \\
\text { atingir a divulgação ativa } \\
\text { - OGD e transparência garantidos meramente } \\
\text { - Dela lei não é suficiente } \\
\text { tecnolrizes deveriam incluir ferramentas para permitir análises automáticas }\end{array}$ \\
\hline $\begin{array}{l}\text { Grimmelikhui } \\
\text { jsen et al. } \\
(2013)\end{array}$ & $\begin{array}{l}\text { Avalia e compara o efeito da } \\
\text { transparência na confiança } \\
\text { dos cidadãos nos governos } \\
\text { dos Países Baixos e Coréia } \\
\text { do Sul }\end{array}$ & $\begin{array}{l}\text { - O efeito da transparência difere por conta dos } \\
\text { valores culturais dos países avaliados } \\
\text { Em ambos os governos a transparência teve } \\
\text { efeito ameno e por vezes negativo na confiança } \\
\text { nos governos }\end{array}$ \\
\hline $\begin{array}{l}\text { Detlor et al. } \\
\text { (2013) }\end{array}$ & $\begin{array}{l}\text { Realizada uma pesquisa } \\
\text { com } 1.279 \text { respondentes } \\
\text { sobre suas percepções de } \\
\text { cinco portais comunitários } \\
\text { municipais na província de } \\
\text { Ontário, Canadá }\end{array}$ & $\begin{array}{l}\text { - A qualidade da informação tem um papel crítico, } \\
\text { porém indireto em influenciar o uso dos portais } \\
\text { pelas pessoas } \\
\text { - A percepção de facilidade de uso dos portais } \\
\text { afeta sua utilização }\end{array}$ \\
\hline
\end{tabular}




\begin{tabular}{|c|c|c|}
\hline $\begin{array}{l}\text { Davies e } \\
\text { Frank (2013) }\end{array}$ & $\begin{array}{l}\text { Estudo de caso com técnicos } \\
\text { do programa de estratégia } \\
\text { digital do governo do Reino } \\
\text { Unido }\end{array}$ & $\begin{array}{l}\text { - Há disseminação de planilhas PDF em } \\
\text { detrimento da presença de dados de texto puro } \\
\text { legíveis por máquina }\end{array}$ \\
\hline $\begin{array}{l}\text { Cruz et al. } \\
(2012)\end{array}$ & $\begin{array}{l}\text { Avaliação de } 96 \text { municípios } \\
\text { brasileiros incluindo os } 100 \\
\text { mais densos em população. } \\
\text { Os autores estabeleceram o } \\
\text { nível de transparência de um } \\
\text { modelo pesquisado } \\
\text { denominado ITGP-M }\end{array}$ & $\begin{array}{l}\text { - Os municípios da amostra não divulgam } \\
\text { completamente as informações a respeito da } \\
\text { administração pública } \\
\text { - Melhores condições socioeconômicas tendem a } \\
\text { envolver maior transparência }\end{array}$ \\
\hline $\begin{array}{l}\text { Youngblood } \\
\text { e } \\
\text { Mackiewicz } \\
\text { (2012) }\end{array}$ & $\begin{array}{l}\text { Comparados websites } \\
\text { municipais no Alabama e } \\
\text { examinada a correlação } \\
\text { entre o índice de usabilidade } \\
\text { e a população, assim como o } \\
\text { índice de usabilidade e a } \\
\text { renda per capita }\end{array}$ & $\begin{array}{l}\text { - Revelou problemas substanciais com a } \\
\text { usabilidade dos websites, incluindo a } \\
\text { acessibilidade das páginas web }\end{array}$ \\
\hline $\begin{array}{l}\text { Bunyakiati e } \\
\text { Voravittayath } \\
\text { orn (2012) }\end{array}$ & $\begin{array}{l}\text { Examina a disseminação de } \\
\text { formatos de dados por } \\
\text { agências de estatísticas, } \\
\text { organizações internacionais } \\
\text { e importantes datasets dos } \\
\text { países asiáticos Tailândia, } \\
\text { Camboja, Laos e Miramar }\end{array}$ & $\begin{array}{l}\text { - A maioria dos datasets pesquisados são } \\
\text { disseminados nos formatos PDF e HTML }\end{array}$ \\
\hline $\begin{array}{l}\text { Armstrong } \\
(2011)\end{array}$ & $\begin{array}{l}\text { Avaliação com } 134 \text { websites } \\
\text { de governos locais no } \\
\text { Estado da Flórida, Estados } \\
\text { Unidos, divididos em duas } \\
\text { categorias: websites de } \\
\text { municípios e websites } \\
\text { educacionais }\end{array}$ & $\begin{array}{l}\text { - Websites escolares disponibilizam mais } \\
\text { informações do que aqueles voltados aos } \\
\text { municípios } \\
\text { - Os dados dos websites municipais são fadados } \\
\text { à rápida mudança, o que impõe maiores } \\
\text { dificuldades para mantê-los atualizados } \\
\text { - O nível de alcance dos serviços públicos por } \\
\text { meio dos websites é um indicador positivo para o } \\
\text { nível de transparência }\end{array}$ \\
\hline
\end{tabular}

Fonte: Elaborado pelo autor. 


\subsection{Levantamento amplo}

Este levantamento (CORRÊA et al., 2017) consistiu de uma visita aos websites de governos municipais do poder executivo. As visitas ocorreram entre o período de 25/04/2014 a 09/12/2014 e os dados foram coletados em um momento no tempo, assim os resultados obtidos têm como base um instantâneo da disponibilidade dos registros durante o momento da coleta.

Para encontrar os websites dos municípios selecionados, tentou-se, primeiramente, o acesso à estrutura de nomeação padrão dos domínios de governo, que consiste do nome do município por extenso e a sigla do estado, seguidos do sufixo gov.br. Caso não fosse encontrado, era realizada uma pesquisa usando serviços de buscas na internet pois vários websites simplesmente não seguiam a estrutura de domínio padronizada.

Os municípios avaliados foram escolhidos aleatoriamente a partir da amostra definida para este levantamento, que foi de 561 websites locais. À época da coleta dos dados, no Brasil havia 5.565 municípios dentro das 27 unidades de federação, de acordo com o IBGE (IBGE, 2013). Para ter resultados consistentes e retratar o tamanho continental do país, calculou-se a amostra em cada unidade de federação proporcionalmente ao número de municípios existentes.

Em primeiro lugar, obteve-se o universo a partir do total de municípios. 0 universo aqui considerado engloba os municípios com mais de 10.000 habitantes. Esta restrição vem da LAl que exige dos municípios com essa população a divulgação das informações pela internet por websites específicos (BRASIL, 2011). Municípios menores podem adotar outros métodos de divulgação.

A Tabela 9 decompõe todas as unidades de federação com o total de municípios, o universo de interesse e tamanho da amostra. O número de habitantes também é mostrado para dar uma ideia do quanto da sociedade é representada pela amostra. A última coluna da tabela (\% univ.) representa a porcentagem do universo, considerando o número de habitantes. Em seguida, a amostra escolhida representa, em média, cerca de $17 \%$ dos habitantes do universo de interesse. A amostra corresponde pela seleção de 561 municípios. 
Tabela 9 - Total de municípios, universo de interesse e cálculo da amostra por unidade de federação.

\begin{tabular}{|c|c|c|c|c|c|c|c|c|}
\hline & & \multicolumn{2}{|c|}{ Total } & \multicolumn{2}{|c|}{$\begin{array}{c}\text { Universo interesse } \\
\text { Hab. > 10,000 }\end{array}$} & \multicolumn{3}{|c|}{ Amostra } \\
\hline \multicolumn{2}{|l|}{ Estados } & Munic. & Hab. & Munic. & Hab. & Munic. & Hab. & $\%$ univ. \\
\hline Acre & $A C$ & 22 & 733.559 & 15 & 681.793 & 3 & 68.690 & $10,1 \%$ \\
\hline Alagoas & $\mathrm{AL}$ & 102 & 3.120 .494 & 74 & 2.943 .785 & 14 & 325.389 & $11,1 \%$ \\
\hline Amapá & $\mathrm{AP}$ & 16 & 669.526 & 9 & 629.521 & 2 & 112.034 & $17,8 \%$ \\
\hline Amazonas & AM & 62 & 3.483 .985 & 57 & 3.442 .499 & 11 & 301.214 & $8,7 \%$ \\
\hline Bahia & $\mathrm{BA}$ & 417 & 14.016 .906 & 348 & 13.505 .977 & 63 & 1.747 .281 & $12,9 \%$ \\
\hline Ceará & CE & 184 & 8.452 .381 & 163 & 8.300 .510 & 30 & 786.289 & $9,5 \%$ \\
\hline Distrito Federal & DF & 1 & 2.570 .160 & 1 & 2.570 .160 & 1 & 2.570 .260 & $100,0 \%$ \\
\hline Espírito Santo & ES & 78 & 3.514 .952 & 66 & 3.422 .101 & 12 & 842.349 & $24,6 \%$ \\
\hline Goiás & $\mathrm{GO}$ & 246 & 6.003 .788 & 91 & 5.289 .573 & 17 & 726.618 & $13,7 \%$ \\
\hline Maranhão & MA & 217 & 6.574 .789 & 179 & 6.323 .710 & 33 & 944.004 & $14,9 \%$ \\
\hline Mato Grosso & MT & 141 & 3.035 .122 & 74 & 2.710 .648 & 14 & 318.432 & $11,7 \%$ \\
\hline Mato Grosso do Sul & MS & 78 & 2.449 .024 & 53 & 2.291 .517 & 10 & 240.024 & $10,5 \%$ \\
\hline Minas Gerais & MG & 853 & 19.597.330 & 362 & 16.997 .609 & 65 & 5.382 .801 & $31,7 \%$ \\
\hline Pará & PA & 143 & 7.581 .051 & 131 & 7.501 .261 & 24 & 926.812 & $12,4 \%$ \\
\hline Paraíba & PB & 223 & 3.766 .528 & 86 & 3.070 .538 & 16 & 380.939 & $12,4 \%$ \\
\hline Paraná & PR & 399 & 10.444 .526 & 196 & 9.379 .110 & 36 & 1.926 .891 & $20,5 \%$ \\
\hline Pernambuco & $\mathrm{PE}$ & 185 & 8.796 .448 & 167 & 8.669 .670 & 30 & 1.046 .691 & $12,1 \%$ \\
\hline Piauí & $\mathrm{PI}$ & 224 & 3.118 .360 & 60 & 2.255 .605 & 11 & 177.021 & $7,8 \%$ \\
\hline Rio de Janeiro & RJ & 92 & 15.989 .929 & 85 & 15.935 .059 & 16 & 2.232 .088 & $14,0 \%$ \\
\hline Rio Grande do Norte & $\mathrm{RN}$ & 167 & 3.168 .027 & 66 & 2.637 .188 & 12 & 436.860 & $16,6 \%$ \\
\hline Rio Grande do Sul & RS & 496 & 10.693 .929 & 165 & 9.312 .280 & 30 & 1.591 .254 & $17,1 \%$ \\
\hline Rondônia & $\mathrm{RO}$ & 52 & 1.562 .409 & 36 & 1.462 .291 & 7 & 304.280 & $20,8 \%$ \\
\hline Roraima & $\mathrm{RR}$ & 15 & 450.479 & 8 & 393.508 & 2 & 25.735 & $6,5 \%$ \\
\hline Santa Catarina & SC & 293 & 6.248 .436 & 121 & 5.439 .616 & 22 & 1.379 .545 & $25,4 \%$ \\
\hline São Paulo & SP & 645 & 41.262 .199 & 366 & 39.888 .244 & 66 & 4.799 .407 & $12,0 \%$ \\
\hline Sergipe & SE & 75 & 2.068 .017 & 47 & 1.907 .543 & 9 & 337.672 & $17,7 \%$ \\
\hline Tocantins & TO & 139 & 1.383 .445 & 26 & 878.203 & 5 & 144.744 & $16,5 \%$ \\
\hline TOTAL & & 5.565 & 190.755 .799 & 3.052 & 177.839 .519 & 561 & 30.075 .324 & $16.9 \%$ \\
\hline
\end{tabular}

Fonte: Adaptado de Corrêa et al. (2017).

O Apêndice A deste trabalho detalha todos os municípios da amostra considerados no levantamento amplo, juntamente com o indicativo da população residente, data da visita e coleta dos dados e o endereço utilizado para acesso ao website. 
A Figura 10 (a) mostra o quantitativo de websites avaliados com 0 desdobramento do número de endereços com a presença de convenção para nomeação de domínios governamentais e a Figura 10 (b) mostra o quantitativo de websites (daqueles avaliados) que tiveram sua acessibilidade verificada.

Figura 10 - (a) Número de websites avaliados e presença de convenção para nomeação de domínios governamentais. (b) Número de websites que tiveram a acessibilidade verificada

(a)

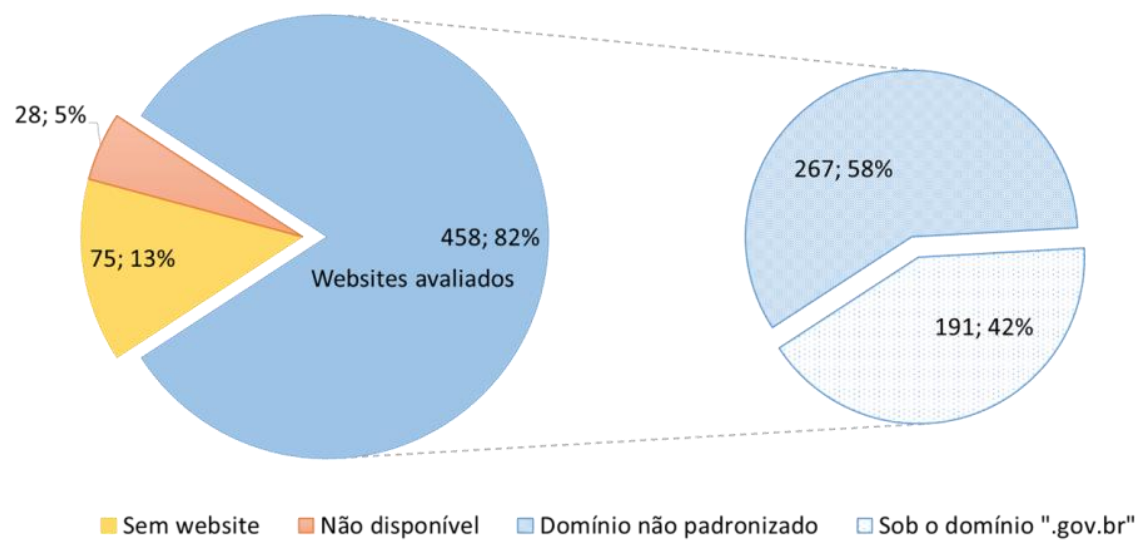

(b)

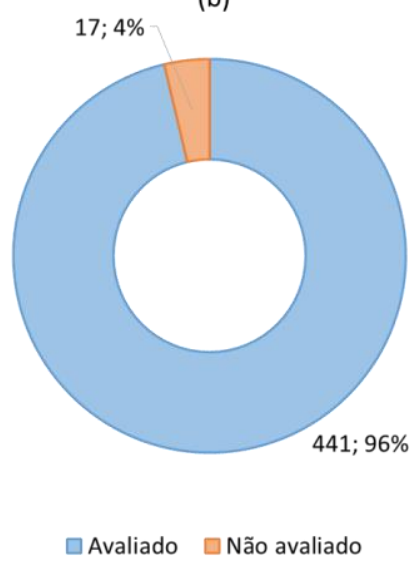

Fonte: Adaptado de Corrêa et al. (2017).

A maioria dos municípios (82\% ou 458 municípios) teve seu website avaliado. Destes, $58 \%$ são divulgados sob domínios não convencionados o que dificulta 0 acesso por parte dos cidadãos habituados a identificar um site oficial de governo. Assim, apenas $42 \%$ dos websites analisados seguiam a convenção. Não foi encontrado qualquer website em 13\% dos municípios da amostra mesmo após utilização de serviço de busca. Apenas $5 \%$ dos websites identificados não foram acessados por problemas técnicos encontrados no momento da consulta, contudo tiverem seu endereço localizado.

Quanto aos recursos de acessibilidade, dentro do conjunto de 458 websites avaliados, 441 ou $96 \%$ deles tiveram sua acessibilidade verificada. Os restantes $4 \%$ apresentaram alguma característica que impediu que a ferramenta de verificação funcionasse corretamente e, portanto, o índice de acessibilidade aferido.

A Figura 11 a seguir mostra os formatos preferenciais adotados para disponibilização dos dados, considerando o total de documentos encontrados nos 
websites que atendiam ou atendiam parcialmente os itens mínimos de divulgação

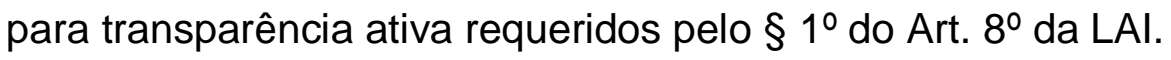

Figura 11 - Formatos preferenciais para a divulgação dos documentos de transparência

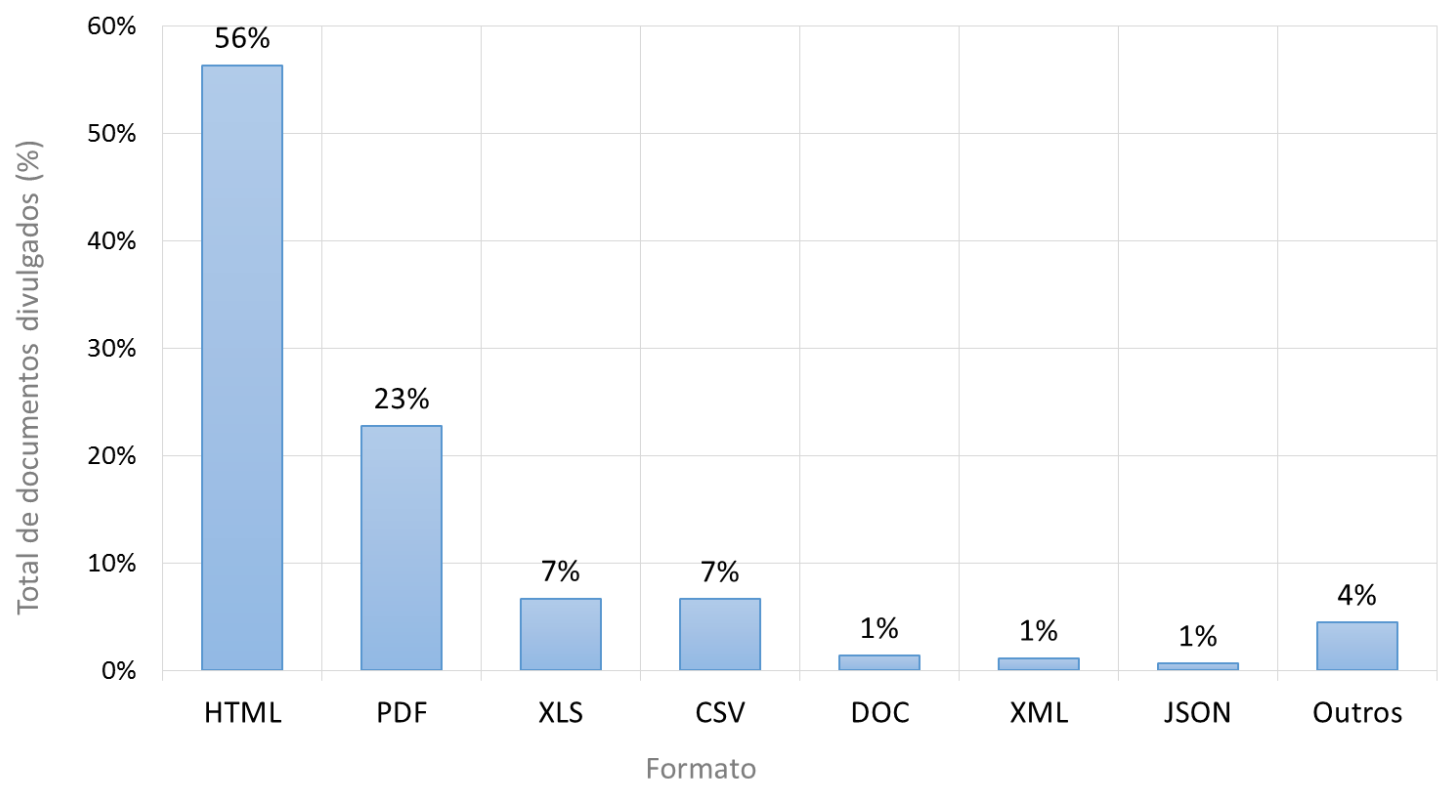

Fonte: Adaptado de Corrêa et al. (2017).

HTML é o formato mais disseminado, encontrado em $56 \%$ do total de documentos divulgados. Em segundo lugar, os arquivos PDF estão presentes em $23 \%$ dos documentos. Formatos legíveis por máquina, tais como XLS, CSV, XML e JSON representam $16 \%$ dos documentos. Outros formatos representam tipos de arquivo incomuns, como Rich Text Format (RTF), Open Document Spreadsheet (ODS), Portable Network Graphics (PNG), Joint Photographic Experts Group (JPEG) e outros, figurando em $4 \%$ do total dos documentos divulgados.

A Figura 12 apresenta o atendimento de cada item necessário usado para a transparência ativa. Os itens necessários (a) - (f) foram extraídos do $\S 1^{\circ}$ do Art. $8^{\circ}$ da LAI (BRASIL, 2011) e são reproduzidos na Tabela 4 da Seção 3.1 - Definição dos critérios deste capítulo. Conforme discutido na seção, definiu-se três tipos de critérios onde Atende indica a divulgação correta do item, Atende parcialmente sugere que 0 item não satisfaz inteiramente a requisição da lei ou fornece informações incompletas e o último critério Não atende simplesmente indica que o munício não cumpre a legislação. 
Figura 12 - Atendimento dos itens mínimos de divulgação para transparência ativa, conforme $\S 1^{\circ}$ do Art. $8^{\circ}$ da LAI

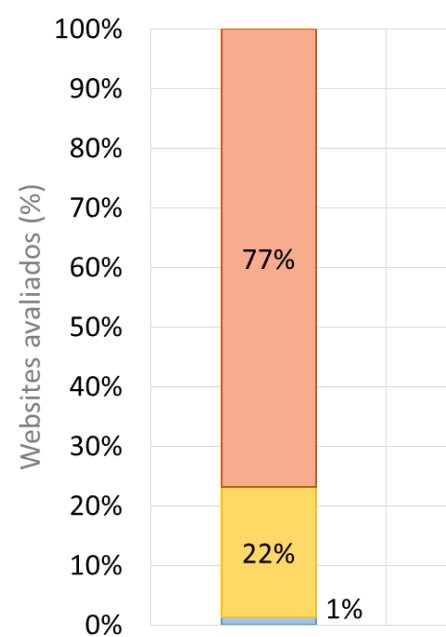

(a)

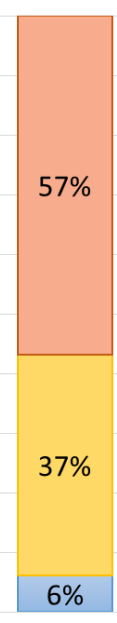

(b)

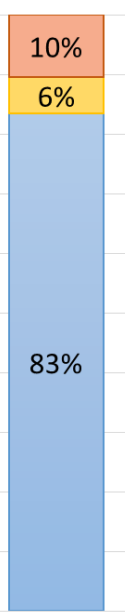

(c)

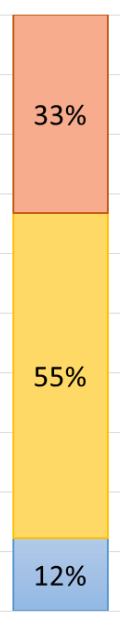

(d)

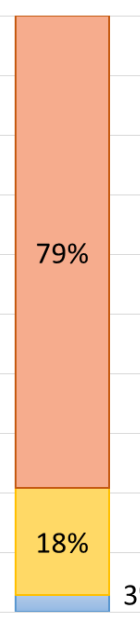

(e)

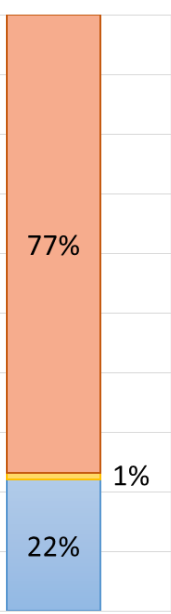

(f)

Itens mínimos de divulgação

$\square$ Atende $\square$ Atende parcialmente $\square$ Não atende

Fonte: Adaptado de Corrêa et al. (2017).

De acordo com os resultados da Figura 12, a melhor avaliação foi a respeito da divulgação dos Registros das despesas (c) com $83 \%$ de atendimento pelos websites avaliados. O pior resultado ficou com a divulgação dos Dados gerais para 0 acompanhamento de programas, ações, projetos e obras de órgãos e entidades (e), com $79 \%$ de não atendimentos pelos websites avaliados. A maioria dos itens indicou não atendimento ou atendimento parcial.

A Figura 13 mostra o agrupamento do número total de itens mínimos de divulgação que atendiam aos requisitos legais. Este gráfico também apresenta uma informação extra que é a média do índice de acessibilidade proveniente do requisito técnico VIII - Acessibilidade definido no $\S 3^{\circ}$ do Art. 8ํ da LAI. Adicionalmente, é apresentado o índice de acessibilidade global para efeito de comparação. O critério

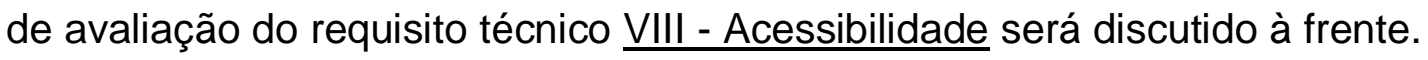


Figura 13 - Atendimento e índice de acessibilidade pelo total de itens mínimos de divulgação

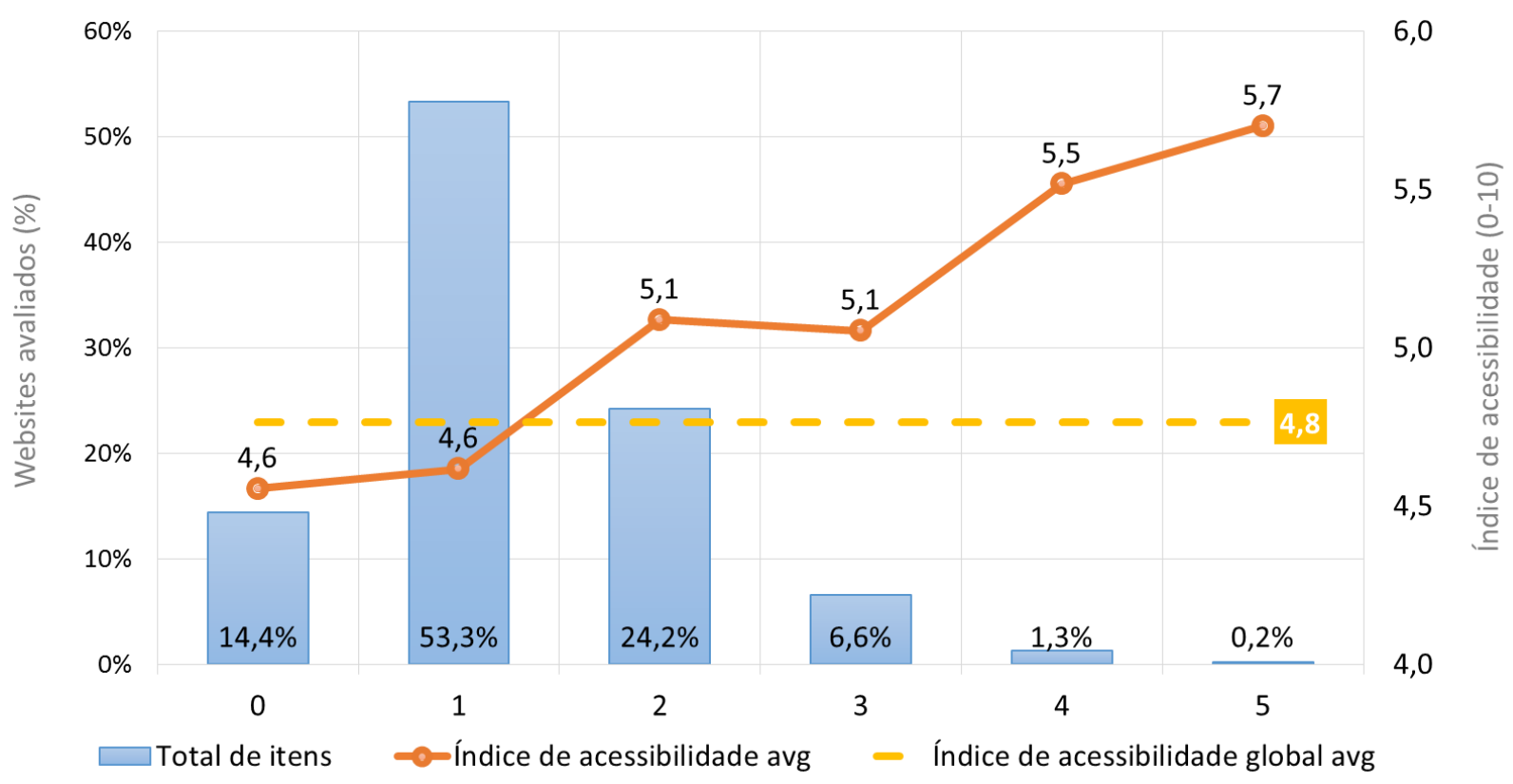

Fonte: Adaptado de Corrêa et al. (2017).

Pela Figura 13 os websites avaliados divulgaram um total de um a cinco itens. Neste ponto, não foi considerado o atendimento parcial; portanto, apenas os itens que receberam a avaliação Atende figuram nas séries, exceto o valor zero que indica o percentual de websites que simplesmente não divulgam qualquer item mínimo necessário.

Nenhum website divulgou o total de seis itens mínimos necessários estabelecidos na LAI. A maioria de 53,3\% dos websites divulgou apenas um item, seguido por dois itens por $24,2 \%$ dos websites. A média do índice de acessibilidade tende a aumentar à medida que os websites divulgavam mais itens. A média do índice de acessibilidade global foi de 4,8 de um intervalo de 0-10.

Quanto aos requisitos técnicos que os websites precisam atender, a Figura 14 mostra como foi o atendimento de acordo com os critérios de avaliação. Neste ponto, ressalta-se que foram definidos apenas dois critérios: Atende e Não atende. Todos os detalhes dos critérios de avaliação para os requisitos técnicos foram previamente discutidos e estão especificados na Tabela 6 da Seção 3.1 - Definição dos critérios. 
Figura 14 - Atendimento dos requisitos técnicos que os websites precisam atender, conforme $\S 3^{\circ}$ do Art. 8 da LAI (mapeados na Tabela 5)

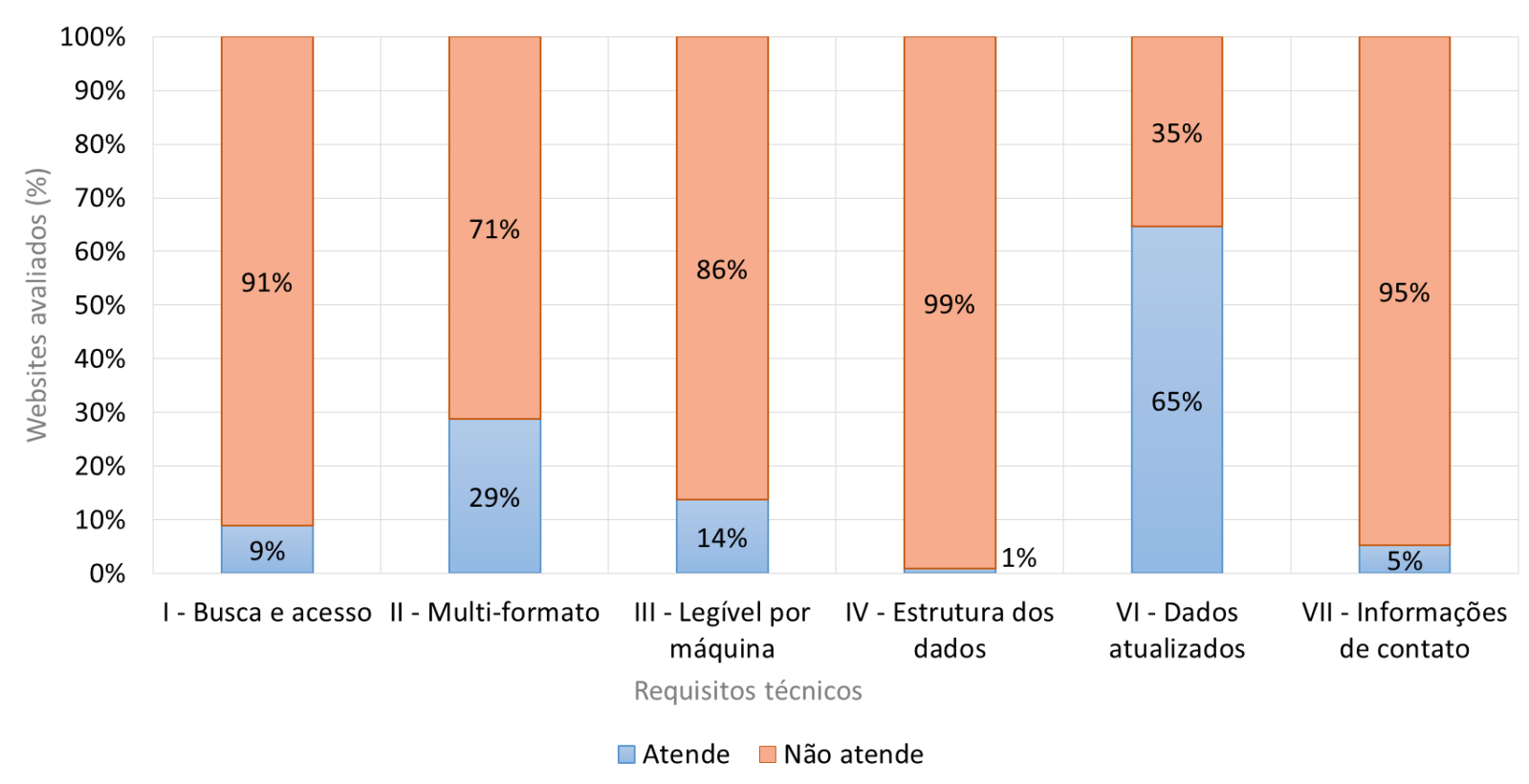

Fonte: Adaptado de Corrêa et al. (2017).

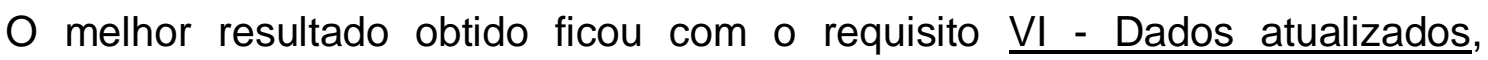
atendido por $65 \%$ dos websites avaliados. Por outro lado, o requisito IV - Estrutura dos dados obteve $99 \%$ de não atendimento pelos websites.

A Figura 15 expõe o agrupamento do total de requisitos técnicos atendidos pelos websites e mostra a média do índice de acessibilidade para cada grupo. Apresenta-se também a média global do índice de acessibilidade para efeito de comparação. 
Figura 15 - Atendimento e índice de acessibilidade pelo total de requisitos técnicos

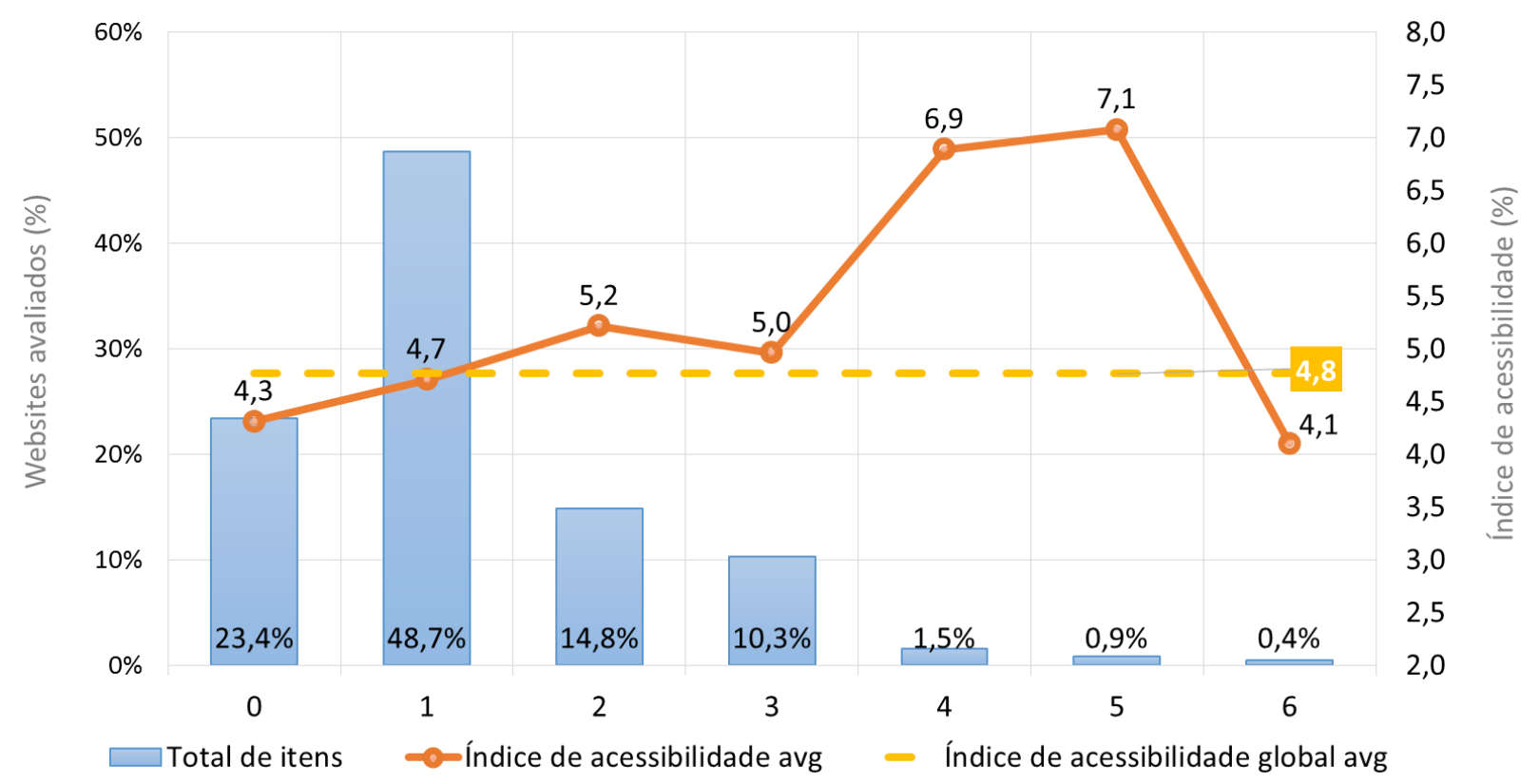

Fonte: Adaptado de Corrêa et al. (2017).

Os websites avaliados atendem a um intervalo de zero a seis requisitos técnicos. Porém, um número expressivo de $48,7 \%$ dos websites analisados atende a apenas um requisito técnico. Apenas $0,4 \%$ dos websites atende a todos os seis requisitos técnicos definidos na LAI. A média do índice de acessibilidade também tende a crescer à medida que os websites atendem a mais requisitos, mas com algumas exceções: aqueles que atendem a três e seis deles.

As Figura 16 e Figura 17 apresentam a totalização do atendimento dos itens de divulgação e requisitos técnicos, agrupados por região geográfica. Apresentam também a média do índice de acessibilidade para efeito de comparação por região. 
Figura 16 - Atendimento e índice de acessibilidade de todos os itens de divulgação avaliados agrupamento por região

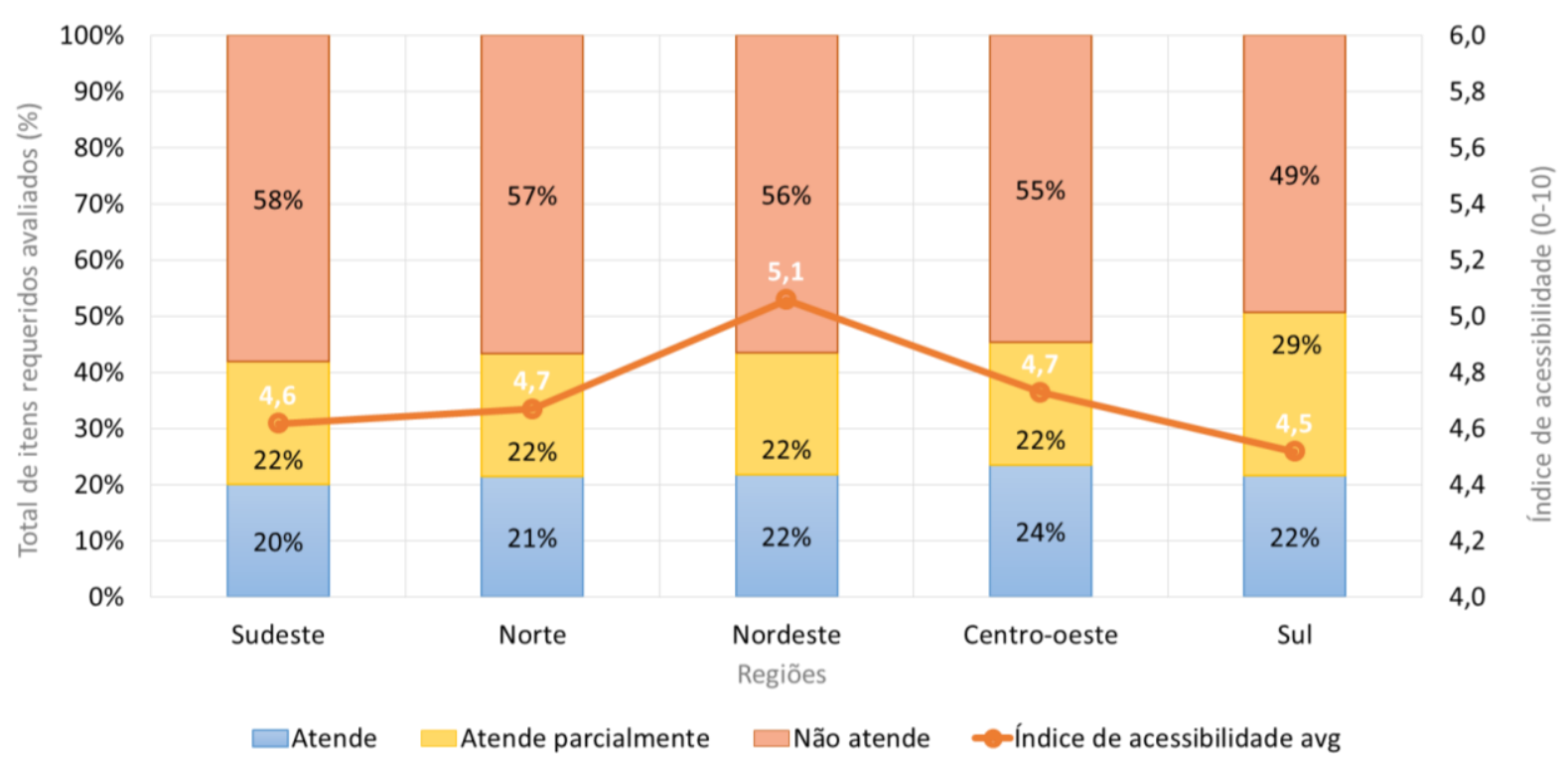

Fonte: Adaptado de Corrêa et al. (2017).

Figura 17 - Atendimento e índice de acessibilidade de todos os requisitos técnicos avaliados agrupamento por região

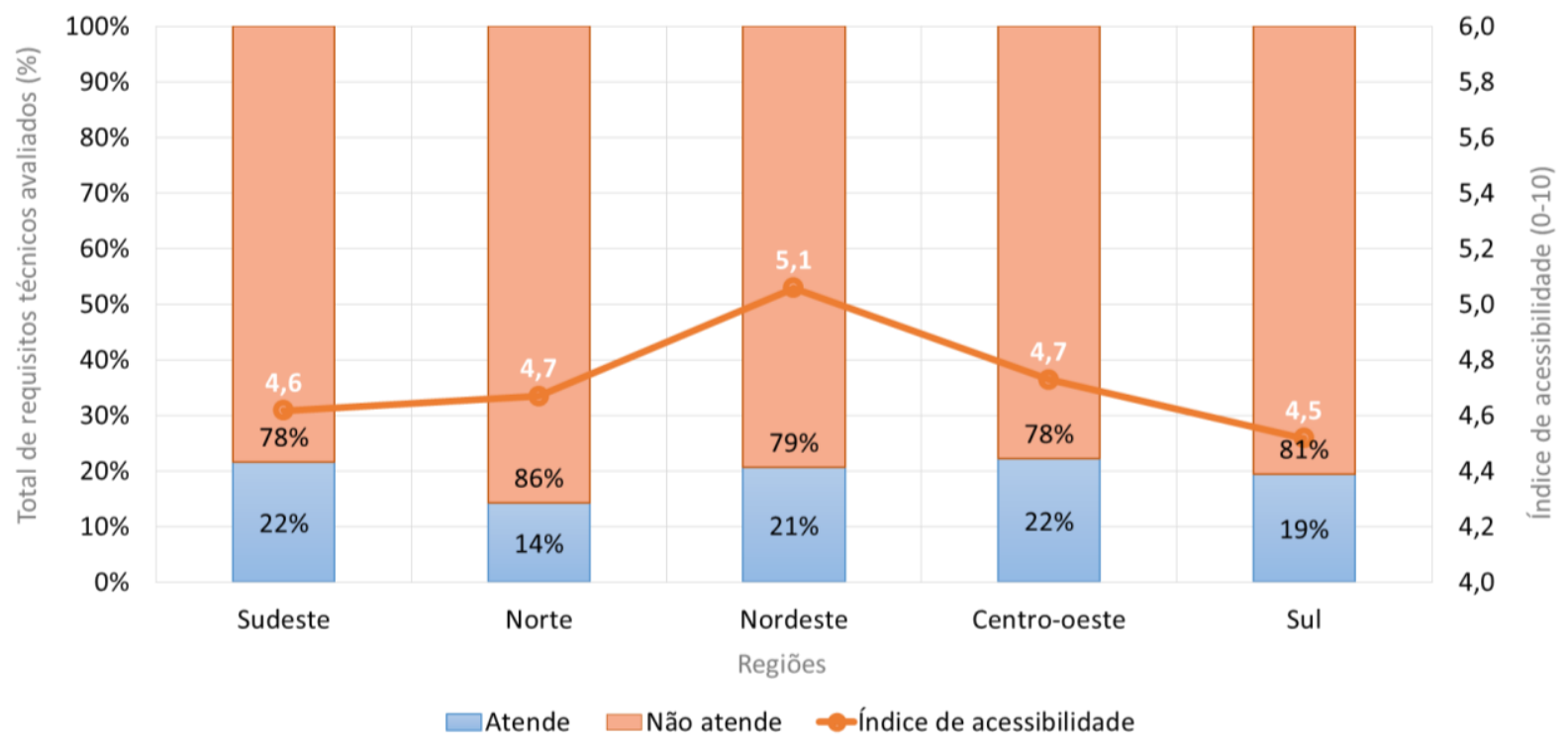

Fonte: Adaptado de Corrêa et al. (2017). 
Não foi verificada diferença significativa nos resultados por regiões geográficas. De todo o modelo, no caso dos itens necessários, a região Centro-oeste apresentou maior percentual de atendimento dentre as regiões. No caso dos requisitos técnicos, verificou-se o pior resultado para a região Norte.

\subsection{Discussão dos resultados}

A partir dos resultados obtidos com os levantamentos nos municípios brasileiros, discute-se primeiramente a presença de um website para permitir a disponibilização dos dados. No levantamento preliminar, este problema não foi revelado devido ao tamanho da amostra e à região escolhida para coleta dos dados (Região Metropolitana de Campinas) com características de alto desenvolvimento tecnológico. No levantamento amplo, por outro lado, verificou-se que em $13 \%$ dos municípios não têm qualquer website e $5 \%$ não estavam disponíveis no momento da consulta devido a problemas técnicos. Assim, o fato de que 18\% (websites ausentes e indisponíveis) dos municípios não disponibilizaram qualquer tipo de informação eletrônica mostra a dificuldade dos governos locais em cumprir a legislação nacional. Isso indica que, de modo geral, as instituições públicas precisam adotar meios efetivos para viabilizar a transparência e que a garantia somente legal não é suficiente. Achado semelhante foi relatado por Lourenço et al. (2013), embora o estudo destes autores não tenha mostrado o número de sites indisponíveis.

O predomínio de formatos não abertos ou que dificultam o processamento por máquina, como HTML e PDF, foi encontrado em $90 \%$ e $79 \%$ do total de documentos divulgados, respectivamente no primeiro e no segundo levantamentos. Isso indica que os municípios estão em processo de adaptação para a efetiva implementação de OGD e ainda não compreenderam os benefícios da abertura dos dados. Achado semelhante foi relatado por Cunha et al. (2015) onde apenas 14,75\% dos municípios pesquisados possuem dados em formato aberto. Especificamente acerca dos formatos encontrados, as pesquisas de Veljković et al. (2014), Davies e Frank (2013) e Bunyakiati e Voravittayathorn (2012) apontam problemas com os formatos HTML e PDF em repositórios em vários níveis de governos de diferentes países do mundo. Como também discutido por Conradie e Choenni (2014), a motivação para a divulgação de informações deve ser direcionada para a responsabilização e maior 
participação da sociedade, desse modo as instituições devem evitar a liberação de dados sem necessidade e de modo que impossibilidade o uso eficaz das informações. Divulgação utilizando formatos não abertos dá uma aparente sensação de transparência, mas não promove a abertura dos registros públicos.

Em relação ao cumprimento dos itens mínimos necessários para a divulgação, os resultados de ambos os levantamentos indicaram que a maioria dos websites não atendem ou atendem parcialmente às exigências. A exceção ficou para os registros de despesas, que é atendido em $83 \%$ dos websites analisados no segundo levantamento. Este achado é semelhante aos resultados encontrados pelo INESC (2014) onde no método de avaliação utilizado pela instituição os registos de

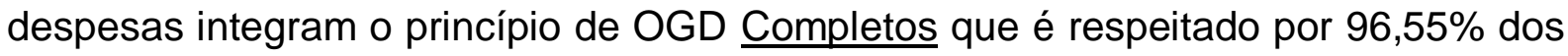
websites analisados, segundo o estudo. Cunha et al. (2015) também apresentam resultados melhores na divulgação de dados financeiros.

Por outro lado, o não atendimento ou atendimento parcial dos demais cinco itens mínimos confirma o que Cruz et al. (2012) encontraram com seu estudo que indica que os municípios não divulgam completamente informações. Resultados semelhantes são encontrados nos estudos de Coelho et al. (2015) e CGU (2015), os quais indicam que os locais pesquisados obtiveram classificações baixas com respeito à divulgação de informações públicas e atendimento da legislação de transparência.

Os resultados referentes aos requisitos técnicos indicaram que a exigência de dados atualizados é cumprida por $95 \%$ e $65 \%$ dos websites avaliados, respectivamente no primeiro e segundo levantamentos. Neste ponto, enfatiza-se que a literatura indica resultado distinto. A pesquisa conduzida pelo INESC (2014) descobriu que a maioria dos governos não fornece informações em tempo oportuno. Armstrong (2011) afirma que geralmente é difícil para os websites municipais se manterem atualizados. Por esta divergência, justifica-se que no método utilizado por INESC (2014) o conceito de informação atualizada é exigente pois considera um dia útil como parâmetro de avaliação. Além disso, a instituição baseia-se em um ponto específico da legislação para esta avaliação, que enfatiza o aspecto dinâmico destes tipos de dados. Conforme discutido, utiliza-se como critério de avaliação para dados 
atualizados o interstício de dois meses como prazo de validade para dados sensíveis ao tempo.

Os demais requisitos técnicos, por outro lado, não são atendidos pela maioria dos websites avaliados, conforme apontado nos resultados de ambos os levantamentos. Os piores resultados são relacionados ao requisito sobre estrutura de dados e ao requisito sobre acessibilidade.

Sobre a acessibilidade, no primeiro levantamento, nenhum website atendeu ao nível mínimo exigido. No segundo levantamento, conforme discutido, mudou-se o método de análise para obtenção de resultados mais granulares. Mesmo assim, de acordo com os resultados, a média global do índice de acessibilidade atingiu 4,8 em uma escala de 0-10. Este índice indica que o acesso à informação não é normalmente assegurado a todos os indivíduos, o que viola o princípio de OGD que exige que os dados devem ser acessíveis a todos os públicos. Este resultado é confirmado por INESC (2014) que identificou situação semelhante na grande maioria dos websites avaliados e por Youngblood e Mackiewicz (2012) que apontam problemas substanciais com a usabilidade, sobretudo a acessibilidade das páginas web.

Em geral, 53,3\% dos websites avaliados divulgaram apenas um item entre todos os seis existente que é exigido pela LAI. Aqueles que divulgaram dois itens totalizaram 24,2\% dos websites. Percebeu-se que o índice de acessibilidade tende a crescer quando os websites atendem mais as exigências da LAI (itens necessários e requisitos técnicos); no entanto, eles ainda permanecem inacessíveis para todos os públicos com necessidades específicas.

Neste estudo analisou-se também o atendimento dos itens necessários, requisitos técnicos e acessibilidade, considerando a perspectiva brasileira das cinco macrorregiões. A razão para ter resultados agregados por região geográfica é verificar se o desenvolvimento social e econômico da região influencia nos resultados. Ressalta-se, contudo, que foge ao escopo deste trabalho análises detalhadas a este respeito e, conforme verificado, não há influência significativa considerando as regiões geográficas. $O$ atendimento dos itens mostrou-se quase o mesmo, independentemente da região. Houve apenas uma pequena diferença em relação à média do índice de acessibilidade. À primeira vista, estes resultados 
parecem ser diferentes dos resultados obtidos por Cruz et al. (2012) e Yavuz e Welch (2014), que afirmam que melhores condições socioeconômicas tendem a envolver maior transparência.

\subsection{Considerações finais}

Este capítulo buscou caracterizar a situação dos dados abertos nos municípios brasileiros, essencialmente a partir da avaliação de uma amostra com 561 websites de governos locais. Para isso, foram definidos os critérios de avaliação a partir de um levantamento preliminar com 20 municípios. A bibliografia relacionada também foi analisada para embasar os resultados obtidos com os levantamentos.

A caraterização obtida neste capítulo teve como objetivo mapear os problemas existentes para levantar os requisitos da arquitetura sendo definida nesta pesquisa. Esses problemas foram identificados, essencialmente, a partir das observações registradas ao longo dos dois levantamentos realizados.

A Tabela 10 a seguir apresenta a síntese dos principais problemas mapeados na caracterização dos dados abertos nos municípios brasileiros com breve discussão para o entendimento dos pontos levantados.

Tabela 10 - Síntese dos principais problemas mapeados na caracterização dos dados abertos nos municípios brasileiros

\begin{tabular}{|c|c|}
\hline Problema & Discussão \\
\hline $\begin{array}{l}\text { Predomínio dos formatos PDF e } \\
\text { HTML para disponibilização de } \\
\text { dados }\end{array}$ & $\begin{array}{l}\text { Apesar de existirem outros formatos de disponibilização, os } \\
\text { formatos PDF e HTML representam juntos os principais meios } \\
\text { para disponibilização de dados. } \\
\text { O requisito a ser mapeado neste ponto deve considerar } \\
\text { prioritariamente os formatos PDF e HTML como fontes de dados } \\
\text { para o processo de estruturação. }\end{array}$ \\
\hline $\begin{array}{l}\text { Necessidade de preenchimento } \\
\text { de parâmetros de pesquisa para } \\
\text { geração de páginas dinâmicas }\end{array}$ & $\begin{array}{l}\text { Este ponto está intrinsicamente relacionado à concepção das } \\
\text { páginas web dinâmicas, predominantemente externadas como } \\
\text { HTML para disponibilizar os dados. } \\
\text { O requisito a ser mapeado neste ponto deve considerar que há } \\
\text { a necessidade de preencher previamente os parâmetros para } \\
\text { obtenção dos dados. Automatização deste processo } \\
\text { demandaria esforços proporcionais à quantidade de websites, }\end{array}$ \\
\hline
\end{tabular}




\begin{tabular}{|c|c|}
\hline & $\begin{array}{l}\text { tendo em vista que cada website impõe seu próprio mecanismo } \\
\text { de seleção. }\end{array}$ \\
\hline $\begin{array}{l}\text { Quase a totalidade dos websites } \\
\text { não externam links de acesso } \\
\text { direto aos dados e pressupõem a } \\
\text { utilização do navegador web } \\
\text { como meio primário de acesso }\end{array}$ & $\begin{array}{l}\text { Este problema é um desdobramento do item anterior. Neste } \\
\text { caso, observou-se que não há meios para acesso direto aos } \\
\text { dados após a construção de parâmetros e filtros de seleção. A } \\
\text { única forma de ter acesso aos dados é utilizar manualmente o } \\
\text { navegador web para construir as consultas. } \\
\text { O requisito a ser mapeado neste ponto deve considerar que os } \\
\text { dados não podem ser acessados por outro meio que não a } \\
\text { forma manual pelo navegador web. }\end{array}$ \\
\hline $\begin{array}{l}\text { Cada website segue sua } \\
\text { tecnologia e formas de } \\
\text { organização e apresentação dos } \\
\text { dados }\end{array}$ & $\begin{array}{l}\text { Identificou-se que cada website implementa sua tecnologia e } \\
\text { formas de organização e apresentação dos dados. Existem } \\
\text { casos que seguem os padrões da web e casos que mostram } \\
\text { claramente o desconhecimento técnico para construção de um } \\
\text { website, resultando em páginas mal formatadas e com erros } \\
\text { primários. } \\
\text { Ressalta-se, também, que foram identificados vários websites } \\
\text { semelhantes, o que revela que vários municípios adquirem } \\
\text { soluções prontas de terceiros para viabilizar sua infraestrutura } \\
\text { de dados. Vale ressaltar que os websites nesta situação } \\
\text { também apresentam problemas e que a contratação de } \\
\text { soluções prontas não garante a adequação à legislação e os } \\
\text { princípios de OGD. } \\
\text { O requisito a ser mapeado neste ponto deve considerar a } \\
\text { impossibilidade de prever os meios de acesso aos websites, } \\
\text { sobretudo do ponto de vista da automatização do processo de } \\
\text { consulta aos dados. }\end{array}$ \\
\hline $\begin{array}{l}\text { Quantidade de websites com } \\
\text { seus próprios mecanismo de } \\
\text { disponibilização de dados }\end{array}$ & $\begin{array}{l}\text { Observou-se que a quantidade de websites é proporcional ao } \\
\text { número de municípios. Cada município constrói seu próprio } \\
\text { mecanismo de disponibilização. } \\
\text { O requisito a ser mapeado neste ponto deve considerar uma } \\
\text { forma de estruturação dos dados cujo esforço seja possível de } \\
\text { ser realizado por vários atores interessados nos dados, como } \\
\text { forma de balanceamento do esforço necessário. }\end{array}$ \\
\hline $\begin{array}{l}\text { Não interferência no processo de } \\
\text { geração dos dados }\end{array}$ & $\begin{array}{l}\text { Este problema é uma inferência a partir de todas as } \\
\text { observações realizadas. Tendo em vista a quantidade de } \\
\text { websites, seus mecanismos próprios e heterogêneos de } \\
\text { disponibilização e os formatos não abertos, observa-se a } \\
\text { impossibilidade de interferência nos processos de geração dos } \\
\text { dados. Isso significa que cada fonte de dados evoluirá de }\end{array}$ \\
\hline
\end{tabular}


acordo com a maturidade das equipes envolvidas e isso será pautado pela exigência da sociedade para o consumo das informações.

$O$ requisito a ser mapeado neste ponto deve considerar a existência de um repositório paralelo que disponibilize os dados estruturados e assim os disponibilize de acordo com os princípios de OGD.

Fonte: Elaborado pelo autor.

Os problemas apresentados na Tabela 10 serão considerados no próximo capítulo, cujo objetivo é definir os requisitos para a arquitetura de referência em estudo. 


\section{DEFINIÇÃO DA ARQUITETURA DE REFERÊNCIA COLABORATIVA}

Este capítulo apresenta o processo de definição da arquitetura. Apesar do título conter o termo definição, em vários pontos do texto utiliza-se também o termo construção ou desenvolvimento como sinônimos por questões de compatibilidade com a bibliografia.

Como a definição de uma arquitetura visa evidenciar a estrutura necessária para raciocinar sobre um sistema (BASS; CLEMENTS; KAZMAN, 2012), este capítulo define a arquitetura com o objetivo de subsidiar futura implementação de um sistema colaborativo para estruturar dados abertos governamentais - aqui simplificadamente chamado de sistema, compreendendo os elementos de software necessários e as relações entre eles, assim como suas respectivas propriedades. Ademais, a partir da arquitetura é possível estimar os demais recursos necessários para implementação do sistema, como a força de trabalho para seu desenvolvimento e o hardware necessário; também é possível avaliar os riscos inerentes ao processo de desenvolvimento e expor com exatidão as intenções para com o sistema.

O processo de construção da arquitetura detalhado neste capítulo foi baseado essencialmente pelo desenvolvimento de um projeto arquitetural seguindo o Método $A D D$, disseminado pela bibliografia e amplamente utilizado pela indústria (BASS; CLEMENTS; KAZMAN, 2012; KAZMAN; CERVANTES, 2016). Segundo os autores, o Método ADD leva em consideração todos os aspectos relevantes para que os balizadores da arquitetura (extraído do negócio) sejam satisfeitos. O Método ADD não traz uma fórmula pronta, mas sim uma sequência de passos a ser seguida onde várias decisões precisam ser tomadas pelo arquiteto de acordo com seu conhecimento sobre engenharia de software. Exemplos dessas decisões são o uso de padrões de projeto, padrões de implementação, formalização com o uso de linguagens de modelagem e táticas arquiteturais que devem ser previamente estudadas e avaliadas antes de aplicadas na arquitetura.

Este capítulo está organizado da seguinte forma. Primeiramente, é desenvolvido e detalhado o modelo de negócio baseado na colaboração, parte importante dos requisitos da arquitetura. Em seguida, são desenvolvidos os requisitos que retratam a realidade do negócio, os quais foram elaborados a partir do 
aspecto colaborativo e dos problemas de acesso e disposição dos dados nos municípios brasileiros. Posteriormente, é apresentado o desenvolvimento do projeto arquitetural proposto pelo Método ADD. Por fim, o capítulo é encerrado com a documentação da arquitetura para servir de meio de comunicação com os stakeholders.

\subsection{Modelo de negócio: o aspecto colaborativo}

Importantes requisitos de qualidade da arquitetura são referentes ao seu modelo de negócio baseado na colaboração da comunidade interessada em transparência pública e dados abertos governamentais. Isso significa que sua disseminação e utilização terão como catalisador a atuação sistemática de pessoas de fora da administração pública para contribuir com a estruturação distribuída dos dados, sem excluir a possibilidade de atuação também de pessoas de dentro das instituições públicas.

A este respeito, o modelo de negócio descreve a razão pela qual uma proposta cria, entrega e gera valor. Um modelo de negócio simples é aquele que é entendido facilmente, ou seja, possa ser descrito em linguagem clara e compreensível pela maioria do público (OSTERWALDER, 2010). Esta seção busca descrever o modelo de negócio colaborativo da arquitetura para que se possa extrair seus requisitos de qualidade.

O modelo de negócio colaborativo não é novo. Algo semelhante e bastante difundido é encontrado na enciclopédia de conteúdo aberto Wikipédia. Nela os artigos podem ser propostos e melhorados por qualquer usuário a partir de seu conhecimento em determinada área. Desde seu lançamento, em 2001, a Wikipédia está entre os mais engenhosos projetos colaborativos on-line e conta com milhões de artigos em centenas de idiomas (BRYANT; FORTE; BRUCKMAN, 2005).

Para entender o processo de participação que alavancou a Wikipédia, Bryant, Forte e Bruckman (2005) conduziram uma pesquisa com vários usuários que contribuíam significativamente com a comunidade, os denominados Wikipedians. Os autores identificaram vários achados dos quais alguns são úteis para entender, 
construir e avançar na descrição do modelo de negócio colaborativo utilizado pela arquitetura:

- Os Wikipedians que editavam um artigo pela primeira vez o faziam em assuntos de seu interesse pessoal. Inicialmente, o objetivo era corrigir pequenos problemas como omissões e imprecisões no texto. Neste estágio os usuários se viam mais como consumidores do que contribuidores da comunidade.

- Em suas primeiras experiências, os usuários não tinham o real senso de comunidade colaborativa. A interação com outros usuários também era escassa. À medida que aumentavam seu envolvimento, aprendiam mais sobre as regras da comunidade e também interagiam com demais contribuidores.

- Ao longo do tempo, os usuários evoluíam na comunidade aumentando seu nível de envolvimento. Passavam da chamada zona periférica de contribuição para fazer parte central da comunidade, onde as atividades e interações se faziam mais complexas por envolver discussões e decisões que auxiliavam o crescimento e qualidade da rede de contribuições, como evitar o vandalismo em artigos controversos e evidenciar artigos em destaque.

- Os Wikipedians contribuíam por que acreditavam naquilo que a comunidade produzia. Os autores observaram que a motivação para contribuir poderia vir de outras fontes como a expectativa de reciprocidade da comunidade no futuro e o senso de reputação, os quais não dependiam de altruísmo puro e simplesmente.

- Os usuários reportaram que a primeira coisa que faziam quando entravam na ferramenta era checar o watch list para verificar alterações em seus artigos de interesse com intuito de identificar rapidamente vandalismo.

A partir dessas observações, a Figura 18 ilustra o aspecto colaborativo envolvido na arquitetura com seus principais elementos que comporão seus requisitos de qualidade. 
Figura 18 - Ilustração do aspecto colaborativo e seus principais elementos

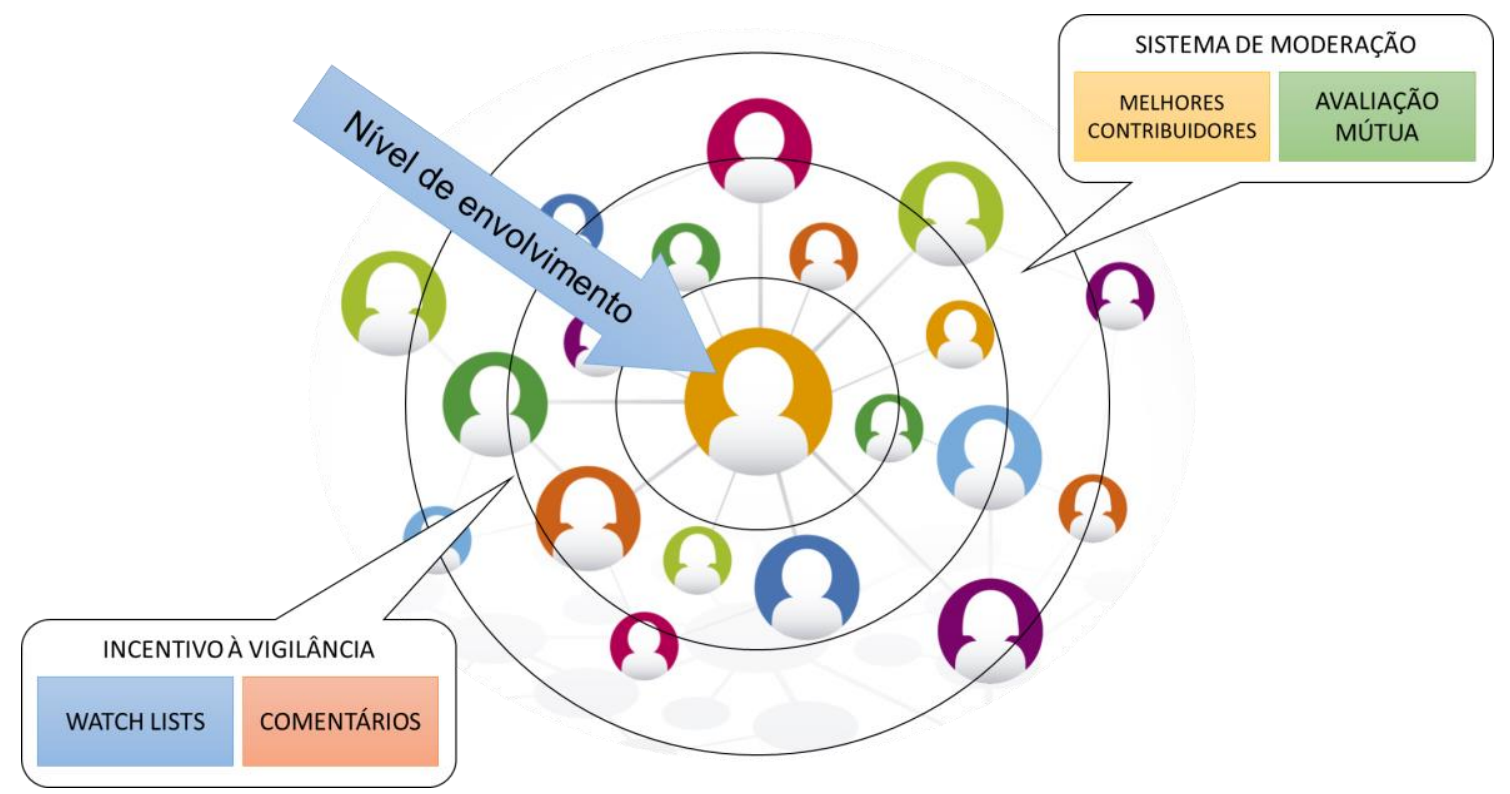

Fonte: Elaborado pelo autor.

A atuação de uma rede de colaboradores é uma estratégia para a infinidade de fontes de dados (abertas ou não) existentes nos diversos níveis de governo, que são eminentemente caracterizadas pelas instituições indicadas a divulgar informações de transparência para consumo pela sociedade.

Espera-se que os colaboradores inicialmente contribuam na sua área de interesse estruturando dados de seu munícipio, por exemplo. Também, possam avaliar a estruturação realizada por outros usuários. À medida que o número de contribuidores cresce, o nível de envolvimento dos usuários tende a aumentar também, consequentemente a quantidade e qualidade das contribuições se torna significativa. Este processo é catalisado pela disseminação de matérias na imprensa a partir da interpretação dos dados estruturados.

A rede de colaboradores, desse modo, poderá ser composta de jornalistas, analistas políticos, economistas e outros, incluindo o cidadão comum. Estes, portanto, seriam os principais beneficiados da proposta de valor a ser entregue pela implementação de um sistema baseada na arquitetura.

A respeito da proposta de valor a ser gerada pela arquitetura, tem-se principalmente os seguintes: 
- Dados reutilizáveis - caracterizado pela disponibilização de datasets que possam ser baixados, remixados ou cruzados com outros dados a fim de verificar a consistência com outras fontes;

- Dados processáveis por máquina - caracterizado pela disponibilização de datasets em formato aberto e intercambiáveis para processamento por qualquer ferramenta de interesse dos usuários;

- APls de acesso - caracterizado pela disponibilização de recursos automatizados para permitir o acesso e extensão das características pelo desenvolvimento de outras funcionalidades com base nas atualmente oferecidas.

A proposta de valor seria entregue por um sistema on-line disponibilizado pela web. Para isso, tem-se como atividades-chave a implementação deste sistema baseada na arquitetura e sua posterior disseminação. Ambas as atividades teriam como parceiros a comunidade interessada nos dados abertos governamentais com a disponibilização de recursos como analistas e desenvolvedores de software.

O modelo de negócio colaborativo é um modelo de solução frente aos requisitos identificados no Capítulo 3, o qual também é uma das hipóteses desta pesquisa para alavancar o processo de estruturação proposto pela arquitetura. Assim como os demais requisitos, o aspecto colaborativo será incluído nas próximas seções dentro do processo de construção da arquitetura.

\subsection{Requisitos da arquitetura}

Nesta seção serão apresentados os requisitos da arquitetura considerados em todo seu processo de construção. Como forma de apresentação, será adotada a notação UML, amplamente utilizada para representar artefatos de engenharia de software. Especificamente, serão utilizados os diagramas de casos de uso. Os casos de uso são aplicados para captar o comportamento pretendido do sistema sem necessidade de especificar como esse comportamento é implementado. Os casos de uso fornecem meios para os stakeholders chegarem a uma compreensão comum 
acerca do sistema e principalmente permitem aos desenvolvedores captar seus requisitos (BOOCH; RUMBAUGH; JACOBSON, 2005).

Faz-se necessário enfatizar que estão sendo considerados dois importantes grupos de entradas para compor os requisitos da arquitetura:

- Problemas de disponibilização e acesso aos dados: neste grupo estão os pontos identificados como requisitos do sistema a partir da caracterização dos dados abertos nos municípios brasileiros, detalhada no Capítulo 3 deste trabalho;

- Aspecto colaborativo: neste grupo estão os pontos construídos pelo autor por meio da exposição do modelo de negócio como hipótese para alavancar a estruturação dos dados por meio de contribuições da comunidade de interessados. O modelo de negócio foi apresentado na Seção 4.1 - Modelo de negócio: o aspecto colaborativo deste capítulo.

A partir desses requisitos, primeiramente é apresentada a Figura 19 que ilustra o diagrama de casos de uso representando o comportamento geral do sistema, onde o usuário pode consumir dados, fazer e avaliar a estruturação. A Tabela 11 descreve, de forma textual, as principais características de cada caso de uso ilustrado no diagrama. Cada caso de uso será unicamente referenciado ao longo deste capítulo com a sigla UC (Use Case) seguida de seu número de ordem único. 
Figura 19 - Diagrama de casos de uso gerais do sistema

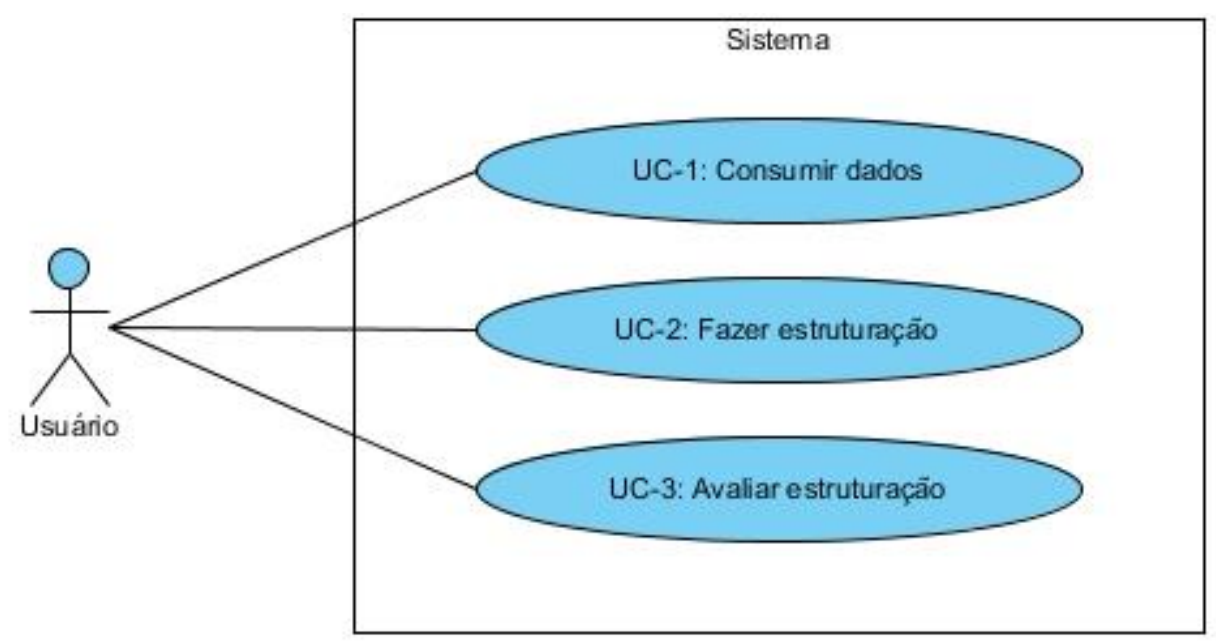

Fonte: Elaborado pelo autor.

Tabela 11 - Descrição dos casos de uso gerais do sistema

\begin{tabular}{l|l}
\hline Caso de uso & \multicolumn{1}{c}{ Descrição } \\
UC-1: & $\begin{array}{l}\text { O usuário acessa o sistema para visualizar os dados previamente estruturados e } \\
\text { catalogados no sistema. O acesso é feito de forma manual, por meio da interface } \\
\text { dados }\end{array}$ \\
$\begin{array}{l}\text { web para busca e consulta dos datasets. A busca poderá ser realizada por } \\
\text { qualquer campo dos metadados. } \\
\text { O acesso também é disponibilizado por meio de APIs para permitir o } \\
\text { processamento automatizado por máquina, sendo que tudo que se faz na interface } \\
\text { web pode ser feito via API. } \\
\text { Para o caso de consumo dos dados, não é permitida qualquer tipo de alteração nos } \\
\text { estruturação }\end{array}$ & $\begin{array}{l}\text { Pados contidos no sistema. } \\
\text { sistema com seu usuário e senha. } \\
\text { O usuário pode decidir colaborar com sua própria estruturação de dados a partir de } \\
\text { uma fonte de dados não estruturada (PDF ou HTML), ou seja, um website de } \\
\text { transparência. } \\
\text { O usuário acessa o website de interesse pelo seu navegador de internet, fornece } \\
\text { todos os parâmetros de consulta necessários, identifica o conteúdo tabular a ser } \\
\text { estruturado e então ativa a extensão do navegador (previamente instalada e } \\
\text { configurada) para acessar as ferramentas de estruturação. A ferramenta permite, } \\
\text { basicamente, identificar a porção de dados caracterizada por um conteúdo tabular }\end{array}$ \\
\hline
\end{tabular}




\begin{tabular}{l|l}
\hline & $\begin{array}{l}\text { e pré-visualizar os dados extraídos para ter certeza que o conteúdo corresponde ao } \\
\text { desejado. } \\
\text { Uma vez delimitado o conteúdo tabular e confirmado pelo usuário, parte-se para a } \\
\text { definição dos metadados para descrever o dataset a ser estruturado. São } \\
\text { fornecidas informações como nome e descrição do dataset, sendo estes campos } \\
\text { de conteúdo de livre escolha do usuário. Por fim, o usuário pode decidir fazer o } \\
\text { carregamento do dataset. } \\
\text { UC sistema registra todos as atividades do processo de estruturação com a } \\
\text { identificação única do usuário. }\end{array}$ \\
\hline $\begin{array}{l}\text { Para este caso, o usuário deverá ter sido previamente registrado e autenticado no } \\
\text { sistema com seu usuário e senha. } \\
\text { O usuário pode contribuir avaliando a estruturação de outros usuários. Para isso, } \\
\text { deve acessar o dataset e localizar o metadado que referencia o processo de } \\
\text { estruturação por meio de um link que leva ao Portal Colaborativo. Nele o usuário } \\
\text { visualizará todos as informações referentes à estruturação, principalmente o nome } \\
\text { do usuário contribuidor responsável. Visualizará também uma escala representada } \\
\text { por cinco estrelas que indica a métrica de avaliação. O usuário selecionará a } \\
\text { quantidade de estrelas conforme seu entendimento sobre a qualidade de } \\
\text { estruturação daquele dataset. } \\
\text { O Portal Colaborativo também disponibiliza interface web para interação com os } \\
\text { usuários para realizar os mecanismos de moderação, watch lists, comentários e } \\
\text { relato de abusos. } \\
\text { O sistema registra todos as atividades do processo de avaliação com a } \\
\text { identificação única do usuário. }\end{array}$ \\
\hline
\end{tabular}

Fonte: Elaborado pelo autor.

Para cada caso de uso descrito na Tabela 11, é apresentado o detalhamento do comportamento do sistema utilizando um diagrama expandido, com objetivo de evidenciar os pontos mais relevantes. Em seguida, são tecidos breves comentários sobre pontos quem embasam o processo de engenharia de requisitos (PRESSMAN, 2011; SOMMERVILLE, 2007), base para as seções que se seguem.

A Figura 20 expressa o diagrama de casos de uso referente à expansão do caso de uso UC-1: Consumir dados. 
Figura 20 - Diagrama de expansão do caso de uso UC-1: Consumir dados

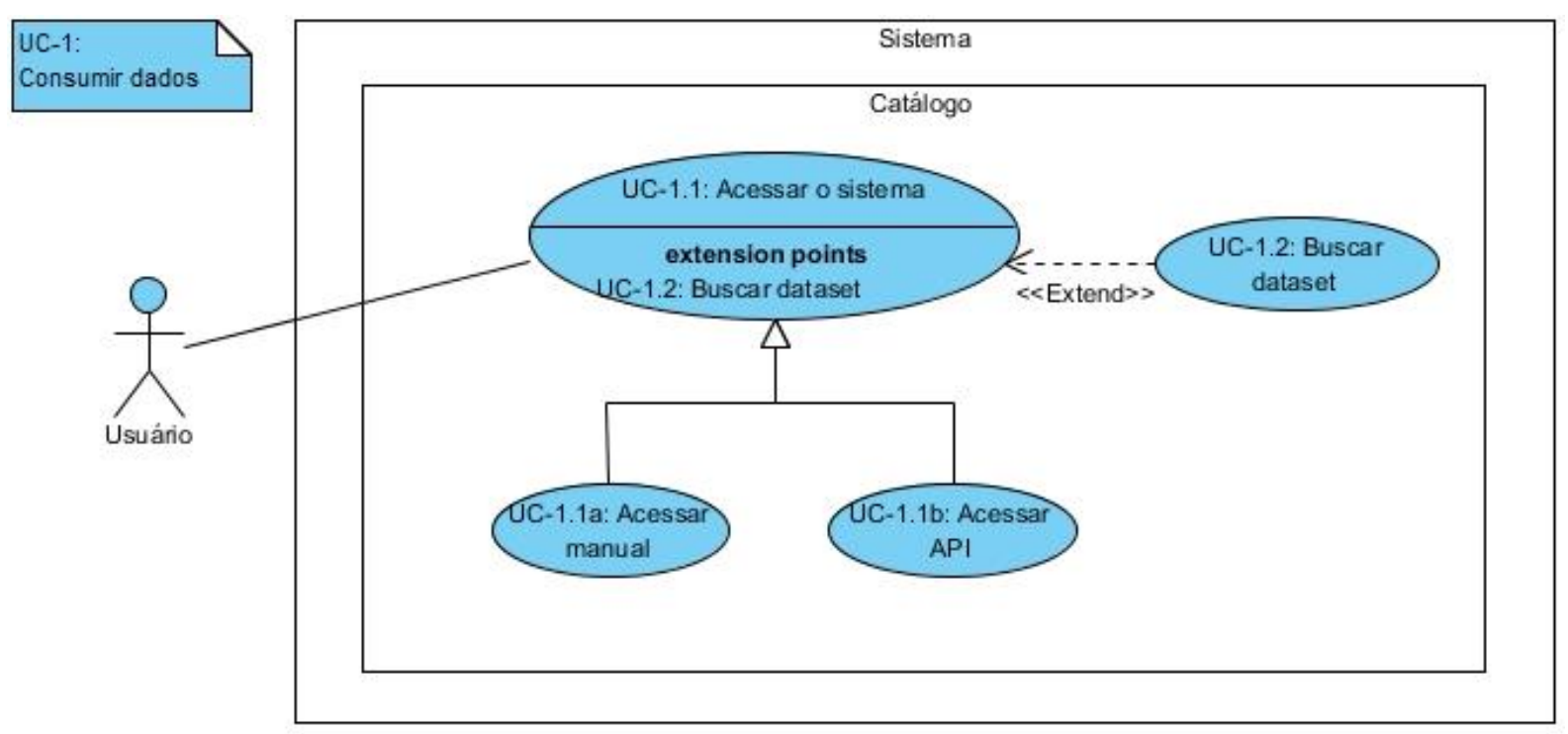

Fonte: Elaborado pelo autor.

O caso de uso UC-1: Consumir dados representa o comportamento mais simples do sistema, onde um usuário acessa o sistema e busca por datasets de seu interesse. Percebe-se que o comportamento de acesso ao sistema é especializado em dois casos particulares (acesso manual e acesso por API), indicando a necessidade de implementação distinta. A busca nos datasets é feita de forma opcional após o usuário acessar o sistema, por isso está grafado com o estereótipo $\leq<$ Extend $>$.

A Figura 21 expressa o diagrama de casos de uso referente à expansão do caso de uso UC-2: Fazer estruturação. 
Figura 21 - Diagrama de expansão do caso de uso UC-2: Fazer estruturação

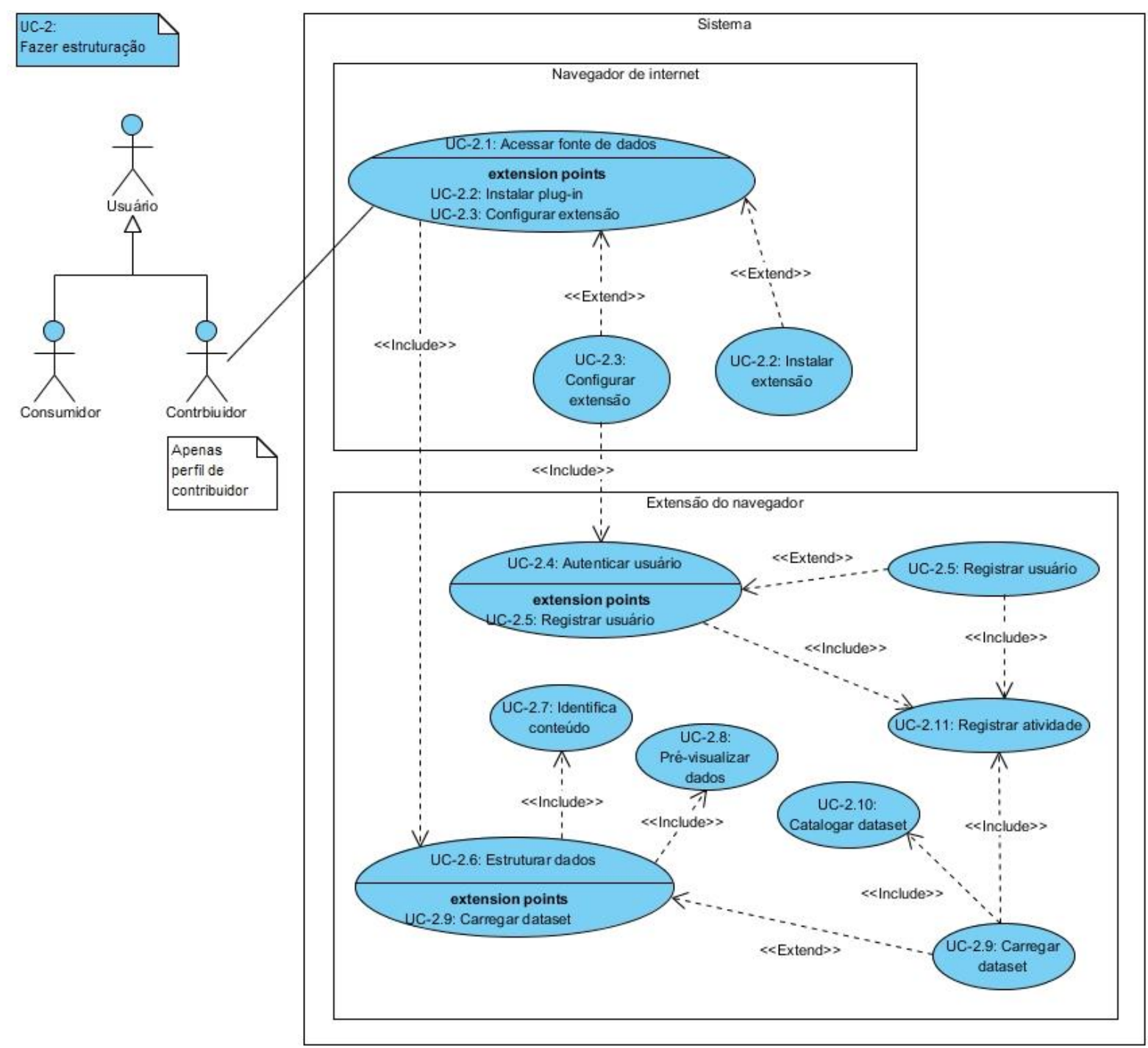

Fonte: Elaborado pelo autor.

O caso de uso UC-2: Fazer estruturação representa o comportamento mais importante do sistema. É nele onde serão tratadas as funcionalidades primordiais de estruturar os dados e disponibiliza-los como abertos. Primeiramente, cabe ressaltar que o ator usuário é especializado em dois casos particulares representando os perfis que cada um assume perante o sistema. O primeiro, denominado consumidor, representa o perfil de usuário apenas interessado na consulta aos datasets, o qual não é relevante para este caso de uso e que foi devidamente retratado no diagrama de expansão do caso de uso UC-1 Consumir dados apresentado na Figura 20. 
O perfil contribuidor é introduzido no diagrama da Figura 21 e representa o usuário que inicialmente acessará pelo seu navegador de internet uma fonte de dados por meio de um website de transparência. Este perfil de usuário precisa instalar e configurar a extensão do navegador que é parte integrante do sistema, a qual também é responsável pela interface de comunicação com os componentes principais disponibilizados por API. Uma vez identificados e pré-visualizados os dados desejados, faz-se o carregamento do dataset e as atividades são registradas no sistema.

A Figura 22 expressa o diagrama de casos de uso referente à expansão do caso de uso UC-3: Avaliar estruturação.

Figura 22 - Diagrama de expansão do caso de uso UC-3: Avaliar estruturação

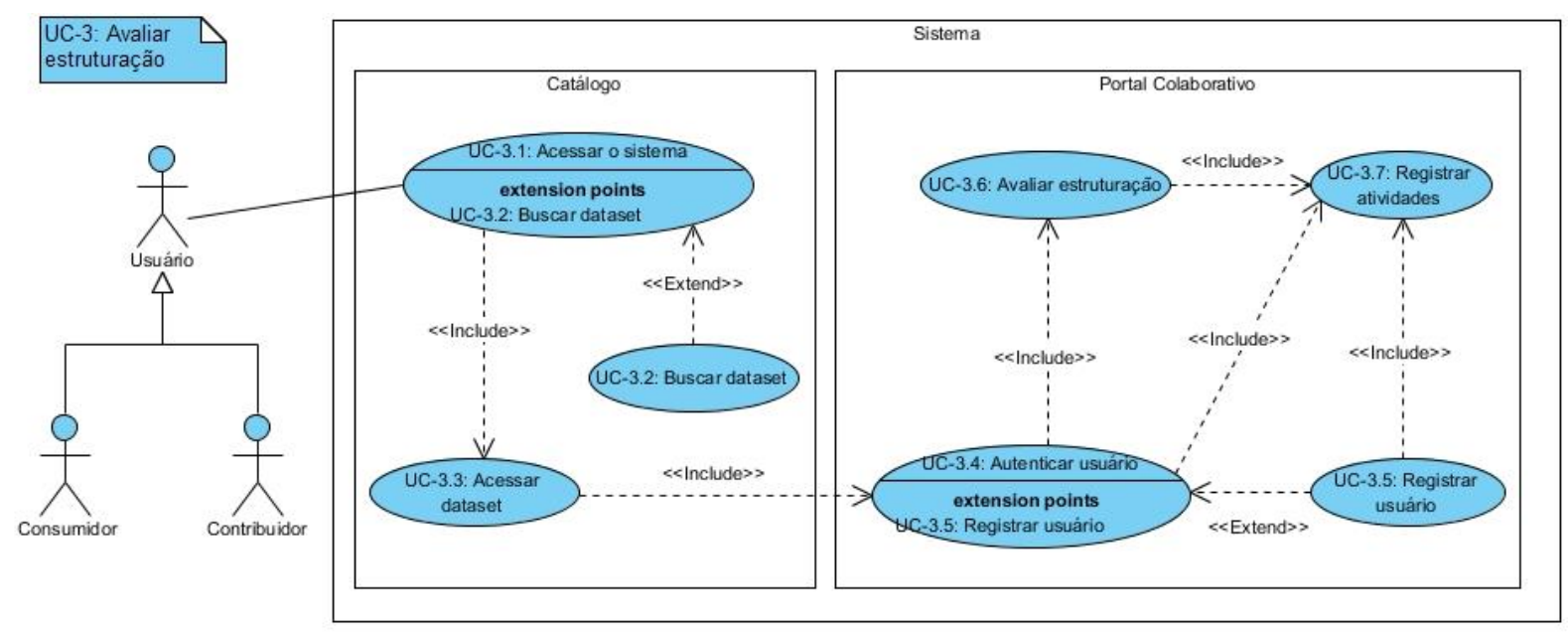

Fonte: Elaborado pelo autor.

O caso de uso UC-3: Avaliar estruturacão representa os comportamentos referentes ao processo colaborativo da arquitetura. Neste caso de uso o usuário é autenticado no sistema e pode acessar os datasets estruturados para avalia-los conforme seu entendimento sobre a qualidade da estruturação. É admitida a avaliação proveniente de todos os perfis de usuário, inclusive a especialização denominada consumidor. Ou seja, não é necessário que o usuário tenha contribuído previamente para avaliar outras contribuições. 


\subsection{Projeto arquitetural}

Nesta seção dá-se início ao processo de construção da arquitetura seguindo o Método ADD que vem sendo utilizado pela indústria há mais de 15 anos. Sua primeira versão foi proposta em 2000 (BACHMANN et al., 2000) e teve atualizações em 2006 (WOJCIK et al., 2006) e 2013 (CERVANTES; VELASCO-ELIZONDO; KAZMAN, 2013). O Método ADD foi desenvolvido e é mantido pelo SEl e disseminado na bibliografia para guiar o desenvolvimento de arquiteturas que abarcam desde sistemas inovadores e altamente arriscados até atualizações minoritárias de sistemas já consolidados (BASS; CLEMENTS; KAZMAN, 2012; KAZMAN; CERVANTES, 2016).

Hofmeister et al. (2007) apresentam um estudo comparativo com os cinco métodos mais utilizados pela indústria como o ADD, o Siemens' 4 Views (S4V), o Rational Unified Process $4+1$ views (RUP4+1), o Business Architecture Process and Organization (BAPO) e o Architectural Separation of Concerns (ASC), de modo a estabelecer um padrão que os autores classificam de ideal para servir de base comparação.

Considerando o estudo de Hofmeister et al. (2007), escolheu-se o Método ADD pela relação intrínseca que o método tem com o ecossistema mantido pelo SEI para, por exemplo, ter seus artefatos validados utilizando o método ATAM (BASS; CLEMENTS; KAZMAN, 2012; GALLAGHER, 2000). Ademais, o Método ADD tem como abordagens principais a tomada de decisões e o foco em cenários para levantamento dos requisitos arquiteturais.

A Figura 23 apresenta a visão geral do Método ADD com seus passos e artefatos gerados ao longo do processo. 
Figura 23 - Passos e artefatos do Método ADD

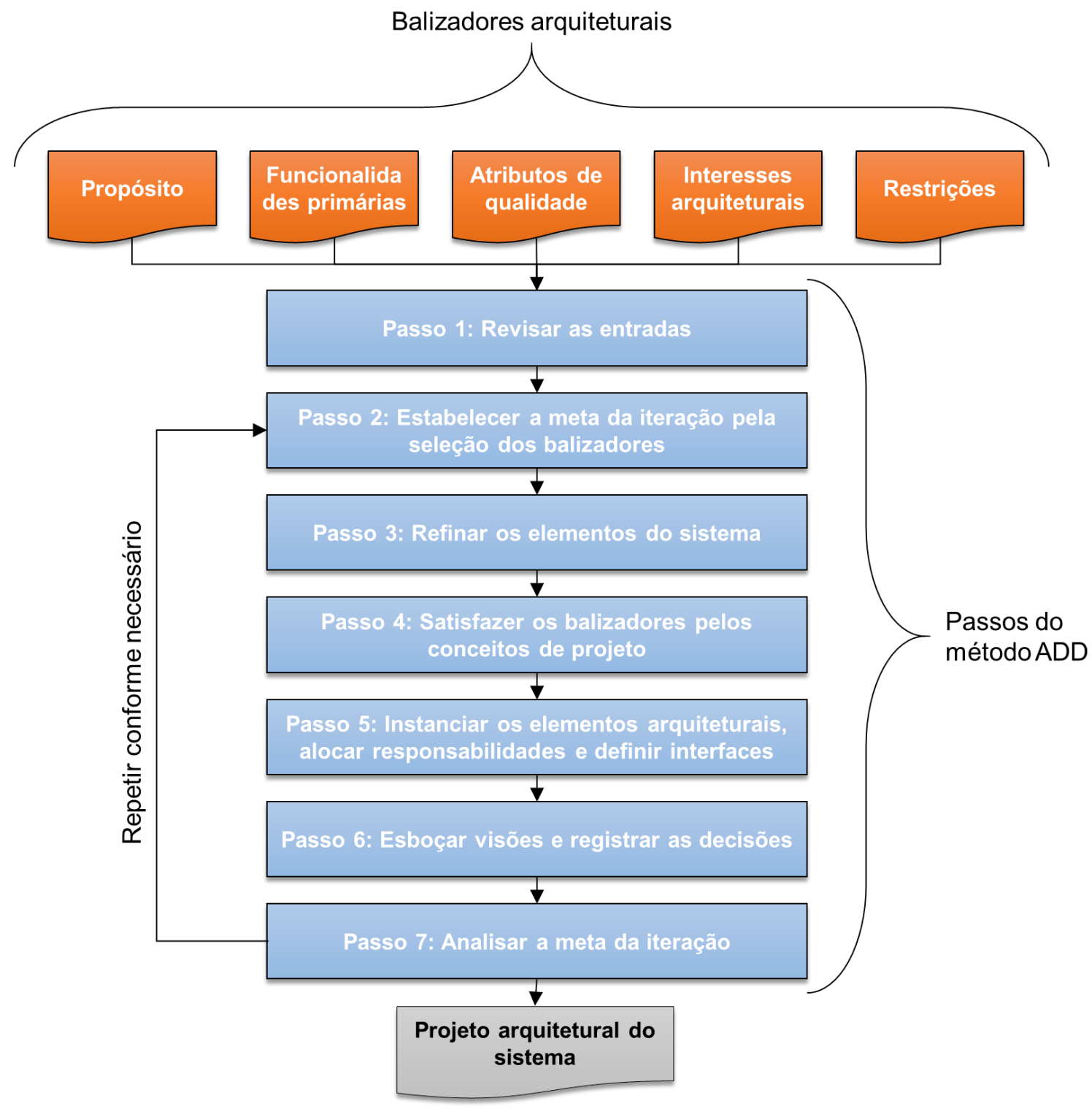

Fonte: Adaptado de Bass, Clements e Kazman (2012); Kazman e Cervantes (2016).

No projeto arquitetural o Método ADD guia a tradução dos atributos da arquitetura em estruturas e componentes, assim como suas propriedades e relações. Um bom projeto arquitetural é aquele que satisfaz os balizadores arquiteturais.

Pela Figura 23, percebe-se, primeiramente, que os balizadores arquiteturais são considerados como entrada para o projeto arquitetural. Desse modo, os 
balizadores arquiteturais refletem os requisitos do negócio e são críticos para o sucesso do sistema. Importante ressaltar que o Método ADD não trata do levantamento dos requisitos do negócio. A este respeito, utilizaram-se técnicas combinadas da engenharia de software clássica, especificadamente a disciplina de engenharia de requisitos, como complemento para viabilizar o levantamento de requisitos de forma efetiva para a arquitetura (KOSCIANSKI; SOARES, 2007; PRESSMAN, 2011; SOMMERVILLE, 2007). Este processo é retratado na Seção 4.2 - Requisitos da arquitetura deste capítulo.

O Método ADD é composto por sete passos definidos por um processo iterativo e incremental. O primeiro passo do método não faz parte da iteração, pois visa evidenciar os balizadores arquiteturais mais relevantes. Na sequência, a interação visa guiar o arquiteto na definição de estruturas com o mínimo de risco possível de não considerar os elementos mais importantes definidos nos balizadores arquiteturais.

Nas subseções seguintes são demonstrados todos os passos sugeridos pelo Método ADD para o projeto arquitetural. Para melhor adequação aos objetivos deste trabalho, algumas atividades foram adaptadas para manter a objetividade e refletir os pontos mais relevantes dos resultados obtidos com a definição da arquitetura.

\subsubsection{ADD - Passo 1: Revisão das entradas}

O primeiro passo visa evidenciar os balizadores arquiteturais mais importantes. Para melhor objetividade, adaptou-se este passo para compreender também a definição dos balizadores arquiteturais. No Método ADD, originalmente, a definição dos balizadores é feita em momento anterior. Acredita-se que com esta adaptação tem-se melhor aproveitamento para os fins pretendidos para com este trabalho.

\subsubsection{Propósito}

O propósito da arquitetura é fornecer artefatos arquiteturais para implementar um sistema colaborativo para estruturar informações em dados abertos e possibilitar o uso e reuso dos dados por qualquer um e para qualquer propósito. 


\subsubsection{Funcionalidades primárias}

As funcionalidades primárias são as habilidades da arquitetura em desempenhar o trabalho para o qual foi projetada. Podem ser declaradas resumidamente conforme a seguir. Cada funcionalidade será unicamente referenciada ao longo deste capítulo com a sigla PF (Primary Functionality) seguida de seu número de ordem único.

- FP-1: Disponibilizar dados por meio de datasets em catálogo OGD e prover mecanismos de acesso e busca manuais ou por meio de automação por APIs.

- FP-2: Estruturar colaborativamente dados pela identificação de conteúdo tabular, pela extração de dados dispostos em formatos desestruturados, pela catalogação e pelo carregamento em datasets descritos com metadados.

- FP-3: Avaliar as contribuições da comunidade provendo mecanismos de moderação e incentivo à vigilância do processo colaborativo.

\subsubsection{Atributos de qualidade}

Atributos de qualidade são definidos como propriedades mensuráveis ou testáveis de um sistema, os quais indicam que o sistema satisfaz as necessidades de seus stakeholders. O cerne de um atributo de qualidade é a resposta do sistema a um determinado estímulo, o qual é demonstrado pela descrição de um cenário de utilização intrinsicamente ligado a um requisito. De acordo com sua importância, fazse necessária a definição de atributos de qualidade a partir da elicitação, especificação e priorização dos requisitos da arquitetura.

Kazman e Cervantes (2016) sugerem algumas técnicas testadas e disseminadas para ajudar na definição dos atributos de qualidade. Uma delas é a árvore de utilidades que sugere a priorização dos atributos em duas dimensões que representam a importância do atributo para o negócio e o risco técnico envolvido. Para cada dimensão é atribuída uma escala representada pelos valores $\underline{\mathrm{H}}$ (high ou alto), $\underline{\mathrm{M}}$ (medium ou médio) e $\underline{\mathrm{L}}$ (low ou baixo). Na primeira dimensão - a importância para o negócio - ㅡㅡ indica um atributo de alta importância para o negócio 
e $\underline{L}$ indica um atributo de baixa importância para o negócio. Do mesmo modo, a segunda dimensão - risco técnico - $\underline{\mathrm{H}}$ indica um alto risco técnico e $\underline{L}$ indica um baixo risco técnico. Em ambas as dimensões também é admitido o valor $\underline{M}$ indicando a valoração em escala intermediária.

A partir da árvore de utilidades adaptada para as características deste trabalho, a Tabela 12 especifica os atributos de qualidade indicando suas prioridades, cenários e casos de uso relacionados. Cada atributo de qualidade será unicamente referenciado ao longo deste capítulo com a sigla QA (Quality Attribute) seguida de seu número de ordem único.

Tabela 12 - Atributos de qualidade da arquitetura

\begin{tabular}{|c|c|c|c|c|}
\hline Prioridade & ID & Atributo & Cenário & $\begin{array}{c}\text { Caso de uso } \\
\text { relacionado } \\
\text { (Tabela 11) }\end{array}$ \\
\hline $\mathrm{M}, \mathrm{H}$ & QA-1 & $\begin{array}{l}\text { Estruturação } \\
\text { incremental }\end{array}$ & $\begin{array}{l}\text { O sistema permite que o usuário } \\
\text { contribua com versões incrementais dos } \\
\text { datasets com base nos próprios dados ou } \\
\text { de contribuições de outros usuários }\end{array}$ & UC-2 \\
\hline $\mathrm{H}, \mathrm{H}$ & QA-2 & $\begin{array}{l}\text { Operação } \\
\text { colaborativa }\end{array}$ & $\begin{array}{l}\text { O sistema permite a estruturação de } \\
\text { dados de um número não determinado de } \\
\text { fontes por meio da colaboração } \\
\text { distribuída pela comunidade de } \\
\text { interessados }\end{array}$ & UC-2 \\
\hline $\mathrm{H}, \mathrm{M}$ & QA-3 & $\begin{array}{l}\text { Moderação } \\
\text { hierarquizada }\end{array}$ & $\begin{array}{l}\text { O sistema fornece meios para o combate } \\
\text { ao abuso e ao vandalismo, moderado } \\
\text { pela hierarquia de usuários reconhecida } \\
\text { pelos mecanismos próprios de reputação } \\
\text { da comunidade }\end{array}$ & UC-3 \\
\hline $\mathrm{H}, \mathrm{M}$ & QA-4 & Avaliação mútua & $\begin{array}{l}\text { O sistema possibilita a avaliação mútua } \\
\text { das contribuições feitas pela comunidade } \\
\text { utilizando critérios simples e objetivos } \\
\text { para construir a reputação dos usuários }\end{array}$ & UC-3 \\
\hline $\mathrm{H}, \mathrm{H}$ & QA-5 & $\begin{array}{l}\text { Operação } \\
\text { baseada no } \\
\text { navegador }\end{array}$ & $\begin{array}{l}\text { O navegador web, interface básica de } \\
\text { operação pelo usuário, leva à fonte de } \\
\text { dados desestruturada e ativa as } \\
\text { ferramentas de estruturação por meio de } \\
\text { extensão desenvolvida especificamente } \\
\text { para o navegador em uso }\end{array}$ & UC-2 \\
\hline
\end{tabular}




\begin{tabular}{l|l|l|l|l}
\hline H, L & QA-6 & $\begin{array}{l}\text { Autenticação do } \\
\text { usuário }\end{array}$ & $\begin{array}{l}\text { O usuário é autenticado e identificado } \\
\text { unicamente dentro do sistema por meio } \\
\text { de usuário e senha }\end{array}$ & $\begin{array}{l}\text { UC-2 } \\
\text { UC-3 }\end{array}$ \\
\hline H, L & QA-7 & $\begin{array}{l}\text { Acesso } \\
\text { autoconcedido }\end{array}$ & $\begin{array}{l}\text { O usuário poderá se auto registrar no } \\
\text { sistema sem a intervenção de outro } \\
\text { usuário }\end{array}$ & $\begin{array}{l}\text { UC-2 } \\
\text { UC-3 }\end{array}$ \\
\hline QA-8 & $\begin{array}{l}\text { Trilha de } \\
\text { registro }\end{array}$ & $\begin{array}{l}\text { O sistema registra todas as operações } \\
\text { realizadas pelos usuários, inclusive os } \\
\text { dados estruturados e suas respectivas } \\
\text { fontes }\end{array}$ & UC-2 \\
\hline UC-3
\end{tabular}

Fonte: Elaborado pelo autor.

\subsubsection{Interesses arquiteturais}

Os interesses arquiteturais indicam os pontos que a priori não possam ser expressos como requisitos tradicionais, pois não estão diretamente ligados aos casos de uso definidos na Seção 4.2 - Requisitos da arquitetura, mas orbitam e influenciam estes. Para esta arquitetura, estão sendo considerados os interesses arquiteturais especificados na Tabela 13. Cada interesse arquitetural será unicamente referenciado ao longo deste capítulo com a sigla CRN (Concern) seguida de seu número de ordem único. 
Tabela 13 - Interesses arquiteturais

\begin{tabular}{|c|c|}
\hline ID & Interesse arquitetural \\
\hline $\begin{array}{l}\text { CRN-1: Em } \\
\text { camadas }\end{array}$ & $\begin{array}{l}\text { A arquitetura seguirá o padrão de projeto organizado em camadas } \\
\text { (RICHARDS, 2015). Cada camada especifica um papel e responsabilidade } \\
\text { para o sistema. As camadas possibilitam um nível suficiente de abstração } \\
\text { para suprimir os detalhes internos da camada que não têm importância } \\
\text { preponderante no contexto geral da arquitetura. O recurso essencial em } \\
\text { arquiteturas padronizadas em camadas é a separação lógica de acordo com } \\
\text { o contexto da atividade que exerce cada camada. }\end{array}$ \\
\hline $\begin{array}{l}\text { CRN-2: } \\
\text { Modelo } \\
\text { relacional }\end{array}$ & $\begin{array}{l}\text { A persistência dos dados no contexto da arquitetura será viabilizada por } \\
\text { Sistema de Gerenciamento de Banco de Dados (SGBD) seguindo o modelo } \\
\text { relacional (HARRINGTON, 2016). Isto é conveniente para compatibilidade } \\
\text { com a disposição tabular convencionalmente encontrada em datasets e que } \\
\text { abarca a grande maioria dos dados de interesse de OGD. }\end{array}$ \\
\hline $\begin{array}{l}\text { CRN-3: } \\
\text { Extensão } \\
\text { nativa }\end{array}$ & $\begin{array}{l}\text { A extensão do navegador será desenvolvida especificamente para os } \\
\text { principais produtos em uso pelo mercado, utilizando as ferramentas e } \\
\text { frameworks de desenvolvimento disponibilizados oficialmente pelos } \\
\text { respectivos desenvolvedores/fabricantes. }\end{array}$ \\
\hline $\begin{array}{l}\text { CRN-4: } \\
\text { Extensão } \\
\text { compatível }\end{array}$ & $\begin{array}{l}\text { A extensão do navegador será atualizada sempre que necessário, sendo } \\
\text { checada sua compatibilidade à medida que os navegadores evoluem para } \\
\text { garantir a segurança e consistência do sistema como um todo. }\end{array}$ \\
\hline $\begin{array}{l}\text { CRN-5: } \\
\text { Previsão } \\
\text { novos } \\
\text { formatos }\end{array}$ & $\begin{array}{l}\text { O sistema possibilitará estender métodos de extração que possibilitem o } \\
\text { tratamento de novos formatos de disponibilização de dados encontrados nos } \\
\text { websites de transparência, além dos já contemplados HTML e PDF. }\end{array}$ \\
\hline $\begin{array}{l}\text { CRN-6: } \\
\text { Modularidade }\end{array}$ & $\begin{array}{l}\text { Eventuais novas bibliotecas ou componentes a serem integrados ao sistema } \\
\text { serão desenvolvidos seguindo os padrões de construção para garantir a alta } \\
\text { coesão e baixo acoplamento da modularidade do sistema (KOSCIANSKI; } \\
\text { SOARES, 2007; PRESSMAN, 2011; SOMMERVILLE, 2007). }\end{array}$ \\
\hline $\begin{array}{l}\text { CRN-7: } \\
\text { Interface } \\
\text { amigável }\end{array}$ & $\begin{array}{l}\text { As ferramentas do processo de estruturação serão desenhadas para a } \\
\text { maioria dos usuários, com pouco ou nenhum conhecimento na área de } \\
\text { análise e processamento de dados. }\end{array}$ \\
\hline
\end{tabular}

Fonte: Elaborado pelo autor. 


\subsubsection{Restrições}

As restrições são decisões previamente estabelecidas que 0 desenvolvedor/implementador tem pouco ou nenhum controle.

À primeira vista, as restrições podem ser confundidas com os interesses arquiteturais definidos na seção anterior, porém a diferença fundamental entre eles é que as restrições estabelecem pontos mandatórios definidos na arquitetura e que devem ser atendidos pelo sistema, com pouca ou nenhuma margem de manobra pelo desenvolvedor/implementador.

Para esta arquitetura, estão sendo consideradas as restrições especificadas na Tabela 14. Cada restrição será unicamente referenciada ao longo deste capítulo com a sigla CON (Constraint) seguida de seu número de ordem único.

Tabela 14 - Restrições aplicadas à arquitetura

\begin{tabular}{l|l}
\hline \multicolumn{1}{c|}{ ID } & \multicolumn{1}{c}{ Restrição } \\
\hline $\begin{array}{l}\text { CON-1: } \\
\text { Open }\end{array}$ & $\begin{array}{l}\text { Todas as bibliotecas, frameworks, Software Development Kits (SDKs), SGBDs e } \\
\text { outros produtos e tecnologias necessários para a implementação da arquitetura } \\
\text { devem ser de código aberto e de licenciamento livre de custos para qualquer } \\
\text { propósito (pessoal, comercial ou acadêmico). }\end{array}$ \\
\hline CON-2: Uso do & O catálogo de OGD utilizado deve ser o CKAN. \\
CKAN & NON-3: \\
interferência & $\begin{array}{l}\text { O processo de estruturação não deverá interferir nos processos existentes de } \\
\text { produção dos dados e não deve exigir que estes sejam compatíveis com dados } \\
\text { abertos. }\end{array}$ \\
\hline $\begin{array}{l}\text { CON-4: } \\
\text { Universalidade } \\
\text { do CSV }\end{array}$ & $\begin{array}{l}\text { O sistema deve considerar o formato CSV para salvaguardar os dados obtidos } \\
\text { pelo processo de estruturação e adotá-lo como formato preferencial de } \\
\text { intercâmbio no contexto da arquitetura. }\end{array}$ \\
\hline CON-5: Sob & $\begin{array}{l}\text { Todas as implementações com base na arquitetura e suas respectivas evoluções } \\
\text { incrementais, inclusive no modelo de software como serviço, devem ser } \\
\text { compartilhadas com a comunidade sob a licença Affero General Public License - } \\
\text { GPL (MEEKER, 2008). Isso se justifica pela previsão da GPL em outros } \\
\text { elementos considerados na arquitetura. Além disso, o objetivo de OGD é } \\
\text { promover o uso e reuso de informações livremente, o que não seria possível caso } \\
\text { licenças restritivas fossem impostas. }\end{array}$ \\
\hline
\end{tabular}

Fonte: Elaborado pelo autor. 
4.3.2 Iteração 1: Estrutura de suporte à colaboração

Nesta seção, e respectivas subseções, são detalhados os passos referentes à primeira iteração do Método ADD. De acordo com este método, faz-se a quantidade de iterações necessárias até que se possa definir suficientemente as estruturas da arquitetura e atender a todos os balizadores definidos.

O foco desta primeira iteração é, portanto, definir a estrutura para dar suporte à colaboração. O foco desta iteração foi assim definido pelo motivo da colaboração ser um dos principais pilares da arquitetura, conforme já discutido nas seções anteriores.

4.3.2.1 ADD - Passo 2: Estabelecer a meta da iteração pela seleção dos balizadores

Neste passo do Método ADD estabelece-se a meta da iteração pela seleção dos balizadores arquiteturais. A seleção é realizada pela relação dos balizadores com o foco da iteração, que neste caso é prover estrutura de suporte à colaboração.

A Figura 24 ilustra a seleção dos balizadores com a exposição de um sigrama de associações que sintetiza o processo. 
Figura 24 - Digrama de associações dos balizadores pela meta da iteração - colaboração

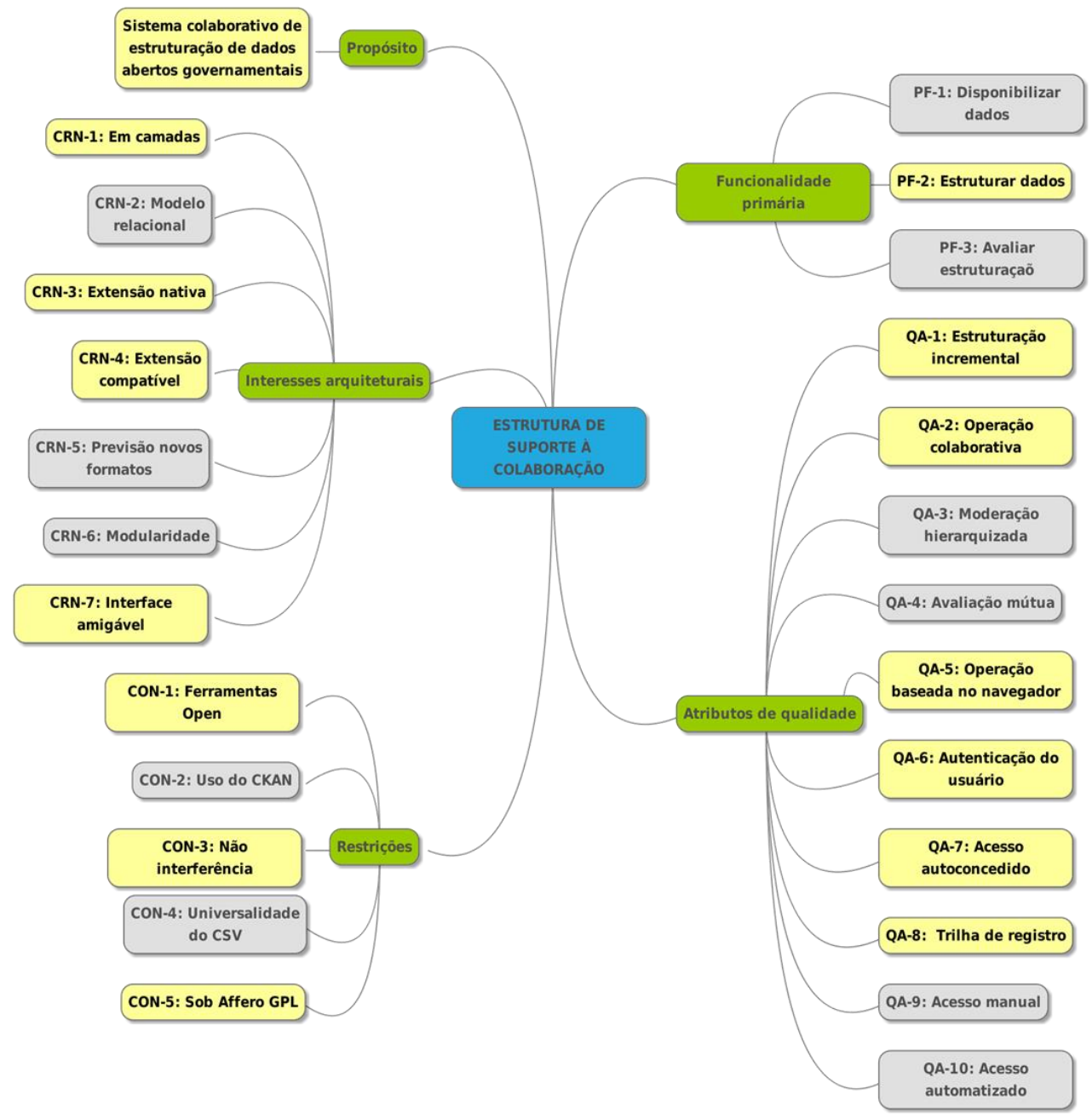

Legenda:

Grupo de balizador

Balizador selecionado

Balizador não selecionado

Fonte: Elaborado pelo autor.

Para analisar e compreender o diagrama de associações exposto na Figura 24 é necessário entender sua composição. Primeiramente, o mapa resume todos os balizadores arquiteturais definidos até o momento. Os nós-pai (em verde) representam os grupos de balizadores arquiteturais para organizar o processo. 0 nós-folha (em amarelo e cinza) representam os balizadores em si. A cor amarela indica a seleção dos balizadores para o foco desta iteração e a cor cinza indica que os balizadores não foram selecionados para esta iteração. 
Os balizadores selecionados guiarão os artefatos (estrutura) a serem gerados nos próximos passos do Método ADD.

\subsubsection{ADD - Passo 3: Refinar os elementos do sistema}

Para suportar o processo colaborativo, tem-se basicamente o navegador web como interface única do usuário para estruturação e o servidor responsável por prover os serviços de apoio que serão detalhados posteriormente.

A Figura 25 ilustra os elementos da estruturação por colaboração exibindo um diagrama de componentes e expondo as interfaces fornecidas e requeridas por cada componente.

Figura 25 - Elementos - colaboração

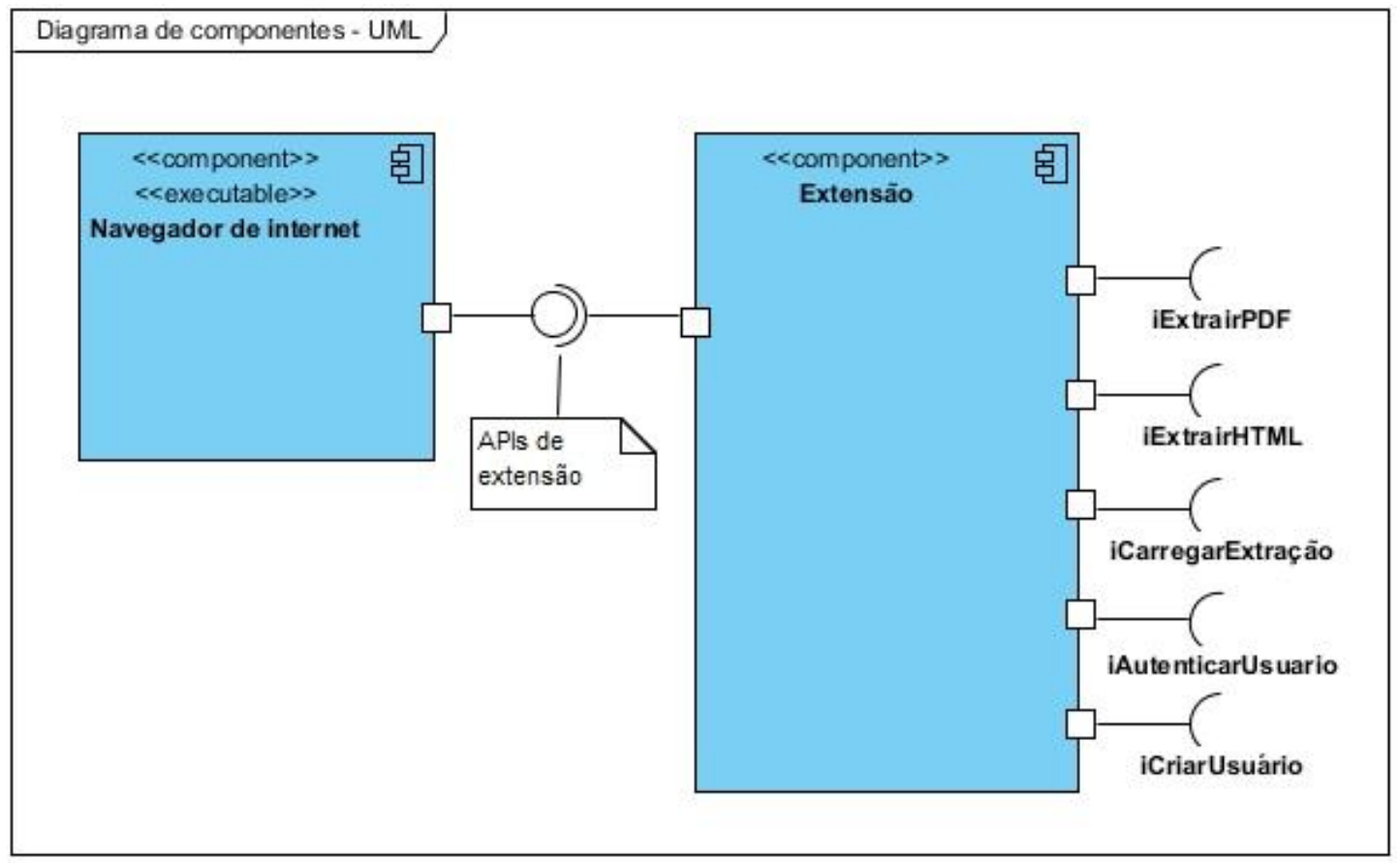

Fonte: Elaborado pelo autor.

A Figura 26 ilustra o diagrama com as principais classes e seus atributos, os relacionamentos e a cardinalidade com a definição do número de ocorrências em cada classe, os quais ajudam a refinar a estrutura que dá suporte à colaboração. 
Figura 26 - Principais classes e relacionamentos - colaboração

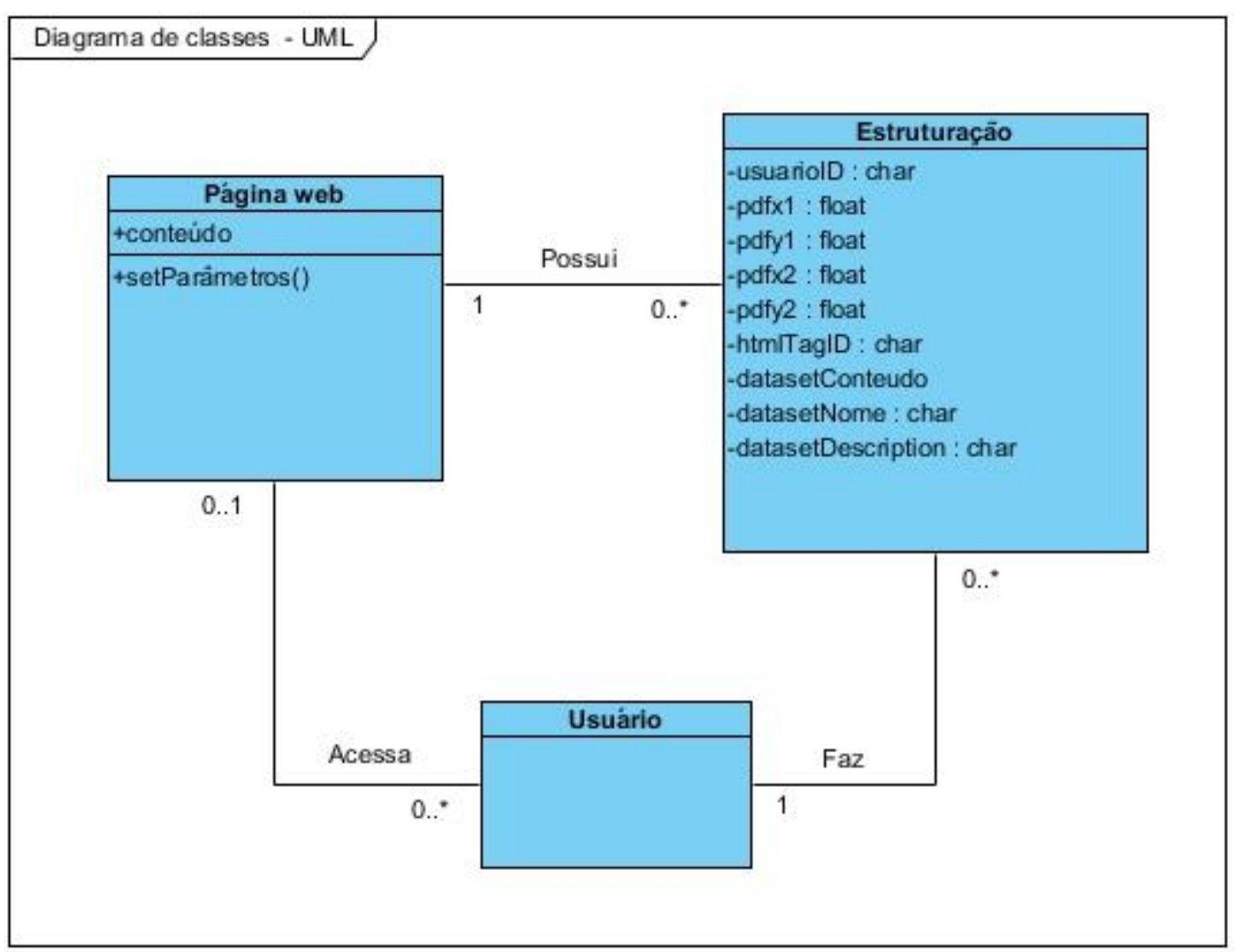

Fonte: Elaborado pelo autor.

\subsubsection{ADD - Passo 4: Satisfazer os balizadores pelos conceitos de projeto}

Neste passo são especificados mais detalhes de como os balizadores serão satisfeitos por meio dos conceitos de projeto decididos para esta iteração. Segundo Kazman e Cervantes (2016), há uma infinidade de conceitos de projetos existentes e não há uma definição clara sobre eles. Os conceitos de projeto visam dar suporte às questões específicas da arquitetura e podem ser definidos pelo arcabouço de diferentes origens metodológicas (bibliografia, boas práticas, experiência do arquiteto, etc.).

A Tabela 15 a seguir especifica as decisões tomadas sobre conceitos de projetos para satisfação dos balizadores desta iteração. Note-se que pode haver referência cruzada aos mesmos balizadores em diferentes decisões. Isso caracteriza e reforça a consistência dos conceitos de projeto no âmbito da iteração. 
Tabela 15 - Decisões sobre conceitos de projeto para satisfação dos balizadores - colaboração

\begin{tabular}{|c|c|}
\hline Decisão & Descrição \\
\hline $\begin{array}{l}\text { Organizar o } \\
\text { desenvolvimento em } \\
\text { camadas }\end{array}$ & $\begin{array}{l}\text { Esta decisão visa atender primariamente ao balizador CRN-1 para } \\
\text { desenvolver uma arquitetura organizada em camadas. Nesta iteração, } \\
\text { realiza-se a camada de colaboração (PF-2, QA-1, QA-2) que será } \\
\text { responsável pela interação do usuário, tendo-se como interface única o } \\
\text { navegador de internet do usuário (QA-5) que é amplamente utilizado e de } \\
\text { fácil operação (CRN-7). }\end{array}$ \\
\hline $\begin{array}{l}\text { Desenvolver extensão } \\
\text { de navegador }\end{array}$ & $\begin{array}{l}\text { Esta decisão visa atender primariamente ao balizador QA-5 para ter uma } \\
\text { operação baseada no navegador. Nesta iteração, realiza-se a construção } \\
\text { de extensão utilizando SDKs (CRN-3) fornecidos pelos próprios } \\
\text { fabricantes/desenvolvedores do navegador evitando o desenvolvimento } \\
\text { cross-browser }{ }^{10} \text {. Deve priorizar a checagem da compatibilidade sempre } \\
\text { que novas versões dos navegadores forem lançadas (CRN-4). A interface } \\
\text { deve ser intuitiva e amigável para possibilitar o uso por todos os públicos } \\
\text { (CRN-7). A extensão terá como princípio a não interferência nas fontes } \\
\text { originárias pois estas não são passíveis de controle ou modificação a } \\
\text { partir de desenvolvedores externos (CON-3). }\end{array}$ \\
\hline $\begin{array}{l}\text { Desenvolver e distribuir } \\
\text { livremente }\end{array}$ & $\begin{array}{l}\text { O desenvolvimento utilizará ferramentas livres e sem custo monetário } \\
\text { (CON-1) e todos os artefatos gerados serão licenciados sob a licença } \\
\text { Affero GPL (CON-5). }\end{array}$ \\
\hline $\begin{array}{l}\text { Prever interfaces } \\
\text { requeridas }\end{array}$ & $\begin{array}{l}\text { Esta decisão visa realizar os balizadores CRN-1 e QA-5 para viabilizar a } \\
\text { organização em camadas e o uso de extensão baseada no navegador do } \\
\text { usuário. Nesta iteração, interfaces são requeridas de outras camadas } \\
\text { para prover a modularização e independência dos componentes por meio } \\
\text { de serviços de estruturação (PF-2), autenticação de usuário (QA-6), auto } \\
\text { registro do usuário (QA-7) e registro de atividades executadas (QA-8). }\end{array}$ \\
\hline
\end{tabular}

Fonte: Elaborado pelo autor.

$10 \mathrm{O}$ desenvolvimento cross-browser define o reuso do processo de desenvolvimento da extensão para funcionamento em mais de um navegador por meio de frameworks de compatibilidade. Apesar dos benefícios aparentes, no momento da escrita deste trabalho, não havia um padrão adotado pela indústria, fazendo que adaptações sejam necessárias e haja incremento de complexidade pelo uso de componentes externos (MEHTA, 2016). 
4.3.2.4 ADD - Passo 5: Instanciar os elementos arquiteturais, alocar responsabilidades e definir interfaces

Neste passo são expostos os elementos arquiteturais desta iteração que estão representados no diagrama de componentes da Figura 25. A Tabela 16 detalha esses elementos com a alocação das responsabilidades e definição das interfaces.

Tabela 16 - Elementos, responsabilidades e interfaces - colaboração

\begin{tabular}{|c|c|c|}
\hline Elemento & Responsabilidade & $\begin{array}{c}\text { Interface } \\
\text { (requerida/fornecida) }\end{array}$ \\
\hline $\begin{array}{l}<<\text { component }>> \\
<<\text { executable }>> \\
\text { Navegador de } \\
\text { internet }\end{array}$ & $\begin{array}{l}\text { Exibir e interagir com as páginas web pelo } \\
\text { usuário através do canvas }{ }^{11} \text { e prover APIs } \\
\text { para acesso e manipulação dos elementos } \\
\text { internos das páginas }\end{array}$ & $\begin{array}{l}\text { Várias que fazem parte das } \\
\text { denominadas APIs de } \\
\text { extensão (fornecidas) }\end{array}$ \\
\hline \multirow[t]{5}{*}{$\begin{array}{l}<<\text { component }>> \\
\text { Extensão }\end{array}$} & $\begin{array}{l}\text { Extrair dados tabulares a partir de documentos } \\
\text { PDF }\end{array}$ & iExtrairPDF (requerida) \\
\hline & $\begin{array}{l}\text { Extrair dados tabulares a partir de arquivos } \\
\text { descritos em HTML }\end{array}$ & iExtrairHTML (requerida) \\
\hline & $\begin{array}{l}\text { Carregar dados extraídos juntamente com os } \\
\text { metadados fornecidos pelo usuário } \\
\text { contribuidor }\end{array}$ & iCarregarExtração (requerida) \\
\hline & $\begin{array}{l}\text { Autenticar usuário para que possa carregar } \\
\text { extrações em seu workspace }\end{array}$ & $\begin{array}{l}\text { iAutenticarUsuário } \\
\text { (requerida) }\end{array}$ \\
\hline & $\begin{array}{l}\text { Criar usuário dentro do processo de } \\
\text { configuração da extensão }\end{array}$ & iCriarUsuário (requerida) \\
\hline
\end{tabular}

Fonte: Elaborado pelo autor.

\subsubsection{ADD - Passo 6: Esboçar visões e registrar as decisões}

Neste passo são esboçadas as visões de importância. No caso, optou-se por evidenciar o sequenciamento dos eventos para caracterizar o processo de colaboração. A Figura 27 apresenta o diagrama de sequência com os eventos previstos.

11 Em computação canvas é um container onde são exibidos os elementos gráficos (figuras, textos, etc.). Neste ponto o termo refere-se à área visível do navegador onde o usuário visualiza e interage com a página web. 
Figura 27 - Sequenciamento dos eventos - colaboração

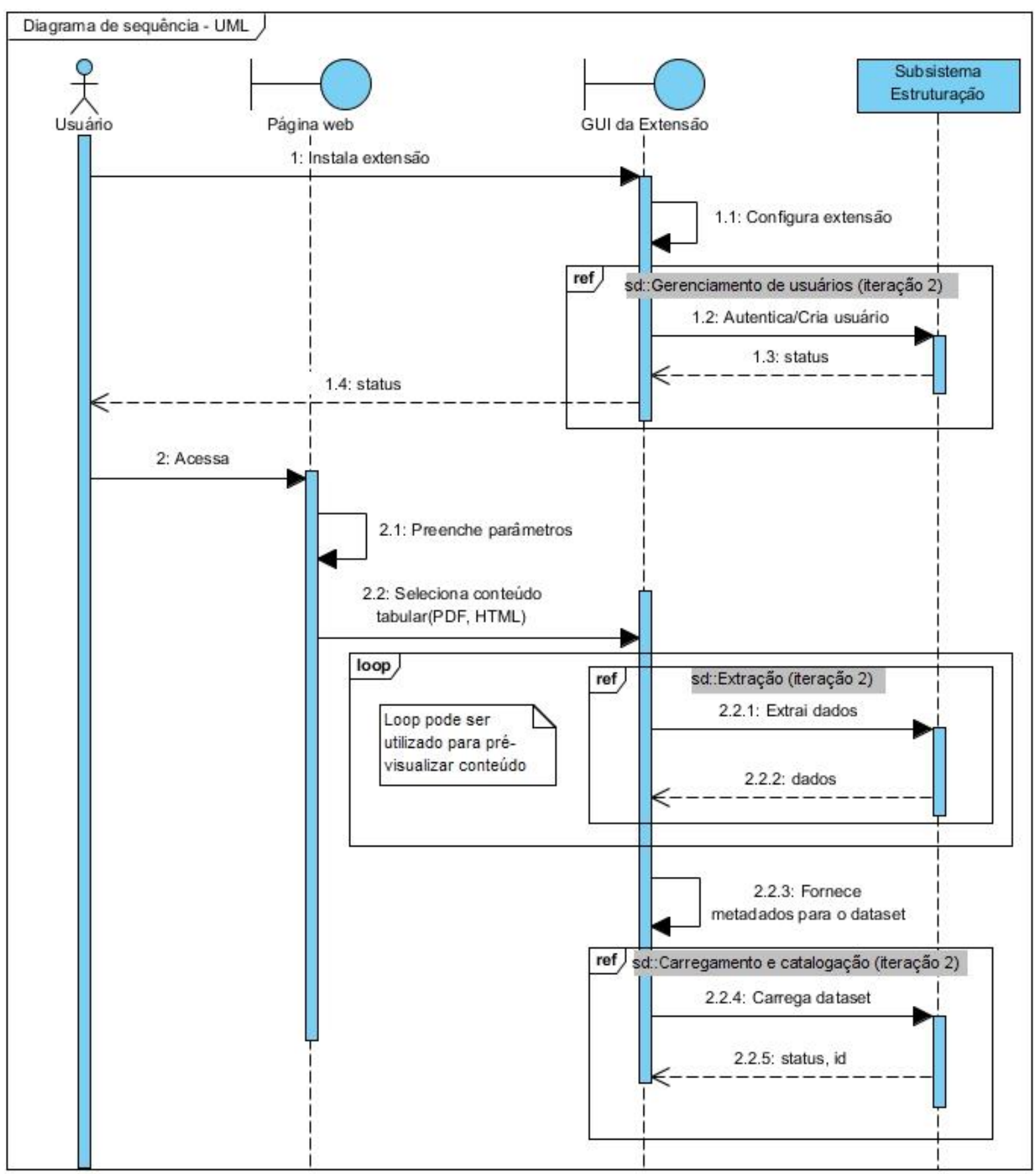

Fonte: Elaborado pelo autor.

Neste diagrama da Figura 27 estão sendo referenciadas interações que serão detalhadas oportunamente na próxima iteração (Seção 4.3.3 - Iteração 2: Estrutura de suporte à estruturação). Estas referências são caracterizadas pelos fragmentos com os estereótipos ref com a indicação de qual diagrama faz referência. 


\subsubsection{ADD - Passo 7: Analisar a meta da iteração}

Este último passo da iteração objetiva fazer um ponto de checagem acerca do atendimento dos balizadores arquiteturais.

A Tabela 17 sintetiza a checagem com a exposição dos balizadores cobertos, cobertos parcialmente ou não cobertos. Também expõe breve análise para deixar claro o que foi realizado, relatando as evidências e as pendências quando aplicáveis.

Tabela 17 - Análise da meta da iteração - colaboração

\begin{tabular}{|c|c|c|c|}
\hline Não coberto & $\begin{array}{c}\text { Coberto } \\
\text { parcialmente }\end{array}$ & $\begin{array}{l}\text { Completamente } \\
\text { coberto }\end{array}$ & Análise (evidências / pendências) \\
\hline & PF-2 & & $\begin{array}{l}\text { A funcionalidade primária foi atendida } \\
\text { parcialmente no que diz respeito à definição } \\
\text { da estrutura de operação do ponto de vista do } \\
\text { usuário (colaboração). } \\
\text { Pendências: instanciar as estruturas do lado } \\
\text { do servidor para fornecer as interfaces } \\
\text { requeridas para a estruturação. }\end{array}$ \\
\hline & & QA-1 & $\begin{array}{l}\text { O atributo de qualidade foi atendido } \\
\text { completamente por possibilitar o acesso a } \\
\text { qualquer página web e estruturar os dados } \\
\text { repetidas vezes. }\end{array}$ \\
\hline & & QA-2 & $\begin{array}{l}\text { O atributo de qualidade foi atendido } \\
\text { completamente por possibilitar a utilização por } \\
\text { qualquer um, desde que instalada e configura } \\
\text { a extensão do navegador. }\end{array}$ \\
\hline & & QA-5 & $\begin{array}{l}\text { O atributo de qualidade foi atendido } \\
\text { completamente por prever a operação pelo } \\
\text { navegador e o uso de extensão para prover as } \\
\text { ferramentas necessárias. }\end{array}$ \\
\hline & $\begin{array}{l}\text { QA-6 } \\
\text { QA-7 }\end{array}$ & & $\begin{array}{l}\text { Os atributos de qualidade foram atendidos } \\
\text { parcialmente com a previsão de evento de } \\
\text { configuração da extensão. } \\
\text { Pendências: instanciar as estruturas do lado } \\
\text { do servidor para fornecer as interfaces } \\
\text { requeridas. }\end{array}$ \\
\hline QA-8 & & & $\begin{array}{l}\text { O atributo de qualidade não foi atendido por } \\
\text { conta da necessidade de previsão de }\end{array}$ \\
\hline
\end{tabular}




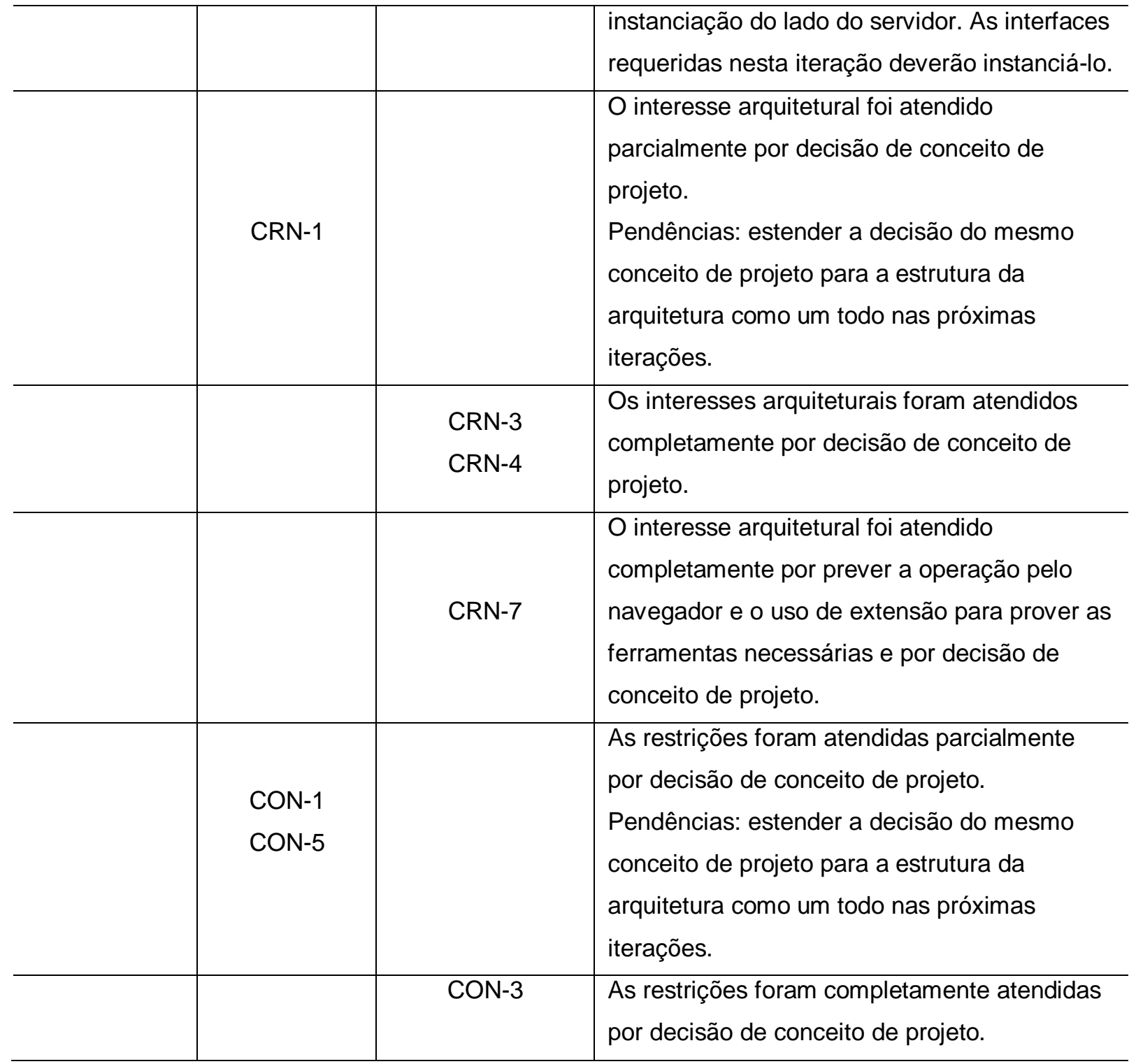

Fonte: Elaborada pelo autor

\subsubsection{Iteração 2: Estrutura de suporte à estruturação}

O foco desta segunda iteração é definir a estrutura de suporte à estruturação. A estruturação é o processo composto pela identificação do conteúdo tabular, pela extração de dados dispostos em formatos desestruturados, pela catalogação e pelo carregamento em datasets descritos com metadados. Parte do processo de estruturação foi tratado na primeira iteração, sendo que nesta segunda iteração será definida a estrutura que falta para completá-lo. 
A partir desta iteração os artefatos gerados serão apresentados de forma mais direta sem a introdução dos passos e as orientações metodológicas que os compõem, tendo em vista que isso já foi tratado na primeira iteração.

4.3.3.1 ADD - Passo 2: Estabelecer a meta da iteração pela seleção dos balizadores

A Figura 28 ilustra a seleção dos balizadores com a exposição de um diagrama de associações que sintetiza o processo. 
Figura 28 - Diagrama de associações de seleção dos balizadores pela meta da iteração estruturação

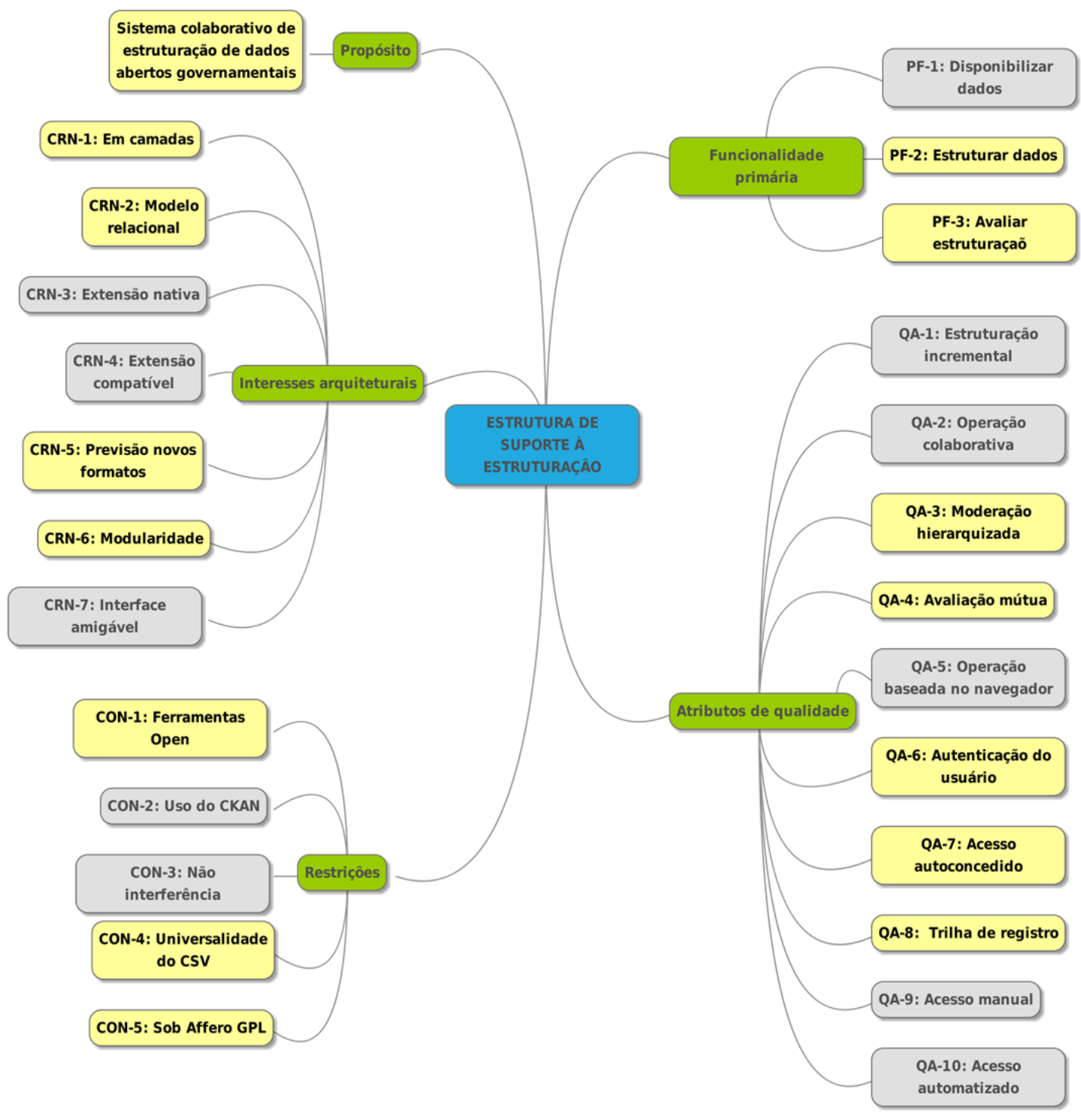

Legenda:

Grupo de balizador

Fonte: Elaborado pelo autor. 
4.3.3.2 ADD - Passo 3: Refinar os elementos do sistema

A Figura 29 ilustra os elementos da estruturação por colaboração exibindo um diagrama de componentes e expondo as interfaces fornecidas e requeridas por cada componente.

Figura 29 - Elementos - estruturação

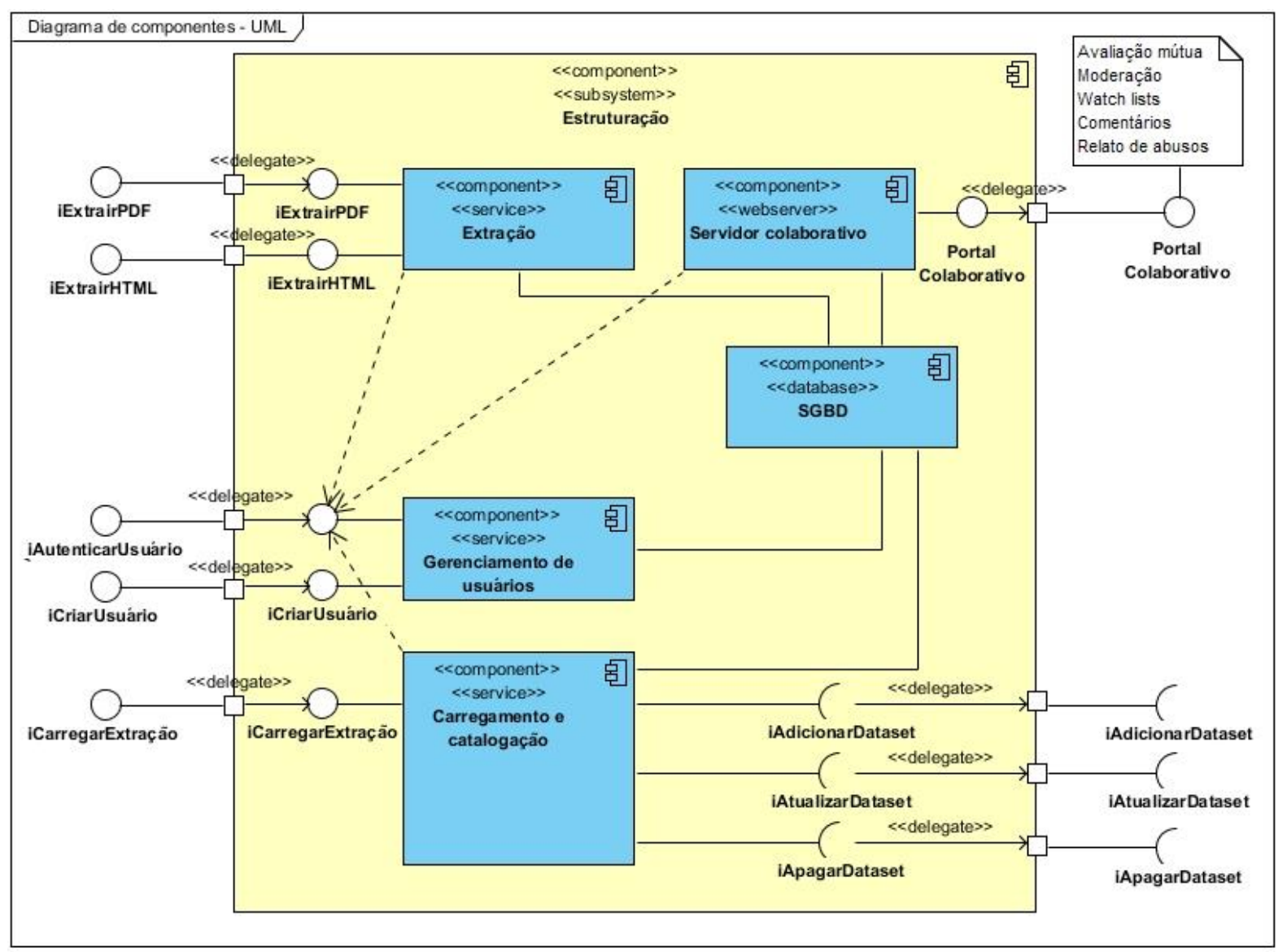

Fonte: Elaborado pelo autor.

O diagrama da Figura 29 estabelece um componente contendo o subsistema para prover os artefatos de estruturação. Nele há os componentes para fornecimento dos serviços de Extração, Gerenciamento de usuários e Carregamento e catalogação, os quais são responsáveis por fornecer as interfaces utilizadas pela extensão do navegador, conforme exposto na primeira iteração pela Figura 25. Especialmente o serviço Carregamento e catalogação é responsável por requerer as interfaces de operação de escrita nos datasets (adicionar, atualizar e apagar) a serem providas pelos serviços do CKAN a serem detalhados na próxima iteração. No subsistema há também o SGBD que é responsável por persistir os dados para 
apoio ao processo de estruturação. A Figura 30 detalha o modelo lógico de dados com as tabelas e visão previstas para o sistema.

Figura 30 - Modelo lógico de dados do SGBD - estruturação

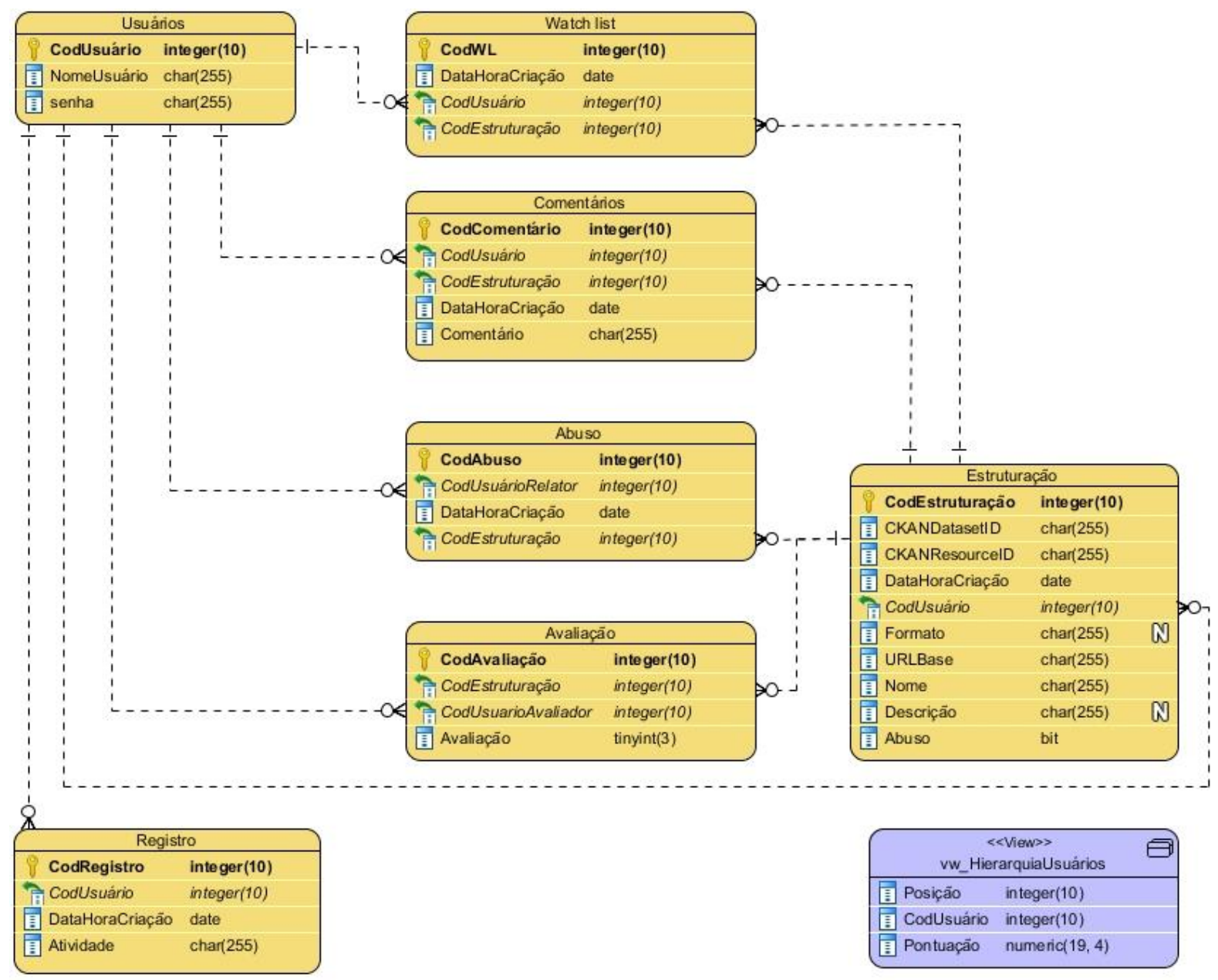

Fonte: Elaborado pelo autor.

\subsubsection{ADD - Passo 4: Satisfazer os balizadores pelos conceitos de projeto}

A Tabela 18 registra as decisões tomadas sobre conceitos de projetos para satisfação dos balizadores desta iteração. 
Tabela 18 - Decisões sobre conceitos de projeto para satisfação dos balizadores - estruturação

\begin{tabular}{l|l}
\hline \multicolumn{1}{c|}{ Decisão } & \multicolumn{1}{c}{ Descrição } \\
\hline $\begin{array}{l}\text { Organizar o } \\
\text { desenvolvimento em } \\
\text { camadas }\end{array}$ & $\begin{array}{l}\text { Esta decisão visa atender primariamente ao balizador CRN-1 para } \\
\text { desenvolver uma arquitetura organizada em camadas. Nesta iteração, } \\
\text { realiza-se a camada de estruturação (PF-2, PF-3, QA-3, QA-4, QA-6, QA- } \\
7, \text { QA-8) com a previsão de um subsistema que compreende os } \\
\text { componentes logicamente organizados sob o contexto de estruturação. }\end{array}$ \\
\hline \multirow{2}{*}{$\begin{array}{l}\text { Modularizar e estender } \\
\text { funcionalidades }\end{array}$} & $\begin{array}{l}\text { Esta decisão define que os componentes sejam desenvolvidos para } \\
\text { prover serviços e funcionalidades de forma independente e modular } \\
\text { (CRN-6). Dessa forma, os componentes podem ser aprimorados ou } \\
\text { substituídos com pouco ou nenhum impacto no sistema. Também, novos } \\
\text { componentes podem ser adicionados (CRN-5). }\end{array}$ \\
\hline Persistir e padronizar & $\begin{array}{l}\text { O SGBD previsto nesta iteração adota o modelo relacional (CRN-2). Os } \\
\text { dados trocados entre serviços são expressos em formato tabular com o } \\
\text { formato CSV (CON-4). }\end{array}$ \\
\hline $\begin{array}{l}\text { Desenvolver e distribuir } \\
\text { livremente }\end{array}$ & $\begin{array}{l}\text { O desenvolvimento utilizará ferramentas livres e sem custo monetário } \\
\text { (CON-1) e todos os artefatos gerados serão licenciados sob a licença } \\
\text { Affero GPL (CON-5). }\end{array}$ \\
\hline
\end{tabular}

Fonte: Elaborado pelo autor.

\subsubsection{ADD - Passo 5: Instanciar os elementos arquiteturais, alocar responsabilidades e definir interfaces}

A Tabela 19 detalha os elementos do subsistema definidos na Figura $29 \mathrm{com}$ a alocação das responsabilidades e definição das interfaces em cada componente. 
Tabela 19 - Elementos, responsabilidades e interfaces - estruturação

\begin{tabular}{|c|c|c|}
\hline Elemento & Responsabilidade & $\begin{array}{c}\text { Interface } \\
\text { (requerida/fornecida) }\end{array}$ \\
\hline \multirow{2}{*}{$\begin{array}{l}<<\text { component }>> \\
<<\text { service }> \\
\text { Extração }\end{array}$} & $\begin{array}{l}\text { Extrair dados tabulares a partir de documentos } \\
\text { PDF }\end{array}$ & iExtrairPDF (fornecida) \\
\hline & $\begin{array}{l}\text { Extrair dados tabulares a partir de arquivos } \\
\text { descritos em HTML }\end{array}$ & iExtrairHTML (fornecida) \\
\hline \multirow{2}{*}{$\begin{array}{l}<<\text { component }>> \\
<<\text { service }> \\
\text { Gerenciamento de } \\
\text { usuários }\end{array}$} & $\begin{array}{l}\text { Autenticar usuário para que possa carregar } \\
\text { extrações em seu workspace ou acionar os } \\
\text { mecanismos com identificação }\end{array}$ & iAutenticarUsuário (fornecida) \\
\hline & $\begin{array}{l}\text { Criar usuário para ter acesso a todas as } \\
\text { funcionalidades do subsistema }\end{array}$ & iCriarUsuário (fornecida) \\
\hline \multirow{4}{*}{$\begin{array}{l}<<\text { component }>> \\
<<\text { service }> \\
\text { Carregamento e } \\
\text { catalogação }\end{array}$} & $\begin{array}{l}\text { Carregar dados extraídos juntamente com os } \\
\text { metadados fornecidos pelo usuário } \\
\text { contribuidor }\end{array}$ & iCarregarExtração (fornecida) \\
\hline & $\begin{array}{l}\text { Adicionar dataset na instância CKAN a partir } \\
\text { do carregamento da estruturação pelo usuário }\end{array}$ & iAdicionarDataset (requerida) \\
\hline & $\begin{array}{l}\text { Atualizar dataset na instância CKAN a partir } \\
\text { do carregamento da estruturação pelo usuário }\end{array}$ & iAtualizarDataset (requerida) \\
\hline & Apagar dataset na instância CKAN & iApagarDataset (requerida) \\
\hline $\begin{array}{l}<<\text { component }>> \\
<<\text { webserver }>> \\
\text { Servidor } \\
\text { colaborativo }\end{array}$ & $\begin{array}{l}\text { Interface web para interação com os usuários } \\
\text { para acesso aos mecanismos de avaliação } \\
\text { mútua, moderação, watch lists, comentários e } \\
\text { relato de abusos }\end{array}$ & $\begin{array}{l}\text { Portal Colaborativo } \\
\text { (fornecida) }\end{array}$ \\
\hline $\begin{array}{l}<<\text { component }>> \\
<<\text { database }>> \\
\text { SGBD }\end{array}$ & $\begin{array}{l}\text { Persistência dos dados para apoio aos } \\
\text { componentes do subsistema de estruturação }\end{array}$ & Banco de dados \\
\hline
\end{tabular}

Fonte: Elaborado pelo autor.

A Tabela 20 detalha as interfaces fornecidas nesta iteração por intermédio de APIs para acesso automatizado, evidenciando os detalhes de funcionamento, os parâmetros de chamada e o retorno obtido. 
Tabela 20 - Detalhamento das interfaces - estruturação

\begin{tabular}{|c|c|c|c|}
\hline Interface & Detalhes do Funcionamento & Parâmetros & Retorno \\
\hline iExtrairPDF & $\begin{array}{l}\text { Extrai conteúdo tabular de um } \\
\text { documento PDF a partir da } \\
\text { indicação de coordenadas } \\
\text { (y1, x1, y2, x2) do retângulo } \\
\text { que identifica o conteúdo } \\
\text { tabular no documento }\end{array}$ & $\begin{array}{l}\text { pdf_file (byte) } \\
\text { y1 (float) } \\
\text { x1 (float) } \\
\text { y2 (float) } \\
\text { x2 (float) }\end{array}$ & csv_file (dictionary[]) \\
\hline iExtrairHTML & $\begin{array}{l}\text { Extrai conteúdo tabular de } \\
\text { uma página HTML a partir da } \\
\text { indicação da tag HTML que } \\
\text { identifica a tabela com os } \\
\text { dados }\end{array}$ & $\begin{array}{l}\text { html_file (byte) } \\
\text { table_id (char) }\end{array}$ & csv_file (dictionary[]) \\
\hline iAutenticarUsuário & $\begin{array}{l}\text { Checa o nome de usuário e } \\
\text { senha armazenados no banco } \\
\text { de dados pelo hash de senha } \\
\text { gerado pela função Secure } \\
\text { Hash Algorithm - SHA } \\
\text { (TANENBAUM; } \\
\text { WETHERALL, 2011, p. 802) }\end{array}$ & $\begin{array}{l}\text { userid (int) } \\
\text { hashpwd (char) }\end{array}$ & status (boolean) \\
\hline iCriarUsuário & $\begin{array}{l}\text { Cria usuário no sistema de } \\
\text { gerenciamento de usuário } \\
\text { pela definição de um nome e } \\
\text { um hash da senha pela } \\
\text { função SHA (TANENBAUM; } \\
\text { WETHERALL, 2011, p. 802) }\end{array}$ & $\begin{array}{l}\text { username (char) } \\
\text { hashpwd (char) }\end{array}$ & $\begin{array}{l}\text { status (boolean) } \\
\text { userid (char) }\end{array}$ \\
\hline iCarregarExtração & $\begin{array}{l}\text { Registra e faz o carregamento } \\
\text { da estruturação no CKAN. O } \\
\text { conteúdo considerado está no } \\
\text { contexto de execução do } \\
\text { usuário que previamente já } \\
\text { fez a extração }\end{array}$ & $\begin{array}{l}\text { userid (int) } \\
\text { dataset (dictionary[]) }\end{array}$ & $\begin{array}{l}\text { status (boolean) } \\
\text { datasetid (char) } \\
\text { resid (char) }\end{array}$ \\
\hline
\end{tabular}

Fonte: Elaborado pelo autor.

Ressalta-se que a interface Portal Colaborativo não foi detalhada na Tabela 20 por se tratar de interface manual de acesso por meio de página web, cujas funções 
foram devidamente citadas na própria tabela de forma textual para entendimento geral das funcionalidades deste componente.

\subsubsection{ADD - Passo 6: Esboçar visões e registrar as decisões}

Nesta seção serão mostrados os diagramas de sequência para evidenciar as interações que acontecem no contexto do subsistema de estruturação foco desta iteração. Cada componente detalhado neste subsistema pela Figura 29 será modelado para expor o sequenciamento dos eventos e interação com os demais elementos.

Primeiramente, a Figura 31 a seguir apresenta o sequenciamento dos eventos no âmbito do componente Gerenciamento de usuários e sua interação com o componente SGBD. 
Figura 31 - Sequenciamento dos eventos do componente Gerenciamento de usuários - estruturação

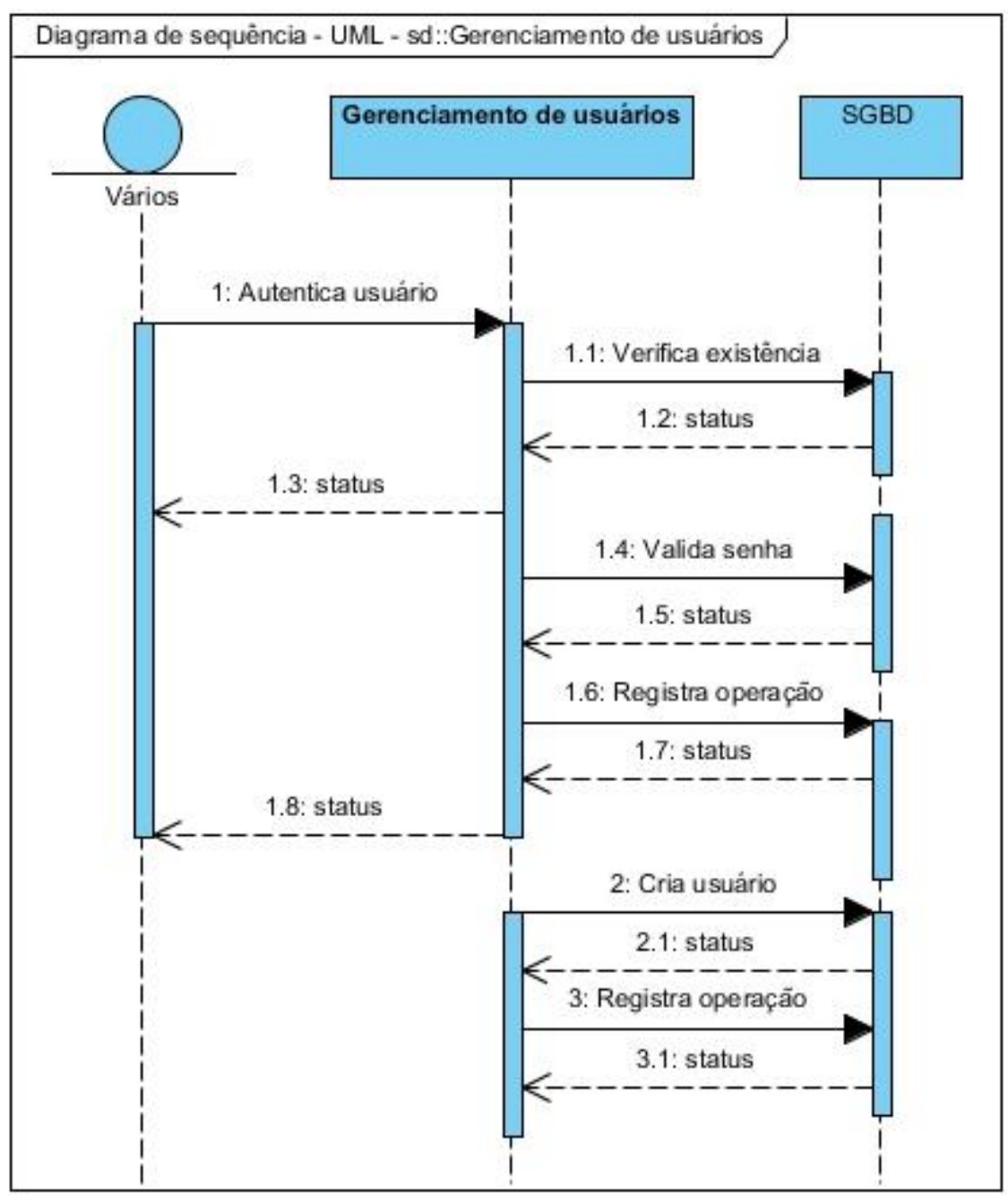

Fonte: Elaborado pelo autor.

A Figura 32 a seguir mostra o sequenciamento dos eventos no âmbito do componente Extração e sua interação com os componentes Gerenciamento de

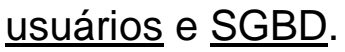


Figura 32 - Sequenciamento dos eventos do componente Extração - estruturação

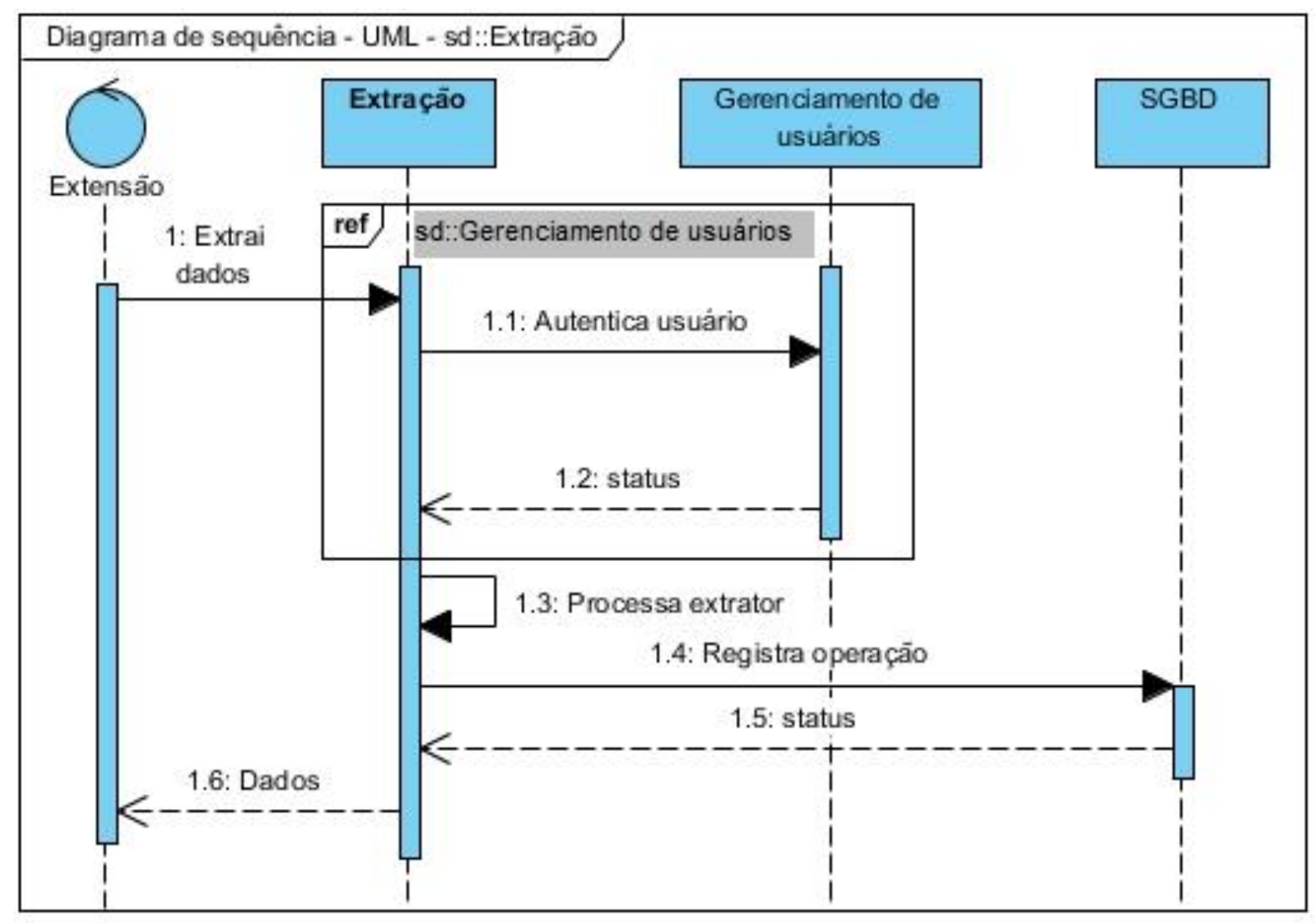

Fonte: Elaborado pelo autor.

A partir deste diagrama da Figura 32 são referenciadas outras interações detalhada anteriormente e que são caracterizadas pelos fragmentos com os estereótipos ref.

A Figura 33 a seguir mostra o sequenciamento dos eventos no âmbito do componente Carregamento e catalogação e sua interação com os componentes Gerenciamento de usuários, $S G B D$ e CKAN, este último externo ao subsistema. 
Figura 33 - Sequenciamento dos eventos do componente Carregamento e catalogação - estruturação

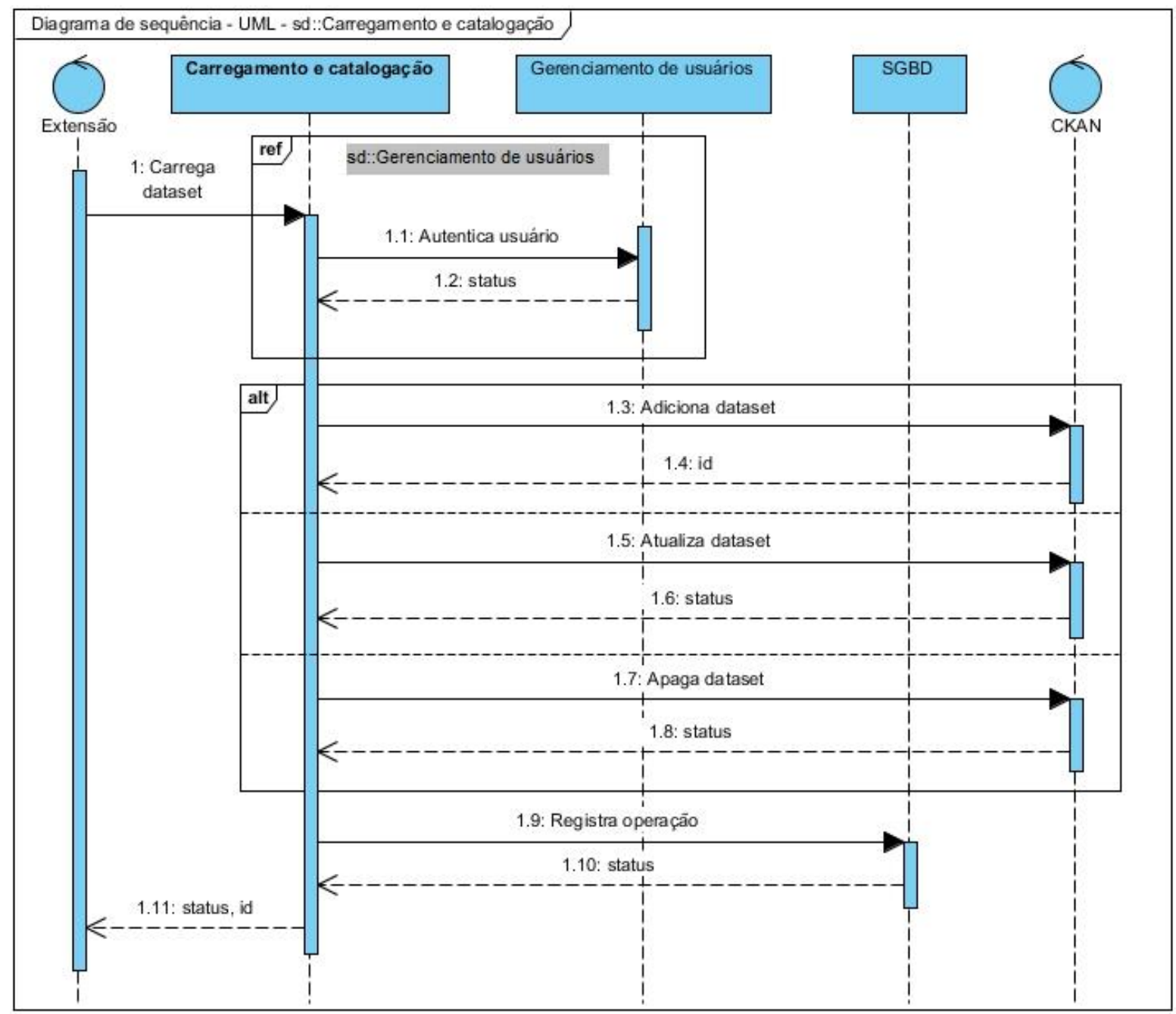

Fonte: Elaborado pelo autor.

A Figura 34 a seguir mostra o sequenciamento dos eventos no âmbito do componente Servidor colaborativo e sua interação com os componentes

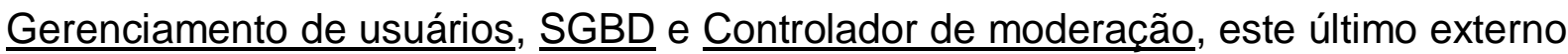
ao subsistema. 
Figura 34 - Sequenciamento dos eventos do componente Servidor colaborativo - estruturação

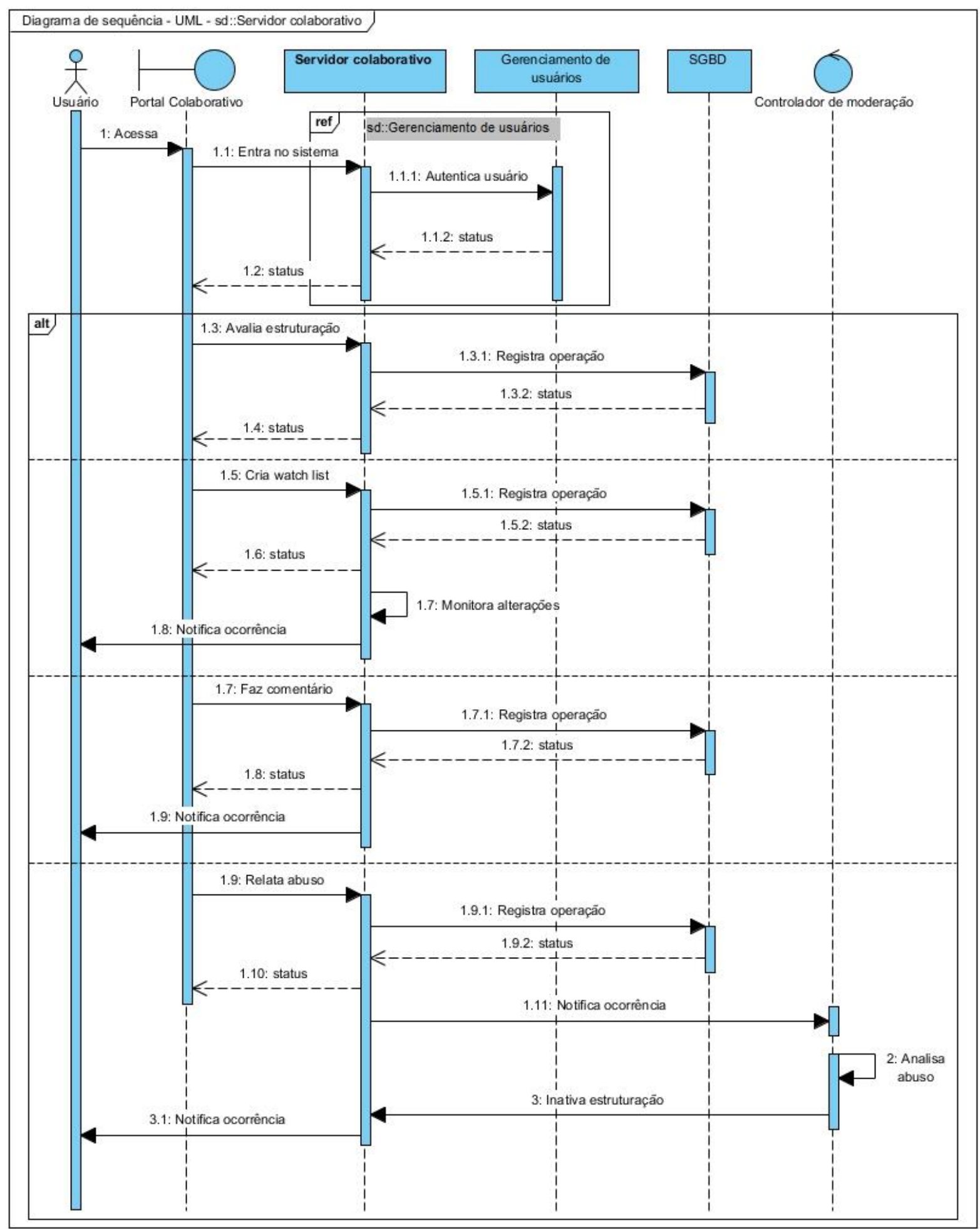

Fonte: Elaborado pelo autor. 
Este diagrama da Figura 34 expõe os eventos que são possíveis no componente. Note-se que há interface exposta pelo Portal Colaborativo, o qual é o principal meio de operação do componente Servidor colaborativo.

\subsubsection{ADD - Passo 7: Analisar a meta da iteração}

A Tabela 21 sintetiza a checagem quanto ao atendimento dos balizadores para esta iteração. Note-se que os balizadores que já tinham sido completamente cobertos na última iteração não estão sendo mencionados, e sim apenas aqueles que estavam como parcialmente cobertos na iteração anterior ou que não tinham sido foco das iterações até o momento. 
Tabela 21 - Análise da meta da iteração - estruturação

\begin{tabular}{|c|c|c|c|}
\hline Não coberto & $\begin{array}{c}\text { Coberto } \\
\text { parcialmente }\end{array}$ & $\begin{array}{l}\text { Completamente } \\
\text { coberto }\end{array}$ & Análise (evidências / pendências) \\
\hline & & $\begin{array}{l}\text { PF-2 } \\
\text { PF-3 }\end{array}$ & $\begin{array}{l}\text { Ambas as funcionalidades primárias foram } \\
\text { completamente atendidas pela instanciação } \\
\text { dos componentes que faltavam do lado do } \\
\text { servidor (PF-2) e o processo de avaliação } \\
\text { detalhado nos passos desta iteração. }\end{array}$ \\
\hline & & $\begin{array}{l}\text { QA-3 } \\
\text { QA-4 } \\
\text { QA-6 } \\
\text { QA-7 } \\
\text { QA-8 }\end{array}$ & $\begin{array}{l}\text { Os atributos de qualidade foram atendidos } \\
\text { completamente pelos artefatos gerados nos } \\
\text { passos desta iteração. }\end{array}$ \\
\hline & CRN-1 & & $\begin{array}{l}\text { O interesse arquitetural foi atendido } \\
\text { parcialmente por decisão de conceito de } \\
\text { projeto. } \\
\text { Pendências: estender a decisão do mesmo } \\
\text { conceito de projeto para a estrutura da } \\
\text { arquitetura como um todo nas próximas } \\
\text { iterações. }\end{array}$ \\
\hline & & $\begin{array}{l}\text { CRN-2 } \\
\text { CRN-5 } \\
\text { CRN-6 }\end{array}$ & $\begin{array}{l}\text { Os interesses arquiteturais foram atendidos } \\
\text { completamente por decisão de conceito de } \\
\text { projeto. }\end{array}$ \\
\hline & $\begin{array}{l}\text { CON-1 } \\
\text { CON-5 }\end{array}$ & & $\begin{array}{l}\text { As restrições foram atendidas parcialmente } \\
\text { por decisão de conceito de projeto. } \\
\text { Pendências: estender a decisão do mesmo } \\
\text { conceito de projeto para a estrutura da } \\
\text { arquitetura como um todo nas próximas } \\
\text { iterações. }\end{array}$ \\
\hline & & CON-4 & $\begin{array}{l}\text { As restrições foram atendidas completamente } \\
\text { por decisão de conceito de projeto. }\end{array}$ \\
\hline
\end{tabular}

Fonte: Elaborado pelo autor. 
4.3.4 Iteração 3: Estrutura de suporte à apresentação dos dados

O foco desta iteração é definir a estrutura de suporte à apresentação dos dados. É nesta estrutura onde se considera o catálogo OGD para disponibilização dos dados e dos metadados com os mecanismos de acesso e edição manuais e automatizados.

4.3.4.1 ADD - Passo 2: Estabelecer a meta da iteração pela seleção dos balizadores

A Figura 35 ilustra a seleção dos balizadores com a exposição de um diagrama de associações que sintetiza o processo. 
Figura 35 - Diagrama de associações de seleção dos balizadores pela meta da iteração apresentação

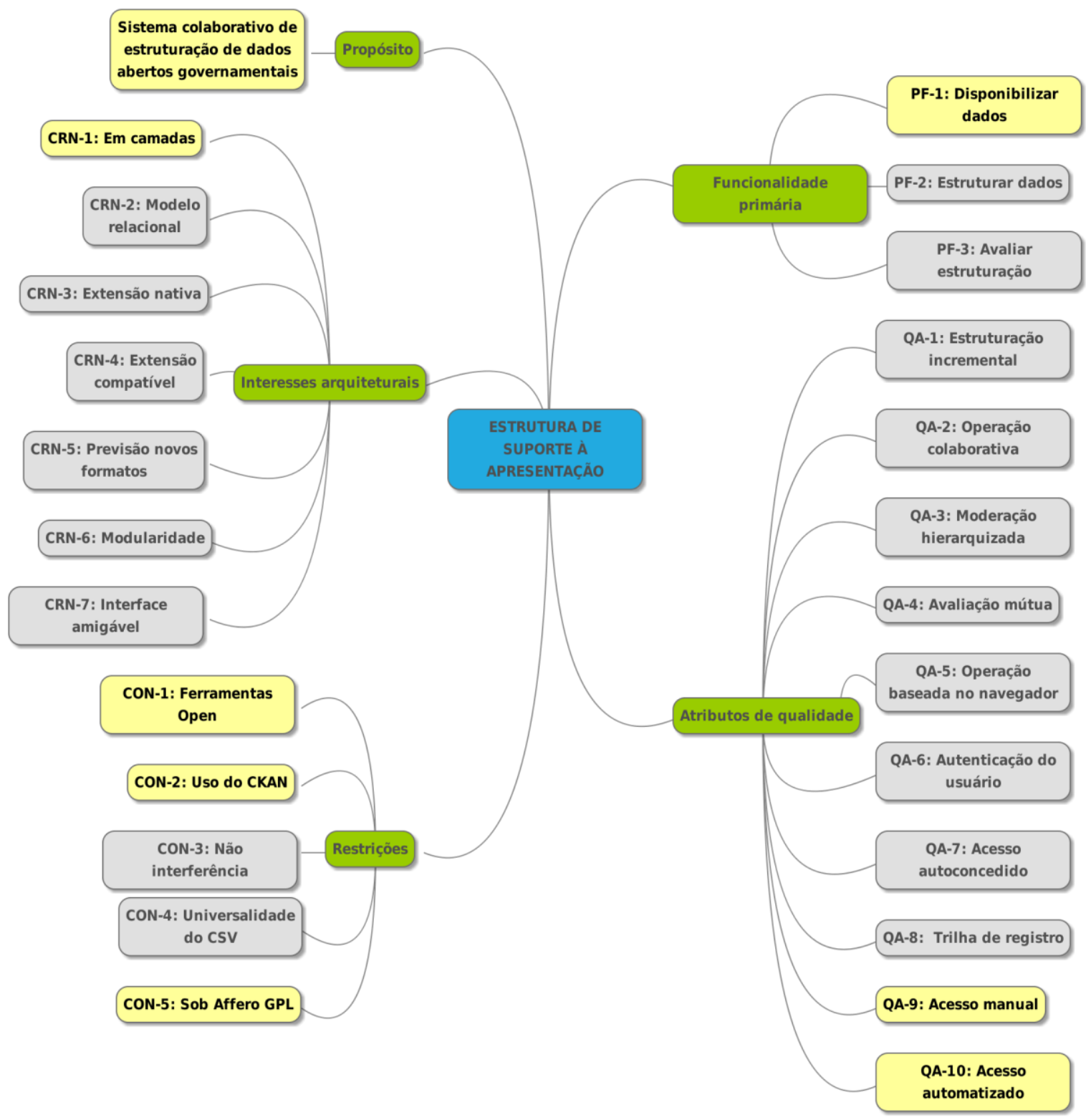

Fonte: Elaborado pelo autor.

\subsubsection{ADD - Passo 3: Refinar os elementos do sistema}

O elemento desta iteração é um subsistema composto pelo catálogo OGD CKAN. Por isso, considera-se a utilização de uma instância do CKAN nas suas configurações originais na forma que são disponibilizadas pela comunidade e estão evidenciadas na documentação oficial do produto. 
A Figura 36 ilustra os elementos da apresentação exibindo um diagrama de componentes e expondo as interfaces fornecidas e requeridas por cada componente.

Figura 36 - Elementos - apresentação

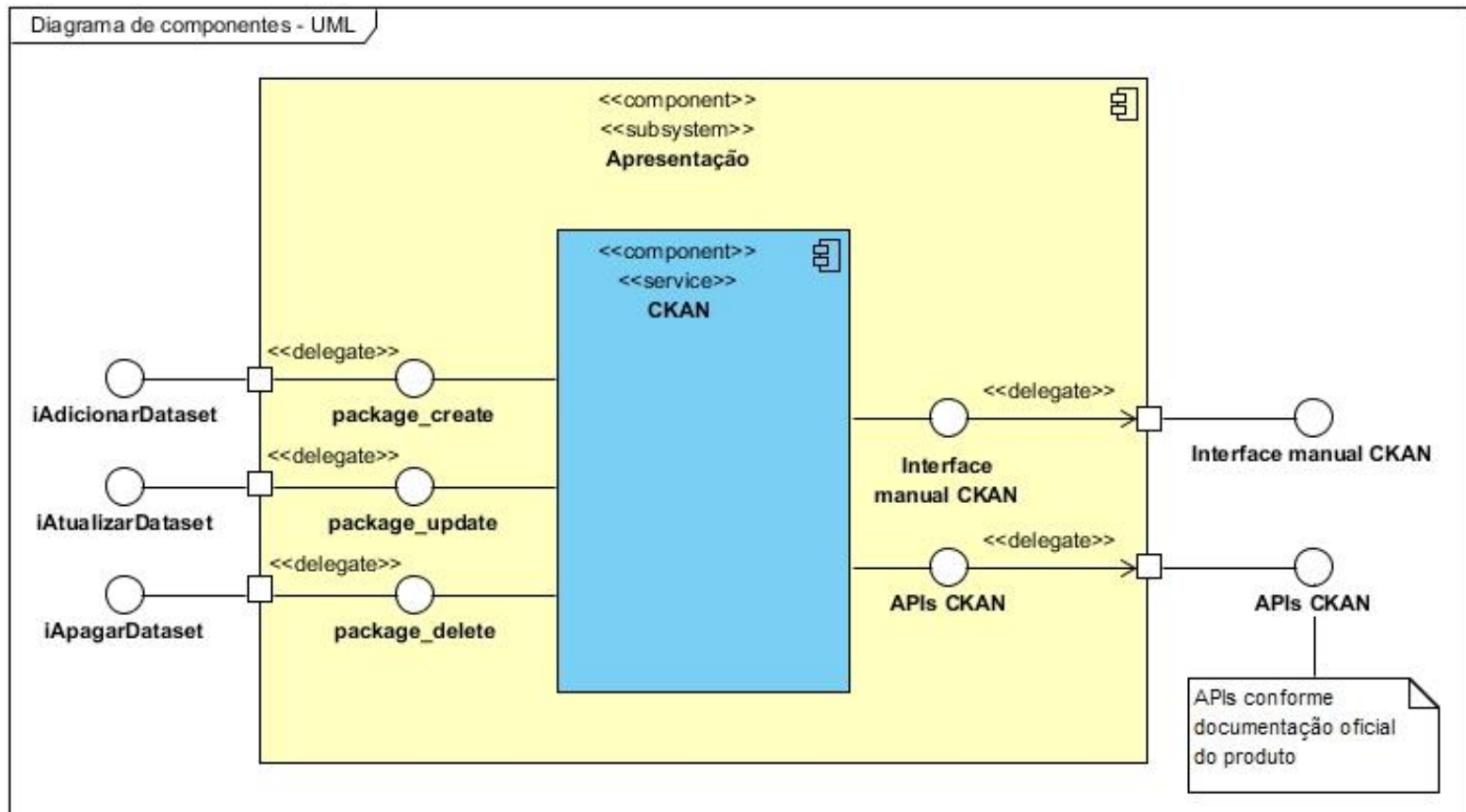

Fonte: Elaborado pelo autor.

O CKAN já oferece um grande número de APIs para manipulação automatizada de suas funcionalidades. No diagrama da Figura 36 estão sendo representadas as interfaces fornecidas para estas APIs e a interface de interação manual que é caracterizada pelas páginas web do CKAN, também representada como interface fornecida.

Neste subsistema de apresentação estão sendo também fornecidas três APls do CKAN para operações básicas de manipulação dos datasets, as quais foram requeridas na iteração anterior.

\subsubsection{ADD - Passo 4: Satisfazer os balizadores pelos conceitos de projeto}

A Tabela 22 registra as decisões tomadas sobre conceitos de projetos para satisfação dos balizadores desta iteração. 
Tabela 22 - Decisões sobre conceitos de projeto para satisfação dos balizadores - apresentação

\begin{tabular}{l|l}
\hline \multicolumn{1}{c|}{ Decisão } & \multicolumn{1}{c}{ Descrição } \\
\hline $\begin{array}{l}\text { Organizar o } \\
\text { desenvolvimento em } \\
\text { camadas }\end{array}$ & $\begin{array}{l}\text { Esta decisão visa atender primariamente ao balizador CRN-1 para } \\
\text { desenvolver uma arquitetura organizada em camadas. Nesta iteração, } \\
\text { realiza-se a camada de apresentação (PF-1) com a utilização do CKAN } \\
(\text { CON-2) para acesso e edição manual e automatizada (QA-9 e QA-10) } \\
\text { dos dados. }\end{array}$ \\
\hline $\begin{array}{l}\text { Desenvolver e distribuir } \\
\text { livremente }\end{array}$ & $\begin{array}{l}\text { O desenvolvimento utilizará ferramentas livres e sem custo monetário } \\
(\text { CON-1) e todos os artefatos gerados serão licenciados sob a licença } \\
\text { Affero GPL (CON-5). }\end{array}$ \\
\hline
\end{tabular}

Fonte: Elaborado pelo autor.

4.3.4.4 ADD - Passo 5: Instanciar os elementos arquiteturais, alocar responsabilidades e definir interfaces

A Tabela 23 detalha os elementos definidos na Figura 36 com a alocação das responsabilidades e definição das interfaces em cada componente.

Tabela 23 - Elementos, responsabilidades e interfaces - apresentação

\begin{tabular}{|c|c|c|}
\hline Elemento & Responsabilidade & $\begin{array}{c}\text { Interface } \\
\text { (requerida/fornecida) }\end{array}$ \\
\hline \multirow{5}{*}{$\begin{array}{l}<<\text { component }>> \\
<<\text { service }>> \\
\text { Extração }\end{array}$} & Adicionar dataset na instância CKAN & package_create (fornecida) \\
\hline & Atualizar dataset na instância CKAN & package_update (fornecida) \\
\hline & Apagar dataset na instância CKAN & package_delete (fornecida) \\
\hline & $\begin{array}{l}\text { Interface web para interação com os } \\
\text { usuários para acesso às funcionalidades } \\
\text { manuais do CKAN para busca e visualização } \\
\text { de datasets }\end{array}$ & $\begin{array}{l}\text { Interface manual CKAN } \\
\text { (fornecida) }\end{array}$ \\
\hline & $\begin{array}{l}\text { Conjunto de APIs originalmente fornecidas e } \\
\text { documentadas pelo CKAN para as diversas } \\
\text { operações possíveis, como busca e } \\
\text { visualização de datasets }\end{array}$ & APIs CKAN (fornecida) \\
\hline
\end{tabular}

Fonte: Elaborado pelo autor.

A Tabela 24 detalha as interfaces fornecidas nesta iteração por intermédio de APIs para acesso automatizado, evidenciando os detalhes de funcionamento, os 
parâmetros de chamada e o retorno obtido. Ressalta-se que estão sendo detalhadas apenas as principais interfaces disponibilizadas pelo CKAN que são essenciais à definição da arquitetura. Vários parâmetros opcionais também foram omitidos por questão de espaço. Todas as APls e seus respectivos detalhes podem ser consultados na documentação ${ }^{12}$ que acompanha o produto.

Tabela 24 - Detalhamento das interfaces - apresentação

\begin{tabular}{|c|c|c|c|}
\hline Interface & Detalhes do Funcionamento & Parâmetros & Retorno \\
\hline package_create & $\begin{array}{l}\text { Adicionar um dataset no } \\
\text { repositório }\end{array}$ & $\begin{array}{l}\text { name (string) } \\
\text { author (string) } \\
\text { author_email (string) } \\
\text { url (string) } \\
\text { resources (dictionary[]) }\end{array}$ & id (string) \\
\hline package_update & Alterar um dataset no repositório & $\begin{array}{l}\text { id (string) } \\
\text { name (string) } \\
\text { author (string) } \\
\text { author_email (string) } \\
\text { url (string) } \\
\text { resources (dictionary[]) }\end{array}$ & id (string) \\
\hline package_delete & Excluir um dataset do repositório & id (string) & - \\
\hline
\end{tabular}

Fonte: Elaborado pelo autor.

As APIs documentadas na Tabela 24 causam alteração na estrutura dos dados. Por isso, precisam ser invocadas com o fornecimento da chave de identificação do criador/modificador de conteúdo dentro da instância CKAN. Este é um recurso de segurança empregado para evitar que usuários não autorizados modifiquem dados no repositório sem o devido acesso, tendo em vista que o catálogo OGD é publicamente disponibilizado. Para esta arquitetura está sendo considerada apenas uma chave de identificação para todo o sistema.

12 guia de referência com todas as APIs do CKAN encontra-se em http://docs.ckan.org/en/latest/api/. 
4.3.4.5 ADD - Passo 6: Esboçar visões e registrar as decisões

A visão e decisão consideradas neste passo remetem-se à estrutura do próprio CKAN, que é organizada hierarquicamente em datasets e recursos. A Figura 37 a seguir ilustra esta organização.

Figura 37 - Organização hierárquica do CKAN

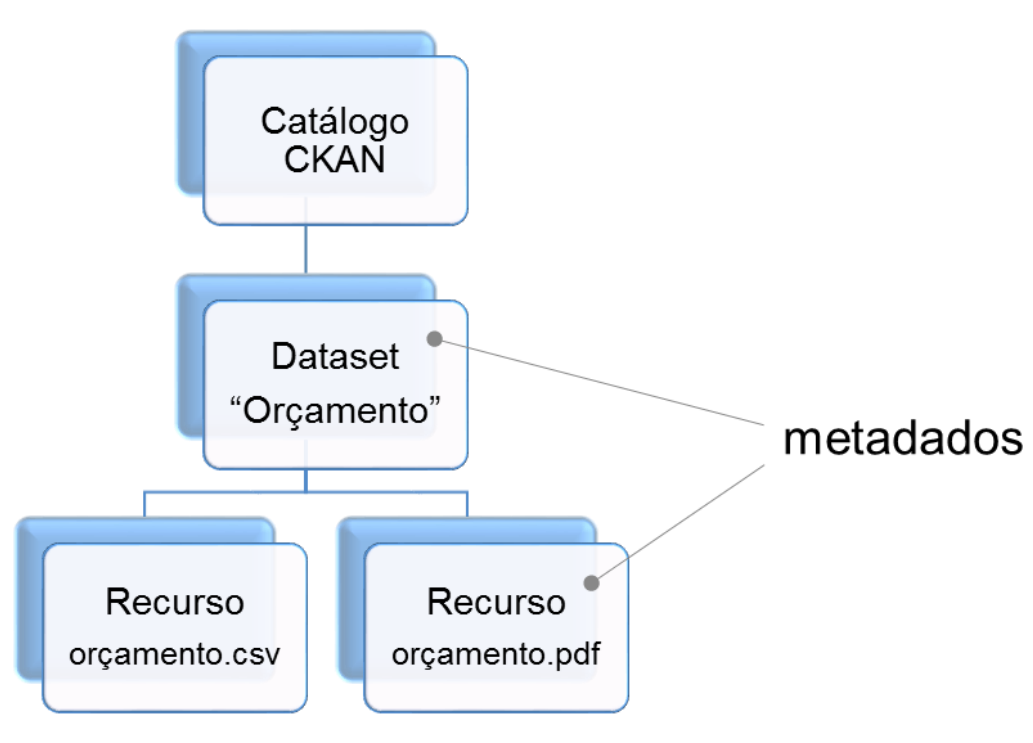

Fonte: Elaborado pelo autor.

O principal elemento na estrutura do CKAN é denominado dataset. Um dataset ou conjunto de dados contém metadados que descrevem os dados, como nome, autor, descrição, licença e outros. Quando um usuário busca por dados no catálogo CKAN, a busca é feita pelos metadados do dataset. Os dados em si são vinculados ao dataset por meio dos recursos. Um recurso pode ser qualquer tipo de arquivo como um CSV, PDF, XLS, etc. Pode também ser um link para um recurso externo. Um dataset pode conter muitos recursos, o que normalmente acontece para disponibilizar o mesmo dado em diferentes formatos (um PDF e o respectivo CSV, por exemplo).

\subsubsection{ADD - Passo 7: Analisar a meta da iteração}

A Tabela 25 sintetiza a checagem quanto ao atendimento dos balizadores para esta iteração. 
Tabela 25 - Análise da meta da iteração - apresentação

\begin{tabular}{l|c|c|l}
\hline Não coberto & $\begin{array}{c}\text { Coberto } \\
\text { parcialmente }\end{array}$ & $\begin{array}{c}\text { Completamente } \\
\text { coberto }\end{array}$ & \multicolumn{1}{|c}{ Análise (evidências / pendências) } \\
\hline & PF-1 & $\begin{array}{l}\text { A funcionalidade primária foi atendida } \\
\text { completamente pela previsão do catálogo com } \\
\text { mecanismos de acesso e busca }\end{array}$ \\
\hline & QA-9 & $\begin{array}{l}\text { Atributo de qualidade atendido completamente } \\
\text { com a disponibilização de interface web }\end{array}$ \\
\hline & QA-10 & $\begin{array}{l}\text { Atributo de qualidade atendido completamente } \\
\text { com as APls de acesso do catálogo }\end{array}$ \\
\hline & CRN-1 & $\begin{array}{l}\text { Interesse arquitetural atendido completamente } \\
\text { por decisão de conceito de projeto }\end{array}$ \\
\hline & CON-1 & $\begin{array}{l}\text { As restrições foram atendidas completamente } \\
\text { por decisão de conceito de projeto. Prevê-se o } \\
\text { desenvolvimento e distribuição livres }\end{array}$ \\
\hline & CON-2 & $\begin{array}{l}\text { A restrição foi atendida completamente pela } \\
\text { previsão explicita do catálogo CKAN como } \\
\text { meio primário de apresentação dos dados }\end{array}$ \\
\hline
\end{tabular}

Fonte: Elaborado pelo autor.

\subsubsection{Análise das metas das iterações}

Com a realização das três iterações para o projeto arquitetural, tem-se suficientemente atendidos todos os balizadores definidos. A Tabela 26 enfatiza esta análise e sintetiza a relação entre os balizadores e as três iterações conduzidas no decorrer do projeto. 
Tabela 26 - Análise das metas de todas as iterações

\begin{tabular}{|c|c|c|c|}
\hline Balizadores & Iteração 1 & Iteração 2 & Iteração 3 \\
\hline Propósito & $X$ & $X$ & $X$ \\
\hline FP-1 & & & $X$ \\
\hline FP-2 & $X$ & $X$ & \\
\hline FP-3 & & $X$ & \\
\hline QA-1 & $X$ & & \\
\hline QA-2 & $X$ & & \\
\hline QA-3 & & $X$ & \\
\hline QA-4 & & $X$ & \\
\hline QA-5 & $X$ & & \\
\hline QA-6 & $X$ & $X$ & \\
\hline QA-7 & $X$ & $\mathrm{X}$ & \\
\hline QA-8 & $X$ & $X$ & \\
\hline QA-9 & & & $X$ \\
\hline QA-10 & & & $X$ \\
\hline CRN-1 & $X$ & $X$ & $X$ \\
\hline CRN-2 & & $\mathrm{X}$ & \\
\hline CRN-3 & $\mathrm{X}$ & & \\
\hline CRN-4 & $X$ & & \\
\hline CRN-5 & & $\bar{X}$ & \\
\hline CRN-6 & & $X$ & \\
\hline CRN-7 & $X$ & & \\
\hline CON-1 & $X$ & $X$ & $X$ \\
\hline CON-2 & & & $X$ \\
\hline CON-3 & $\mathrm{X}$ & & \\
\hline CON-4 & & $X$ & \\
\hline CON-5 & $X$ & $X$ & $X$ \\
\hline
\end{tabular}

Fonte: Elaborado pelo autor.

Percebe-se que alguns balizadores foram trabalhados em apenas uma iteração, enquanto outros se estendem por outras iterações. A visão fornecida pela Tabela 26 é útil para avaliar se o número de iterações foi suficiente para definir a 
arquitetura, pois enquanto houver balizadores não trabalhados deve-se conduzir mais iterações.

\subsection{Documentação da arquitetura}

Uma vez definida a arquitetura, deve-se comunicá-la aos stakeholders para que seu objetivo possa ser atingido. Assim, esta seção busca documentar o resultado da arquitetura desenvolvida ao longo deste capítulo destacando os mais importantes elementos de sua estrutura.

Segundo Clements et al. (2010) a documentação pode ou não incluir algum nível de formalização e pode ou não incluir modelos para descrever a arquitetura. Tudo depende do uso pretendido para com a documentação. Os autores ressaltam que existem basicamente três usos para documentação de uma arquitetura, que podem ser (1) como meio de educação (no sentido de facilitar o entendimento), (2) como veículo de comunicação primário com os stakeholders e (3) como base para análise e construção de um sistema.

Neste sentido, o uso aqui considerado permeia a educação para transmitir o avanço do conhecimento obtido com a arquitetura e servir como veículo de comunicação com os stakeholders. Não é objetivo desta seção servir como base para análise e construção de um sistema, visto que para este uso a Seção 4.3 Projeto arquitetural é mais apropriada por expor o detalhamento da arquitetura com a formalização necessária e a prescrição dos elementos que a compõem.

As próximas subseções descrevem a arquitetura de modo objetivo e conciso para facilitar o entendimento de sua estrutura pelos stakeholders.

\subsubsection{Visão geral da arquitetura}

Como resposta à corrente proliferação de documentos nos formatos PDF e HTML, é apresentada nesta seção uma arquitetura de referência para estruturar informações de transparência. No contexto da arquitetura localiza-se um middleware colaborativo essencialmente responsável pelas principais ações previstas na tarefa principal de estruturar os dados com base na colaboração da comunidade envolvida. 
O conceito de middleware é levado em consideração por abarcar o desenho e desenvolvimento de componentes de forma intermediária dentro da arquitetura, dispostos entre o catálogo OGD (p. ex.: CKAN) e as fontes de dados desestruturadas (p. ex.: portais de transparência).

O termo colaborativo indica a possibilidade de qualquer interessado com acesso a uma fonte de informação desestruturada, a princípio disponibilizada nos formatos PDF e HTML, possa proceder com a transformação para um formato intercambiável e compatível com os princípios de OGD. Esta tarefa coloca-se como a mais trabalhosa e desafiadora na estruturação de dados abertos, tendo em vista a heterogeneidade das fontes de informação e sua complexidade de acesso e extração.

A arquitetura organiza-se em quatro camadas denominadas Apresentação, Estruturação, Colaborativa e Fonte de dados. A Figura 38 ilustra a visão geral da arquitetura expondo a organização de suas camadas, as principais funções e o fluxo de informação entre seus elementos. 
Figura 38 - Visão geral da arquitetura expondo a organização de suas camadas, as principais funções e o fluxo de informação

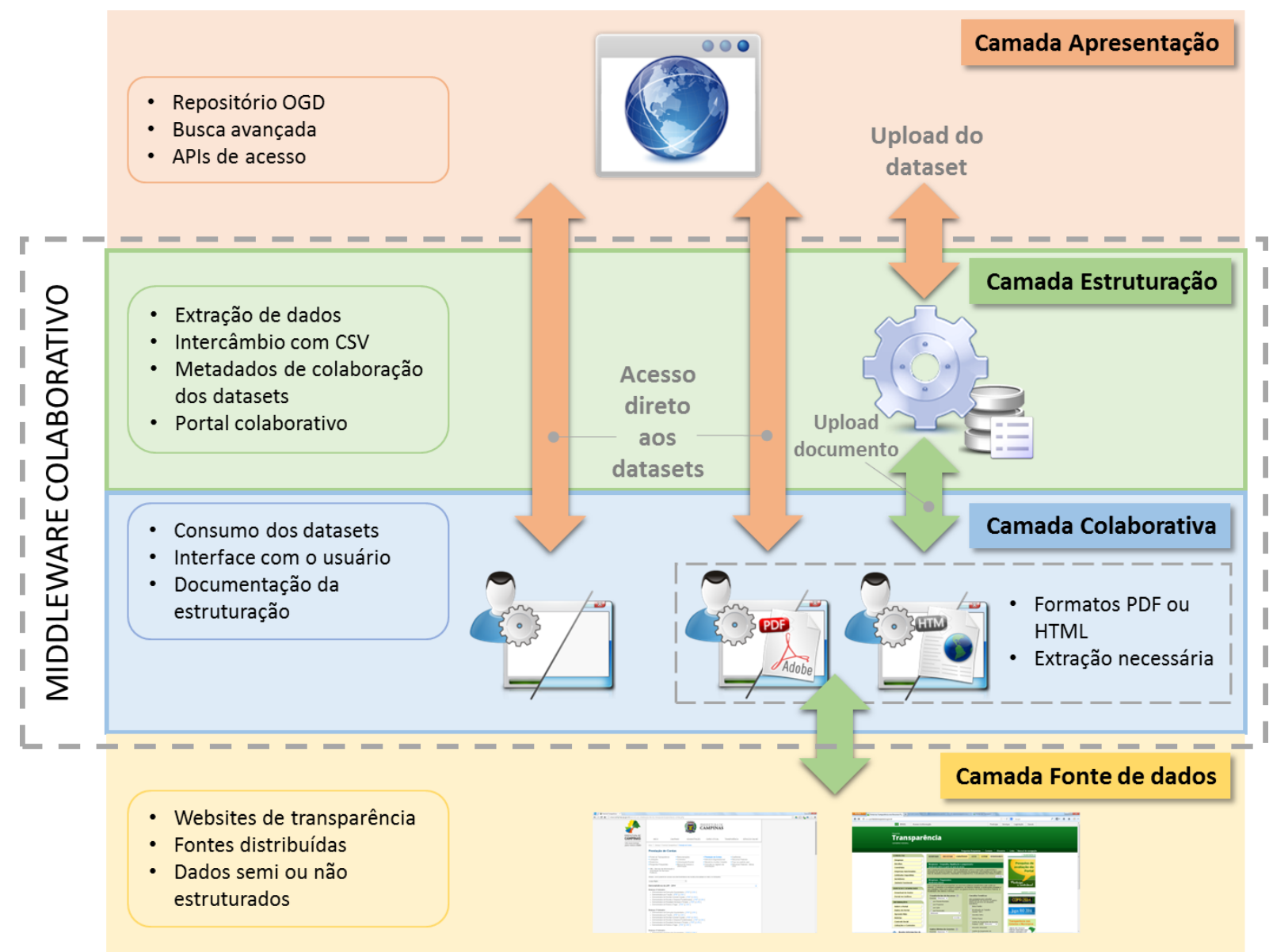

Fonte: Elaborado pelo autor.

As camadas da arquitetura são diferenciadas pelo papel que cada uma desempenha. O middleware colaborativo delimita-se nas camadas Estruturação e Colaborativa. De modo geral, a camada Estruturação é responsável por prover a extração dos dados e o repositório que registra o processo de extração para apoiar o processo colaborativo. Já a camada Colaborativa disponibiliza o interfaceamento com o usuário e as ferramentas de interação com as fontes desestruturadas.

As quatro camadas trabalham independentemente pelo provimento de serviços umas às outras por meio da disponibilização de APIs (RICHARDSON; RUBY, 2007). Neste sentido, é possível estender suas características com o desenvolvimento de outras funcionalidades com base nas originalmente oferecidas. 
A interação do usuário ocorre no contexto da arquitetura principalmente quando identifica uma fonte de dados desestruturada, que é passível de estruturação utilizando as ferramentas prescritas pelos elementos da arquitetura. Para ilustrar, a Figura 39 apresenta o diagrama de sequência no contexto geral de utilização de um possível sistema baseado na arquitetura para expor a interação entre seus elementos.

Figura 39 - Diagrama de sequência expondo a interação no contexto da arquitetura

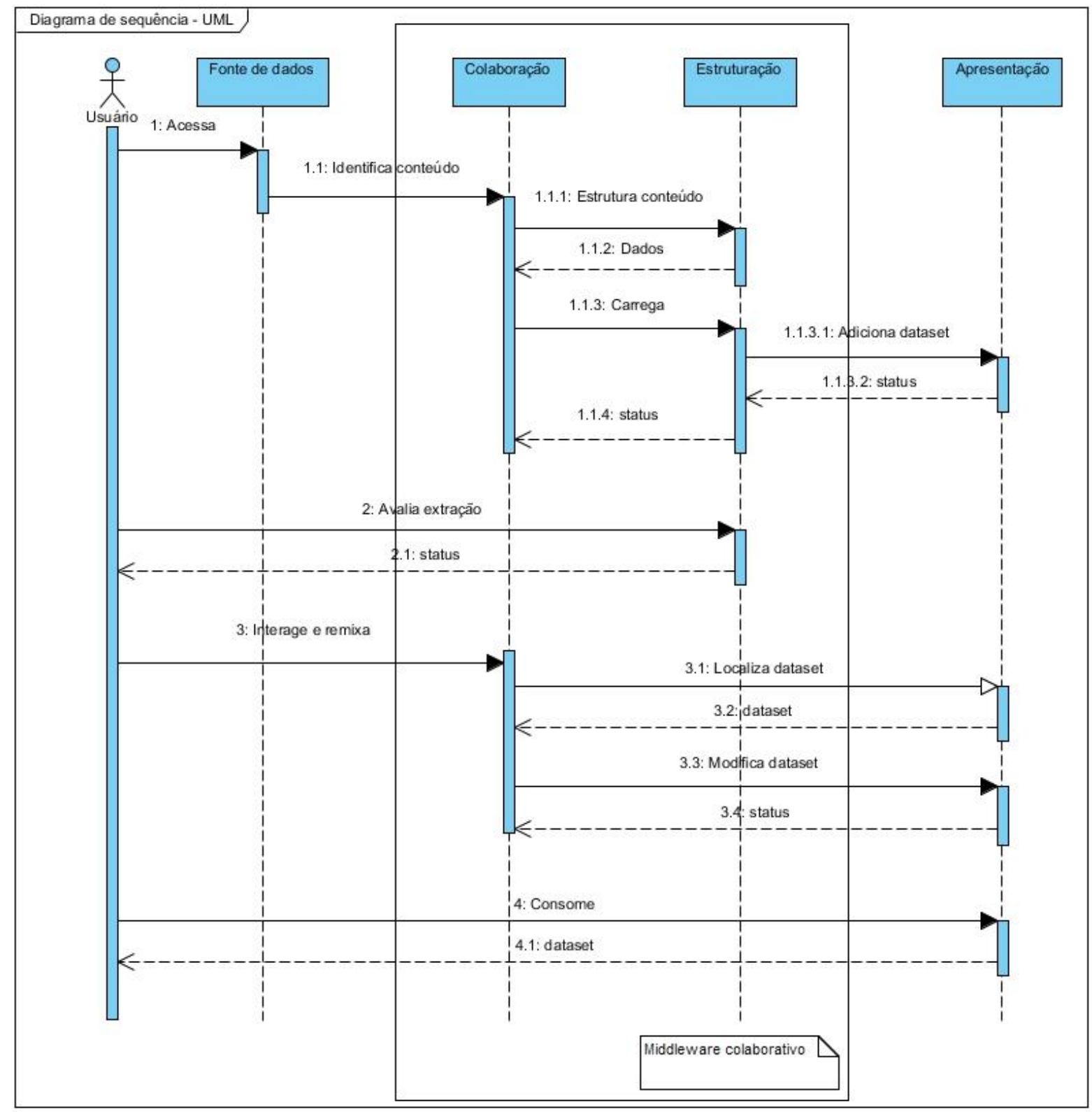

Fonte: Elaborado pelo autor.

Pela Figura 39 percebe-se, resumidamente, que são possíveis quatro formas de interação de usuário no contexto da arquitetura, de acordo com a situação. A 
Tabela 27 a seguir detalha as formas de interação com base nas situações encontradas pelo usuário.

Tabela 27 - Interações do usuário no contexto da arquitetura

\begin{tabular}{l|l}
\hline \multicolumn{1}{c|}{ Situação } & Estereótipo \\
\hline - Ainda não há estruturação realizada pela comunidade & $1:$ Acessa \\
- Há a necessidade de acesso à fonte de dados desestruturada & \\
\hline - Já existe estruturação anterior realizada por outro membro da comunidade & $2:$ Avalia extração \\
- Usuário avalia a estruturação com base em sua percepção de qualidade & \\
\hline - Já existe estruturação anterior realizada por outro membro da comunidade & 3: Interage e remixa \\
- Usuário interage com datasets previamente carregados para remixar seu & \\
conteúdo com sua nova contribuição & \\
\hline - Já existe estruturação anterior realizada por outro membro da comunidade & $4:$ Consome \\
- Usuário apenas busca e consome os datasets diretamente do catálogo & \\
OGD, sem permissão de qualquer modificação & \\
\hline
\end{tabular}

Fonte: Elaborado pelo autor.

A principal situação encontrada está voltada para a possibilidade do usuário acessar uma fonte de dados desestruturada, como um portal de transparência. Ao identificar conteúdo passível de estruturação no contexto da camada Colaborativa com as respectivas ferramentas diretamente pelo navegador de internet, o usuário invoca os serviços responsáveis pela pré-visualização da extração dos dados da camada Estruturação. A partir de então, estes são carregados no catálogo OGD e têm seu processo de estruturação registrado.

Uma vez realizada a estruturação, o usuário efetiva sua contribuição. A partir de então os demais usuários têm condições de fazer a avaliação da contribuição com intuito de construir o mecanismo de reputação da rede de contribuidores. Esta avaliação é realizada diretamente pelo usuário invocando o respectivo serviço proveniente da camada Estruturação.

Outra possibilidade dada ao usuário é o acesso de modificação dos dados já carregados em datasets. Neste sentido, aqueles datasets criados pelo usuário são passíveis de alteração, que compreende os metadados ou mesmo os dados em si. 
A última interação possível é no sentido de consumo de datasets diretamente pelo catálogo OGD. Esta interação figura como comum e ideal, tendo em vista que é o esperado a disponibilização de dados abertos.

Nas subseções seguintes são descritas com mais detalhes as camadas que compõem a visão geral da arquitetura, expondo seus principais componentes, relações, requisitos e serviços providos.

\subsubsection{Camada Apresentação}

O catálogo OGD, implementado com o CKAN, está localizado nesta camada e é onde os datasets serão visualizados pelos usuários. O catálogo OGD é disponibilizado por meio de interface web.

Com o uso do CKAN é possível realizar consultas avançadas usando sua interface web ou acessar as APIs providas pelo software. As APls permitem não apenas o consumo dos datasets e seus metadados, mas também todas as rotinas de carregamento automatizado de novos datasets diretamente com o uso de suas APIs.

Esta camada disponibiliza serviços essencialmente à camada Estruturação onde há o consumo dos serviços ligados ao gerenciamento dos datasets. É também possível que a camada Apresentação seja acessada diretamente pela camada Colaborativa no caso de haver consumo dos datasets pela interface do usuário para promover a composição de fontes de dados já dispostas no CKAN.

\subsubsection{Camada Estruturação}

Nesta camada estão localizadas as APls de estruturação e o Portal Colaborativo. Esta camada invoca os serviços da camada Apresentação e disponibiliza o consumo de serviços essencialmente pela camada Colaborativa.

As APIs de estruturação são compostas pelos serviços de extração de dados e geração de CSV a partir de documentos desestruturados, como documentos PDF e páginas HTML. Outros formatos podem ser considerados com a extensão de funcionalidades desta camada. Uma vez extraídos, os dados são dispostos no formato CSV para permitir o intercâmbio universal e fácil manuseio dos dados no fluxo de funcionamento do sistema com base na arquitetura. 
O Portal Colaborativo, por sua vez, é responsável para apoiar o processo de colaboração provendo interfaces de interação e que detalha a estruturação efetuada pelos contribuidores.

O processo de colaboração requer mecanismos de moderação e avaliação, tendo em vista a possibilidade de uso impróprio das ferramentas prescritas pela arquitetura. Neste caso, a comunidade de usuários possui meios para reportar abusos, classificar as extrações mais úteis e checar o nível de contribuição dos usuários da comunidade.

Para isso, propõe-se um mecanismo de avaliação que visa apoiar a mensuração da qualidade de estruturação para a comunidade, onde o usuário acessa o Portal Colaborativo por meio de uma página web sendo disponibilizada pela camada Estruturação. Esta página contém as estruturações efetuadas, o link do dataset para o CKAN (camada Apresentação) e o mecanismo de avaliação baseado na escala de uma a cinco estrelas, significando uma estrela a pior situação e cinco estrelas a melhor situação. Estas informações, em conjunto com o detalhamento da estruturação (descrição, localização e formato da fonte originária, usuário contribuidor, etc.) são tratadas e armazenadas em banco de dados próprio também localizado nesta camada.

Além da interação por página web para fazer a avaliação da estruturação, a camada Estruturação disponibiliza serviços por meio de APIs para a mesma finalidade, a fim de possibilitar a independência das camadas e meios de personalização das funcionalidades no contexto da arquitetura.

Convém enfatizar que a avaliação considerada no âmbito desta camada, e externada pelo Portal Colaborativo, refere-se tão somente ao processo de estruturação. Esta observação se faz necessária por conta da existência de mecanismo semelhante de avaliação diretamente pelo CKAN. Dessa forma, não é intenção deste trabalho substituir esta funcionalidade provida nativamente pelo software, e sim criar uma base de sustentação para estender outras funcionalidades para uso futuro. A extensão poderá compreender, por exemplo, mecanismos de recompensa para incentivar usuários a colaborar cada vez mais e serem reconhecidos pela comunidade. 


\subsubsection{Camada Colaborativa}

Na camada Colaborativa é onde estão localizadas as ferramentas responsáveis pela interação do usuário no processo de estruturação de dados. É pressuposto desta camada a existência do navegador web do usuário como meio primário de acesso e apresentação dos dados desestruturados por meio de páginas web.

A ideia é possibilitar ao usuário a visita a uma fonte de dados desestruturada e assim decidir por realizar a extração do conteúdo tabular e transformá-lo em datasets legíveis por máquina com a indicação de sua estrutura e metadados associados. Para isto, a camada Colaborativa é construída sobre o navegador web do usuário na forma de extensão para carregar o conjunto de ferramentas de estruturação que estão ligados às camadas superiores e que acessam os serviços por elas disponibilizados.

O desenvolvimento sobre o navegador web é atualmente suportado por praticamente todos os navegadores de mercado. Inclusive disponibilizam mecanismos para instalar, desinstalar e gerenciar facilmente o uso de extensões de modo a permitir controle total pelo usuário da aplicação. Neste modelo, os componentes de software utilizados estão todos contidos nos SDKs dos navegadores e cada fabricante institui seu próprio modelo de desenvolvimento.

\subsubsection{Camada Fonte de dados}

Esta camada da arquitetura representa os repositórios de informações ou dados desestruturados que são usualmente encontrados em websites dedicados à transparência.

A característica principal dos dados contidos nesta camada é o formato utilizado para sua divulgação. Considera-se, no contexto e limitação deste trabalho, os formatos PDF e HTML, normalmente encontrados na grande maioria dos repositórios governamentais, conforme justificado por meio de levantamento já discutido anteriormente.

Tem-se, como premissa, que as fontes de dados representadas por esta camada continuarão disponibilizando dados desestruturados, tendo em vista que a disponibilização de dados originalmente compatíveis com dados abertos demandará 
esforços e tempo incompatíveis com a necessidade de OGD para benefícios à sociedade.

\subsection{Considerações finais}

Este capitulo apresentou o processo de definição da arquitetura como referência ao desenvolvimento de um sistema colaborativo para estruturar dados abertos governamentais.

O processo de definição foi embasado pelo método ADD com consideração dos balizadores arquiteturais. A este respeito, discorreu-se sobre o modelo de negócio baseado na colaboração como estratégia principal de sucesso da arquitetura complementada na elucidação dos requisitos retratados pela realidade do atual panorama de acesso e disponibilização dos dados nos municípios brasileiros.

No projeto arquitetural, desenvolvido neste capítulo, foi possível verificar os detalhes de construção da arquitetura com apoio da linguagem UML entre outros recursos como descrições textuais, tabelas e diagramas associativos e modelo lógico de dados. Os artefatos gerados neste capítulo servem como base para análise e construção de um sistema, pois a característica prescritiva da estrutura e dos elementos da arquitetura viabilizam a implementação de sua instância.

O capítulo é encerrado com a documentação da arquitetura, que é caracterizada pela representação concisa e objetiva da arquitetura com o objetivo de orientar os stakeholders no entendimento de sua estrutura e elementos primordiais. 


\section{VALIDAÇÃO DA ARQUITETURA}

A arquitetura de referência definida nesta pesquisa teve como origem os requisitos elaborados por meio da caracterização dos dados abertos obtida por levantamento amostral nos municípios brasileiros. Este processo, por si só, já endereça os problemas reais encontrados e que poderão ser tratados pela arquitetura e com sua respectiva instanciação pelo desenvolvimento de um sistema.

Para certificar que a arquitetura definida de fato serve aos propósitos para os quais foi desenvolvida, podem ser aplicadas técnicas de validação que possibilitam checar 0 atendimento das expectativas. Isso garante que todo o processo de compreensão dos requisitos de negócio e a tradução destes em requisitos arquiteturais foram conduzidos com sucesso e de fato atendem às expectativas dos stakeholders.

Bass, Clements e Kazman (2012) observam que um processo de validação pode ser realizado de três formas: (1) validação pelo arquiteto, (2) validação por pares e (3) validação por consultores externos. Os autores também consideram, dentro do contexto de desenvolvimento da arquitetura, a avaliação por métodos de engenharia. O método utilizado há mais de uma década na avaliação de arquiteturas de software para diversos domínios é denominado ATAM, o qual também é desenvolvido e acreditado pelo SEI (BASS; CLEMENTS; KAZMAN, 2012; GALLAGHER, 2000).

Neste capítulo é discutido o procedimento de validação da arquitetura definida. Fundamentalmente, está sendo considerada a validação com base no método ATAM, o que permite a consistência da arquitetura a partir da visão de uma amostra dos potenciais stakeholders, em especial os usuários, que são externos ao desenvolvimento da arquitetura. Discute-se também neste capítulo um protótipo de implementação que é parte do processo de instanciação com base na arquitetura.

A seção inicial introduz brevemente o método ATAM e a agenda necessária para sua consecução. Em seguida, é detalhado o procedimento conduzido por este trabalho com a qualificação do time de validação. Em seção posterior, são descritos os resultados obtidos da validação da arquitetura definida por este trabalho. Por fim, é relatado o desenvolvimento do protótipo da arquitetura. 


\subsection{Método de validação}

Primeiramente, faz-se necessário justificar a terminologia aqui empregada com relação ao uso do termo validação. A bibliografia que trata do desenvolvimento de arquiteturas de software utiliza o termo avaliação, considerando a tradução literal do termo evaluation. No entanto, entende-se que deve haver consonância com os termos consolidados pela engenharia de software, especificamente pela disciplina de teste de software. Nesse sentido, conforme observa Sommerville (2011, p. 207), o termo validação indica o procedimento que garante que o software (neste caso arquitetura) satisfaz às expectativas do cliente, e não apenas garante que os requisitos estão sendo atendidos. Esta sútil diferença faz da validação um procedimento mais exigente, tendo em vista que os requisitos poderiam estar distorcidos ou equivocados. Já as expectativas do cliente são os resultados que justificam os esforços para o desenvolvimento de uma arquitetura.

O método ATAM é direcionado para validação por partes que não precisam necessariamente conhecer a arquitetura e seus requisitos de negócio, pois estes serão detalhados oportunamente pelo arquiteto durante o processo de validação. Tem como principais vantagens a possibilidade de validação de arquiteturas que ainda não tenham sido instanciadas e a validação de arquiteturas com grande número de stakeholders envolvidos (BASS; CLEMENTS; KAZMAN, 2012).

O ATAM prevê a participação e colaboração mútua de três grupos de pessoas envolvendo (1) o time de validação, (2) os decisores de projeto e (3) os stakeholders. O método utiliza cenários priorizados com os atributos de qualidade como base para a validação da arquitetura. Assim, os cenários são expostos ao time de validadores que são solicitados a opinar sobre o quanto a arquitetura em questão atende às expectativas, que compreende a documentação das decisões arquiteturais efetuada pelo time de validadores.

A partir da validação com ATAM, produz-se como saída um conjunto de questões ou pontos de preocupação sobre a arquitetura. Estes são utilizados para compor o relatório que ilustra o procedimento conduzido e sumariza a captura dos cenários e a análise obtida a partir deles pelo time de validadores. 
Bass, Clements e Kazman (2012) observam que o método ATAM é bastante compreensivo e pode exigir o envolvimento de 20 a 30 pessoas em projetos grandes cujo o tempo e esforço dispendidos na validação fazem sentido apenas em projetos onde os riscos de erros são inadmissíveis para o sistema. Por isso, os autores desenvolveram uma versão compacta do ATAM denominada Lightweight Architecture Evaluation que é conduzida por um número reduzido de pessoas e em menor tempo. Esta versão é indicada para projetos de arquiteturas menores e com menos riscos ao sistema.

O roteiro do Lightweight Architecture Evaluation é o mesmo preconizado pela versão clássica do ATAM. Os passos de execução têm seus tempos reduzidos e alguns passos são omitidos ou fundidos a outros, assim o processo de validação é conduzido em apenas um dia ou parte de um dia. Os procedimentos de preparação, artefatos gerados e saídas esperadas são os mesmos definidos no ATAM. Apesar de ser uma versão enxuta, considera-se que o método é o ATAM.

A Tabela 28 sumariza o roteiro do processo de validação pelo método ATAM a partir da proposta de Bass, Clements e Kazman (2012) para o Lightweight Architecture Evaluation.

Tabela 28 - Roteiro do processo de validação pelo método ATAM do Lightweight Architecture Evaluation.

\begin{tabular}{|c|c|c|}
\hline Passo & Tempo & Descrição \\
\hline $\begin{array}{l}\# 0 \\
\text { Início dos } \\
\text { trabalhos } \\
\text { apresentação do } \\
\text { ATAM }\end{array}$ & $00: 15$ & $\begin{array}{l}\text { São apresentados aos participantes os objetivos do trabalho e a } \\
\text { importância de participarem do processo de validação. São } \\
\text { coletados os principais dados para a qualificação do time de } \\
\text { validadores deixando claro quais dados serão tornados públicos. A } \\
\text { autorização de gravação e uso de recursos audiovisuais também é } \\
\text { coletada no início deste passo. } \\
\text { Neste mesmo passo é apresentado o método ATAM com breve } \\
\text { digressão de seu histórico e quais são as expectativas para com a } \\
\text { utilização do método e os resultados esperados. }\end{array}$ \\
\hline $\begin{array}{l}\# 1 \\
\text { Apresentação do } \\
\text { modelo de } \\
\text { negócio }\end{array}$ & $00: 15$ & $\begin{array}{l}\text { São apresentados aos participantes o modelo de negócio e suas } \\
\text { prioridades. }\end{array}$ \\
\hline \#2 & 01:00 & A arquitetura é apresentada em um nível suficiente de detalhes. Os \\
\hline
\end{tabular}




\begin{tabular}{|c|c|c|}
\hline $\begin{array}{l}\text { Apresentação da } \\
\text { arquitetura e das } \\
\text { abordagens } \\
\text { arquiteturais }\end{array}$ & & $\begin{array}{l}\text { principais componentes e fluxo de informações são discutidos. O } \\
\text { apresentador deve garantir que os participantes entendam a } \\
\text { arquitetura e seu propósito de existir utilizando cenários para ilustrar } \\
\text { seu funcionamento. As abordagens arquiteturais para alguns } \\
\text { atributos de qualidade são ilustradas em conjunto com a visão da } \\
\text { arquitetura. }\end{array}$ \\
\hline $\begin{array}{ll}\# 3 & \\
\text { Exposição } & \text { da } \\
\text { árvore } & \text { de } \\
\text { utilidades } & \end{array}$ & $00: 15$ & $\begin{array}{l}\text { É apresentada a árvore de utilidades com os atributos de qualidade } \\
\text { definidos para a arquitetura juntamente com os cenários. }\end{array}$ \\
\hline $\begin{array}{l}\# 4 \\
\text { Análise } \\
\text { arquitetural }\end{array}$ & 02:00 & $\begin{array}{l}\text { O apresentador utiliza os cenários definidos na árvore de utilidades } \\
\text { cujas prioridades são mais altas e explica aos participantes como a } \\
\text { arquitetura suporta cada um deles. } \\
\text { Neste momento o time de validação documenta suas análises com } \\
\text { as decisões arquiteturais relevantes e identifica e cataloga os riscos, } \\
\text { os não riscos, os pontos sensíveis e as compensações, os quais } \\
\text { fazem parte da Ficha de Análise Arquitetural a ser preenchida. } \\
\text { Para eficiência e eficácia deste passo, o apresentador inicia os } \\
\text { trabalhos fornecendo exemplo de como deve ser realizado o trabalho } \\
\text { de análise e anotação nas fichas de análise arquitetural, que é o } \\
\text { principal instrumento de documentação do time de validação. }\end{array}$ \\
\hline $\begin{array}{l}\# 5 \\
\text { Apresentação } \\
\text { dos resultados }\end{array}$ & $00: 15$ & $\begin{array}{l}\text { O time de validação revisa e discute as fichas de análise arquitetural } \\
\text { e eventualmente complementa as informações que julgarem } \\
\text { necessárias. }\end{array}$ \\
\hline
\end{tabular}

Fonte: Elaborado pelo autor.

O roteiro constante na Tabela 28 é esperado que seja realizado em um período de quatro horas com a participação do time de validação, que será apresentado na seção seguinte. Bass, Clements e Kazman (2012) afirmam que a qualidade dos resultados obtidos dependem de como o time de validação entende os objetivos do método, suas técnicas e o sistema sendo demonstrado por meio da arquitetura de referência.

A Figura 40 ilustra o fluxo conceitual do ATAM clássico definido por Clements; Kazman e Klein (2001) adaptado com o mapeamento dos passos de acordo com o roteiro do Lightweight Architecture Evaluation (BASS; CLEMENTS; KAZMAN, 2012) definido na Tabela 28. 
Figura 40 - Fluxo conceitual do ATAM mapeado com os passos do roteiro do Lightweight Architecture Evaluation

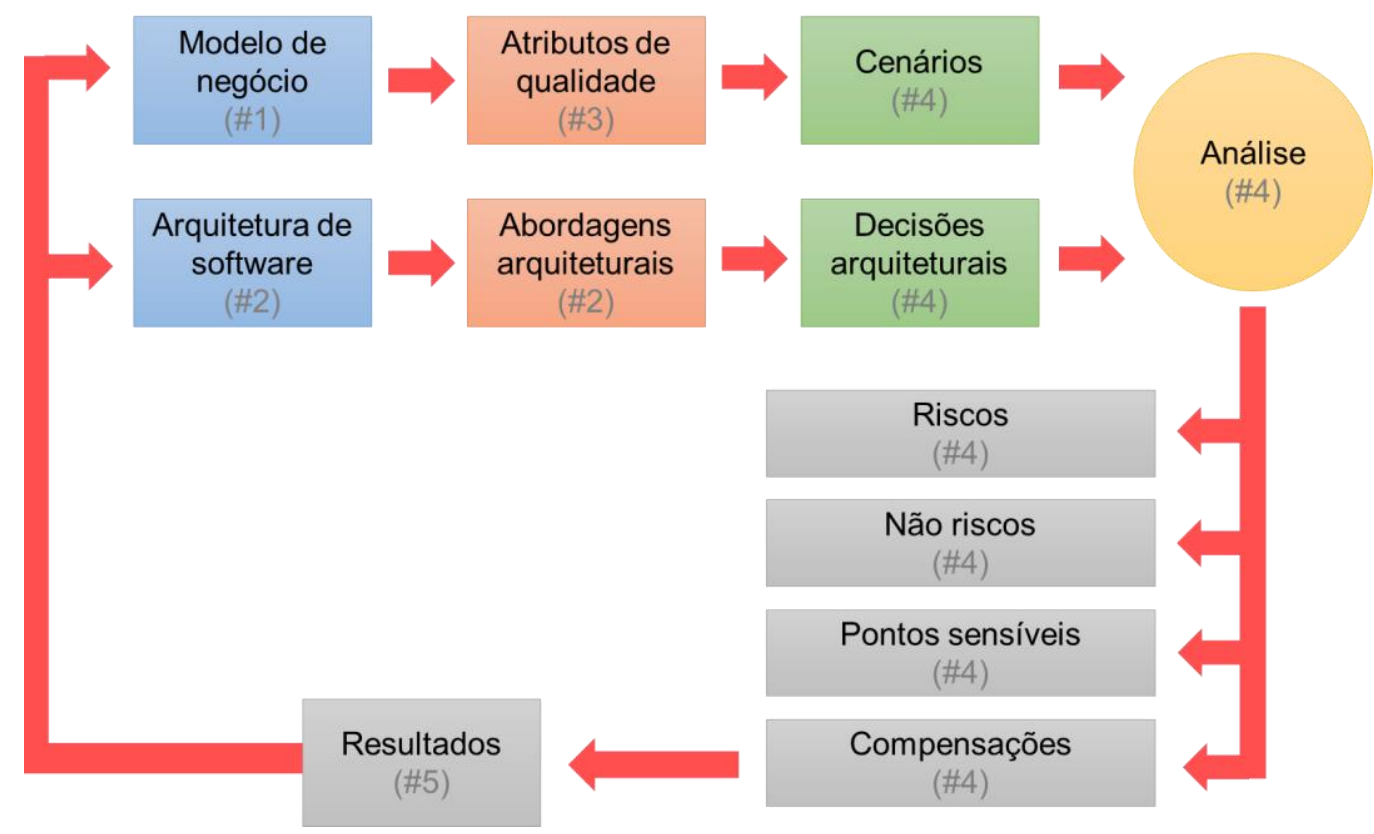

Fonte: Adaptado de Clements, Kazman e Klein (2001).

$\mathrm{Na}$ próxima seção será detalhado o procedimento seguido para executar o método ATAM para validação da arquitetura definida nesta pesquisa.

\subsection{Procedimento de validação}

Para condução do método ATAM foi providenciado primeiramente os preparativos que antecederam a execução do método, que consistiu em definir a data de validação, traçar perfil do time de validadores e possíveis candidatos, o local com os recursos audiovisuais necessários e a preparação da apresentação e materiais de uso dos validadores.

A validação foi conduzida no dia 22/11/2016 com a participação de três pessoas compondo o time de validadores. A seleção dos validadores foi realizada por meio de contato direto aos candidatos que o autor deste trabalho possuía no seu círculo profissional, porém sem afinidade pessoal para manter a devida imparcialidade do processo. Na seleção do time foi considerado o perfil de atuação de cada um previamente ao convite aos candidatos. Os perfis definidos são 
especificados na Tabela 29 com breve comentário sobre a justificativa de escolha de cada perfil.

Tabela 29 - Definição dos perfis para composição do time de validação

\begin{tabular}{l}
\hline Perfil \\
\hline Gestor público com atuação na área \\
de transparência
\end{tabular}

\section{Comentário}

Este perfil possibilita a análise e consistência a partir da experiência de quem atua com transparência pública ou controle interno da administração pública. Sua visão está mais voltada para os aspectos legais e normativos que regem a disponibilização de dados pelos governos. Tem conhecimento também das limitações dos sistemas e processos existentes na administração pública.

\#2

Desenvolvedor de software atuante na área de governo eletrônico

Este perfil possibilita a análise e consistência a partir da experiência de quem atua no desenvolvimento de software voltado a governo eletrônico. Sua visão está mais voltada aos aspectos técnicos e às tecnologias envolvidas na arquitetura. Sua contribuição enriquece a seleção de produtos e tecnologias que sustentam a continuidade tecnológica da arquitetura, assim como evidencia as restrições quanto às suas limitações.

\#3 defesa dos direitos da sociedade Este perfil possibilita a análise e consistência a partir da experiência de quem cobra da administração pública os direitos definidos em lei, sobretudo aqueles relacionados ao acesso à informação. Sua visão contribui com o aprimoramento dos mecanismos que viabilizam a estruturação e o acesso às fontes de dados.

Fonte: Elaborado pelo autor.

A preparação do material usado no dia da validação consistiu na elaboração das Fichas de Análise Arquitetural previamente preenchidas com os atributos de qualidade priorizados para a validação. Também foi desenvolvida a apresentação que guiou todo o processo de validação.

A Figura 41 ilustra o modelo da Ficha de Análise Arquitetural utilizado. O modelo da ficha foi adaptado a partir a proposta de Bass, Clements e Kazman (2012). Cada atributo de qualidade, com seu respectivo cenário, gerou uma ficha de análise arquitetural. 
Figura 41 - Modelo da Ficha de Análise Arquitetural
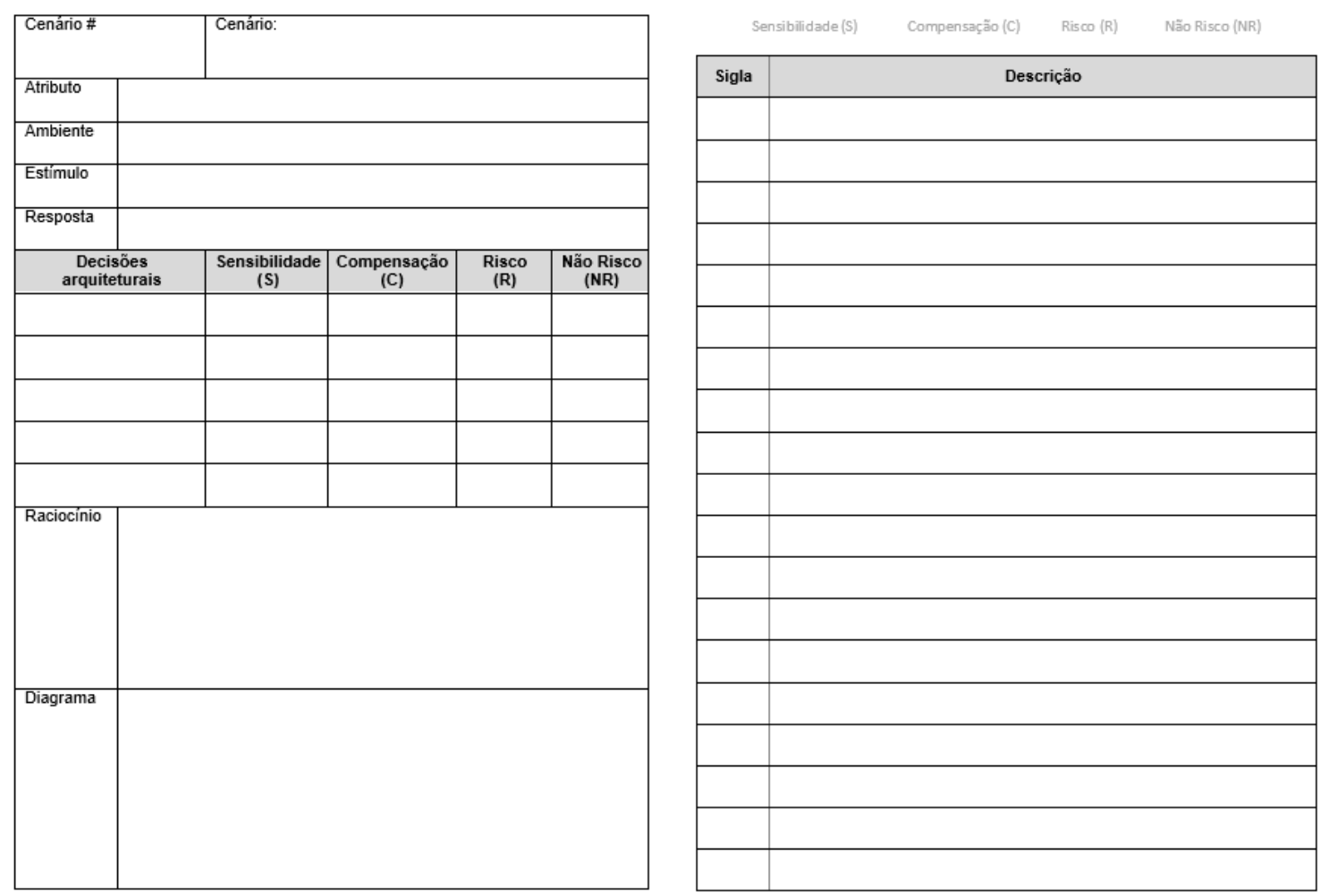

Fonte: Elaborado pelo autor.

A Tabela 30 evidencia os atributos de qualidade priorizados para a validação. Esses atributos têm origem na Tabela 12 do Capítulo 4, com a diferença que aqui estão sendo exibidos apenas os atributos com prioridade alta na dimensão de importância para o negócio, os quais foram selecionados para exposição ao time de validadores. 
Tabela 30 - Atributos de qualidade da arquitetura priorizados para as fichas de análise arquitetural

\begin{tabular}{|c|c|c|}
\hline Prioridade & Atributo & Cenário \\
\hline $\mathrm{H}, \mathrm{H}$ & $\begin{array}{l}\text { QA-2: Operação } \\
\text { colaborativa }\end{array}$ & $\begin{array}{l}\text { \#A1: O sistema permite a estruturação de dados de um número } \\
\text { não determinado de fontes por meio da colaboração distribuída } \\
\text { pela comunidade de interessados }\end{array}$ \\
\hline $\mathrm{H}, \mathrm{M}$ & $\begin{array}{l}\text { QA-3: } \\
\text { Moderação } \\
\text { hierarquizada }\end{array}$ & $\begin{array}{l}\text { \#A2: O sistema fornece meios para o combate ao abuso e } \\
\text { vandalismo, moderado pela hierarquia de usuários reconhecida } \\
\text { pelos mecanismos próprios de reputação da comunidade }\end{array}$ \\
\hline $\mathrm{H}, \mathrm{M}$ & $\begin{array}{l}\text { QA-4: Avaliação } \\
\text { mútua }\end{array}$ & $\begin{array}{l}\text { \#A3: O sistema possibilita a avaliação mútua das contribuições } \\
\text { feitas pela comunidade utilizando critérios simples e objetivos para } \\
\text { construir a reputação dos usuários }\end{array}$ \\
\hline $\mathrm{H}, \mathrm{H}$ & $\begin{array}{l}\text { QA-5: Operação } \\
\text { baseada no } \\
\text { navegador }\end{array}$ & $\begin{array}{l}\text { \#A4: O navegador web, interface básica de operação pelo usuário, } \\
\text { leva à fonte de dados desestruturada e ativa as ferramentas de } \\
\text { estruturação por meio de extensão desenvolvida especificamente } \\
\text { para o navegador em uso }\end{array}$ \\
\hline $\mathrm{H}, \mathrm{L}$ & $\begin{array}{l}\text { QA-6: } \\
\text { Autenticação do } \\
\text { usuário }\end{array}$ & $\begin{array}{l}\text { \#A5: O usuário é autenticado e identificado unicamente dentro do } \\
\text { sistema por meio de usuário e senha }\end{array}$ \\
\hline $\mathrm{H}, \mathrm{L}$ & $\begin{array}{l}\text { QA-7: Acesso } \\
\text { autoconcedido }\end{array}$ & $\begin{array}{l}\text { \#A6: O usuário poderá se auto registrar no sistema sem a } \\
\text { intervenção de outro usuário }\end{array}$ \\
\hline $\mathrm{H}, \mathrm{M}$ & $\begin{array}{l}\text { QA-9: Acesso } \\
\text { manual }\end{array}$ & $\begin{array}{l}\text { \#A7: O sistema fornece interfaces manuais para pesquisa e } \\
\text { obtenção dos dados }\end{array}$ \\
\hline $\mathrm{H}, \mathrm{H}$ & $\begin{array}{l}\text { QA-10: Acesso } \\
\text { automatizado }\end{array}$ & $\begin{array}{l}\text { \#A8: O sistema disponibiliza APIs para interfaceamento dentro de } \\
\text { seu contexto (comunicação entre componentes) e acesso por } \\
\text { outras ferramentas a serem desenvolvidas e integradas com o } \\
\text { sistema (catálogo) }\end{array}$ \\
\hline
\end{tabular}

Fonte: Elaborado pelo autor.

O processo de validação seguiu estritamente o roteiro detalhado na Tabela 28. A Figura 42 a seguir mostra o registro dos trabalhos com uma fotografia do time de validadores (com autorização dos participantes) produzindo as fichas de análise arquitetural e o apresentador conduzindo a apresentação conforme roteiro sugerido pelo ATAM. 
Figura 42 - Fotografia tirada durante o processo de validação

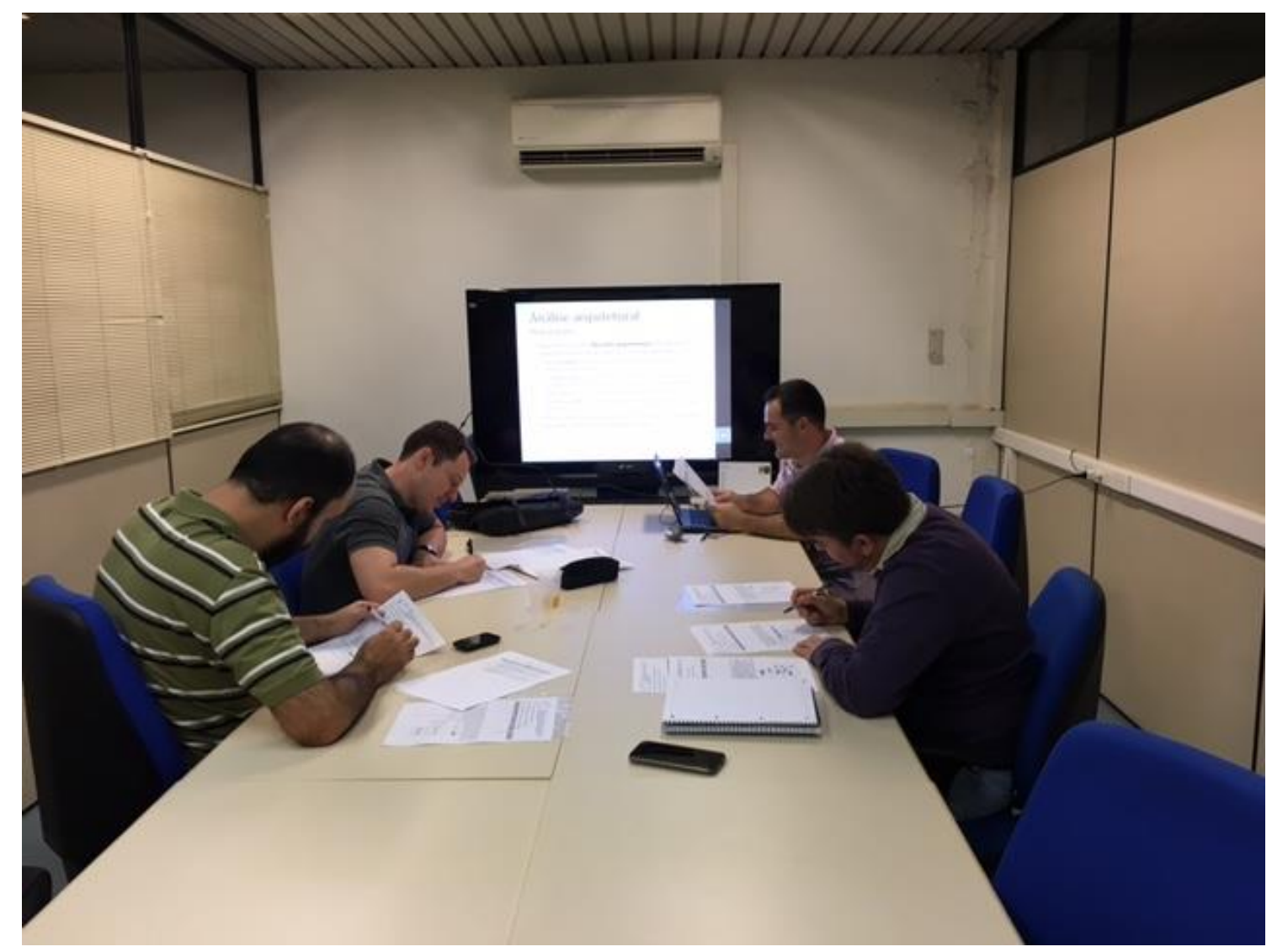

Fonte: Elaborado pelo autor.

Todo o processo de validação teve seu áudio e imagens gravados com a devida autorização dos participantes. Isto permite o registro das evidências e posterior análise para melhor compreensão dos resultados obtidos.

\subsection{Resultados da validação}

Conforme discutido anteriormente, o principal resultado obtido pela condução do método ATAM é o conjunto de decisões arquiteturais geradas pelo preenchimento das fichas de análise arquitetural. Nelas os validadores expuseram sua contribuição a partir do entendimento da arquitetura, por meio da exposição de pontos de sensibilidade, compensação, risco e não risco. 
As fichas de análise arquitetural preenchidas pelo time de validadores são reproduzidas na íntegra no Apêndice $C$ deste documento.

As Tabelas 31 a 38 transcrevem as decisões arquiteturais manuscritas pelo time de validadores, já com a categorização dos resultados após análise dos pontos emitidos pelos participantes. Ressalta-se que os textos fornecidos pelos avaliadores foram transcritos na íntegra para manter sua contribuição original. Por isso, observase que a redação dos textos das Tabelas 31 a 38 possa estar incompatível com o estilo de escrita pretendido por este documento.

Ademais, faz-se necessário fornecer as legendas utilizadas para compor as Tabelas 31 a 38. Na coluna Usuário identifica-se com numeração de 1 (um) a 3 (três) o usuário que efetuou a contribuição, que corresponde à numeração definida na Tabela 29 com os perfis dos participantes. Na coluna Ponto identificam-se as categorias dos pontos utilizados com uma letra e um número sequencial, tendo a letra os seguintes significados:

- $S$ = Sensibilidade;

- $\mathrm{C}=$ Compensação;

- $\mathrm{R}=\mathrm{Risco}$;

- $\mathrm{NR}=$ Não risco.

A coluna Categoria exprime o resultado da análise pelo projetista por meio de uma categoria que indica o nível de contribuição para arquitetura, sendo 0 (zero) 0 menor nível e 3 (três) o maior nível, conforme análise a seguir:

- $0=$ Não aplicável ou fora de contexto. Significa que a decisão arquitetural indicada pelo validador não é aplicável para a arquitetura ou está fora de contexto, o que não indica contribuição significativa para a especificação da arquitetura.

- 1 = Compreendido pela arquitetura. Significa que a decisão arquitetural indicada pelo validador está compreendida pela especificação atual da arquitetura e que sua contribuição pode, no máximo, melhorar a descrição e formalização para deixar claro o objetivo da decisão. 
- 2 = Detalhamento de um atributo existente. Significa que a decisão arquitetural indicada pelo validador viabiliza melhor detalhamento da especificação da arquitetura a partir das decisões já compreendidas na sua definição, mesmo que indiretas. Este tipo de contribuição melhora o entendimento de sua especificação para pontos que podem ter sido omitidos ou mesmo ausentes no projeto.

- 3 = Melhoria significativa em potencial. Significa que a decisão arquitetural indicada pelo validador não foi prevista na especificação da arquitetura. Este tipo de contribuição é uma melhoria em potencial que enriquece o projeto a partir da vivência ímpar do validador.

Tabela 31 - Decisões arquiteturais levantadas e a categorização após a análise para o cenário \#A1 referente ao atributo QA-2 - Operação colaborativa

\begin{tabular}{|c|c|c|c|}
\hline Usuário & Ponto & $\begin{array}{l}\text { Decisão arquitetural } \\
\text { Descrição }\end{array}$ & Categoria \\
\hline$\# 1$ & $\mathrm{R} 1$ & $\begin{array}{l}\text { Identificação do usuário } \\
\text { Falta de identificação fidedigna; duplicidades de identificações pelo } \\
\text { mesmo usuário }\end{array}$ & 2 \\
\hline$\# 1$ & S2 & $\begin{array}{l}\text { Identificação do conteúdo } \\
\text { Conteúdos relevantes de dados públicos fora do ambiente de } \\
\text { transparência }\end{array}$ & 1 \\
\hline$\# 1$ & S3 & $\begin{array}{l}\text { Qualidade das definições do dataset } \\
\text { A identificação de baixa qualidade ou com erros pode impactar o } \\
\text { resultado }\end{array}$ & 1 \\
\hline \#2 & $\mathrm{R} 1$ & $\begin{array}{l}\text { Tipo de dado } \\
\text { O usuário poderia inserir um dado de um tipo diferente }\end{array}$ & 0 \\
\hline \#2 & S2 & $\begin{array}{l}\text { Navegador } \\
\text { A extensão pode deixar de funcionar com a nova versão }\end{array}$ & 1 \\
\hline \#2 & S3 & $\begin{array}{l}\text { Alteração de página } \\
\text { Para o caso de HTML, houver mudanças no leiaute }\end{array}$ & 1 \\
\hline$\# 2$ & C4 & $\begin{array}{l}\text { Alteração de página } \\
\text { Caso haja alteração no leiaute, mandar um e-mail ao usuário } \\
\text { informando se houve alteração }\end{array}$ & 1 \\
\hline \#2 & R5 & $\begin{array}{l}\text { Alteração de página } \\
\text { Para o caso da página HTML (ou mesmo arquivo PDF) ter sido } \\
\text { excluído (o erro 404) }\end{array}$ & 0 \\
\hline
\end{tabular}




\begin{tabular}{c|c|l|c}
\hline$\# 3$ & S1 & $\begin{array}{l}\text { Acesso ao website pelo navegador do cliente } \\
\text { Verificar as condições de uso da internet, velocidade, versões de } \\
\text { navegador, tipos de navegador (Explorer, Chrome, Mozilla, etc) }\end{array}$ & 1 \\
\hline$\# 3$ & NR2 & $\begin{array}{l}\text { Acesso ao website pelo navegador do cliente } \\
\text { Verificar se o sistema pode ser acessado por tablet e smartphone }\end{array}$ & 1 \\
\hline$\# 3$ & R3 & $\begin{array}{l}\text { Nome e descrição do dataset } \\
\text { Para evitar que sejam de "livre escolha" do usuário a descrição e o } \\
\text { nome do dataset, o sistema poderia sugerir o nome e descrição } \\
\text { com base na "identificação prévia" }\end{array}$ & 3 \\
\hline$\# 3$ & R4 & $\begin{array}{l}\text { Identificação única do usuário } \\
\text { Como garantir que uma mesma pessoa tenha dois ou mais } \\
\text { usuários? Para evitar perfis semelhantes o usuário estar amarrado } \\
\text { ao CPF e RG? }\end{array}$ \\
\hline
\end{tabular}

Fonte: Elaborado pelo autor.

Tabela 32 - Decisões arquiteturais levantadas e a categorização após a análise para o cenário \#A2 referente ao atributo QA-3 - Moderação hierarquizada

\begin{tabular}{|c|c|c|c|}
\hline Usuário & Ponto & $\begin{array}{c}\text { Decisão arquitetural } \\
\text { Descrição }\end{array}$ & Categoria \\
\hline$\# 1$ & C1 & $\begin{array}{l}\text { Frequência do watch list } \\
\text { A possibilidade de moderação do watch list pode trazer maior } \\
\text { eficácia à ferramenta }\end{array}$ & 0 \\
\hline$\# 1$ & NR2 & $\begin{array}{l}\text { Priorização de comentários } \\
\text { Priorizar comentários traz mais valor aos comentários que são, de } \\
\text { fato, relevantes }\end{array}$ & 3 \\
\hline$\# 1$ & R3 & $\begin{array}{l}\text { Interação do abuso com o governo/estado } \\
\text { A criação de interação da ferramenta com o governo em caso de } \\
\text { abusos traz uma relação de confiança }\end{array}$ & 3 \\
\hline$\# 1$ & NR4 & $\begin{array}{l}\text { Interação do abuso com o governo/estado } \\
\text { Não há previsão na descrição do \#A2 acerca de interação com } \\
\text { governos no caso de abusos }\end{array}$ & 3 \\
\hline$\# 1$ & S5 & $\begin{array}{l}\text { Sobrecarga de relatos de abuso } \\
\text { Os abusos podem ser relatados em excesso e macular a } \\
\text { ferramenta }\end{array}$ & 2 \\
\hline \#2 & C1 & $\begin{array}{l}\text { Relatar abusos } \\
\text { Um usuário (ou um grupo de usuários) pode "abusar" da ferramenta } \\
\text { de relatar abusos ou combinarem de relatar coletivamente } \\
\text { determinado conteúdo }\end{array}$ & 2 \\
\hline
\end{tabular}




\begin{tabular}{c|c|l|c}
\hline$\# 2$ & R3 & $\begin{array}{l}\text { Relatar abusos } \\
\text { O mesmo usuário (com contas diferentes) pode "abusar" do uso } \\
\text { dessa ferramenta }\end{array}$ & 2 \\
\hline$\# 2$ & C2 & $\begin{array}{l}\text { Envio de comentários } \\
\text { Usuários podem usar essa ferramenta para enviar comentários com } \\
\text { palavrões e outras palavras de baixo calão }\end{array}$ & 1 \\
\hline$\# 2$ & R4 & $\begin{array}{l}\text { Análise de abuso } \\
\text { Quem garante que a análise de abuso será imparcial? }\end{array}$ & 0 \\
\hline$\# 3$ & NR1 & $\begin{array}{l}\text { Cria watch list } \\
\text { Pensar outras formas de notificação além do e-mail, como SMS ou } \\
\text { WhatsApp, além do Painel de Notificações no sistema }\end{array}$ & 3 \\
\hline$\# 3$ & C3 & $\begin{array}{l}\text { Relatar abusos } \\
\text { Pensar mecanismos para que o usuário possa enviar contra prova } \\
\text { (fotos, documentos ou outras fontes de dados) para que possa } \\
\text { provar o abuso e facultar a análise do abuso }\end{array}$ & $\begin{array}{l}\text { Faz comentário } \\
\text { Além de quem fez o comentário ou o relato do abuso, quem fez o } \\
\text { dataset supostamente errado tem que ser notificado para que } \\
\text { possa saber das denúncias de abuso e se defender. Pois, } \\
\text { certamente, pode estar correto, e quem está relatando o abuso } \\
\text { possa estar errado }\end{array}$ \\
\hline
\end{tabular}

Fonte: Elaborado pelo autor.

Tabela 33 - Decisões arquiteturais levantadas e a categorização após a análise para o cenário \#A3 referente ao atributo QA-4 - Avaliação mútua

\begin{tabular}{|c|c|c|c|}
\hline Usuário & Ponto & $\begin{array}{l}\text { Decisão arquitetural } \\
\text { Descrição }\end{array}$ & Categoria \\
\hline$\# 1$ & NR1 & $\begin{array}{l}\text { Utilidade } \\
\text { Além da qualidade em si, a avaliação acerca da estruturação do } \\
\text { dado pode levar em consideração a utilidade da estruturação e dos } \\
\text { metadados }\end{array}$ & 3 \\
\hline \#2 & $\mathrm{R} 1$ & $\begin{array}{l}\text { Má fé na avaliação } \\
\text { Um usuário pode, por má fé, avaliar negativamente outro usuário }\end{array}$ & 2 \\
\hline \#2 & S2 & $\begin{array}{l}\text { Má fé na avaliação } \\
\text { Como o sistema tratará as avaliações (e os avaliados) que } \\
\text { receberam muitas avaliações negativas inadvertidamente }\end{array}$ & 2 \\
\hline \#2 & NR3 & $\begin{array}{l}\text { Utilidade } \\
\text { O que acorrerá com as baixas avaliações? }\end{array}$ & 2 \\
\hline
\end{tabular}




\begin{tabular}{c|c|l|c}
\hline$\# 3$ & S1 & $\begin{array}{l}\text { Avaliar a estruturação } \\
\text { Avaliação de cinco estrelas é subjetiva - pensar também campo } \\
\text { para comentário qualitativo além da avaliação das estrelas }\end{array}$ & 1 \\
\hline$\# 3$ & NR2 & $\begin{array}{l}\text { Avaliar a estruturação } \\
\text { Além de visualizar os dados da estruturação, mostrar o dado de } \\
\text { origem, ou seja, o link lá na página da prefeitura que o dado estava, } \\
\text { para fundamentar a avaliação }\end{array}$ & 1 \\
\hline$\# 3$ & NR3 & $\begin{array}{l}\text { Status } \\
\text { O usuário que gerou o dataset que está sendo avaliado também } \\
\text { deve ser modificado, para também ser transparente no processo de } \\
\text { avaliação. Afinal, estamos falando de processos políticos, e os } \\
\text { conflitos vão ocorrer de todos os lados, situação quanto oposição }\end{array}$ & \\
\hline$\# 3$ & NR4 & $\begin{array}{l}\text { Controlador moderação } \\
\text { Estabelecer os requisitos do controlador de moderação: } \\
\text { - Quem vai determinar se está certo ou errado? } \\
\text { - Quais os critérios? } \\
\text { - Qual o fluxo de moderação até a decisão final? } \\
- \text { Esta é uma ferramenta política que pode ser bem utilizada ou } \\
\text { deturpada para outros fins. }\end{array}$ & 2 \\
\hline
\end{tabular}

Fonte: Elaborado pelo autor.

Tabela 34 - Decisões arquiteturais levantadas e a categorização após a análise para o cenário \#A4 referente ao atributo QA-5 - Operação baseada no navegador

\begin{tabular}{|c|c|c|c|}
\hline Usuário & Ponto & $\begin{array}{l}\text { Decisão arquitetural } \\
\text { Descrição }\end{array}$ & Categoria \\
\hline$\# 1$ & S1 & $\begin{array}{l}\text { Perfil de contribuidor } \\
\text { A abertura ampla para a contribuição pode ocasionar contribuidores } \\
\text { pouco preparados ou mal-intencionados }\end{array}$ & 1 \\
\hline$\# 1$ & $\mathrm{C} 2$ & $\begin{array}{l}\text { Perfil de contribuidor } \\
\text { Há compensação em ampliar as possibilidades de perfil de } \\
\text { contribuidor, pois um ambiente multidisciplinar tende a enriquecer a } \\
\text { ferramenta }\end{array}$ & 1 \\
\hline$\# 1$ & R3 & $\begin{array}{l}\text { Perfil de contribuidor } \\
\text { Se quem contribuir também pode avaliar há problema de } \\
\text { validação/legitimidade }\end{array}$ & 1 \\
\hline$\# 2$ & R1 & $\begin{array}{l}\text { Versão do navegador } \\
\text { Caso o navegador seja atualizado e a extensão deixe de funcionar }\end{array}$ & 1 \\
\hline$\# 2$ & S2 & Desempenho & 0 \\
\hline
\end{tabular}




\begin{tabular}{c|c|l|c}
\hline & & $\begin{array}{l}\text { A extensão pode acarretar numa perda de desempenho para o } \\
\text { navegador (como maior consumo de memória) }\end{array}$ & \\
\hline$\# 2$ & NR3 & $\begin{array}{l}\text { Versões específicas } \\
\text { Talvez haja necessidade de versões para cada navegador }\end{array}$ & 1 \\
\hline$\# 2$ & R4 & $\begin{array}{l}\text { Comunicação com servidor } \\
\text { A extensão pode se comunicar com o servidor, porém o servidor } \\
\text { pode estar fora do ar }\end{array}$ & 1 \\
\hline$\# 3$ & NR1 & $\begin{array}{l}\text { Selecionar conteúdo } \\
\text { Incluir outras fontes de dados como Excel, doc, etc }\end{array}$ & 3 \\
\hline S2 & $\begin{array}{l}\text { Instalar a extensão } \\
\text { Existem pré-requisitos, ou seja, funciona em qualquer navegador, } \\
\text { qualquer configuração de computador, tablet ou smartphone? }\end{array}$ & 3 \\
\hline C3 & $\begin{array}{l}\text { Status ID } \\
\text { Além de nome e ID, perguntar para o usuário se ele quer seguir } \\
\text { aqueles dados (watch list) }\end{array}$ & 2 \\
\hline
\end{tabular}

Fonte: Elaborado pelo autor.

Tabela 35 - Decisões arquiteturais levantadas e a categorização após a análise para o cenário \#A5 referente ao atributo QA-6 - Autenticação do usuário

\begin{tabular}{|c|c|c|c|}
\hline Usuário & Ponto & $\begin{array}{l}\text { Decisão arquitetural } \\
\text { Descrição }\end{array}$ & Categoria \\
\hline$\# 2$ & NR1 & $\begin{array}{l}\text { Esqueceu senha } \\
\text { O usuário pode ter esquecido a senha dele. Daí poderia ser } \\
\text { enviada uma nova senha a ele por e-mail }\end{array}$ & 2 \\
\hline$\# 2$ & NR2 & $\begin{array}{l}\text { Redes sociais } \\
\text { Poder logar-se com contas de redes sociais (Google+, Facebook, } \\
\text { Twitter, etc.) }\end{array}$ & 2 \\
\hline \#3 & S1 & $\begin{array}{l}\text { Autentica usuário } \\
\text { Incluir outras formas de autenticação de usuário como Facebook, } \\
\text { Google+, além do WhatsApp pois aparece/carrega a foto neste } \\
\text { mundo político, os "rostos" são muito importantes, também para } \\
\text { evitar os fakes }\end{array}$ & 2 \\
\hline$\# 3$ & $\mathrm{R} 2$ & $\begin{array}{l}\text { Checar as credenciais do usuário } \\
\text { Como o sistema vai identificar que não tem robôs ou usuários } \\
\text { fakes? Checar de qual organização ele pertence: partido, ONG, } \\
\text { prefeitura, câmara, etc? }\end{array}$ & 2 \\
\hline
\end{tabular}

Fonte: Elaborado pelo autor. 
Tabela 36 - Decisões arquiteturais levantadas e a categorização após a análise para o cenário \#A6 referente ao atributo QA-7 - Acesso autoconcedido

\begin{tabular}{|c|c|c|c|}
\hline Usuário & Ponto & $\begin{array}{l}\text { Decisão arquitetural } \\
\text { Descrição }\end{array}$ & Categoria \\
\hline$\# 1$ & $\mathrm{R} 1$ & $\begin{array}{l}\text { Registros mal-intencionados } \\
\text { O aceite de registros mal-intencionados ( } p \text {. ex. com forte variável } \\
\text { política num período de eleição) pode prejudicar o sistema e } \\
\text { incomodar usuários bem-intencionados. }\end{array}$ & 1 \\
\hline \#2 & NR1 & $\begin{array}{l}\text { E-mail } \\
\text { Caso o usuário use um e-mail que não existe }\end{array}$ & 1 \\
\hline \#2 & $\mathrm{R} 2$ & $\begin{array}{l}\text { E-mail } \\
\text { O usuário pode se registrar com um e-mail já existente }\end{array}$ & 1 \\
\hline$\# 3$ & NR1 & $\begin{array}{l}\text { Criar usuário } \\
\text { Facebook, Google+ e WhatsApp }\end{array}$ & 2 \\
\hline
\end{tabular}

Fonte: Elaborado pelo autor.

Tabela 37 - Decisões arquiteturais levantadas e a categorização após a análise para o cenário \#A7 referente ao atributo QA-9 - Acesso manual

\begin{tabular}{|c|c|c|c|}
\hline Usuário & Ponto & $\begin{array}{l}\text { Decisão arquitetural } \\
\text { Descrição }\end{array}$ & Categoria \\
\hline$\# 1$ & S1 & $\begin{array}{l}\text { Utilização de APIs } \\
\text { A utilização de APIs mal estruturadas por um usuário pode resultar } \\
\text { em conclusões equivocadas }\end{array}$ & 0 \\
\hline$\# 1$ & S2 & $\begin{array}{l}\text { Qualidade de APIs } \\
\text { As APIs com qualidade devem ser a meta de toda a ferramenta }\end{array}$ & 1 \\
\hline$\# 2$ & $\mathrm{R} 1$ & $\begin{array}{l}\text { Servidor fora do ar } \\
\text { O acesso a API pode ser feito quando o servidor estiver fora do ar }\end{array}$ & 0 \\
\hline \#2 & NR2 & $\begin{array}{l}\text { Vários tipos } \\
\text { Um mesmo dataset pode ter vários tipos. Daí a API poderia } \\
\text { informar qual o tipo a ser consumido }\end{array}$ & 1 \\
\hline$\# 2$ & C3 & $\begin{array}{l}\text { Vários tipos } \\
\text { O tipo a ser consumido pode não existir mais, ou estar corrompido }\end{array}$ & 0 \\
\hline$\# 3$ & $\mathrm{~S} 1$ & $\begin{array}{l}\text { Acesso manual } \\
\text { Disponibilizar os dados em Excel ou doc, se for o caso, para que o } \\
\text { cidadão comum possa trabalhar os dados conforme as formações e } \\
\text { conhecimento que possui }\end{array}$ & 2 \\
\hline
\end{tabular}




\begin{tabular}{l|l|l|c}
\hline$\# 3$ & NR2 & $\begin{array}{l}\text { Acesso manual } \\
\text { Além da busca relativa do usuário, o sistema pode estimular a } \\
\text { busca de dados. O usuário pode cadastrar seus dados de interesse } \\
\text { - educação, cultura, saúde, etc - e sempre que tiver "algo novo no } \\
\text { sistema", os usuários cadastrados podem ser notificados }\end{array}$ & 3 \\
\hline
\end{tabular}

Fonte: Elaborado pelo autor.

Tabela 38 - Decisões arquiteturais levantadas e a categorização após a análise para o cenário \#A8 referente ao atributo QA-10 - Acesso automatizado

\begin{tabular}{|c|c|c|c|}
\hline Usuário & Ponto & $\begin{array}{l}\text { Decisão arquitetural } \\
\text { Descrição }\end{array}$ & Categoria \\
\hline$\# 1$ & R1 & $\begin{array}{l}\text { Atualização de APls } \\
\text { Há risco de conclusões equivocadas caso as APIs não forem } \\
\text { atualizadas de acordo com a legislação relacionada aos metadados }\end{array}$ & 0 \\
\hline$\# 2$ & NR1 & $\begin{array}{l}\text { Várias versões } \\
\text { O dataset pode ter diversos tipos de dados distintos. Ficaria a cargo } \\
\text { de mais um parâmetro dizendo qual o tipo de dado }\end{array}$ & 1 \\
\hline \#2 & S2 & $\begin{array}{l}\text { Chave (API key) } \\
\text { Para evitar abuso no uso da API, oferecer o uso de uma chave (API } \\
\text { key) }\end{array}$ & 1 \\
\hline \#2 & $\mathrm{R} 4$ & $\begin{array}{l}\text { Chave (API key) } \\
\text { Evitar com que haja vazamento dessas chaves }\end{array}$ & 1 \\
\hline$\# 2$ & C3 & $\begin{array}{l}\text { Dispositivos } \\
\text { A API deve ser simples de ser usada pelos mais diversos } \\
\text { dispositivos existentes }\end{array}$ & 1 \\
\hline$\# 3$ & NR1 & $\begin{array}{l}\text { Catálogo } \\
\text { Já existe um levantamento prévio de possíveis APIs ou sistemas } \\
\text { semelhantes para que esta ferramenta possa se conectar ou ser } \\
\text { conectada? }\end{array}$ & 0 \\
\hline
\end{tabular}

Fonte: Elaborado pelo autor.

De acordo com as Tabelas 31 a 38, o time de validadores identificou e catalogou um total de 63 pontos de contribuição para a arquitetura. Desse total, 16 foram classificados como Sensibilidade, nove como Compensação, 18 como $\underline{\text { Risco e }}$ 20 como Não risco. Após a análise de todos esses pontos, chegou-se ao quadro- 
resumo de pontos identificadas no processo de validação mostrado na Tabela 39 a seguir.

Tabela 39 - Quadro-resumo de pontos identificados no processo de validação

\begin{tabular}{l|c|c}
\hline \multirow{2}{*}{ Nível de contribuição } & \multicolumn{2}{|c}{ Total identificado } \\
\cline { 2 - 3 } & Qtde & $\%$ \\
\hline Não indica contribuição significativa (0) & 10 & $16 \%$ \\
\hline Pode contribuir para melhor descrição e formalização (1) & 25 & $40 \%$ \\
\hline Contribui para melhoria incremental (2) & 16 & $25 \%$ \\
\hline Contribui para melhoria significativa (3) & 12 & $19 \%$ \\
\hline Total & 63 & $100 \%$ \\
\hline
\end{tabular}

Fonte: Elaborado pelo autor.

Os resultados apresentados na Tabela 39 indicam que a arquitetura não só foi entendida pelos validadores, como também foi enriquecida durante o processo de validação. Isso caracteriza uma das principais intenções em conduzir o método ATAM, o que viabiliza o raciocínio sobre a arquitetura sendo validada. $O$ raciocínio sobre a arquitetura leva a resultados melhores e mais precisos, pois estimula a avaliação dos diversos aspectos obtidos pelo projetista.

Conforme a Tabela 39, o principal achado refere-se ao percentual de $40 \%$ dos pontos identificados que já estavam compreendidos pela especificação da arquitetura e categorizados pelo nível de contribuição (1). Isso significa que os validadores apontaram itens já presentes na arquitetura, porém indicaram potenciais melhorias na sua descrição. Este achado é reforçado pela sobreposição de entendimento entre os validadores. Essa argumentação é complementada pelo desmembramento dos pontos identificados por usuário, conforme Tabela 40. 
Tabela 40 - Desmembramento dos pontos identificados por usuário

\begin{tabular}{r|c|c|c|c|c|c}
\hline & \multicolumn{2}{|c|}{$\begin{array}{c}\text { Usuário \#1 } \\
\text { (Gestor público) }\end{array}$} & $\begin{array}{c}\text { Usuário \#2 } \\
\text { (Desenvolvedor) }\end{array}$ & \multicolumn{2}{c}{$\begin{array}{c}\text { Usuário \#3 } \\
\text { (Ativista político) }\end{array}$} \\
\hline & Qtde & $\%$ & Qtde & $\%$ & Qtde & $\%$ \\
\hline Não indica contribuição (0) & 3 & $19 \%$ & 6 & $22 \%$ & 1 & $5 \%$ \\
\hline $\begin{array}{l}\text { Pode contribuir para melhor descrição e } \\
\text { formalização (1) }\end{array}$ & 7 & $44 \%$ & 14 & $52 \%$ & 4 & $20 \%$ \\
\hline Contribui para melhoria incremental (2) & 2 & $13 \%$ & 7 & $26 \%$ & 7 & $35 \%$ \\
\hline Contribui para melhoria significativa (3) & 4 & $25 \%$ & 0 & $0 \%$ & 8 & $40 \%$ \\
\hline TOTAL & 16 & - & 27 & - & 20 & - \\
\hline
\end{tabular}

Fonte: Elaborado pelo autor.

Pela Tabela 40 percebe-se que o nível de contribuição (1) foi o mais encontrado nos perfis de usuário \#1 (Gestor público) e \#2 (Desenvolvedor) com 44\% e $52 \%$, respectivamente.

Outro achado obtido pela análise da Tabela 40 indica que o perfil de usuário \#3 (Ativista político) direcionou a maioria de seus pontos para contribuição significativa da arquitetura, o que pode mostrar um perfil mais ousado em termos de funcionalidades propostas pela arquitetura. Já o perfil de usuário \#2 (Desenvolvedor) concentrou o maior número absoluto de contribuições (43\%) comparado com os demais perfis, porém suas contribuições já estavam previstas na arquitetura com possível necessidade de melhor detalhamento.

\subsection{Implementação}

Até a presente seção validou-se a arquitetura definida nesta pesquisa com base em seus atributos de qualidade e sob o ponto de vista dos potenciais stakeholders, de acordo com o método ATAM, sem a necessidade de implementação do sistema proposto pela arquitetura. 
Kazman e Cervantes (2016) observam que a materialização da arquitetura se dá por sua instanciação ou implementação, cujos resultados só são percebidos pela operação em ambiente real de funcionamento. Porém, para chegar a este ponto, todos os recursos humanos e materiais, além do tempo necessário para sua implementação, devem ser atendidos.

Esta seção busca demonstrar uma implementação ou instanciação parcial da arquitetura, obtida pelo desenvolvimento de um protótipo compreendendo os principais componentes e bibliotecas. Os resultados demonstrados na próxima seção não compreendem uma versão funcional do sistema, mas apenas uma demonstração de sua viabilidade técnica considerando o estágio corrente dos produtos e tecnologias encontrados no mercado.

Inicialmente, discorre-se brevemente acerca dos conceitos básicos que norteiam a componentização e disponibilização de web services. Em seguida, a introdução de ferramentas livres e de código aberto que podem ser adaptadas para extração de dados tabulares de documentos PDF e HTML e, finalmente, o protótipo em si com para visualização das principais partes do sistema.

\subsubsection{Middleware, Web services e APIs}

Middleware é um termo genérico que descreve um software que fornece serviços para outros sistemas. Estes serviços são expostos por meio de uma infraestrutura que fornece aplicações (também pela internet) para tornar a comunicação e gerenciamento de dados entre as diferentes camadas de abstração de um sistema. É um arranjo conceitual que indica um mediador.

Quando uma infraestrutura de middleware envolve aplicações utilizando a internet (ou mais precisamente a web), simplesmente define-se esta infraestrutura como sendo baseada em web service. Também classificado como um termo amplo, web service baseia-se no HyperText Transfer Protocol (HTTP) para transmitir dados pela rede invocando componentes de software chamados métodos da web, normalmente a partir de programas autônomos que se opõem a um navegador (RICHARDSON; RUBY, 2007). Apesar do processo de chamada também ser possível a partir de um navegador web, os resultados de chamadas autônomas são 
direcionados para o processamento por máquina, em vez de páginas da web com textos e imagens projetadas para a leitura humana.

O processo de chamada é viabilizado com o uso das APls, que são um conjunto de especificações que definem funcionalidades (ou serviços) expostos pela web sem se preocupar com os detalhes de implementação. É apenas necessário saber 0 nome e o endereço de um recurso, algo como http://datahub.io/api/rest/dataset/contracts, em que Datahub é o endereço da web e contracts é o nome de um recurso - neste caso, um dataset localizado na instância CKAN Datahub. Os resultados retornados nessa chamada geram uma representação de texto em JSON com todos os metadados do dataset e os dados em si para download. Os resultados - voltadas para o processamento por máquina são o principal benefício das APls que podem ser acessadas por clientes independentemente da tecnologia envolvida e por meio de protocolos pré-definidos.

\subsubsection{Ferramentas de extração de conteúdo tabular}

Conteúdo tabular é o principal meio adotado para dispor dados em documentos PDF ou páginas HTML. Há uma grande variedade de ferramentas que possibilitam especificamente a extração de conteúdo tabular destes formatos. No Apêndice D estão relacionadas comparativamente as ferramentas que foram analisadas no decorrer deste trabalho. As próximas seções detalharam quais ferramentas foram escolhidas e integradas ao protótipo do sistema aqui sendo demonstrado.

\subsubsection{Extração PDF}

O formato PDF é padronizado pela norma ISO 32000-1:2008 como padrão aberto deste 2008 (INTERNATIONAL ORGANIZATION FOR STANDARDIZATION, 2008). Porém, do ponto de vista de OGD, o PDF não disponibiliza dados estruturados e muito menos dados abertos. Sua estrutura é construída para prover documentos semelhantes a relatórios impressos e a leitura está direcionada para humanos. Os objetos dentro de um PDF são textos, gráficos e tabelas aperfeiçoados para melhor experiência visual. Assim, o princípio de OGD que prevê o processamento por máquina não está presente em arquivos PDF, já que exige esforços técnicos para extrair dados a partir deles. 
Nesse contexto, surge o Tabula PDF ${ }^{13}$ como ferramenta para extrair o conteúdo tabular a partir de PDFs para arquivos de texto puro como o CSV. O Tabula foi introduzido por Manuel Aristarán no final de 2012 como software livre e de código aberto, disponível sob a Licença Massachusetts Institute of Technology (MIT). O autor foi inspirado por alguns trabalhos (GÖBEL et al., 2012; YILDIZ; KAISER; MIKSCH, 2005) sobre a análise e extração de conteúdo tabular (ARISTARÁN; TIGAS, 2013).

O Tabula disponibiliza uma compilação executável baseada na web que funciona em sistemas operacionais Windows, Mac e Linux. Há também uma versão Java disponível em seu repositório GitHub ${ }^{14}$ que recebe melhorias de contribuidores ao redor do mundo. No protótipo está sendo utilizada a versão Java para integração com ambiente de programação.

Essencialmente, o Tabula funciona a partir da identificação do conteúdo tabular dentro de um documento PDF. Este processo pode ser feito automaticamente (ainda em estágio experimental) ou definido manualmente obtendo-se as coordenadas da área que delimita o conteúdo tabular. A Figura 43 mostra o conteúdo tabular em PDF sendo identificado com uma área retangular delimitada que representa 0 arranjo dos dados e colunas.

\footnotetext{
${ }^{13} \mathrm{http}: / /$ tabula.technology/

${ }^{14} \mathrm{https}: / /$ github.com/tabulapdf
} 
Figura 43 - Identificação de conteúdo tabular dentro de um arquivo PDF utilizando o Tabula

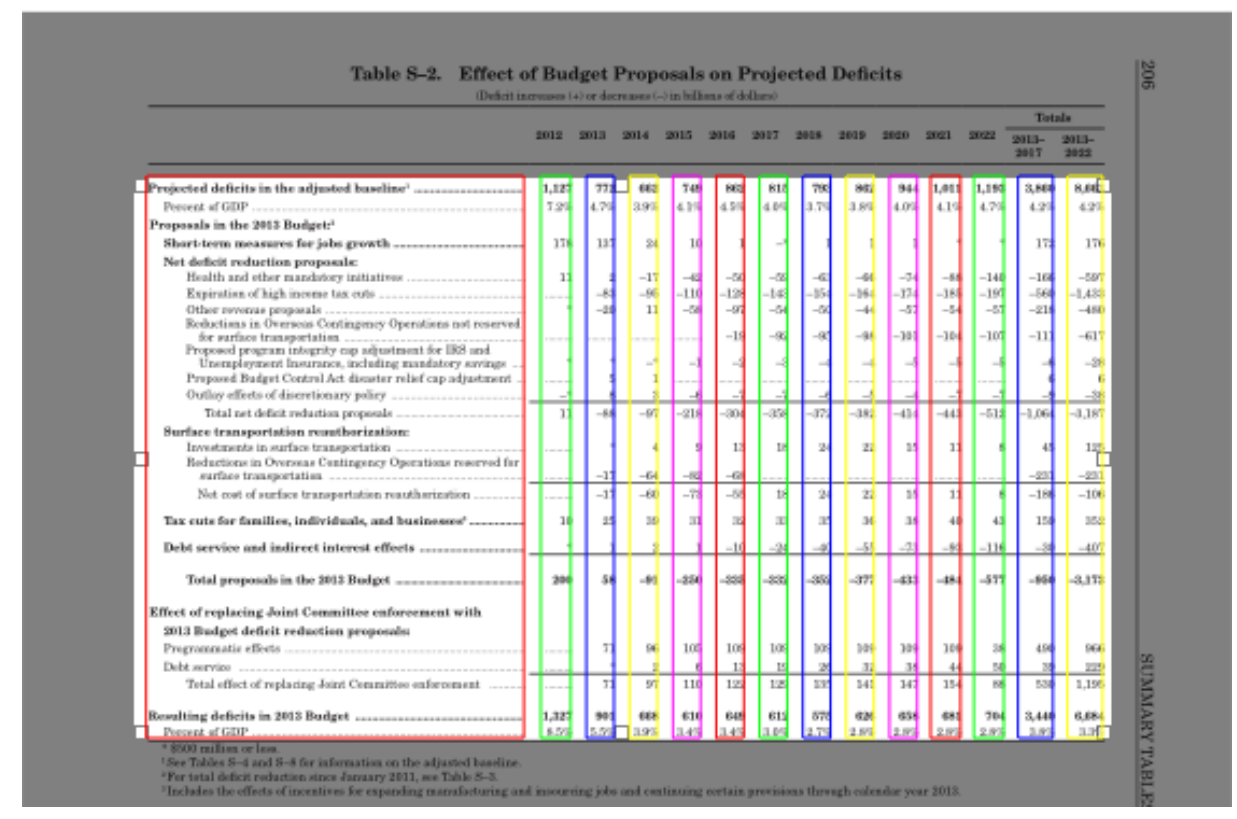

Fonte: Adaptado de Aristarán e Tigas (2013).

\subsubsection{Extração HTML}

Uma página web HTML é descrita como um documento baseado em tags utilizando o XML. Cada tag é responsável pela saída visual através do navegador web que a interpreta. Em geral, as tags HTML de alguma forma estruturam os dados dentro das páginas. No entanto, a tag em si não tem sentido em termos de semântica (BIZER; HEATH; BERNERS-LEE, 2009), sendo a razão pela qual se refere às páginas HTML como documentos semiestruturados.

Além disso, outro problema com o HTML reside na sua construção dinâmica como uma página da web. Isso significa que para acessar uma tabela com dados do governo os usuários normalmente precisam fornecer parâmetros ou filtros de antemão. Ignorando esta etapa, a essência da construção dinâmica das páginas web deixa de existir, descaracterizando a revolução que esta tecnologia trouxe para o mercado.

Uma possível solução é extrair o conteúdo tabular (descrito normalmente por uma tag table) apenas depois de preenchidos os parâmetros fornecidos pelo 
usuário. Há uma biblioteca eficiente nesta tarefa denominada HTML Agility Pack ${ }^{15}$ (HAP), que é uma biblioteca aberta para analisar arquivos HTML (parser) com o apoio de consultas XML Path Language (XPath) que permitem o acesso direto às tags HTML, a fim de recuperar o seu conteúdo, mesmo que o código HTML esteja malformado.

O HAP integra-se ao ambiente de desenvolvimento Microsoft .NET e pode ser instalado como um pacote. Não há necessidade de profundo conhecimento das especificações HTML e XPath tendo em vista que a biblioteca simplifica o modelo de implementação para a maioria dos desenvolvedores.

\subsubsection{Protótipo}

O protótipo do sistema consiste no desenvolvimento do middleware contido no contexto da arquitetura. Conforme detalhado na definição da arquitetura, o protótipo de software concentra-se nas camadas Estruturação e Colaborativa, mas também possui alguns serviços localizados na camada Apresentação que interagem em complemento aos serviços oferecidos pelo CKAN (catálogo OGD), que por sua vez tem seu funcionamento também externado por APIs para interação com seus serviços.

$\mathrm{Na}$ camada Estruturação localizam-se as APIs de estruturação e o Portal Colaborativo. Esta camada invoca os serviços da camada Apresentação e disponibiliza o consumo de serviços essencialmente pela camada Colaborativa.

$\mathrm{Na}$ camada Colaboração é onde estão localizadas as ferramentas responsáveis pela interação do usuário no processo de estruturação dos dados. É pressuposto desta camada a existência do navegador web do usuário como meio fundamental de acesso e apresentação dos dados desestruturados por intermédio de páginas web.

A Figura 44 ilustra um quadro-resumo que expõe os componentes de software utilizados e os artefatos produzidos para desenvolvimento do protótipo do sistema, de acordo com a arquitetura.

\footnotetext{
$15 \mathrm{http} / / \mathrm{htmlagilitypack.codeplex.com}$
} 
Figura 44 - Quadro-resumo dos componentes utilizados e artefatos produzidos no contexto do protótipo do sistema

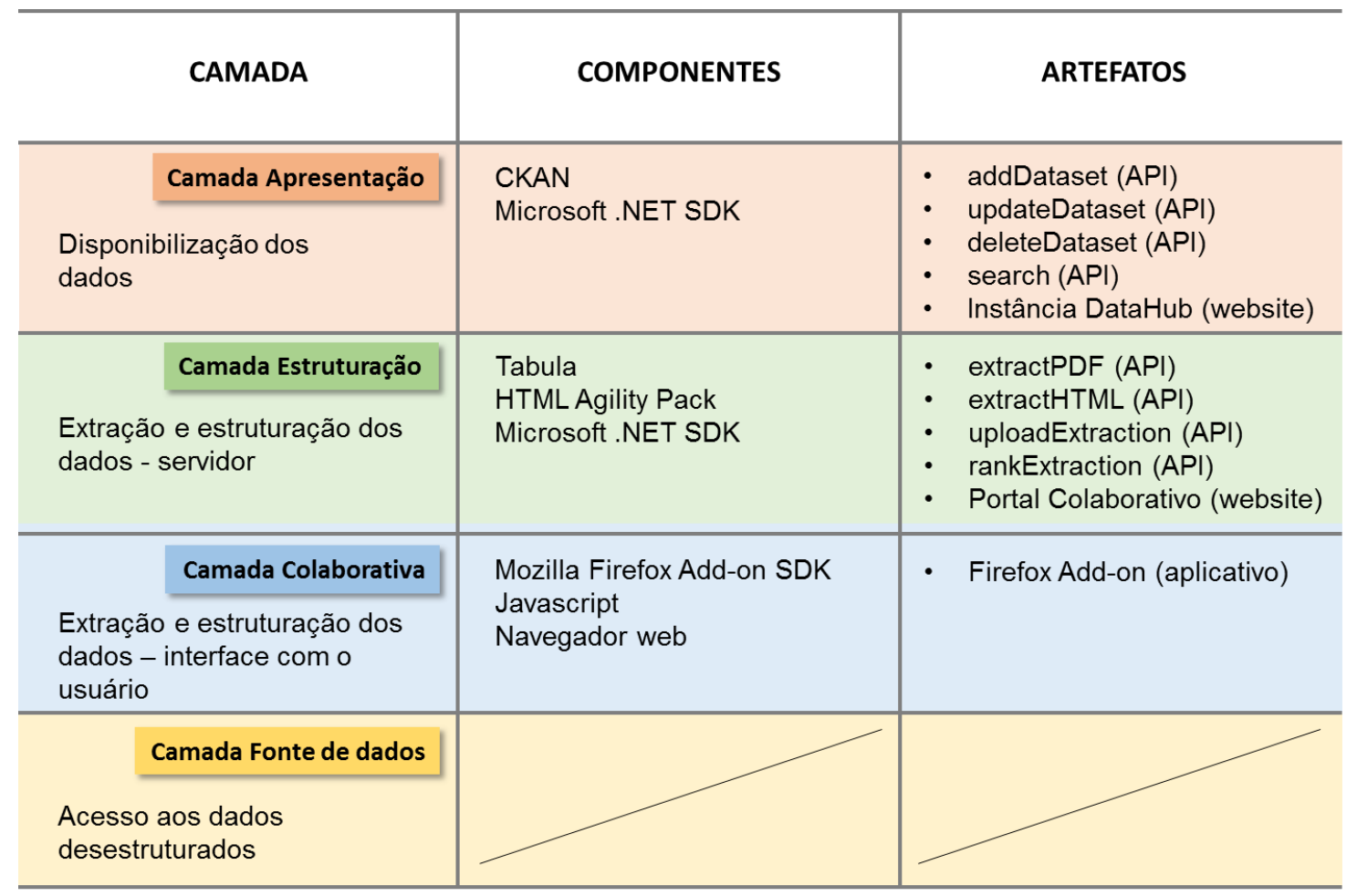

Fonte: Elaborado pelo autor.

$\mathrm{Na}$ camada Apresentação encontra-se essencialmente o CKAN, por meio de uma instância no Datahub. A organização configurada foi denominada OGD USP Brazil$^{16}$. Foram desenvolvidas APIs utilizando o ambiente de desenvolvimento Microsoft .NET para estender os serviços providos pelo CKAN para realizar operações básicas com os datasets, como adicionar, atualizar, excluir e localizar, as quais são acessadas diretamente pela programação das camadas inferiores da arquitetura. Nesta camada, a interface visível disponibilizada ao usuário da comunidade é um por meio de um sistema web, que é a instância configurada no Datahub onde são disponibilizados os datasets fruto da estruturação dos dados realizada no contexto do sistema. A interface é semelhante à mostrada a seguir pela Figura 45.

${ }^{16} \mathrm{~A}$ organização pode ser acessada pelo endereço https://datahub.io/organization/ogd-usp-brazil. 
Figura 45 - Instância configurada do CKAN com a organização OGD USP Brazil

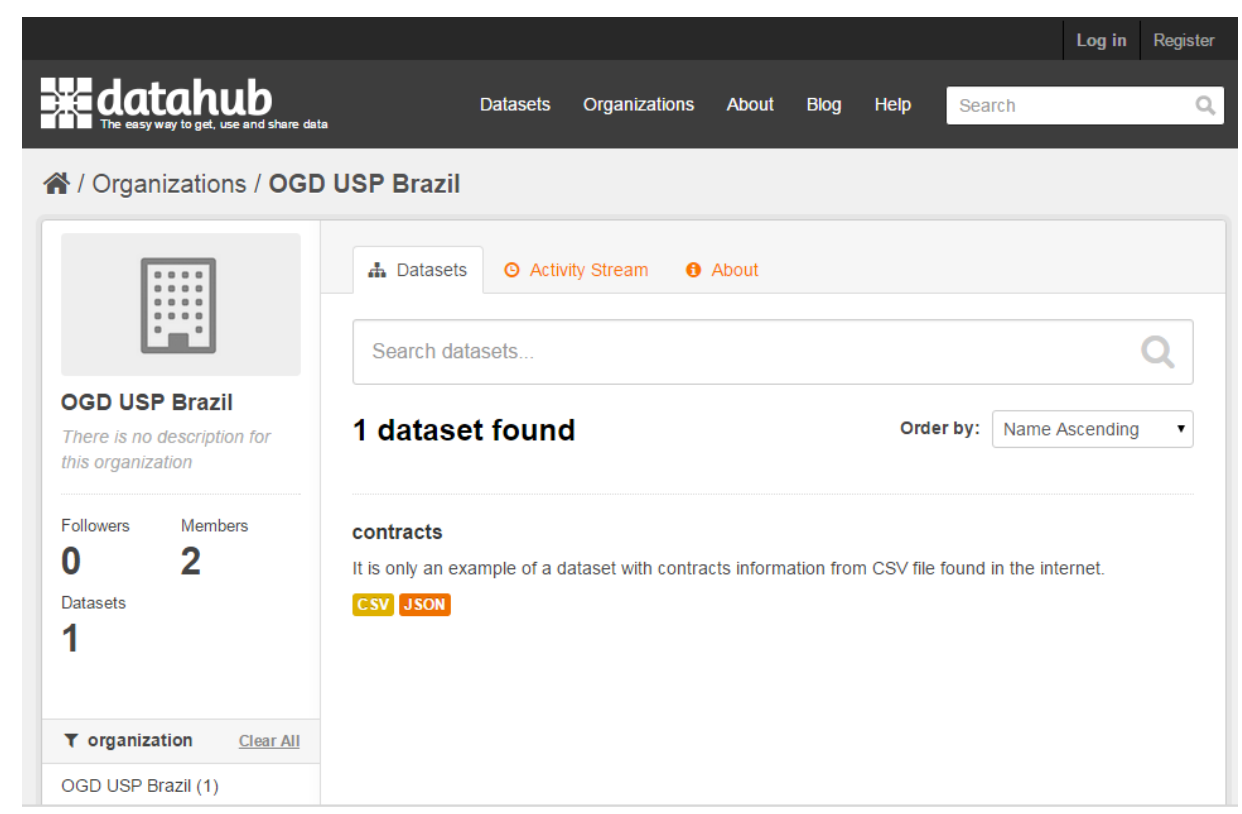

Fonte: Adaptado de OGD USP Brazil (2016).

$\mathrm{Na}$ camada Estruturação foram desenvolvidas as APIs de extração e estruturação dos dados (parte servidora), considerando num primeiro momento os componentes HAP para extrair páginas HTML e Tabula para extrair PDFs. As APIs para carregamento dos dados no CKAN e classificação das extrações também são artefatos desenvolvidos nesta camada. Também foi utilizado o ambiente de desenvolvimento Microsoft .NET para a programação dos serviços. A interface visível por esta camada denomina-se Portal Colaborativo, onde são detalhadas as extrações realizadas pela comunidade com os respectivos metadados e a localização dos datasets no CKAN. A Figura 46 mostra o protótipo do Portal Colaborativo externado aos usuários. 
Figura 46 - Protótipo do Portal Colaborativo externado aos usuários

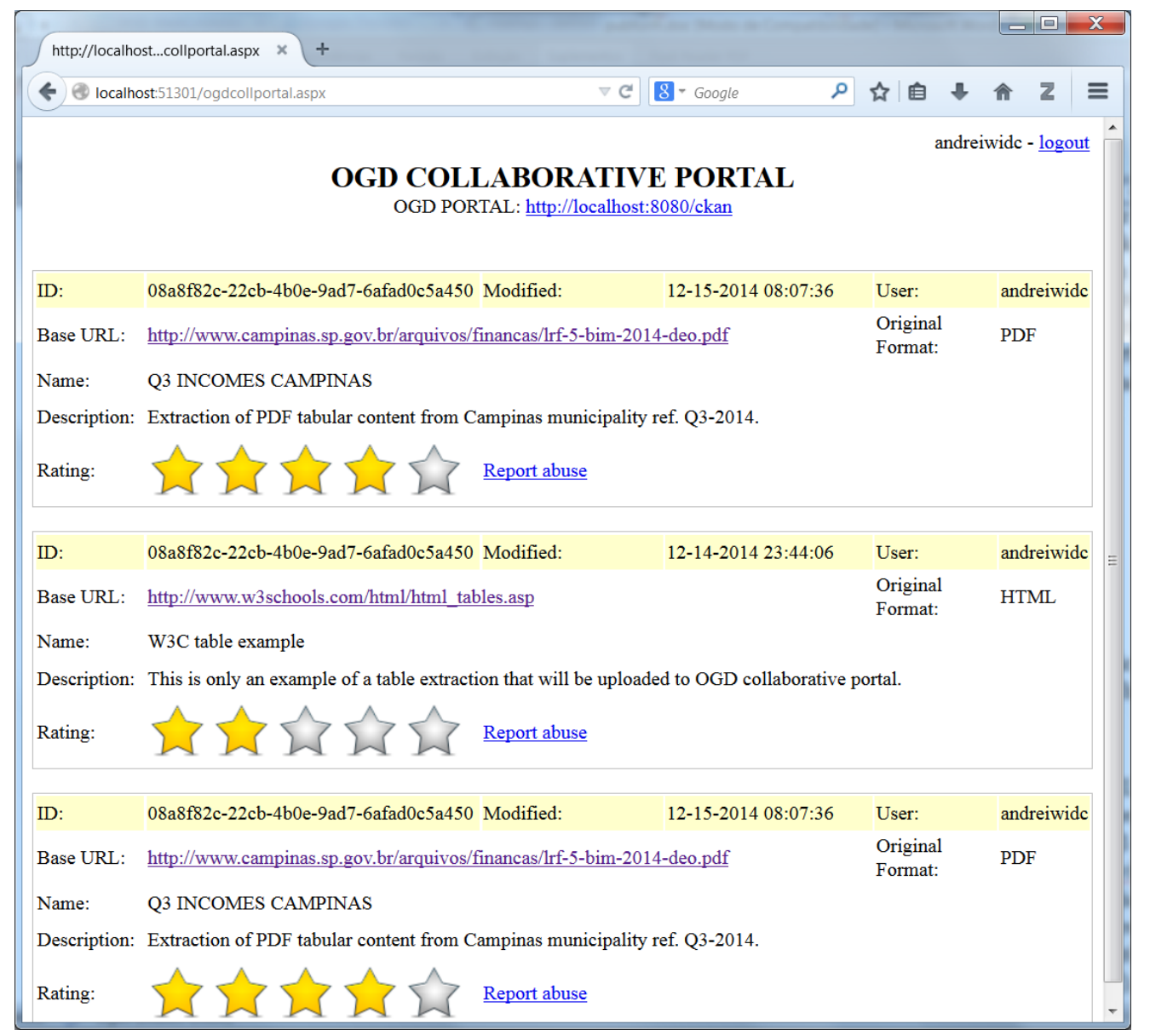

Fonte: Adaptado de Corrêa, Corrêa e Silva (2015).

$\mathrm{Na}$ camada Colaboração é onde acontecem o processo de extração e estruturação dos dados do ponto de vista do usuário. Nesta camada o usuário final encontra as ferramentas necessárias para acessar a fonte de dados desestruturada e assim proceder com sua estruturação. O ambiente de desenvolvimento adotado é o Mozilla Firefox Add-on SDK que visa a criação de aplicativos sobre o navegador web (Firefox). A linguagem Javascript é utilizada para manipulação dos objetos da página com os dados de interesse para estruturação. Nesta camada as interfaces exibidas ao usuário são semelhantes às mostradas na Figura 47. 
Figura 47 - Interface do usuário expondo o processo de estruturação por meio do navegador web com a extensão instalada. (a) Dados tabulares dento de uma página HTML. (b) Dados tabulares dentro de um documento PDF

(a)

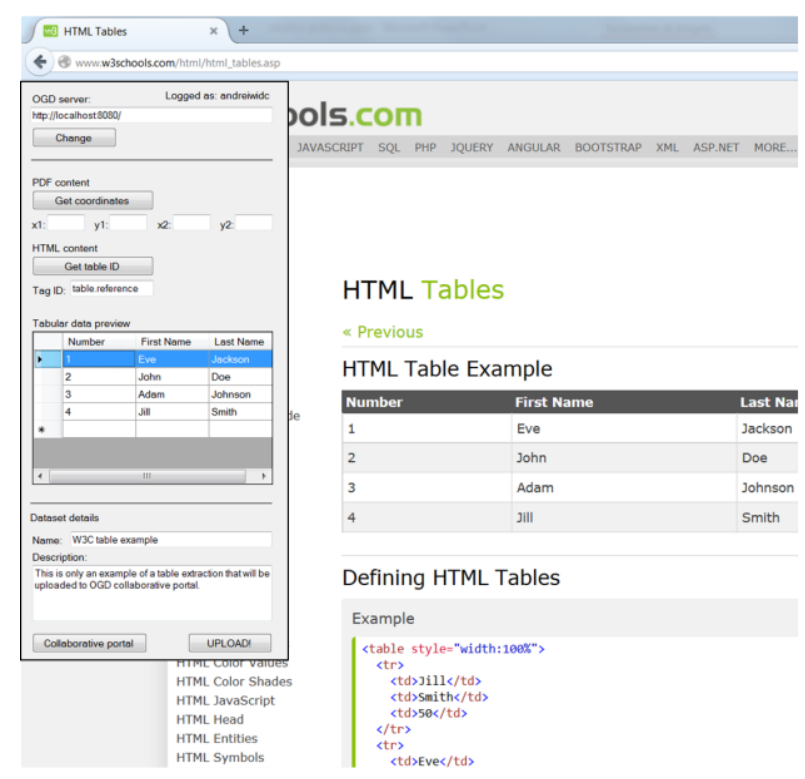

(b)

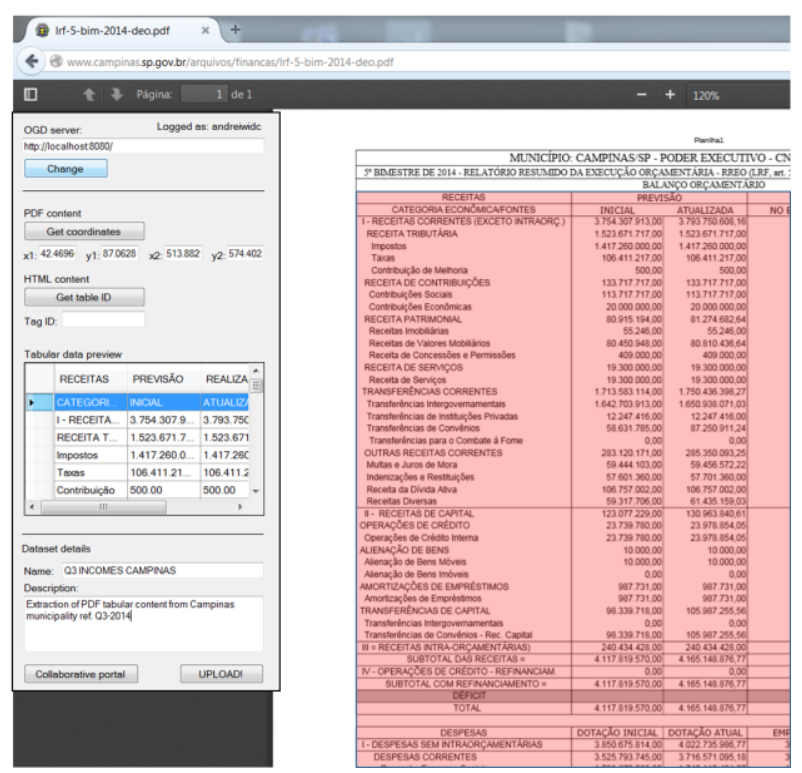

Fonte: Adaptado de Corrêa, Corrêa e Silva (2015).

Conforme apresentado na Figura 47, as ferramentas se apresentam em uma janela flutuante que se habilita por cima das páginas de interesse. Desse modo, o usuário pode selecionar o conteúdo tabular em ambos tipos de arquivos, HTML ou PDF. É possível pré-visualizar os dados da extração antes de carregá-los em definitivo no CKAN.

\subsection{Considerações finais}

Este capítulo buscou validar a arquitetura definida nesta pesquisa de modo a assegurar que seus atributos de qualidade de fato atendem aos requisitos dos stakeholders. A validação conduzida é um argumento substancial onde se demonstrou que a solução de um problema real proposta por esta pesquisa pode ser atendida com a especificação de um sistema de software por meio de sua arquitetura. 
O procedimento de validação foi conduzido conforme o método ATAM, que dispõe de um roteiro adaptável e flexível do processo para compreender arquiteturas ainda não instanciadas ou implementadas. Nele foi possível contar com um número de validadores compatível com os objetivos desta pesquisa e obter resultados consistentes com os resultados pretendidos para com a definição da arquitetura.

A validação foi complementada pela implementação parcial da arquitetura por meio de um protótipo de software, cujo o objetivo foi demonstrar sua viabilidade técnica considerando o estágio atual dos produtos e tecnologias encontrados no mercado. 


\section{CONCLUSÃO}

O objetivo geral desta pesquisa é definir uma arquitetura de referência colaborativa para estruturação de informações de transparência pública, à luz dos dados abertos governamentais.

Segundo Wazlawick (2009) os objetivos específicos são subprodutos do objetivo geral, não triviais e verificáveis ao final do trabalho. Desse modo, nos itens a seguir, reproduz-se os objetivos específicos definidos nesta pesquisa e evidenciamse resumidamente os respectivos resultados obtidos que são verificáveis ao longo do trabalho:

- Definir método para levantamento e identificação dos problemas de acesso e disponibilização de dados abertos. Este objetivo específico foi atingido pelo estabelecimento dos critérios de avaliação, a definição das amostras, a realização dos levantamentos de dados, a revisão e comparação da bibliografia relacionada e a análise dos resultados obtidos nos levantamentos. O desenvolvimento e resultados deste objetivo são encontrados no Capítulo 3.

- Construir projeto arquitetural como referência para um sistema de estruturação de dados. Este objetivo específico foi atingido pela revisão da bibliografia relacionada e a definição da arquitetura de referência compreendendo os elementos de software e as relações entre eles, com base na identificação dos requisitos arquiteturais a partir dos problemas de acesso e disponibilização dos dados encontrados na amostra de websites analisados. O desenvolvimento e resultados deste objetivo são encontrados no Capítulo 4.

- Validar os atributos de qualidade da arquitetura pela percepção de utilidade dos potenciais usuários. Este objetivo específico foi atingido pela condução do processo de validação da arquitetura com stakeholders externos ao projeto de definição da arquitetura e sua implementação parcial por meio de um protótipo de software para 
demonstrar sua viabilidade técnica considerando o estágio atual dos produtos e tecnologias encontrados no mercado. $O$ desenvolvimento $\mathrm{e}$ resultados deste objetivo são encontrados no Capítulo 5.

Nas seções seguintes são evidenciadas as contribuições obtidas com esta pesquisa, as dificuldades encontradas no decorrer do trabalho e as considerações que encerram a tese com a visualização de trabalhos futuros percebidos ao longo do desenvolvimento desta pesquisa.

\subsection{Contribuições}

A contribuição principal para a Engenharia de Computação foi a definição da arquitetura por desenvolver um modelo de solução para a problemática de disponibilização de dados, mesmo quando as fontes ainda não se encontram adequadas segundo os princípios de OGD.

No momento atual, tem-se a existência de websites heterogêneos cuja transparência é baseada na divulgação de documentos. As equipes técnicas responsáveis pela transparência na administração pública não conhecem OGD e seus perfis são de publicadores de conteúdo. Já na situação ideal, tem-se a existência de repositórios OGD que catalogam datasets. As equipes técnicas conhecem e implementam OGD e os perfis são de cientistas de dados.

A situação atual e a ideal colocam-se como estágios distintos na evolução para OGD. Esta evolução é estimulada pelo redesenho dos processos de trabalho das instituições públicas, cuja demanda vem da própria sociedade.

Enquanto não há o redesenho dos processos para considerar OGD desde a geração dos dados, há uma oportunidade para estabelecer um estágio intermediário de evolução, onde tanto a administração pública quanto a sociedade possam ser beneficiados. É neste contexto que a arquitetura proposta por esta pesquisa atua, como sendo um modelo de solução propulsor para que a sociedade perceba os benefícios de OGD e as equipes técnicas dos governos promovam mudanças organizacionais nos processos de trabalho. 
Além disso, esta pesquisa também contribuiu com um modelo de processo para construção de uma arquitetura de referência. Esse modelo de processo foi baseado em métodos utilizados pela indústria, que compreendem a construção e validação de arquiteturas.

\subsection{Desafios}

No início desta pesquisa, em 2013, houve o primeiro desafio que foi entender como os dados abertos estavam sendo operados no cenário nacional e internacional. Havia poucas referências na bibliografia sobre o cenário de aplicação de dados abertos governamentais, sobretudo no cenário nacional brasileiro. Mas este desafio acabou se tornando em uma oportunidade e com isso foi possível estabelecer a caracterização dos dados abertos por meio dos levantamentos que compõem este trabalho.

$\mathrm{Na}$ caracterização dos dados abertos dois outros desafios se seguiram. Num primeiro momento, estabelecer o método de levantamento foi desafiador. Não havia qualquer indicativo na bibliografia, principalmente pelo fato da análise necessitar compreender a legislação nacional, que é a LAl, sem esquecer dos princípios de OGD já consolidados. Neste sentido, foi desenvolvido o método especificamente no âmbito desta pesquisa compreendendo os critérios de avaliação e a definição da amostra.

A esse respeito, por conseguinte, no levantamento de dados amplo com amostra de 561 municípios, coletar dados de todos eles também se insere em um dos principais desafios desta pesquisa. Foram necessários oito meses de trabalho intenso somente para a coleta dos dados. Contou-se com a ajuda de alunos bolsistas de iniciação científica do Instituo Federal de Educação, Ciência e Tecnologia de São Paulo - IFSP, os quais atuaram em parte do trabalho. Sentiu-se a necessidade de estabelecer mecanismos rígidos de padronização e controle da coleta de dados, com a exigência de evidências de visitação dos websites para dirimir possíveis dúvidas a respeito dos resultados potencialmente negativos que viriam a ser revelados a respeito da caracterização dos dados abertos no cenário nacional. 
Do ponto de vista da implementação da arquitetura, no início tinha-se em mente o desenvolvimento de um produto totalmente funcional e acabado, além da arquitetura em si. Porém, percebeu-se que o esforço necessário para desenvolver um sistema com esta complexidade por apenas um pesquisador seria incompatível com o tempo disponível para concluir um programa de doutorado. Foi assim que os ensinamentos de Wazlawick (2009, p. 108-109) vieram à tona ao referenciar o trabalho de Chinneck (1988) onde o renomado autor observa que uma tese de doutorado não é sobre uma ferramenta e sim sobre a contribuição ao conhecimento que ela traz. Neste sentido, a contribuição ao conhecimento é viabilizada pela arquitetura. Mesmo assim, este trabalho compreende uma seção no Capítulo 5 que descreve os esforços empregados para desenvolver uma implementação parcial da arquitetura com resultados positivos.

\subsection{Trabalhos futuros}

No decorrer desta pesquisa foram identificados alguns possíveis pontos de melhoria que podem ser desenvolvidos como trabalhos futuros pela extensão do conhecimento aqui gerado. São eles:

- Desenvolver um método automatizado para avaliação dos websites de transparência. Ambos os levantamentos realizados foram conduzidos de forma manual, pela visita a cada website o que refletia um momento no tempo. Pensou-se, então, em uma forma de automatizar este processo e desenvolver mecanismos de acesso e coleta de dados de forma automatizada. Assim, a avaliação poderia ocorrer continuamente e repetidas vezes de modo a reavaliar as inovações empregadas nos websites ao longo do tempo.

- Revisar o método de levantamento e os respectivos critérios de validação para refletir as inovações dos conhecimentos disseminados pela bibliografia nos últimos dois anos que antecederam à conclusão deste trabalho.

- Implementar ou instanciar a arquitetura na íntegra com o uso dos produtos e tecnologias que aceleram seu desenvolvimento. $\mathrm{Na}$ 
implementação, considerar a extensão dos formatos de dados que podem ser estruturados, em adição aos atualmente previstos.

\subsection{Considerações finais}

Este trabalho buscou definir uma arquitetura colaborativa de estruturação para contornar os atuais obstáculos na disponibilização de dados abertos governamentais operada pela maioria dos entes governamentais atuais.

Os resultados esperados para com a arquitetura definida vão ao encontro da necessidade do público interessado em transparência, sobretudo a comunidade de dados abertos que milita para a abertura dos registros públicos. Com a arquitetura, e seu aspecto colaborativo envolvido, será possível implementar sistemas de software que disponibilizarão ferramentas aos usuários para facilmente abrir os dados de qualquer instituição que utilize a internet para disseminar informações de transparência.

A arquitetura aqui definida foi validada por stakeholders externos ao projeto arquitetural. Os validadores reconheceram a importância da arquitetura e a lacuna existente que justifica seu desenvolvimento. O processo de validação também evidenciou potenciais melhorias que poderão ser atendidas em trabalhos futuros. 


\section{REFERÊNCIAS}

ALANI, H. et al. Unlocking the potential of public sector information with semantic web technology. Proceedings of the 6th international the semantic web and 2nd Asian conference on Asian semantic web conference. Anais eletrônicos...: ISWC'07/ASWC'07.Berlin: SPRINGER-VERLAG, 2007. Disponível em: <http://dl.acm.org/citation.cfm?id=1785162.1785215>. Acesso em: 5 set. 2013

ANGELOV, S.; TRIENEKENS, J. J. M.; GREFEN, P. Towards a Method for the Evaluation of Reference Architectures: Experiences from a Case. In: MORRISON, R.; BALASUBRAMANIAM, D.; FALKNER, K. (Eds.). Software Architecture. Lecture Notes in Computer Science. [s.I.] Springer Berlin Heidelberg, 2008. p. 225-240.

ARISTARÁN, M.; TIGAS, M. Introducing Tabula - Features - Source: An OpenNews project. Disponível em: <https://source.opennews.org/enUS/articles/introducing-tabula/>. Acesso em: 2 dez. 2014.

ARMSTRONG, C. L. Providing a clearer view: An examination of transparency on local government websites. Government Information Quarterly, v. 28, n. 1, p. 1116, jan. 2011.

BACHMANN, F. et al. The Architecture Based Design Method. Disponível em: <http://resources.sei.cmu.edu/library/asset-view.cfm?Asset|D=5147>. Acesso em: 5 mar. 2016.

BASS, L.; CLEMENTS, P.; KAZMAN, R. Software Architecture in Practice. 3rd. ed. USA: Addison-Wesley Professional, 2012.

BELL, M. Incremental Software Architecture. [s.I.] John Wiley \& Sons, 2016.

BERNERS-LEE, T. Linked Data. W3C Design Issues. Disponível em: <http://www.w3.org/Designlssues/LinkedData.html>. Acesso em: 13 dez. 2013.

BERNERS-LEE, T. Five-star Open Data. Disponível em: <http://5stardata.info/en/>. Acesso em: 9 abr. 2017.

BERNERS-LEE, T.; HENDLER, J.; LASSILA, O. The Semantic Web: Scientific American. Scientific American, n. 05, 2001.

BERTOT, J. C.; JAEGER, P. T.; GRIMES, J. M. Using ICTs to create a culture of transparency: E-government and social media as openness and anti-corruption tools for societies. Government Information Quarterly, v. 27, n. 3, p. 264-271, 2010.

BIZER, C.; HEATH, T.; BERNERS-LEE, T. Linked Data - The Story So Far: International Journal on Semantic Web and Information Systems, v. 5, n. 3, p. 1-22, 2009.

BOLYCHEVSKY, I. U.S. government's data portal Data.gov relaunched on CKAN | ckan - The open source data portal software. Disponível em: <http://ckan.org/2013/05/23/data-gov-relaunch-on-ckan/>. Acesso em: 2 dez. 2014. 
BONSÓN, E. et al. Local e-government 2.0: Social media and corporate transparency in municipalities. Government Information Quarterly, v. 29, n. 2, p. 123-132, 2012.

BOOCH, G.; RUMBAUGH, J.; JACOBSON, I. UML: Guia do usuário. Rio de Janeiro: Elsevier, 2005.

BOTEIN, B.; CROSS, H. L. The People's Right to Know. Legal Access to Public Records and Proceedings. Harvard Law Review, v. 67, n. 5, p. 920, 1954.

BRASIL. Lei $n^{\circ} 12.527$ de 18 de novembro de 1996. Regula o acesso a informações previsto no inciso XXXIII do art. 5o, no inciso II do § 30 do art. 37 e no $\S 20$ do art. 216 da Constituição Federal; altera a Lei no 8.112, de 11 de dezembro de 1990; revoga a Lei no 11.111, de 5 de maio de 2005, e dispositivos da Lei no 8.159 , de 8 de janeiro de 1991; e dá outras providências. Brasília. 18 nov. 2011.

BRICKLEY, D.; GUHA, R. V. RDF Schema 1.1. Disponível em: <http://www.w3.org/TR/2014/REC-rdf-schema-20140225/>. Acesso em: 30 out. 2016.

BRYANT, S. L.; FORTE, A.; BRUCKMAN, A. Becoming Wikipedian: Transformation of Participation in a Collaborative Online Encyclopedia. Proceedings of the 2005 International ACM SIGGROUP Conference on Supporting Group Work. Anais eletrônicos...: GROUP '05.New York, NY, USA: ACM, 2005Disponível em: <http://doi.acm.org/10.1145/1099203.1099205>. Acesso em: 26 ago. 2016

BUNYAKIATI, P.; VORAVITTAYATHORN, P. Dissemination formats and major statistic data sets of the AEC countries: A survey. Information Science and Service Science and Data Mining (ISSDM), 2012 6th International Conference on New Trends in. Anais... In: INFORMATION SCIENCE AND SERVICE SCIENCE AND DATA MINING (ISSDM), 2012 6TH INTERNATIONAL CONFERENCE ON NEW TRENDS IN. out. 2012

CALDWELL, B. et al. Web Content Accessibility Guidelines (WCAG) 2.0. Disponível em: <http://www.w3.org/TR/WCAG20/>. Acesso em: 13 dez. 2013.

CERVANTES, H.; VELASCO-ELIZONDO, P.; KAZMAN, R. A Principled Way to Use Frameworks in Architecture Design. IEEE Software, v. 30, n. 2, p. 46-53, 2013.

CGI.BR. Manual dos dados abertos: desenvolvedores. São Paulo: Comitê Gestor da Internet no Brasil, 2011a.

CGI.BR. Manual dos dados abertos: governo. São Paulo: Comitê Gestor da Internet no Brasil, 2011b.

CGU. Acesso à Informação Pública: Uma introdução à Lei n 12.527, de 18 de novembro de 2011. Brasília: CGU, 2011.

CGU. Escala Brasil Transparente. Disponível em:

$<$ http://www.cgu.gov.br/assuntos/transparencia-publica/escala-brasiltransparente/escala-brasil-transparente>. Acesso em: 15 jun. 2015. 
CHINNECK, J. W. How to Organize your Thesis. Disponível em:

<http://www.sce.carleton.ca/faculty/chinneck/thesis.html>. Acesso em: 27 nov. 2016.

CLEMENTS, P. et al. Documenting Software Architectures. Views and Beyond. Second ed. [s.l.] Addison-Wesley Professional, 2010.

CLEMENTS, P.; KAZMAN, R.; KLEIN, M. Evaluating software architectures. Methods and case studies. [s.I.] Addison-Wesley Professional, 2001.

COELHO, T. R. et al. Transparência governamental nos estados e grandes municípios brasileiros: uma "dança dos sete véus" incompleta? . In: XXXIX ENANPAD 2015. Belo Horizonte, MG: 2015

COELHO, V.; WAISBICH, L. Mecanismo Independente de Avaliação: Brasil Relatório de Progresso 2011-2013. Disponível em:

$<$ http://www.governoaberto.cgu.gov.br/central-de-

conteudo/documentos/arquivos/irm-relatorio-progresso-brasil-2011-13.pdf>. Acesso em: 29 abr. 2015.

CONRADIE, P.; CHOENNI, S. On the barriers for local government releasing open data. Government Information Quarterly, ICEGOV 2012 Supplement TOWARDS SMARTER GOVERNMENTS: NEW TECHNOLOGIES AND INNOVATION IN THE PUBLIC SECTOR. v. 31, Supplement 1, p. S10-S17, 2014.

CORRÊA, A. S. et al. Transparency and open government data: a wide national assessment of data openness in Brazilian local governments. Transforming Government: People, Process and Policy, v. 11, n. 1, 2017.

CORRÊA, A. S.; CORRÊA, P. L. P.; SILVA, F. S. C. DA. Transparency Portals Versus Open Government Data: An Assessment of Openness in Brazilian Municipalities. Proceedings of the 15th Annual International Conference on Digital Government Research. Anais eletrônicos...: dg.o '14.New York, NY, USA: ACM, 2014. Disponível em: <http://doi.acm.org/10.1145/2612733.2612760>. Acesso em: 10 out. 2014

CORRÊA, A. S.; CORRÊA, P. L. P.; SILVA, F. S. C. DA. A Collaborative-oriented Middleware for Structuring Information to Open Government Data. Proceedings of the 16th Annual International Conference on Digital Government Research. Anais eletrônicos...: dg.o '15.New York, NY, USA: ACM, 2015. Disponível em: <http://doi.acm.org/10.1145/2757401.2757409>. Acesso em: 11 jun. 2015

CRUZ, C. F. et al. Transparency of the municipal public management: a study from the homepages of the large Brazilian municipalities. Revista de Administração Pública, v. 46, n. 1, p. 153-176, 2012.

CUNHA, M. A. V. C. DA et al. Dados abertos nos municípios, estados e governo federal brasileiros. Technical Report. Disponível em:

<http://bibliotecadigital.fgv.br/dspace/handle/10438/16373>. Acesso em: 3 out. 2016.

DASHOFY, E.; MEDVIDOVIC, N.; TAYLOR, R. Software Architecture:

Foundations, Theory, and Practic. USA: John Wiley \& Sons, 2009. 
DAVIES, T.; FRANK, M. "There"s No Such Thing As Raw Data': Exploring the Socio-technical Life of a Government Dataset. Proceedings of the 5th Annual ACM Web Science Conference. Anais eletrônicos...: WebSci '13.New York, NY, USA: ACM, 2013. Disponível em: <http://doi.acm.org/10.1145/2464464.2464472>. Acesso em: 9 dez. 2013

DETLOR, B. et al. Information quality and community municipal portal use.

Government Information Quarterly, v. 30, n. 1, p. 23-32, 2013.

DODDS, L.; NEWMAN, A. Modelo de Maturidade de Dados Abertos. Avaliando a publicação e a utilização de dados abertos. Versão traduzida Português BR. Open Data Institute, , 2015. Disponível em:

$<$ http://ceweb.br/media/docs/publicacoes/13/Guia_Modelo_de_Maturidade_de_Dado s_Abertos.pdf>. Acesso em: 26 ago. 2016

EAVES, D. The Three Laws of Open Government Data. Disponível em: <http://eaves.ca/2009/09/30/three-law-of-open-government-data/>. Acesso em: 27 nov. 2014.

ERMILOV, I.; AUER, S.; STADLER, C. User-driven Semantic Mapping of Tabular Data. Proceedings of the 9th International Conference on Semantic Systems. Anais eletrônicos...: I-SEMANTICS '13.New York, NY, USA: ACM, 2013. Disponível em: <http://doi.acm.org/10.1145/2506182.2506196>. Acesso em: 24 nov. 2014

FLORINI, A. (ED.). The Right to Know: Transparency for an Open World. [s.I.] Columbia University Press, 2007.

FUNDAÇÃO PARA A CIÊNCIA E TECNOLOGIA. AccessMonitor. Validador automático para as WCAG desenvolvido pela Unidade ACESSO da FCT Fundação para a Ciência e a Tecnologia, IP. Disponível em:

<http://www.acessibilidade.gov.pt/accessmonitor/>. Acesso em: 7 jan. 2015.

GALLAGHER, B. P. Using the Architecture Tradeoff Analysis Method to Evaluate a Reference Architecture: A Case Study. Technical Note CMU/SEI2000-TN-007. Software Engineering Institute, Carnegie Mellon University, , jun. 2000. Disponível em: <http://www.sei.cmu.edu/reports/00tn007.pdf>. Acesso em: 22 ago. 2016

GÖBEL, M. et al. A Methodology for Evaluating Algorithms for Table Understanding in PDF Documents. Proceedings of the 2012 ACM Symposium on Document Engineering. Anais eletrônicos...: DocEng '12.New York, NY, USA: ACM, 2012. Disponível em: <http://doi.acm.org/10.1145/2361354.2361365>. Acesso em: 2 dez. 2014

GOVERNO ELETRÔNICO. eMAG - Modelo de Acessibilidade em Governo Eletrônico. Disponível em: <http://emag.governoeletronico.gov.br/>. Acesso em: 18 out. 2016.

GRIMMELIKHUIJSEN, S. et al. The Effect of Transparency on Trust in Government: A Cross-National Comparative Experiment. Public Administration Review, v. 73, n. 4, p. 575-586, 2013. 
HANMER, R. Pattern-Oriented Software Architecture For Dummies. [s.I.] For Dummies, 2013.

HARRINGTON, J. L. Relational Database Design and Implementation. 4. ed. USA: Morgan Kaufmann, 2016.

HELBIG, N. et al. The dynamics of opening government data. Center for Technology in Government.[Online]. Available: http://www. ctg. albany. edu/publications/reports/opendata, 2012.

HENDLER, J. et al. US Government Linked Open Data: Semantic.data.gov. IEEE Intelligent Systems, v. 27, n. 3, p. 25-31, 2012.

HOFMEISTER, C. et al. A general model of software architecture design derived from five industrial approaches. Journal of Systems and Software, v. 80, n. 1, p. 106-126, 2007.

IBGE. Pesquisa de Informações Básicas Municipais. Perfil dos Municípios Brasileiros - 2012. Rio de Janeiro: IBGE, 2013.

IBGE. Pesquisa de Informações Básicas Municipais. Perfil dos Municípios Brasileiros - 2015. 13. ed. Rio de Janeiro: IBGE, 2016.

INESC. Measuring open data's impact of Brazilian national and sub-national budget transparency websites and its impacts on people's rights. Brasília: Nathalie Beghin and Carmela Zigoni, 2014.

INTERNATIONAL ORGANIZATION FOR STANDARDIZATION. ISO 32000-1:2008. Disponível em:

<http://www.iso.org/iso/home/store/catalogue_tc/catalogue_detail.htm?csnumber $=51$ 502>. Acesso em: 2 dez. 2014.

ISOTANI, S.; BITTENCOURT, I. I. Dados abertos conectados. São Paulo: Novatec, 2015.

JETZEK, T.; AVITAL, M.; BJORN-ANDERSEN, N. Data-Driven Innovation through Open Government Data. Journal of theoretical and applied electronic commerce research, v. 9, n. 2, p. 100-120, 2014.

KAZMAN, R.; CERVANTES, H. Designing Software Architectures: A Practical Approach. Boston: Addison-Wesley Professional, 2016.

KONG, X. Y. Arquitetura para Publicação de Dados Abertos em Sistemas de Governo: O Exemplo do SIASG. Dissertação (mestrado)—Rio de Janeiro: UFRJ/COPPE, 2015.

KOSCIANSKI, A.; SOARES, M. DOS S. Qualidade de Software: Aprenda as metodologias e técnicas mais modernas para o desenvolvimento de software.

2. ed. São Paulo: Novatec, 2007. 
LAMBAIS, G. B. R. The Metropolitan Region of Campinas, Brazil: applying the technopolis framework. MPRA Paper. Disponível em: <http://mpra.ub.unimuenchen.de/24347/>. Acesso em: 28 abr. 2014.

LOURENÇO, R. P. et al. Online Transparency for Accountability: One Assessing Model and two Applications. Electronic Journal of e-Government (EJEG), v. 11, n. 2, p. pp279-291, 2013.

MACHADO, A. L.; OLIVEIRA, J. M. P. DE. DIGO: An Open Data Architecture for eGovernment. 2011 IEEE 15th International Enterprise Distributed Object Computing Conference Workshops. Anais... In: 2011 IEEE 15TH INTERNATIONAL ENTERPRISE DISTRIBUTED OBJECT COMPUTING CONFERENCE WORKSHOPS. ago. 2011

MATHEUS, R.; RIBEIRO, M. M.; VAZ, J. C. New Perspectives for Electronic Government in Brazil: The Adoption of Open Government Data in National and Subnational Governments of Brazil. Proceedings of the 6th International Conference on Theory and Practice of Electronic Governance. Anais eletrônicos...: ICEGOV '12.New York, NY, USA: ACM, 2012. Disponível em: <http://doi.acm.org/10.1145/2463728.2463734>. Acesso em: 9 dez. 2013

MEEKER, H. J. The Open Source Alternative: Understanding Risks and Leveraging Opportunities. New Jersey: John Wiley \& Sons, 2008.

MEHTA, P. Introduction to Google Chrome Extensions. In: Creating Google Chrome Extensions. [s.I.] Apress, 2016. p. 1-33.

MENDOZA, G. Q. Open Government in Latin America Limited to Transparency, and Access to Information. Proceedings of the 14th Annual International Conference on Digital Government Research. Anais eletrônicos...: dg.o '13.New York, NY, USA: ACM, 2013. Disponível em:

<http://doi.acm.org/10.1145/2479724.2479767>. Acesso em: 9 dez. 2013

MITRA, T. Practical Software Architecture: Moving from System Context to Deployment. USA: IBM Press, 2015.

MIZUKAMI, P. N. et al. Exceptions and limitations to copyright in Brazil: a call to reform. In: Access to Knowledge in Brazil. New Haven, CT: Information Society Project, 2008. p. 67-122.

OASIS. OASIS Open Data Protocol (OData) TC | OASIS. Disponível em: $<$ https://www.oasis-open.org/committees/tc_home.php?wg_abbrev=odata $>$. Acesso em: 28 abr. 2015.

OBAMA, B. Transparency and Open Government | The White House. Disponível em:

<http://www.whitehouse.gov/the_press_office/TransparencyandOpenGovernment/>. Acesso em: 13 dez. 2013.

OECD. Open Government: Fostering Dialogue with Civil Society. Paris: OECD, $2003 a$. 
OECD. The e-Government Imperative. Paris: OECD Publishing, 2003b.

OGD USP BRAZIL. OGD USP Brazil - Organizations - the Datahub. Disponível em: <https://datahub.io/organization/ogd-usp-brazil>. Acesso em: 9 abr. 2017.

O'HARA, K. Transparency, Open Data and Trust in Government: Shaping the Infosphere. Proceedings of the 3rd Annual ACM Web Science Conference. Anais eletrônicos...: WebSci '12.New York, NY, USA: ACM, 2012. Disponível em: <http://doi.acm.org/10.1145/2380718.2380747>. Acesso em: 9 dez. 2013

OPEN DATA BAROMETER. ODB Global Report. Third Edition. Disponível em: $<$ http://opendatabarometer.org/doc/3rdEdition/ODB-3rdEdition-GlobalReport.pdf>. Acesso em: 18 out. 2016.

OPEN KNOWLEDGE FOUNDATION. Open Data Handbook Documentation, 14 nov. 2012. Disponível em: <http://opendatahandbook.org/>. Acesso em: 18 nov. 2014

OPEN KNOWLEDGE FOUNDATION. CKAN instances around the world | ckan The open source data portal software. Disponível em: $<$ http://ckan.org/instances/\#>. Acesso em: 28 jun. 2016.

OPENGOVDATA. Eight Principles of Open Government Data -

OpenGovData.org. Disponível em: <http://opengovdata.org/>. Acesso em: 27 nov. 2014.

OSTERWALDER, A. Business Model Generation: A Handbook for Visionaries, Game Changers, and Challengers. [s.I.] John Wiley \& Sons, 2010.

PEW RESEARCH CENTER'S INTERNET \& AMERICAN LIFE PROJECT. Government Online. The internet gives citizens new paths to government services and information. Disponível em:

$<$ http://www.pewinternet.org/Reports/2010/Government-Online.aspx>. Acesso em: 18 nov. 2014.

PIRES, M. T. Guia de Dados Abertos. CGI.BR, 2015. Disponível em: $<$ http://ceweb.br/media/docs/publicacoes/13/Guia_Dados_Abertos.pdf>

PRESSMAN, R. S. Engenharia de Software - Uma Abordagem Profissional. 7. ed. Porto Alegre: AMGH, 2011.

REINHARD, N.; GERMANO, E. C. Guia de incentivo ao (re)uso de dados abertos. São Paulo: CGI.BR, 2016.

RELLY, J. E.; SABHARWAL, M. Perceptions of transparency of government policymaking: A cross-national study. Government Information Quarterly, v. 26, n. 1, p. 148-157, 2009.

RIBEIRO, M. M.; MATHEUS, R.; VAZ, J. C. New perspectives for electronic government: the adoption of open government data in brazil. Anais do $8^{\circ}$ CONTECSI. Anais eletrônicos... In: CONTECSI - INTERNATIONAL CONFERENCE ON INFORMATION SYSTEMS AND TECHNOLOGY 
MANAGEMENT. Brasil: 2011. Disponível em:

<http://www.contecsi.fea.usp.br/envio/index.php/contecsi/8contecsi/paper/view/2875/ 1636>. Acesso em: 14 out. 2016

RICHARDS, M. Software Architecture Patterns. USA: O'Reilly Media, 2015.

RICHARDSON, L.; RUBY, S. RESTful Web Services. 1. ed. California, USA:

O’Reilly Media, 2007.

SANGWAN, R. S. Software and Systems Architecture in Action. Boston, MA, USA: Auerbach Publications, 2015.

SANTANA, R. C. G.; RODRIGUES, F. DE A. Acessando dados para visualização de afinidades nas votações entre parlamentares do Senado. Informação \& Sociedade: Estudos, v. 23, n. 1, 2013.

SHADBOLT, N. et al. Linked Open Government Data: Lessons from Data.gov.uk. IEEE Intelligent Systems, v. 27, n. 3, p. 16-24, 2012.

SHADBOLT, N.; O'HARA, K. Linked Data in Government. IEEE Internet Computing, v. 17, n. 4, p. 72-77, 2013.

SOFTWARE PÚBLICO BRASILEIRO. Avaliador e Simulador de Acessibilidade em Sítios (ASES). Disponível em: <https://softwarepublico.gov.br/social/ases>. Acesso em: 17 out. 2016.

SOMMERVILLE, I. Engenharia de Software. 8. ed. São Paulo: Pearson AddisonWesley, 2007.

SOMMERVILLE, I. Software Engineering. 9. ed. [s.I.] Addison Wesley, 2011.

TANENBAUM, A. S.; WETHERALL, D. J. Computer networks. 5. ed. [s.I.] Person, 2011.

TAUBERER, J. Open Government Data: The Book - Second Edition, 2014.

Disponível em: <https://opengovdata.io/>. Acesso em: 18 nov. 2014

THORSBY, J. et al. Understanding the content and features of open data portals in American cities. Government Information Quarterly, 2016.

VELJKOVIĆ, N.; BOGDANOVIĆ-DINIĆ, S.; STOIMENOV, L. Benchmarking open government: An open data perspective. Government Information Quarterly, v. 31, n. 2, p. 278-290, 2014.

VERBLE, J. The NSA and Edward Snowden: Surveillance in the 21st Century. SIGCAS Comput. Soc., v. 44, n. 3, p. 14-20, 2014.

WAZLAWICK, R. S. Metodologia de pesquisa para ciência da computação. Rio de Janeiro: Elsevier, 2009. 
WOJCIK, R. et al. Attribute-Driven Design (ADD), Version 2.0. Disponível em:

$<$ http://resources.sei.cmu.edu/library/asset-view.cfm?AssetID=8147>. Acesso em: 16 jun. 2016.

YAVUZ, N.; WELCH, E. W. Factors affecting openness of local government websites: Examining the differences across planning, finance and police departments.

Government Information Quarterly, v. 31, n. 4, p. 574-583, 2014.

YILDIZ, B.; KAISER, K.; MIKSCH, S. pdf2table: A Method to Extract Table Information from PDF Files. Proceedings of the 2nd Indian International Conference on Artificial Intelligence, Pune, India, December 20-22, 2005. Anais eletrônicos...IICAl, 2005. Disponível em: <http://dblp.unitrier.de/rec/bib/conf/iicai/2005>. Acesso em: 12 jun. 2014

YOUNGBLOOD, N. E.; MACKIEWICZ, J. A usability analysis of municipal government website home pages in Alabama. Government Information Quarterly, Social Media in Government - Selections from the 12th Annual International Conference on Digital Government Research (dg.02011). v. 29, n. 4, p. 582-588, 2012.

ZUIDERWIJK, A.; JANSSEN, M. The Negative Effects of Open Government Data - Investigating the Dark Side of Open Data. Proceedings of the 15th Annual International Conference on Digital Government Research. Anais eletrônicos...: dg.o '14.New York, NY, USA: ACM, 2014. Disponível em: <http://doi.acm.org/10.1145/2612733.2612761>. Acesso em: 25 ago. 2016 


\section{APÊNDICE A - Detalhamento da amostra do levantamento amplo}

Este apêndice fornece o detalhamento da amostra de municípios utilizada no levantamento amplo com 561 websites. A tabela a seguir indica os municípios selecionados, a população residente a data da visita ao respectivo website e a Uniform Resource Locator (URL) ou endereço eletrônico de localização do website.

\begin{tabular}{|c|c|c|c|c|c|}
\hline $\begin{array}{l}\text { Cód. } \\
\text { IBGE }\end{array}$ & UF & Município & População & Data da visita & URL \\
\hline 120010 & $\mathrm{AC}$ & Brasiléia & 21.398 & 25-Apr-14 & http://e-gov.betha.com.br/transparencia/recursos.faces \\
\hline 120030 & $\mathrm{AC}$ & Feijó & 32.412 & 25-Apr-14 & http://www.feijo.ac.gov.br/ \\
\hline 120080 & $A C$ & Porto Acre & 14.880 & 25-Apr-14 & $\begin{array}{l}\text { http://www.portoacre.ac.gov.br/transparencia/sel_exercicio/sel_ex } \\
\text { ercicio.php?glo_codificacao=1156690000345 }\end{array}$ \\
\hline 270100 & $\mathrm{AL}$ & $\begin{array}{l}\text { Boca da } \\
\text { Mata }\end{array}$ & 25.776 & 02-Jun-14 & $\begin{array}{l}\text { http://200.199.148.179/sicap/contabil/transparencia/pesquisar.php } \\
\text { ?Municipio=2\&nome_mun=Boca+da+Mata }\end{array}$ \\
\hline 270260 & $A L$ & $\begin{array}{l}\text { Feira } \\
\text { Grande }\end{array}$ & 21.321 & 28-Apr-14 & [Não possui] \\
\hline 270300 & $\mathrm{AL}$ & Ibateguara & 15.149 & 30-May-14 & [Não possui] \\
\hline 270310 & $\mathrm{AL}$ & Igaci & 25.188 & 02-Jun-14 & [Não possui] \\
\hline 270320 & $\mathrm{AL}$ & Igreja Nova & 23.292 & 30-May-14 & $\begin{array}{l}\text { http://200.199.148.179/sicap/contabil/transparencia/pesquisar.php } \\
\text { ?Municipio=29\&nome_mun=Igreja+Nova }\end{array}$ \\
\hline 270330 & $\mathrm{AL}$ & Inhapi & 17.898 & 02-Jun-14 & http://www.inhapi.al.gov.br/V1/transparencia/pm.php \\
\hline 270450 & $\mathrm{AL}$ & Maragogi & 28.749 & 28-Apr-14 & [Não possui] \\
\hline 270560 & $\mathrm{AL}$ & Novo Lino & 12.060 & 30-May-14 & http://www.novolino.al.gov.br/v1/index.php/contas-publicas \\
\hline 270570 & $\mathrm{AL}$ & $\begin{array}{l}\text { Olho } \\
\text { D'Água das } \\
\text { Flores }\end{array}$ & 20.364 & 28-Apr-14 & http://e-gov.betha.com.br/transparencia/main.faces \\
\hline 270690 & $\mathrm{AL}$ & Pilar & 33.305 & 30-May-14 & [Não possui] \\
\hline 270830 & $\mathrm{AL}$ & $\begin{array}{l}\text { São José } \\
\text { da Laje }\end{array}$ & 22.686 & 25-Apr-14 & http://www.saojosedalaje.al.gov.br/index.php?pg=contabilidade \\
\hline 270840 & $\mathrm{AL}$ & $\begin{array}{l}\text { São José } \\
\text { da Tapera }\end{array}$ & 30.088 & 02-Jun-14 & [Não possui] \\
\hline 270920 & $\mathrm{AL}$ & Traipu & 25.702 & 02-Jun-14 & [Não possui] \\
\hline 270640 & $\mathrm{AL}$ & $\begin{array}{l}\text { Pão de } \\
\text { Açúcar }\end{array}$ & 23.811 & 30-May-14 & $\begin{array}{l}\text { http://e- } \\
\text { gov.betha.com.br/transparencia/recursos.faces?mun=BzzFNKTF } \\
\text { OTk= }\end{array}$ \\
\hline 130010 & AM & Anori & 16.317 & 02-Jun-14 & http://www.transparenciamunicipalam.com.br/anori/ \\
\hline 130063 & AM & Beruri & 15.486 & 30-Apr-14 & http://www.transparenciamunicipalam.com.br/beruri/ \\
\hline 130068 & AM & $\begin{array}{l}\text { Boa Vista } \\
\text { dos Ramos }\end{array}$ & 14.979 & 04-Jun-14 & $\begin{array}{l}\text { http://www.boavistadoramos.am.gov.br/portal1/municipio/noticia.a } \\
\text { sp?ildMun=100113012\&ildNoticia=19376 }\end{array}$ \\
\hline 130070 & AM & $\begin{array}{l}\text { Boca do } \\
\text { Acre }\end{array}$ & 30.632 & 04-Jun-14 & http://www.transparenciamunicipalam.com.br/bocadoacre \\
\hline 130110 & AM & Careiro & 32.734 & 05-Jun-14 & [Não possui] \\
\hline 130115 & AM & $\begin{array}{l}\text { Careiro da } \\
\text { Várzea }\end{array}$ & 23.930 & 04-Jun-14 & http://www.transparenciamunicipalam.com.br/careirodavarzea/ \\
\hline 130140 & AM & Eirunepé & 30.665 & 02-Jun-14 & http://www.transparenciamunicipalam.com.br/eirunepe \\
\hline 130220 & AM & Juruá & 10.802 & 30-Apr-14 & http://www.transparenciamunicipalam.com.br/jurua/ \\
\hline 130250 & AM & $\begin{array}{l}\text { Manacapur } \\
\text { u }\end{array}$ & 85.141 & 30-Apr-14 & $\begin{array}{l}\text { http://e- } \\
\text { gov.betha.com.br/transparencia/recursos.faces?mun=YSeAaMUy } \\
0 \_\mathrm{A}=\end{array}$ \\
\hline 130330 & AM & $\begin{array}{l}\text { Novo } \\
\text { Aripuanã }\end{array}$ & 21.451 & 02-Jun-14 & http://www.transparenciamunicipalam.com.br/novoaripuana/ \\
\hline 130410 & AM & Tapauá & 19.077 & 04-Jun-14 & http://www.transparenciamunicipalam.com.br/tapaua/ \\
\hline 160015 & AP & $\begin{array}{l}\text { Pedra } \\
\text { Branca do } \\
\text { Amaparí }\end{array}$ & 10.772 & 28-Apr-14 & [Não possui] \\
\hline 160060 & $\mathrm{AP}$ & Santana & 101.262 & 28-Apr-14 & http://transparencia.net.br/870 \\
\hline 290130 & BA & Andaraí & 13.960 & 16-Jun-14 & $\begin{array}{l}\text { http://www.andarai.ba.io.org.br/acessoainformacao I| } \\
\text { http://186.235.237.178:5020/portal/ }\end{array}$ \\
\hline 290135 & $\mathrm{BA}$ & Andorinha & 14.414 & 18-Jun-14 & http://ba.portaldatransparencia.com.br/prefeitura/andorinha/ \\
\hline 290225 & $\mathrm{BA}$ & Arataca & 10.392 & 16-Jun-14 & http://www.arataca.ba.gov.br/crbst_9.html \\
\hline 290265 & $\mathrm{BA}$ & Banzaê & 11.814 & 28-Jun-14 & http://ba.portaldatransparencia.com.br/prefeitura/banzae/ \\
\hline
\end{tabular}




\begin{tabular}{|c|c|c|c|c|c|}
\hline 292080 & BA & $\begin{array}{l}\text { Barra da } \\
\text { Estiva }\end{array}$ & 21.187 & 05-Jun-14 & http://transparencia.net.br/896 \\
\hline 290300 & BA & $\begin{array}{l}\text { Barra Do } \\
\text { Mendes }\end{array}$ & 13.987 & 27-Jun-14 & http://transparencia.net.br/168 \\
\hline 290323 & BA & Barro Alto & 13.612 & 28-Jun-14 & http://www.barroalto.ba.io.org.br/transparencia \\
\hline 290370 & $\mathrm{BA}$ & Boa Nova & 15.411 & 18-Jun-14 & http://ba.portaldatransparencia.com.br/prefeitura/boanova/ \\
\hline 290380 & BA & $\begin{array}{l}\text { Boa Vista } \\
\text { do Tupim }\end{array}$ & 17.991 & 11-Jun-14 & http://pmboavistadotupim.ba.ipmbrasil.org.br/Transparencia.aspx \\
\hline 290390 & BA & $\begin{array}{l}\text { Bom Jesus } \\
\text { da Lapa }\end{array}$ & 63.480 & 27-Jun-14 & http://www.bomjesusdalapa.ba.io.org.br/transparencia \\
\hline 290470 & $\mathrm{BA}$ & Buerarema & 18.605 & 09-Jun-14 & https://buerarema-ba.portaltp.com.br/ \\
\hline 290485 & BA & $\begin{array}{l}\text { Cabaceiras } \\
\text { do } \\
\text { Paraguaçu }\end{array}$ & 17.327 & 27-Jun-14 & $\begin{array}{l}\text { http://www.cabaceirasdoparaguacu.ba.gov.br/canal- } \\
\text { transparencia.php }\end{array}$ \\
\hline 290515 & BA & Caetanos & 13.639 & 09-Jun-14 & $\begin{array}{l}\text { http://www.doem.org.br/doem/form.jsp?sys=DOE\&action=openfor } \\
\text { m\&formID=34\&align=0\&mode=-1\&goto=- } \\
\text { 1\&filter=doe_entidades.ent_codigo=514\&scrolling=yes }\end{array}$ \\
\hline 290650 & BA & Candeias & 83.158 & 28-Jun-14 & $\begin{array}{l}\text { http://e-gov.betha.com.br/transparencia/recursos.faces || } \\
\text { http://receitaedespesa.org.br/ba/candeias }\end{array}$ \\
\hline 290670 & BA & \begin{tabular}{|l|} 
Cândido \\
Sales \\
\end{tabular} & 27.918 & 27-Jun-14 & http://www.candidosales.ba.gov.br/transparencia \\
\hline 290682 & BA & Canudos & 15.732 & 11-Jun-14 & http://www.canudos.ba.gov.br/prefeitura/contas.asp \\
\hline 290689 & BA & Caraíbas & 10.222 & 18-Jun-14 & $\begin{array}{l}\text { http://www.caraibas.ba.io.org.br/transparencia \| } \\
\text { http://ba.portaldatransparencia.com.br/prefeitura/caraibas/ || } \\
\text { http://transparencia.net.br/836 }\end{array}$ \\
\hline 290730 & BA & $\begin{array}{l}\text { Castro } \\
\text { Alves }\end{array}$ & 25.408 & 10-Jun-14 & http://castroalves.ba.gov.br/transparencia-publica/ \\
\hline 290770 & BA & Chorrochó & 10.734 & 10-Jun-14 & http://ba.portaldatransparencia.com.br/prefeitura/chorrocho/ \\
\hline 290940 & BA & Cotegipe & 13.636 & 16-Jun-14 & [Acesso indisponível] \\
\hline 290970 & $\mathrm{BA}$ & Cristópolis & 13.280 & 11-Jun-14 & [Acesso indisponível] \\
\hline 291010 & BA & $\begin{array}{l}\text { Dom } \\
\text { Basílio } \\
\end{array}$ & 11.355 & 27-Jun-14 & [Não possui] \\
\hline 291130 & BA & $\begin{array}{l}\text { Gentio do } \\
\text { Ouro }\end{array}$ & 10.662 & 28-Jun-14 & $\begin{array}{l}\text { http://www.gentiodoouro.ba.gov.br/portal1/intro.asp?ildMun=1001 } \\
29138\end{array}$ \\
\hline 291185 & BA & Heliópolis & 13.192 & 30-Jun-14 & http://heliopolis.ba.gov.br/?page id=162 \\
\hline 291240 & $\mathrm{BA}$ & Ibipeba & 17.008 & $30-A p r-14$ & http://www.ibipeba.ba.gov.br/transparencia.html \\
\hline 291340 & $\mathrm{BA}$ & Igaporã & 15.205 & 24-Nov-14 & http://177.38.240.58:5031/portalpmigapora/ \\
\hline 291350 & BA & Iguaí & 25.705 & 10-Jun-14 & http://www.iguai.ba.io.org.br/transparencia \\
\hline 291370 & $\mathrm{BA}$ & Inhambupe & 36.306 & 11-Jun-14 & http://ba.portaldatransparencia.com.br/prefeitura/inhambupe/ \\
\hline 291430 & $\mathrm{BA}$ & Iramaia & 11.990 & 28-Jun-14 & http://iramaia.ba.gov.br/transparencia/ \\
\hline 291520 & BA & Itagibá & 15.193 & 10-Jun-14 & https://pmitagiba.ba.ipmbrasil.org.br/Transparencia.aspx \\
\hline 291580 & BA & Itambé & 23.089 & 16-Jun-14 & http://e-gov.betha.com.br/transparencia/recursos.faces \\
\hline 291720 & BA & Ituaçu & 18.127 & 09-Jun-14 & $\begin{array}{l}\text { http://ba.portaldatransparencia.com.br/prefeitura/ituacu/ } \\
\text { http://transparencia.net.br/1052 }\end{array}$ \\
\hline 291733 & $\mathrm{BA}$ & luiú & 10.900 & 26-Jun-14 & [Acesso indisponível] \\
\hline 291750 & $\mathrm{BA}$ & Jacobina & 79.247 & 30-Apr-14 & [Não possui] \\
\hline 291915 & BA & Lapão & 25.646 & 27-Jun-14 & [Acesso indisponível] \\
\hline 291920 & BA & $\begin{array}{l}\text { Lauro de } \\
\text { Freitas }\end{array}$ & 163.449 & 27-Jun-14 & $\begin{array}{l}\text { http://www.transparenciapublica.com.br/webcasp.php?chave=PM } \\
\text { LFREITAS\&poder=2 }\end{array}$ \\
\hline 292045 & $\mathrm{BA}$ & Mansidão & 12.592 & 16-Jun-14 & [Acesso indisponível] \\
\hline 292100 & BA & $\begin{array}{l}\text { Mata de } \\
\text { São João }\end{array}$ & 40.183 & 18-Jun-14 & $\begin{array}{l}\text { http://www.matadesaojoao.ba.gov.br/prestando- } \\
\text { contas/orcamento.php }\end{array}$ \\
\hline 292240 & $\mathrm{BA}$ & Mutuípe & 21.449 & 5-Aug-14 & http://189.28.166.113:5020/portalpm \\
\hline 292265 & BA & Nordestina & 12.371 & 10-Jun-14 & http://www.nordestina.ba.gov.br/ \\
\hline 292310 & BA & Olindina & 24.943 & 30-Jun-14 & http://www.olindina.ba.io.org.br/transparencia \\
\hline 292380 & BA & Paripiranga & 27.778 & 10-Jun-14 & http://www.paripiranga.ba.io.org.br/acessoainformacao \\
\hline 292530 & BA & $\begin{array}{l}\text { Porto } \\
\text { Seguro }\end{array}$ & 126.929 & 10-Jun-14 & http://www.portoseguro.ba.io.org.br/acessoainformacao \\
\hline 292575 & $B A$ & \begin{tabular}{|l|} 
Presidente \\
Tancredo \\
Neves \\
\end{tabular} & 23.846 & 27-Jun-14 & [Acesso indisponível] \\
\hline 292590 & $\mathrm{BA}$ & Quijingue & 27.228 & 09-Jun-14 & http://www.quijingue.ba.io.org.br/acessoainformacao \\
\hline 292650 & BA & $\begin{array}{l}\text { Ribeira do } \\
\text { Amparo }\end{array}$ & 14.276 & 27-Jun-14 & [Não possui] \\
\hline 292660 & BA & $\begin{array}{l}\text { Ribeira do } \\
\text { Pombal }\end{array}$ & 47.518 & 28-Jun-14 & [Não possui] \\
\hline 292690 & BA & $\begin{array}{l}\text { Rio do } \\
\text { Pires }\end{array}$ & 11.918 & 10-Jun-14 & [Não possui] \\
\hline 292700 & $\mathrm{BA}$ & Rio Real & 37.164 & 11-Jun-14 & http://rioreal.ba.io.org.br/transparencia \\
\hline 292890 & BA & São & 27.659 & 26-Jun-14 & \\
\hline
\end{tabular}




\begin{tabular}{|c|c|c|c|c|c|}
\hline & & Desidério & & & $\begin{array}{l}\text { http://www.ba.portaldatransparencia.com.br/prefeitura/saodesideri } \\
\text { o/ || } \quad \text { http://trpsdesiderio.freireinformatica.com.br:5570/pm/ }\end{array}$ \\
\hline 292910 & BA & São Felipe & 20.305 & 05-Jun-14 & [Acesso indisponível] \\
\hline 293040 & $\mathrm{BA}$ & Serra Preta & 15.401 & 28-Jun-14 & http://ba.portaldatransparencia.com.br/prefeitura/serrapreta/ \\
\hline 293080 & BA & $\begin{array}{l}\text { Souto } \\
\text { Soares }\end{array}$ & 15.899 & 10-Jun-14 & http://www.soutosoares.ba.io.org.br/acessoainformacao \\
\hline 293160 & BA & Teolândia & 14.836 & 27-Jun-14 & [Acesso indisponível] \\
\hline 293190 & BA & Tucano & 52.418 & 5-Aug-14 & http://177.73.217.75:5020/portal// \\
\hline 293230 & $\mathrm{BA}$ & Ubatã & 25.004 & 18-Jun-14 & http://www.ubata.ba.io.org.br/transparencia \\
\hline 293240 & BA & Uibaí & 13.625 & 05-Jun-14 & http://www.gestaocomtransparencia.com.br/Consulta.aspx \\
\hline 293260 & $\mathrm{BA}$ & Urandi & 16.466 & 26-Jun-14 & http://www.urandi.ba.gov.br/v1/contas-publicas/ \\
\hline 293290 & BA & Valença & 88.673 & 05-Jun-14 & http://www.municipioonline.com.br/ba/prefeitura/valenca \\
\hline 293300 & $\mathrm{BA}$ & Valente & 24.560 & 26-Jun-14 & [Acesso indisponível] \\
\hline 293305 & BA & $\begin{array}{l}\text { Várzea da } \\
\text { Roça }\end{array}$ & 13.786 & 09-Jun-14 & http://www.receitaedespesa.org.br/ba/varzeadaroca/ \\
\hline 293360 & BA & $\begin{array}{l}\text { Xique- } \\
\text { Xique }\end{array}$ & 45.536 & 16-Jun-14 & $\begin{array}{l}\text { http://www.transparenciapublica.com.br/webcasp.php?chave=pm } \\
\text { xiquexique\&poder=2 }\end{array}$ \\
\hline 292620 & BA & $\begin{array}{l}\text { Riachão } \\
\text { das Neves }\end{array}$ & 21.937 & 27-Jun-14 & [Acesso indisponível] \\
\hline 230075 & CE & Amontada & 39.232 & 07-Jul-14 & $\begin{array}{l}\text { https://www.governotransparente.com.br/principal. } . x h t m l ? \text { mun=11 } \\
\text { 53\&ent=489 }\end{array}$ \\
\hline 230130 & $\mathrm{CE}$ & Araripe & 20.685 & \begin{tabular}{|c|}
$01-J u l-14$ \\
\end{tabular} & http://www.araripe.tudotransparente.com.br/ \\
\hline 230185 & CE & Banabuiú & 17.315 & 30-Jun-14 & $\begin{array}{l}\text { http://www.governotransparente.com.br/principal. } . x h t m l ? m u n=117 \\
\text { 5\&ent=490 }\end{array}$ \\
\hline 230190 & CE & Barbalha & 55.323 & 30-Jun-14 & http://www.barbalha.ce.gov.br/v2/index.php?ml=transparencia \\
\hline 230200 & CE & Barro & 21.514 & 5-Aug-14 & http://www.gdip.com.br/1181489 \\
\hline 230210 & CE & Baturité & 33.321 & 7-Aug-14 & http://www.baturite.ce.gov.br/transparencia/index.html \\
\hline 230230 & CE & Bela Cruz & 30.878 & 13-May-14 & http://www.governotransparente.com.br/transparencia.xhtml \\
\hline 230250 & CE & Brejo Santo & 45.193 & 11-Jul-14 & [Não possui] \\
\hline 230270 & CE & $\begin{array}{l}\text { Campo } \\
\text { Sales }\end{array}$ & 26.506 & 01-Jul-14 & [Não possui] \\
\hline 230290 & CE & Capistrano & 17.062 & 02-Jul-14 & http://www.gdip.com.br/principal. $x$ html?mun=1199\&ent=490 \\
\hline 230425 & CE & Cruz & 22.479 & 11-Jul-14 & http://www.cruz.ce.gov.br/portal/pt/portaltransparencia.html \\
\hline 230445 & CE & Fortim & 14.817 & 02-Jul-14 & http://www.gdip.com.br/principal.xhtml?mun=1243\&ent=489 \\
\hline 230450 & CE & $\begin{array}{l}\text { Frecheirinh } \\
\text { a }\end{array}$ & 12.991 & 30-Jun-14 & $\begin{array}{l}\text { http://www.sstransparenciamunicipal. net/transparencia/pagament } \\
\text { o.php?entcod=43 }\end{array}$ \\
\hline 230490 & CE & Groaíras & 10.228 & 07-Jul-14 & $\begin{array}{l}\text { http://www.governotransparente.com.br/principal. } x \text { html? } \text { mun=125 } \\
\text { 3\&ent=487 }\end{array}$ \\
\hline 230495 & CE & Guaiúba & 24.091 & 01-Jul-14 & $\begin{array}{l}\text { http://www.sstransparenciamunicipal.net/transparencia/empenho. } \\
\text { php?entcod=61 }\end{array}$ \\
\hline 230500 & CE & $\begin{array}{l}\text { Guaraciba } \\
\text { do Norte }\end{array}$ & 37.775 & 13-May-14 & $\begin{array}{l}\text { http://www.guaraciabadonorte.ce.gov.br/site/index.php/transparen } \\
\text { cia-municipal }\end{array}$ \\
\hline 230526 & CE & Ibaretama & 12.922 & 7-Aug-14 & http://www.governotransparente.com.br/1264483 \\
\hline 230533 & CE & Ibicuitinga & 11.335 & 01-Jul-14 & $\begin{array}{l}\text { http://www.governotransparente.com.br/principal. } . x h t m l ? m u n=126 \\
\text { 7\&ent=490 }\end{array}$ \\
\hline 230560 & CE & $\begin{array}{l}\text { Independên } \\
\text { cia }\end{array}$ & 25.573 & 07-Jul-14 & http://www.independencia.ce.gov.br/transparenciapublicalink \\
\hline 230565 & CE & Ipaporanga & 11.343 & 11-Jul-14 & $\begin{array}{l}\text { http://www.governotransparente.com.br/principal. } . \text { htm } 1 ? \text { mun=127 } \\
6 \& \text { ent=488 }\end{array}$ \\
\hline 230590 & CE & Ipueiras & 37.862 & 7-Aug-14 & http://www.governotransparente.com.br/1281488 \\
\hline 230655 & CE & Itarema & 37.471 & 6-Aug-14 & http://www.governotransparente.com.br/1295489 \\
\hline 230740 & $\mathrm{CE}$ & Jucás & 23.807 & 6-Aug-14 & http://www.gdip.com.br/1313490 \\
\hline 230870 & CE & $\begin{array}{l}\text { Morada } \\
\text { Nova }\end{array}$ & 62.065 & 13-May-14 & $\begin{array}{l}\text { http://www.gdip.com.br/transparencia.xhtml;jsessionid=ifGi5Fpjc8 } \\
\text { xR5Vk-ke-yNrIT.undefined }\end{array}$ \\
\hline 230930 & CE & $\begin{array}{l}\text { Nova } \\
\text { Russas }\end{array}$ & 30.965 & 30-Jun-14 & http://www.governotransparente.com.br/principal.xhtml \\
\hline 230940 & CE & $\begin{array}{l}\text { Novo } \\
\text { Oriente }\end{array}$ & 27.453 & 07-Jul-14 & $\begin{array}{l}\text { http://www.governotransparente.com.br/principal } . x h t m l ? m u n=135 \\
\text { 5\&ent=488 }\end{array}$ \\
\hline 231100 & CE & Poranga & 12.001 & 7-Aug-14 & $\begin{array}{l}\text { http://www.tcm.ce.gov.br/transparencia/index.php/municipios/sho } \\
\text { w/mun/139/versao/2012 }\end{array}$ \\
\hline 231150 & CE & Quixeré & 19.412 & 01-Jul-14 & http://www.tcm.ce.gov.br/transparencia/index.php/municipios/sho \\
\hline
\end{tabular}




\begin{tabular}{|c|c|c|c|c|c|}
\hline & & & & & w/mun/147/versao/2014 \\
\hline 231360 & $\mathrm{CE}$ & Ubajara & 31.787 & 02-Jul-14 & http://www.ubajara.ce.gov.br/index.php/transparencia-municipal \\
\hline 231390 & CE & Uruoca & 12.883 & 11-Jul-14 & http://www.uruoca.ce.gov.br/?id=21 \\
\hline 530010 & DF & Brasília & 2.570 .260 & 13-May-14 & http://www.transparencia.df.gov.br/Pages/inicio.aspx \\
\hline 320016 & ES & $\begin{array}{l}\text { Água Doce } \\
\text { do Norte }\end{array}$ & 11.771 & 13-May-14 & [Não possui] \\
\hline 320090 & ES & $\begin{array}{l}\text { Barra de } \\
\text { São } \\
\text { Francisco }\end{array}$ & 40.649 & 11-Aug-14 & https://barradesaofrancisco-es.portaltp.com.br/ \\
\hline 320100 & ES & $\begin{array}{l}\text { Boa } \\
\text { Esperança }\end{array}$ & 14.199 & 11-Aug-14 & https://boaesperanca-es.portaltp.com.br/ \\
\hline 320190 & ES & $\begin{array}{l}\text { Domingos } \\
\text { Martins }\end{array}$ & 31.847 & 8-Aug-14 & https://domingosmartins-es.portaltp.com.br/ \\
\hline 320210 & ES & $\begin{array}{l}\text { Ecoporang } \\
\text { a }\end{array}$ & 23.212 & 11-Aug-14 & $\begin{array}{l}\text { http://wilburwright.el.com.br/pm_es_ecoporanga/transparencia/ind } \\
\text { ex.php }\end{array}$ \\
\hline 320240 & ES & Guarapari & 105.286 & 8-Aug-14 & [Acesso indisponível] \\
\hline 320270 & ES & Itaguaçu & 12.134 & 11-Aug-14 & https://itaguacu-es.portaltp.com.br/ \\
\hline 320320 & ES & Linhares & 141.306 & 16-May-14 & https://linhares-es.portaltp.com.br/ \\
\hline 320460 & ES & $\begin{array}{l}\text { Santa } \\
\text { Teresa }\end{array}$ & 21.823 & 8-Aug-14 & https://santateresa-es.portaltp.com.br/ \\
\hline 320480 & ES & $\begin{array}{l}\text { São José } \\
\text { do Calçado }\end{array}$ & 10.408 & 8-Aug-14 & http://prefeitura.pmsjc.es.gov.br/portal/ \\
\hline 320500 & ES & Serra & 409.267 & 8-Aug-14 & http://www.serra.es.gov.br/portal_da_transparencia/ \\
\hline 320506 & ES & $\begin{array}{l}\text { Venda } \\
\text { Nova do } \\
\text { Imigrante }\end{array}$ & 20.447 & 16-May-14 & https://vendanovadoimigrante-es.portaltp.com.br/ \\
\hline 520010 & GO & Abadiânia & 15.757 & 12-Aug-14 & http://www.abadiania.go.gov.br/\#!portal-transparencia/cv2a \\
\hline 520030 & GO & Alexânia & 23.814 & 19-May-14 & http://www.alexania.go.gov.br/transparencia_alexania/ \\
\hline 520440 & $\mathrm{GO}$ & Caiapônia & 16.757 & 19-May-14 & http://caiaponia.megasofttransparencia.com.br/index.jsf \\
\hline 520549 & GO & $\begin{array}{l}\text { Cidade } \\
\text { Ocidental }\end{array}$ & 55.915 & 12-Aug-14 & $\begin{array}{l}\text { http://177.15.73.50:8080/servicosonline/portaldatransparencia.ht } \\
\mathrm{ml \#}\end{array}$ \\
\hline 520620 & GO & Cristalina & 46.580 & 13-Aug-14 & http://www.cristalina.go.gov.br/site/portal_transparencia.php \\
\hline 520640 & GO & Crixás & 15.760 & 13-Aug-14 & https://app.centi.com.br/crixas/portalcidadao/ \\
\hline 520840 & GO & Goianápolis & 10.695 & $13-A u g-14$ & http://goianapolis.megasofttransparencia.com.br/index.jsf \\
\hline 520860 & GO & Goianésia & 59.549 & $11-$ Aug-14 & http://goianesia.web1021.kinghost.net/portal-da-transparencia \\
\hline 520910 & GO & Goiatuba & 32.492 & 13-Aug-14 & http://187.52.105.154/servicosonline/portaldatransparencia.html\# \\
\hline 520970 & $\mathrm{GO}$ & Hidrolândia & 17.398 & 12-Aug-14 & http://200.193.231.11:8085/transparencia/index.jsf \\
\hline 521040 & GO & Itaberaí & 35.371 & 12-Aug-14 & $\begin{array}{l}\text { http://itaberai.megasofttransparencia.com.br/index.jsf \| } \\
\text { http://www.itaberai.go.gov.br/index.php/component/content/article } \\
\text { ?id=147 }\end{array}$ \\
\hline 521120 & GO & Itapuranga & 26.125 & 12-Aug-14 & http://itapuranga.megasofttransparencia.com.br/index.jsf \\
\hline 521190 & GO & Jataí & 88.006 & $12-A u g-14$ & http://transparencia.jatai.go.gov.br/transparencia/index.jsf \\
\hline 521310 & GO & Mineiros & 52.935 & 11-Aug-14 & $\begin{array}{l}\text { http://www.mineiros.go.gov.br/mineiros/index.php\#portal- } \\
\text { transparencia.php }\end{array}$ \\
\hline 521730 & GO & Pirenópolis & 23.006 & 19-May-14 & http://www.pirenopolis.go.gov.br/transparencia/ \\
\hline 521880 & GO & Rio Verde & 176.424 & 12-Aug-14 & http://www.rioverdegoias.com.br/transparencia/ \\
\hline 522010 & GO & $\begin{array}{l}\text { São Luís } \\
\text { de Montes } \\
\text { Belos }\end{array}$ & 30.034 & 11-Aug-14 & http://sImb.bsit-br.com.br/transparencia/index.jsf \\
\hline 210047 & MA & $\begin{array}{l}\text { Alto Alegre } \\
\text { do Pindaré }\end{array}$ & 31.057 & 19-Aug-14 & http://www.altoalegredopindare.ma.gov.br/?page_id=5218 \\
\hline 210050 & MA & $\begin{array}{l}\text { Alto } \\
\text { Parnaíba }\end{array}$ & 10.766 & 19-May-14 & http://altoparnaiba.ma.gov.br/transparencia/ \\
\hline 210140 & MA & Balsas & 83.528 & 18-Aug-14 & http://177.136.111.11/scpiweb_pmbalsas/ \\
\hline 210200 & MA & $\begin{array}{l}\text { Bom } \\
\text { Jardim }\end{array}$ & 39.049 & 15-Aug-14 & [Acesso indisponível] \\
\hline 210280 & MA & Carolina & 23.959 & 19-Aug-14 & $\begin{array}{l}\text { http://www.fenix.com.br/pdtr/chamarelatorio.php?uf=ma\&id=6598 } \\
0\end{array}$ \\
\hline 210310 & MA & Cedral & 10.297 & 14-Aug-14 & http://cedral.ma.gov.br/transparencia/ \\
\hline 210330 & MA & Codó & 118.038 & 15-Aug-14 & [Não possui] \\
\hline 210360 & MA & Coroatá & 61.725 & $15-$ Aug-14 & http://186.232.111.58/SCPIWEB_PMCOROATA/ \\
\hline 210375 & MA & Davinópolis & 12.579 & 18-Aug-14 & $\begin{array}{l}\text { http://www.prefeituradavinopolis.com.br/novo_site/portaltranspare } \\
\text { ncia/ }\end{array}$ \\
\hline 210409 & MA & $\begin{array}{l}\text { Formosa } \\
\text { da Serra } \\
\text { Negra }\end{array}$ & 17.757 & 14-Aug-14 & [Não possui] \\
\hline 210430 & MA & $\begin{array}{l}\text { Godofredo } \\
\text { Viana }\end{array}$ & 10.635 & 19-May-14 & http://godofredoviana.ma.gov.br/transparencia/ \\
\hline 210450 & MA & Governador & 10.205 & 15-Aug-14 & [Não possui] \\
\hline
\end{tabular}




\begin{tabular}{|c|c|c|c|c|c|}
\hline & & Archer & & & \\
\hline 210520 & MA & $\begin{array}{l}\text { Igarapé } \\
\text { Grande } \\
\end{array}$ & 11.041 & 15-Aug-14 & http://www.igarapegrande.ma.gov.br/site/transparencia.html \\
\hline 210542 & MA & $\begin{array}{l}\text { Itinga do } \\
\text { Maranhão }\end{array}$ & 24.863 & 15-Aug-14 & [Não possui] \\
\hline 210570 & MA & $\begin{array}{l}\text { Lago da } \\
\text { Pedra }\end{array}$ & 46.083 & 14-Aug-14 & http://www.gdip.com.br/2238489 \\
\hline 210610 & MA & Loreto & 11.390 & 15-Aug-14 & [Não possui] \\
\hline 210630 & MA & $\begin{array}{l}\text { Magalhães } \\
\text { de Almeida }\end{array}$ & 17.587 & 19-Aug-14 & $\begin{array}{l}\text { http://magalhaesdealmeida.ma.gov.br/?page=Transparencia\&tipo } \\
=-1\end{array}$ \\
\hline 210640 & MA & Mata Roma & 15.150 & 15-Aug-14 & http://mataroma.ma.gov.br/transparencia/ \\
\hline 210663 & MA & $\begin{array}{l}\text { Matões do } \\
\text { Norte }\end{array}$ & 13.794 & 14-Aug-14 & http://www.governotransparente.com.br/2267490 \\
\hline 210670 & MA & Mirador & 20.452 & 19-Aug-14 & http://www.mirador.ma.gov.br/publishing-files \\
\hline 210680 & MA & Mirinzal & 14.280 & 19-May-14 & [Não possui] \\
\hline 210720 & MA & $\begin{array}{l}\text { Nina } \\
\text { Rodrigues } \\
\end{array}$ & 12.464 & 18-Aug-14 & http://ninarodrigues.ma.gov.br/transparencia/menu/menu.php \\
\hline 210870 & MA & Pio XII & 22.016 & 18-Aug-14 & http://www.prefeituradepioxii.com.br/index.php/transparencia.html \\
\hline 210880 & MA & Pirapemas & 17.381 & 18-Aug-14 & [Não possui] \\
\hline 210920 & MA & $\begin{array}{l}\text { Presidente } \\
\text { Juscelino }\end{array}$ & 11.541 & 15-Aug-14 & [Não possui] \\
\hline 211000 & MA & Santa Luzia & 74.043 & 14-Aug-14 & http://www.santaluzia.ma.gov.br/?page_id=1196 \\
\hline 211003 & MA & $\begin{array}{l}\text { Santa Luzia } \\
\text { do Paruá }\end{array}$ & 22.644 & 18-Aug-14 & http://www.governotransparente.com.br/2353490 \\
\hline 211023 & MA & $\begin{array}{l}\text { Santana do } \\
\text { Maranhão }\end{array}$ & 11.661 & 18-Aug-14 & http://santanadomaranhao.ma.gov.br/contaspublicas \\
\hline 211070 & MA & \begin{tabular}{|l|} 
São \\
Domingos \\
do \\
Maranhão \\
\end{tabular} & 33.607 & 14-Aug-14 & $\begin{array}{l}\text { http://www.saodomingosdomaranhao.ma.gov.br/?page=Transpar } \\
\text { encia\&tipo=-1 }\end{array}$ \\
\hline 211105 & MA & $\begin{array}{l}\text { São João } \\
\text { do Paraíso }\end{array}$ & 10.814 & 18-Aug-14 & [Não possui] \\
\hline 211170 & MA & \begin{tabular}{|l|} 
São \\
Vicente \\
Ferrer \\
\end{tabular} & 20.863 & 18-Aug-14 & [Não possui] \\
\hline 211260 & MA & $\begin{array}{l}\text { Urbano } \\
\text { Santos }\end{array}$ & 24.573 & 15-Aug-14 & $\begin{array}{l}\text { http://www.urbanosantos.ma.gov.br/?page=Transparencia\&tipo=- } \\
1\end{array}$ \\
\hline 210860 & MA & Pinheiro & 78.162 & 18-Aug-14 & http://189.17.66.163/scpiweb_pinheiro/ \\
\hline 310170 & MG & Almenara & 38.775 & 26-Aug-14 & https://almenara-mg.portaltp.com.br/ \\
\hline 310260 & MG & Andradas & 37.270 & 27-Aug-14 & http://www.andradas.mg.gov.br/portalcidadao.php \\
\hline 310450 & MG & Arinos & 17.674 & 2-Sep-14 & http://www.arinos.mg.gov.br/transparencia.html \\
\hline 310560 & $\mathrm{MG}$ & Barbacena & 126.284 & 3-Sep-14 & http://www.barbacena.mg.gov.br/transparencia.php \\
\hline 310620 & $M G$ & $\begin{array}{l}\text { Belo } \\
\text { Horizonte }\end{array}$ & 2.375 .151 & 2-Sep-14 & $\begin{array}{l}\text { http://portalpbh.pbh.gov.br/pbh/ecp/comunidade.do?app=acessoi } \\
\text { nformacao }\end{array}$ \\
\hline 310650 & MG & Berilo & 12.300 & 20-May-14 & $\begin{array}{l}\text { http://cidadesmg.com.br/hlh_pt_web/faces/portalDaTransparencia } \\
\text {.xhtml?Param=Berilo }\end{array}$ \\
\hline 310670 & MG & Betim & 378.089 & 28-Aug-14 & http://www.betim.mg.gov.br/transparencia/ \\
\hline 310900 & MG & $\begin{array}{l}\text { Brumadinh } \\
\text { o }\end{array}$ & 33.973 & 28-Aug-14 & http://www.brumadinho.mg.gov.br/portal-da-transparencia \\
\hline 310910 & $M G$ & \begin{tabular}{|l|} 
Bueno \\
Brandão \\
\end{tabular} & 10.892 & 26-Aug-14 & $\begin{array}{l}\text { http://buenobrandao.mg.gov.br/novosite/portal-da-transparencia- } \\
2 /\end{array}$ \\
\hline 310970 & MG & $\begin{array}{l}\text { Cachoeira } \\
\text { de Minas }\end{array}$ & 11.034 & 2-Sep-14 & http://www.cachoeirademinas.mg.gov.br/acesso-a-informacao/ \\
\hline 311070 & MG & $\begin{array}{l}\text { Cambuquir } \\
\text { a }\end{array}$ & 12.602 & 3-Sep-14 & http://mg.transparencia.gov.br/Cambuquira \\
\hline 311120 & MG & $\begin{array}{l}\text { Campo } \\
\text { Belo }\end{array}$ & 51.544 & 24-Nov-14 & http://www.campobelo.mg.gov.br/index.php/portal-transparencia \\
\hline 311270 & $M G$ & $\begin{array}{l}\text { Capitão } \\
\text { Enéas }\end{array}$ & 14.206 & 24-Nov-14 & http://transparencia.memory.com.br/home \\
\hline 311410 & MG & $\begin{array}{l}\text { Carmo de } \\
\text { Minas }\end{array}$ & 13.750 & 3-Sep-14 & [Não possui] \\
\hline 311800 & MG & Congonhas & 48.519 & 29-Aug-14 & http://portaltransparencia.congonhas.mg.gov.br/ \\
\hline 312230 & $\mathrm{MG}$ & Divinópolis & 213.016 & 5 -Sep-14 & http://www.divinopolis.mg.gov.br/portal/informacao/acesso.php \\
\hline 312320 & MG & $\begin{array}{l}\text { Dores do } \\
\text { Indaiá }\end{array}$ & 13.778 & 3-Sep-14 & [Acesso indisponível] \\
\hline 312410 & MG & Esmeraldas & 60.271 & 1-Sep-14 & [Não possui] \\
\hline 312450 & $M G$ & Estiva & 10.845 & 26-Aug-14 & $\begin{array}{l}\text { http://sif.netgov.com.br/sif/relatorios.php? municipio=2546\&cod_m } \\
\text { unicipio=3124500\&entidade_selecionada=906_2\&tipo_seleciona }\end{array}$ \\
\hline
\end{tabular}




\begin{tabular}{|c|c|c|c|c|c|}
\hline & & & & & $\mathrm{do}=\mathrm{LC} 131 \&$ exercicio_selecionado $=2014$ \\
\hline 312610 & MG & Formiga & 65.128 & 1-Sep-14 & http://www.formiga.mg.gov.br/?pg=18 \\
\hline 312650 & MG & $\begin{array}{l}\text { Francisco } \\
\text { Badaró }\end{array}$ & 10.248 & 3-Sep-14 & [Acesso indisponível] \\
\hline 312870 & MG & Guaxupé & 49.430 & 8-Sep-14 & http://www.guaxupe.mg.gov.br:8080/portalcidadao \\
\hline 313115 & MG & Ipaba & 16.708 & 1-Sep-14 & http://sif.netgov.com.br/sif/relatorios.php?municipio=2627 \\
\hline 313210 & MG & Itacarambi & 17.720 & $27-$ Aug-14 & [Não possui] \\
\hline 313220 & MG & Itaguara & 12.372 & $29-A u g-14$ & [Não possui] \\
\hline 313250 & MG & $\begin{array}{l}\text { Itamarandib } \\
\text { a }\end{array}$ & 32.175 & 27-Aug-14 & https://itamarandiba-mg.portaltp.com.br/ \\
\hline 313270 & MG & Itambacuri & 22.809 & 26-Aug-14 & https://itambacuri-mg.portaltp.com.br/ \\
\hline 313320 & MG & Itanhomi & 11.856 & 3-Sep-14 & [Não possui] \\
\hline 313330 & MG & Itaobim & 21.001 & $28-A u g-14$ & http://186.202.136.73:8080/transparencia/?entidade $=037702$ \\
\hline 313380 & MG & Itaúna & 85.463 & 28 -Aug-14 & http://189.76.236.131/pronimtb/index.asp \\
\hline 313400 & MG & Itinga & 14.407 & 27-Aug-14 & [Não possui] \\
\hline 313420 & MG & Ituiutaba & 97.171 & 27-Aug-14 & [Não possui] \\
\hline 313550 & MG & Jequeri & 12.848 & 1-Sep-14 & $\begin{array}{l}\text { http://minastransparente.tce.mg.gov.br/index.asp?codMunicipio=3 } \\
135506\end{array}$ \\
\hline 313650 & MG & Jordânia & 10.324 & 8-Sep-14 & https://jordania-mg.portaltp.com.br/ \\
\hline 314080 & MG & $\begin{array}{l}\text { Matias } \\
\text { Barbosa }\end{array}$ & 13.435 & 27-Aug-14 & http://publicacao.pm-mbarbosa.siplanweb.com.br/ \\
\hline 314090 & MG & Matipó & 17.639 & 29-Aug-14 & $\begin{array}{l}\text { http://www.sif.netgov.com.br/sif/relatorios.php?operacao=entidad } \\
\text { e_selecionado }\end{array}$ \\
\hline 314330 & MG & $\begin{array}{l}\text { Montes } \\
\text { Claros }\end{array}$ & 361.915 & 20-May-14 & http://www.montesclaros.mg.gov.br/transparencia/index.htm \\
\hline 314400 & $\mathrm{MG}$ & Mutum & 26.661 & \begin{tabular}{|l|l|} 
8-Sep-14 \\
\end{tabular} & http://www.mutum.mg.gov.br/index.php/portal-de-transparencia \\
\hline 314460 & MG & $\begin{array}{l}\text { Nepomuce } \\
\text { no }\end{array}$ & 25.733 & 28-Aug-14 & $\begin{array}{l}\text { http://www.nepomuceno.mg.gov.br/index.php?option=com_wrapp } \\
\text { er\&view=wrapper\&ltemid=105 }\end{array}$ \\
\hline 314470 & $\mathrm{MG}$ & Nova Era & 17.528 & 26 -Aug-14 & http://portaltransparencia.novaera.mg.gov.br/ \\
\hline 314510 & MG & $\begin{array}{l}\text { Nova } \\
\text { Resende }\end{array}$ & 15.374 & 3-Sep-14 & $\begin{array}{l}\text { http://www.novaresende.mg.gov.br/portal\%20da\%20transp.\%20p } \\
\text { ref/pricipal\%20portal\%20da\%20transparencia.htm }\end{array}$ \\
\hline 314530 & MG & $\begin{array}{l}\text { Novo } \\
\text { Cruzeiro }\end{array}$ & 30.725 & 2-Sep-14 & http://jmsbhz.com.br/PortalTransparencia/?CodEntidade=3 \\
\hline 314710 & MG & $\begin{array}{l}\text { Pará de } \\
\text { Minas }\end{array}$ & 84.215 & 3-Sep-14 & $\begin{array}{l}\text { http://www.sif.netgov.com.br/sif/relatorios.php?municipio=2823\&e } \\
\text { ntidade_selecionada=1049_2\&tipo_selecionado=HTCU\&exercicio } \\
\text { _selecionado=2013\&sem_voltar=1 }\end{array}$ \\
\hline 314720 & MG & Paraguaçu & 20.245 & 1-Sep-14 & $\begin{array}{l}\text { http://e- } \\
\text { gov.betha.com.br/transparencia/recursos.faces?mun=GSJbAPBc } \\
7 \mathrm{Hw}=\end{array}$ \\
\hline 314870 & MG & Pedra Azul & 23.839 & 26-Aug-14 & https://pedraazul-mg.portaltp.com.br/ \\
\hline 315120 & MG & Pirapora & 53.368 & 5-Sep-14 & http://jmsbhz.com.br/PortalTransparencia/?CodEntidade=1 \\
\hline 315150 & MG & Piumhi & 31.883 & 26-Aug-14 & http://transparencia.memory.com.br/home \\
\hline 315340 & MG & $\begin{array}{l}\text { Presidente } \\
\text { Olegário }\end{array}$ & 18.577 & 9-Dec-14 & http://transparencia.memory.com.br/home \\
\hline 315410 & $\mathrm{MG}$ & Recreio & 10.299 & 5-Sep-14 & [Não possui] \\
\hline 315430 & MG & Resplendor & 17.089 & 2-Sep-14 & $\begin{array}{l}\text { http://www.adpmnet.com.br/index.php?option=com_contpubl\&idor } \\
\text { g=483\&tpform }=1\end{array}$ \\
\hline 315460 & MG & $\begin{array}{l}\text { Ribeirão } \\
\text { das Neves }\end{array}$ & 296.317 & 8-Sep-14 & $\begin{array}{l}\text { https://www.ribeiraodasneves.mg.gov.br/index.php/portal- } \\
\text { transparencia }\end{array}$ \\
\hline 315490 & MG & Rio Casca & 14.201 & 27-Aug-14 & $\begin{array}{l}\text { http://e- } \\
\text { gov.betha.com.br/transparencia/recursos.faces?mun=QXSmkxYr } \\
\text { dN5IUyETX-8tYboacwTogfr1 }\end{array}$ \\
\hline 315720 & MG & $\begin{array}{l}\text { Santa } \\
\text { Bárbara }\end{array}$ & 27.876 & 2-Sep-14 & http://www.sif.netgov.com.br/sif/relatorios.php?municipio=1 \\
\hline 316180 & MG & $\begin{array}{l}\text { São } \\
\text { Gonçalo do } \\
\text { Pará }\end{array}$ & 10.398 & 5-Sep-14 & http://www.saogoncalodopara.mg.gov.br/arquivo/transparencia \\
\hline 316200 & MG & $\begin{array}{l}\text { São } \\
\text { Gonçalo do } \\
\text { Sapucaí }\end{array}$ & 23.906 & 28-Aug-14 & [Não possui] \\
\hline 316210 & MG & $\begin{array}{l}\text { São } \\
\text { Gotardo }\end{array}$ & 31.819 & 2-Aug-14 & http://177.69.10.204/transparencia.php \\
\hline 316240 & MG & $\begin{array}{l}\text { São João } \\
\text { da Ponte }\end{array}$ & 25.358 & 20-May-14 & [Não possui] \\
\hline 316245 & MG & $\begin{array}{l}\text { São João } \\
\text { das } \\
\text { Missões }\end{array}$ & 11.715 & 8-Sep-14 & [Não possui] \\
\hline
\end{tabular}




\begin{tabular}{|c|c|c|c|c|c|}
\hline 316470 & MG & $\begin{array}{l}\text { São } \\
\text { Sebastião } \\
\text { do Paraíso }\end{array}$ & 64.980 & 27-Aug-14 & http://www.ssparaiso.mg.gov.br/ \\
\hline 316500 & MG & São Tiago & 10.561 & 27-Aug-14 & http://ptn.saotiago.mg.gov.br/ \\
\hline 316680 & MG & $\begin{array}{l}\text { Serra do } \\
\text { Salitre }\end{array}$ & 10.549 & 28-Aug-14 & http://200.202.222.225:1000/portaltransparencia/ \\
\hline 316940 & MG & $\begin{array}{l}\text { Três } \\
\text { Pontas }\end{array}$ & 53.860 & 8-Sep-14 & http://portaltransparencia.trespontas.mg.gov.br/ \\
\hline 317052 & MG & Urucuia & 13.604 & 29-Aug-14 & http://www.urucuia.mg.gov.br/transparencia \\
\hline 317160 & MG & $\begin{array}{l}\text { Virgem da } \\
\text { Lapa }\end{array}$ & 13.619 & 29-Aug-14 & http://virgemdalapa.mg.gov.br/portal-da-transparencia/ \\
\hline 312160 & MG & Diamantina & 45.880 & 9-Dec-14 & http://transparencia.mg.gov.br/municipios/diamantina \\
\hline 500070 & MS & Anastácio & 23.835 & 20-May-14 & http://www.anastacio.ms.gov.br/transparencia/ \\
\hline 500100 & MS & $\begin{array}{l}\text { Aparecida } \\
\text { do } \\
\text { Taboado }\end{array}$ & 22.320 & 25-Aug-14 & http://e-gov.betha.com.br/transparencia/recursos.faces \\
\hline 500110 & MS & $\begin{array}{l}\text { Aquidauan } \\
\text { a }\end{array}$ & 45.614 & 22-Aug-14 & $\begin{array}{l}\text { http://e-gov.betha.com.br/transparencia/recursos.faces?mun=tR- } \\
\text { qJvZ6sQY= }\end{array}$ \\
\hline 500460 & MS & Itaquiraí & 18.614 & 25-Aug-14 & $\begin{array}{l}\text { http://e- } \\
\text { gov.betha.com.br/transparencia/recursos.faces?mun=QKBgJkx3 } \\
\text { Atw= }\end{array}$ \\
\hline 500500 & MS & Jardim & 24.346 & 24-Nov-14 & http://187.6.253.220:8081/transparencia/publico/index.xhtml \\
\hline 500570 & MS & Naviraí & 46.424 & 25-Aug-14 & http://187.6.10.178/pronimtb/ \\
\hline 500580 & MS & Nioaque & 14.391 & 24-Nov-14 & http://www.nioaque.ms.gov.br/ \\
\hline 500690 & MS & \begin{tabular}{|l|} 
Porto \\
Murtinho \\
\end{tabular} & 15.375 & 25-Aug-14 & http://e-gov.betha.com.br/transparencia/recursos.faces \\
\hline 500740 & MS & \begin{tabular}{|l|} 
Rio Verde \\
de Mato \\
Grosso \\
\end{tabular} & 18.890 & 25-Aug-14 & $\begin{array}{l}\text { http://e- } \\
\text { gov.betha.com.br/transparencia/recursos.faces?mun=1V1CqHrgZ } \\
6 \mathrm{~s}=\end{array}$ \\
\hline 500795 & MS & Tacuru & 10.215 & 24-Nov-14 & $\begin{array}{l}\text { http://tacuru.prefeitura.ms.etransparencia.com.br/portal/transpare } \\
\text { ncia.aspx }\end{array}$ \\
\hline 510050 & MT & \begin{tabular}{|l|} 
Alto \\
Paraguai \\
\end{tabular} & 10.066 & 20-Aug-14 & http://www.altoparaguai.mt.gov.br/portal-da-transparencia/ \\
\hline 510260 & MT & $\begin{array}{l}\text { Campinápo } \\
\text { lis }\end{array}$ & 14.305 & 22-Aug-14 & http://campinapolis-mt.cloudapp.net/ \\
\hline 510267 & MT & \begin{tabular}{|l|} 
Campo \\
Verde
\end{tabular} & 31.589 & 21-Aug-14 & http://portal.campoverde.mt.gov.br:10080/portaltransparencia/ \\
\hline 510330 & MT & Comodoro & 18.178 & $20-$ Aug-14 & http://www.comodoro.mt.gov.br/Transparencia/ \\
\hline 510515 & MT & Juína & 39.255 & 21-Aug-14 & [Acesso indisponível] \\
\hline 510610 & MT & $\begin{array}{l}\text { Nossa } \\
\text { Senhora do } \\
\text { Livramento }\end{array}$ & 11.609 & 19-May-14 & http://187.55.179.236/ \\
\hline 510622 & MT & $\begin{array}{l}\text { Nova } \\
\text { Mutum }\end{array}$ & 31.649 & 20-Aug-14 & $\begin{array}{l}\text { http://www.novamutum.mt.gov.br/servicos/portal-da- } \\
\text { transparencia }\end{array}$ \\
\hline 510623 & MT & $\begin{array}{l}\text { Nova } \\
\text { Olímpia } \\
\end{array}$ & 17.515 & 20-Aug-14 & http://177.202.40.50/PortalTransparencia/Principal.aspx \\
\hline 510650 & MT & Poconé & 31.779 & 21-Aug-14 & [Acesso indisponível] \\
\hline 510700 & MT & Poxoréo & 17.599 & 22-Aug-14 & http://www.poxoreu.mt.gov.br/ \\
\hline 510704 & MT & $\begin{array}{l}\text { Primavera } \\
\text { do Leste }\end{array}$ & 52.066 & 20-Aug-14 & $\begin{array}{l}\text { http://primaveradoleste.prefeitura.mt.etransparencia.com.br/portal } \\
\text { /transparencia.aspx }\end{array}$ \\
\hline 510787 & MT & Sapezal & 18.094 & 19-May-14 & http://sic.tce.mt.gov.br/home/index/id_entidade/74 \\
\hline 510850 & MT & Vera & 10.235 & 19-May-14 & [Não possui] \\
\hline 510550 & MT & $\begin{array}{l}\text { Vila Bela } \\
\text { da } \\
\text { Santíssima } \\
\text { Trindade } \\
\end{array}$ & 14.493 & 22-Aug-14 & http://www.vilabeladasantissimatrindade.mt.gov.br/Transparencia/ \\
\hline 150020 & PA & Acará & 53.569 & 10-Sep-14 & [Acesso indisponível] \\
\hline 150060 & PA & Altamira & 99.075 & 9-Sep-14 & http://altamira.pa.gov.br/portal/?page_id=572 \\
\hline 150090 & PA & $\begin{array}{l}\text { Augusto } \\
\text { Corrêa }\end{array}$ & 40.497 & 21-May-14 & [Não possui] \\
\hline 150120 & PA & Baião & 36.882 & 9-Sep-14 & http://www.baiao.pa.gov.br/portal-da-transparencia/ \\
\hline 150170 & PA & Bragança & 113.227 & 10-Sep-14 & [Não possui] \\
\hline 150275 & PA & $\begin{array}{l}\text { Concórdia } \\
\text { do Pará }\end{array}$ & 28.216 & 10-Sep-14 & [Não possui] \\
\hline 150276 & PA & $\begin{array}{l}\text { Cumaru do } \\
\text { Norte }\end{array}$ & 10.466 & 11-Sep-14 & $\begin{array}{l}\text { http://www.fenix.com.br/pdtr/chamarelatorio.php?relatorio=empen } \\
\text { ho\&id=68392 }\end{array}$ \\
\hline 150285 & PA & Curuá & 12.254 & 11-Sep-14 & http://www.prefeituracurua.com.br/novo_site/portaltransparencia/ \\
\hline 150304 & PA & $\begin{array}{l}\text { Floresta do } \\
\text { Araguaia }\end{array}$ & 17.768 & 9-Sep-14 & $\begin{array}{l}\text { http://www.pmflorestadoaraguaia.com.br/novo_site/portaltranspar } \\
\text { encia/ }\end{array}$ \\
\hline
\end{tabular}




\begin{tabular}{|c|c|c|c|c|c|}
\hline 150310 & PA & Gurupá & 29.062 & 11-Sep-14 & [Não possui] \\
\hline 150345 & PA & $\begin{array}{l}\text { Ipixuna do } \\
\text { Pará }\end{array}$ & 51.309 & 10-Sep-14 & http://www.gdip.com.br/4449488 \\
\hline 150503 & PA & $\begin{array}{l}\text { Novo } \\
\text { Progresso }\end{array}$ & 25.124 & 21-May-14 & [Acesso indisponível] \\
\hline 150520 & PA & $\begin{array}{l}\text { Oeiras do } \\
\text { Pará }\end{array}$ & 28.595 & 9-Sep-14 & [Não possui] \\
\hline 150550 & PA & $\begin{array}{l}\text { Paragomin } \\
\text { as }\end{array}$ & 97.819 & 9-Sep-14 & http://www.governotransparente.com.br/4505490 \\
\hline 150610 & PA & Primavera & 10.268 & 9-Sep-14 & [Unavailable access] \\
\hline 150613 & PA & Redenção & 75.556 & $10-$ Sep-14 & [Não possui] \\
\hline 150616 & PA & Rio Maria & 17.774 & 21-May-14 & http://www.gdip.com.br/transparencia.xhtml \\
\hline 150635 & PA & $\begin{array}{l}\text { Santa } \\
\text { Bárbara do } \\
\text { Pará }\end{array}$ & 17.141 & 11-Sep-14 & [Não possui] \\
\hline 150660 & PA & $\begin{array}{l}\text { Santa } \\
\text { Maria do } \\
\text { Pará }\end{array}$ & 23.026 & 11-Sep-14 & [Não possui] \\
\hline 150745 & PA & $\begin{array}{l}\text { São } \\
\text { Geraldo do } \\
\text { Araguaia }\end{array}$ & 25.587 & 12-Sep-14 & [Não possui] \\
\hline 150747 & PA & $\begin{array}{l}\text { São João } \\
\text { de Pirabas }\end{array}$ & 20.647 & 10-Sep-14 & [Não possui] \\
\hline 150790 & PA & Soure & 23.001 & 10-Sep-14 & [Não possui] \\
\hline 150800 & PA & Tomé Açu & 56.518 & $11-$ Sep-14 & $\begin{array}{l}\text { http://186.202.178.187/index.php?estado=1\&descestado=Par\%C } \\
\text { 3\%A1\&cidade=18\&desccidade=Tom\%C3\%A9- } \\
\text { A\%C3\%A7u\&entidade=31\&descentidade=Prefeitura }\end{array}$ \\
\hline 150835 & PA & $\begin{array}{l}\text { Vitória do } \\
\text { Xingu }\end{array}$ & 13.431 & 10-Sep-14 & [Não possui] \\
\hline 250080 & PB & Araçagi & 17.224 & 21-May-14 & [Não possui] \\
\hline 250130 & PB & Aroeiras & 19.082 & 17-Sep-14 & http://www.portalelmar.com.br/transparencia/?e=201017 \\
\hline 250190 & PB & Belém & 17.093 & 16-Sep-14 & http://e-ticons.com.br/portal/portal.jsf \\
\hline 250460 & PB & Conde & 21.400 & 17-Sep-14 & http://e-ticons.com.br/portal/portal.jsf \\
\hline 250610 & PB & Fagundes & 11.405 & 16-Sep-14 & $\begin{array}{l}\text { http://www.transparenciaativa.com.br/Entidade/EscolherEntidade. } \\
\text { aspx?Entidade=58 }\end{array}$ \\
\hline 250690 & PB & Itabaiana & 24.481 & 12-Sep-14 & http://e-ticons.com.br/portal/portal.jsf?info=09072430000193 \\
\hline 250700 & PB & Itaporanga & 23.192 & 12-Sep-14 & $\begin{array}{l}\text { http://portaldatransparencia.publicsoft.com.br/sistemas/Contabilid } \\
\text { adePublica/views/ }\end{array}$ \\
\hline 250790 & PB & Juripiranga & 10.237 & 16-Sep-14 & http://www.governotransparente.com.br/4783490 \\
\hline 250970 & PB & Monteiro & 30.852 & 16-Sep-14 & http://monteiro.pb.gov.br/transparencia/ \\
\hline 251080 & PB & Patos & 100.674 & 17-Sep-14 & http://www.patos.pb.gov.br/servicos/portal_da_transparencia \\
\hline 251240 & PB & Puxinanã & 12.923 & 17-Sep-14 & [Acesso indisponível] \\
\hline 251250 & PB & Queimadas & 41.049 & 16-Sep-14 & $\begin{array}{l}\text { http://www.transparenciaativa.com.br/Entidade/EscolherEntidade. } \\
\text { aspx?Entidade=25 }\end{array}$ \\
\hline 251310 & PB & $\begin{array}{l}\text { Salgado de } \\
\text { São Félix }\end{array}$ & 11.976 & 21-May-14 & $\begin{array}{l}\text { http://www.governotransparente.com.br/transparencia.xhtml;jsess } \\
\text { ionid=-DjbVdVf0MDb+y9D5tYMP+GC.undefined }\end{array}$ \\
\hline 251640 & PB & Tacima & 10.262 & 16-Sep-14 & http://www.portalelmar.com.br/transparencia/?e=201051 \\
\hline 251650 & PB & Taperoá & 14.936 & 17-Sep-14 & http://e-ticons.com.br/portal/portal.jsf?info=08749525000136 \\
\hline 251670 & PB & Teixeira & 14.153 & 21-May-14 & $\begin{array}{l}\text { http://portaldatransparencia.publicsoft.com.br/sistemas/Contabilid } \\
\text { adePublica/views/ }\end{array}$ \\
\hline 260005 & PE & $\begin{array}{l}\text { Abreu e } \\
\text { Lima }\end{array}$ & 94.429 & 7-Oct-14 & http://186.208.2.1:8080/SOL/open.do?action=open\&sys=POR \\
\hline 260010 & PE & $\begin{array}{l}\text { Afogados } \\
\text { da } \\
\text { Ingazeira }\end{array}$ & 35.088 & 7-Oct-14 & http://ns148.hostgator.com.br/ afoga205/portaltransparencia \\
\hline 260020 & $\mathrm{PE}$ & Afrânio & 17.586 & 1-Oct-14 & http://187.12.48.74:5757/transparencia/ \\
\hline 260120 & PE & Arcoverde & 68.793 & 2-Oct-14 & $\begin{array}{l}\text { http://www.transparencianomunicipio.com.br/portal2013/arcoverd } \\
\text { epe/sistemav7/index_entidade/index_entidade.php }\end{array}$ \\
\hline 260130 & PE & $\begin{array}{l}\text { Barra de } \\
\text { Guabiraba }\end{array}$ & 12.776 & $1-$ Oct-14 & http://www.barradeguabirabape.com/\#!transparencia/cxf4 \\
\hline 260140 & $\mathrm{PE}$ & Barreiros & 40.732 & \begin{tabular}{|l|}
$6-O c t-14$ \\
\end{tabular} & http://www.transparenciagovernamental.com.br/barreiros \\
\hline 260170 & $\mathrm{PE}$ & Belo Jardim & 72.432 & 2-Oct-14 & $\begin{array}{l}\text { http://www.transparencianomunicipio.com.br/portal2013/belojardi } \\
\text { mpe/sistemav7/index/index.php?municipio=24 }\end{array}$ \\
\hline 260180 & $\mathrm{PE}$ & Betânia & 12.003 & 6-Oct-14 & [Não possui] \\
\hline 260280 & $\mathrm{PE}$ & Buíque & 52.105 & \begin{tabular}{|l|}
$2-O c t-14$ \\
\end{tabular} & \\
\hline
\end{tabular}




\begin{tabular}{|c|c|c|c|c|c|}
\hline & & & & & $\begin{array}{l}\text { http://transparencia1.com.br/buiquepe/sistemav7/index/index.php } \\
\text { ?municipio=67 }\end{array}$ \\
\hline 260300 & $\mathrm{PE}$ & Cabrobó & 30.873 & 1-Oct-14 & http://cabrobo.altdigital.com.br/ \\
\hline 260330 & PE & Calçado & 11.125 & 1-Oct-14 & $\begin{array}{l}\text { http://transparencia } 1 . c o m . b r / c a l c a d o p e / s i s t e m a v 7 / \text { index/index.ph } \\
\text { p?municipio=63 }\end{array}$ \\
\hline 260345 & PE & $\begin{array}{l}\text { Camaragib } \\
\text { e }\end{array}$ & 144.466 & 21-May-14 & http://www.camaragibe.pe.gov.br/Portal/pmcg/transparencia.html \\
\hline 260380 & $\mathrm{PE}$ & Capoeiras & 19.593 & 26-May-14 & [Não possui] \\
\hline 260390 & PE & Carnaíba & 18.574 & 7-Oct-14 & $\begin{array}{l}\text { http://portaldatransparencia.publicsoft.com.br/sistemas/Contabilid } \\
\text { adePublica/views/ }\end{array}$ \\
\hline 260440 & PE & $\begin{array}{l}\text { Chã de } \\
\text { Alegria }\end{array}$ & 12.404 & 7-Oct-14 & http://www.transparenciagovernamental.com.br/chadealegria \\
\hline 260590 & $\mathrm{PE}$ & Gameleira & 27.912 & 1-Oct-14 & http://gameleira.pe.gov.br/?page_id=5 \\
\hline 260765 & $\mathrm{PE}$ & Itambé & 35.398 & $2-$ Oct-14 & http://itambe.pe.gov.br/portal_transparencia.html \\
\hline 260800 & $\mathrm{PE}$ & Jataúba & 15.819 & 1-Oct-14 & [Não possui] \\
\hline 260810 & PE & $\begin{array}{l}\text { João } \\
\text { Alfredo }\end{array}$ & 30.743 & 7-Oct-14 & $\begin{array}{l}\text { http://cidadaobi.tce.pe.gov.br/QvAJAXZfc/opendoc.htm?documen } \\
\text { t=portal/Portal.qvw\&host=Local\&anonymous=true }\end{array}$ \\
\hline 260825 & PE & Jucati & 10.604 & 1-Oct-14 & $\begin{array}{l}\text { http://it- } \\
\text { solucoes.com/transparenciaMunicipal/carregaPortal.aspx?ID=1\& } \\
\mathrm{e}=\mathrm{P}\end{array}$ \\
\hline 261430 & $\mathrm{PE}$ & Moreilândia & 11.132 & 6-Oct-14 & [Acesso indisponível] \\
\hline 261140 & $\mathrm{PE}$ & Primavera & 13.439 & 6 -Oct-14 & [Não possui] \\
\hline 261240 & PE & Sanharó & 21.955 & 6-Oct-14 & http://servicos.sanharo.pe.gov.br/ \\
\hline 261245 & $\mathrm{PE}$ & Santa Cruz & 13.594 & 7-Oct-14 & [Não possui] \\
\hline 261280 & PE & $\begin{array}{l}\text { Santa } \\
\text { Terezinha }\end{array}$ & 10.991 & 6-Oct-14 & [Acesso indisponível] \\
\hline 261340 & PE & $\begin{array}{l}\text { São José } \\
\text { da Coroa } \\
\text { Grande }\end{array}$ & 18.180 & 6-Oct-14 & http://www.transparenciagovernamental.com.br/sjcg \\
\hline 261380 & PE & $\begin{array}{l}\text { São } \\
\text { Vicente } \\
\text { Ferrer }\end{array}$ & 17.000 & 2-Oct-14 & [Não possui] \\
\hline 261480 & $\mathrm{PE}$ & Tacaratu & 22.068 & 7-Oct-14 & http://transparencianacidade.com/cidade/tacaratu/ \\
\hline 261500 & PE & $\begin{array}{l}\text { Taquariting } \\
\text { a do Norte }\end{array}$ & 24.903 & $1-$ Oct-14 & http://pmtaqdonorte.com.br/ \\
\hline 261640 & PE & $\begin{array}{l}\text { Vitória de } \\
\text { Santo } \\
\text { Antão }\end{array}$ & 129.974 & 26-May-14 & $\begin{array}{l}\text { http://cloud.publica.inf.br/clientes/santo_antao_pm/portaltranspare } \\
\text { ncia/ }\end{array}$ \\
\hline 220050 & $\mathrm{PI}$ & Amarante & 17.305 & 7-Oct-14 & [Não possui] \\
\hline 220110 & $\mathrm{PI}$ & $\begin{array}{l}\text { Avelino } \\
\text { Lopes }\end{array}$ & 11.067 & 7-Oct-14 & [Não possui] \\
\hline 220115 & $\mathrm{PI}$ & $\begin{array}{l}\text { Baixa } \\
\text { Grande do } \\
\text { Ribeiro }\end{array}$ & 10.516 & 7-Oct-14 & http://www.transparencia.appm.org.br/baixa-grande-do-ribeiro/ \\
\hline 220200 & $\mathrm{PI}$ & $\begin{array}{l}\text { Buriti dos } \\
\text { Lopes }\end{array}$ & 19.074 & 26-May-14 & [Não possui] \\
\hline 220350 & $\mathrm{PI}$ & $\begin{array}{l}\text { Elesbão } \\
\text { Veloso }\end{array}$ & 14.512 & 8-Oct-14 & http://transparencia.elesbaoveloso.pi.gov.br/ \\
\hline 220430 & $\mathrm{PI}$ & Fronteiras & 11.117 & 8-Oct-14 & http://www.fronteiras.pi.gov.br/?page_id=392 \\
\hline 220440 & $\mathrm{PI}$ & Gilbués & 10.402 & 7-Oct-14 & [Não possui] \\
\hline 220500 & $\mathrm{PI}$ & Itainópolis & 11.109 & 8-Oct-14 & [Não possui] \\
\hline 220620 & $\mathrm{PI}$ & $\begin{array}{l}\text { Miguel } \\
\text { Alves }\end{array}$ & 32.289 & 26-May-14 & [Não possui] \\
\hline 220830 & $\mathrm{PI}$ & Piracuruca & 27.553 & 26-May-14 & $\begin{array}{l}\text { http://www.responsabilidadefiscal.org/new_layout/index.php?cod } \\
\text { Cliente=PIR }\end{array}$ \\
\hline 221080 & $\mathrm{PI}$ & $\begin{array}{l}\text { Simplício } \\
\text { Mendes }\end{array}$ & 12.077 & 7-Oct-14 & [Não possui] \\
\hline 410080 & PR & $\begin{array}{l}\text { Alvorada } \\
\text { do Sul }\end{array}$ & 10.283 & 29-Sep-14 & http://177.1.0.18:7474/esportal/esportalprincipal.index.logic \\
\hline 410210 & PR & Astorga & 24.698 & 30-Sep-14 & http://200.155.36.249:8080/portaltransparencia/ \\
\hline 410345 & PR & Cafelândia & 14.662 & 24-Nov-14 & http://online.cafelandia.pr.gov.br:8080/esportal/scplrf.load.logic \\
\hline 410370 & PR & Cambé & 96.733 & 29-Sep-14 & http://portal.cambe.pr.gov.br:8091/portal/classic/ \\
\hline 410445 & PR & Cantagalo & 12.952 & $29-S e p-14$ & http://200.150.69.123:7474/esportal/esportalprincipal.index.logic \\
\hline 410480 & PR & Cascavel & 286.205 & 24-Nov-14 & http://transparencia.cascavel.pr.gov.br:8787/pronimtb/ \\
\hline 410530 & PR & Céu Azul & 11.032 & 29-Sep-14 & $\begin{array}{l}\text { http://www.ceuazul.pr.gov.br/portal } 1 / \text { municipio/documento.asp?ild } \\
=40663 \& \text { ildMun=100141075 }\end{array}$ \\
\hline 410620 & PR & Contenda & 15.891 & 18-Sep-14 & http://187.52.196.117:7474/esportal/esportalprincipal.index.logic \\
\hline 410630 & PR & Corbélia & 16.312 & $30-$ Sep-14 & http://controle.corbelia.pr.gov.br:8080/portaltransparencia/ \\
\hline
\end{tabular}




\begin{tabular}{|c|c|c|c|c|c|}
\hline 410750 & PR & $\begin{array}{l}\text { Engenheiro } \\
\text { Beltrão }\end{array}$ & 13.906 & 29-Sep-14 & $\begin{array}{l}\text { https://e- } \\
\text { gov.betha.com.br/transparencia/recursos.faces?mun=EQzb9d0c } \\
\text { VYIUO8XJMAnr0x0okJDkf3yV }\end{array}$ \\
\hline 410765 & PR & $\begin{array}{l}\text { Fazenda } \\
\text { Rio Grande }\end{array}$ & 81.675 & 26-May-14 & $\begin{array}{l}\text { http://e- } \\
\text { gov.betha.com.br/transparencia/recursos.faces?mun=JuEZoW- } \\
\text { XUik= }\end{array}$ \\
\hline 410860 & PR & Goioerê & 29.018 & 30-Sep-14 & http://e-gov.betha.com.br/transparencia/recursos.faces \\
\hline 410930 & PR & Guaraniaçu & 14.582 & $30-$ Sep-14 & [Acesso indisponível] \\
\hline 410940 & PR & $\begin{array}{l}\text { Guarapuav } \\
\text { a }\end{array}$ & 167.328 & 21-May-14 & http://transparencia.guarapuava.pr.gov.br/ \\
\hline 411010 & PR & Imbituva & 28.455 & 29-Sep-14 & http://177.70.201.13:7474/esportal/esportalprincipal.index.logic \\
\hline 411125 & PR & Itaperuçu & 23.887 & 30-Sep-14 & http://177.220.133.146:7474/esportal/esportalprincipal.index.logic \\
\hline 411150 & PR & Ivaiporã & 31.816 & 18-Sep-14 & http://187.95.103.148:8080/portaltransparencia/ \\
\hline 411210 & PR & $\begin{array}{l}\text { Jandaia do } \\
\text { Sul }\end{array}$ & 20.269 & 17-Sep-14 & http://177.220.130.12:8080/pronimtb/index.asp \\
\hline 411320 & PR & Lapa & 44.932 & 17-Sep-14 & http://sistemas.lapa.pr.gov.br:5656/portaltransparencia/ \\
\hline 411330 & PR & $\begin{array}{l}\text { Laranjeiras } \\
\text { do Sul }\end{array}$ & 30.777 & 17-Sep-14 & [Acesso indisponível] \\
\hline 411390 & PR & Mallet & 12.973 & 17-Sep-14 & http://e-gov.betha.com.br/transparencia/recursos.faces \\
\hline 411450 & PR & $\begin{array}{l}\text { Manoel } \\
\text { Ribas }\end{array}$ & 13.169 & 30-Sep-14 & http://200.150.98.147:8081/portaltransparencia/ \\
\hline 411460 & PR & $\begin{array}{l}\text { Marechal } \\
\text { Cândido } \\
\text { Rondon }\end{array}$ & 46.819 & 30-Sep-14 & http://www.atende.net/transparencia/portal.php?cliente=512 \\
\hline 411520 & PR & Maringá & 357.077 & 30-Sep-14 & $\begin{array}{l}\text { http://www2.maringa.pr.gov.br/site/index.php?sessao=f6240e4b9 } \\
28 \text { nf6 }\end{array}$ \\
\hline 411540 & PR & Marmeleiro & 13.900 & 30-Sep-14 & http://www.marmeleiro.pr.gov.br:8085/pronimtb/ \\
\hline 411570 & PR & Matinhos & 29.428 & 29-Sep-14 & http://187.5.36.19/pronimtb/ \\
\hline 411725 & PR & $\begin{array}{l}\text { Nova Prata } \\
\text { do Iguaçu }\end{array}$ & 10.377 & 17-Sep-14 & $\begin{array}{l}\text { http://transparencia.npi.pr.gov.br:7474/esportal/esportalprincipal.i } \\
\text { ndex.logic }\end{array}$ \\
\hline 411840 & PR & Paranavaí & 81.590 & 26-Sep-14 & http://e-gov.betha.com.br/transparencia/recursos.faces \\
\hline 411915 & PR & Pinhais & 117.008 & 26-Sep-14 & http://www.pinhais.pr.gov.br/prestacao/ \\
\hline 412060 & PR & $\begin{array}{l}\text { Prudentópo } \\
\text { lis }\end{array}$ & 48.792 & 18-Sep-14 & http://www.prudentopolis.pr.gov.br/portal \\
\hline 412140 & PR & Realeza & 16.338 & $26-5$ & http:// \\
\hline 412215 & PR & $\begin{array}{l}\text { Rio Bonito } \\
\text { do Iguaçu }\end{array}$ & 13.661 & 17-Sep-14 & http://177.44.173.246:7474/esportal/esportalprincipal.index.logic \\
\hline 412340 & PR & Santa Fé & 10.432 & 25-Nov-14 & http://201.55.130.10:8088/portaltransparencia/ \\
\hline 412560 & PR & $\begin{array}{l}\text { São } \\
\text { Mateus do } \\
\text { Sul }\end{array}$ & 41.257 & 29-Sep-14 & $\begin{array}{l}\text { http://e- } \\
\text { gov.betha.com.br/transparencia/recursos.faces?mun=BFajgIVxrB } \\
\text { S= }\end{array}$ \\
\hline 412750 & PR & Tibagi & 19.344 & 18-Sep-14 & http://www.tibagi.pr.gov.br/transparencia.html \\
\hline 412770 & PR & Toledo & 119.313 & 30-Sep-14 & http://www.toledo.pr.gov.br/pagina/portal-da-transparencia \\
\hline 330015 & RJ & Aperibé & 10.213 & 9-Oct-14 & $\begin{array}{l}\text { http://186.219.112.74:8080/sapiturConsulta/bin/transparencia.htm } \\
\text { I }\end{array}$ \\
\hline 330070 & RJ & Cabo Frio & 186.227 & 9-Oct-14 & http://www.cabofrio.rj.gov.br/transparencia/portal \\
\hline 330190 & RJ & Itaboraí & 218.008 & 9-Oct-14 & http://itaborai.rj.gov.br/novosite/acesso-a-informacao/ \\
\hline 330260 & RJ & $\begin{array}{l}\text { Mangaratib } \\
\text { a }\end{array}$ & 36.456 & 8-Oct-14 & $\begin{array}{l}\text { https://e- } \\
\text { gov.betha.com.br/transparencia/recursos.faces?mun=WppxBH47 } \\
\text { Kza1Cw1IEux3UylrmolL_iuG }\end{array}$ \\
\hline 330270 & RJ & Maricá & 127.461 & 9-Oct-14 & http://187.108.190.211:6080/ecidade_transparencia/ \\
\hline 330285 & RJ & Mesquita & 168.376 & 9-Oct-14 & http://servicos.mesquita.rj.gov.br/pronimtb/ \\
\hline 330385 & RJ & $\begin{array}{l}\text { Paty do } \\
\text { Alferes }\end{array}$ & 26.359 & 9-Oct-14 & http://patydoalferes.rj.gov.br/portal-transparencia/ \\
\hline 330395 & RJ & Pinheiral & 719 & ay-14 & tp://www.pinheiral.rj.gov.br/portal-transparencia \\
\hline 330412 & $\mathrm{RJ}$ & Quatis & 12.793 & 26-May-14 & http://www.quatis.rj.gov.br/transparencia2014.php \\
\hline 330420 & RJ & Resende & 119.769 & 9-Oct-14 & http://www.resende.rj.gov.br/portal-da-transparencia.asp \\
\hline 330430 & $\mathrm{RJ}$ & Rio Bonito & 55.551 & 9-Oct-14 & http://www.riobonito.rj.gov.br/prefeitura/\# \\
\hline 330490 & RJ & $\begin{array}{l}\text { São } \\
\text { Gonçalo }\end{array}$ & 999.728 & 8-Oct-14 & $\begin{array}{l}\text { https://portal.pmsg.rj.gov.br/pmsaogoncalo/websis/siapegov/porta } \\
\text { l/index.php?cliente=pmsaogoncalo }\end{array}$ \\
\hline 330500 & RJ & $\begin{array}{l}\text { São João } \\
\text { da Barra }\end{array}$ & 32.747 & 9-Oct-14 & http://www.sjb.rj.gov.br/transparencia \\
\hline 330540 & RJ & Sapucaia & 17.525 & 9-Oct-14 & $\begin{array}{l}\text { http://www.sapucaia.rj.gov.br/site/index.php/portal-transparencia- } \\
\text { pms }\end{array}$ \\
\hline 330580 & RJ & Teresópolis & 163.746 & 26-May-14 & http://e-gov.betha.com.br/transparencia/recursos.faces \\
\hline 330620 & $\mathrm{RJ}$ & Vassouras & 34.410 & 9-Oct-14 & http://www.vassouras.rj.gov.br/avisos.php \\
\hline 240180 & $\mathrm{RN}$ & Brejinho & 11.577 & 14-Oct-14 & [Não possui] \\
\hline 240210 & $\mathrm{RN}$ & $\begin{array}{l}\text { Campo } \\
\text { Redondo }\end{array}$ & 10.266 & 14-Oct-14 & http://topdown.servehttp.com:8080/transparencia/pmcamporedon \\
\hline
\end{tabular}




\begin{tabular}{|c|c|c|c|c|c|}
\hline & & & & & do/despesas.aspx \\
\hline 240220 & $\mathrm{RN}$ & $\begin{array}{l}\text { Canguareta } \\
\text { ma }\end{array}$ & 30.916 & 26-May-14 & [Não possui] \\
\hline 240350 & RN & $\begin{array}{l}\text { Espírito } \\
\text { Santo }\end{array}$ & 10.475 & 14-Oct-14 & http://www.espiritosanto.rn.gov.br/acesso-a-informacao \\
\hline 240420 & RN & Goianinha & 22.481 & 14-Oct-14 & http://www.gdip.com.br/6697490 \\
\hline 240580 & RN & \begin{tabular}{|l|} 
João \\
Câmara
\end{tabular} & 32.227 & 14-Oct-14 & [Não possui] \\
\hline 240770 & $\mathrm{RN}$ & Montanhas & 11.413 & 14-Oct-14 & [Não possui] \\
\hline 240800 & RN & Mossoró & 259.815 & 15-Oct-14 & http://200.164.111.106/transparencia/despesas.aspx \\
\hline 240910 & RN & $\begin{array}{l}\text { Passa e } \\
\text { Fica }\end{array}$ & 11.100 & 27-May-14 & [Acesso indisponível] \\
\hline 240895 & $\mathrm{RN}$ & $\begin{array}{l}\text { Rio do } \\
\text { Fogo }\end{array}$ & 10.059 & 15-Oct-14 & http://riodofogo.rn.gov.br/ \\
\hline 241230 & $\mathrm{RN}$ & $\begin{array}{l}\text { São José } \\
\text { do } \\
\text { Campestre }\end{array}$ & 12.356 & 14-Oct-14 & [Não possui] \\
\hline 241400 & $\mathrm{RN}$ & Tangará & 14.175 & 27-May-14 & [Acesso indisponível] \\
\hline 110002 & RO & Ariquemes & 90.353 & 27-May-14 & http://apps.ariquemes.ro.gov.br/transparencia/home/index \\
\hline 110045 & $\mathrm{RO}$ & Buritis & 32.383 & 21-Oct-14 & http://www.buritis.ro.gov.br/portal-transparencia \\
\hline 110008 & RO & \begin{tabular}{|l|} 
Costa \\
Marques \\
\end{tabular} & 13.678 & 27-May-14 & http://www.costamarques.ro.gov.br/portal-da-transparencia \\
\hline 110009 & RO & $\begin{array}{l}\text { Espigão } \\
\text { d'Oeste }\end{array}$ & 28.729 & 22-Oct-14 & http://177.129.124.83:5659/scpitransparencia/ \\
\hline 110012 & $\mathrm{RO}$ & Ji-Paraná & 116.610 & 22-Oct-14 & http://201.3.59.82:5659/scpitransparencia/ \\
\hline 110330 & RO & $\begin{array}{l}\text { Mirante da } \\
\text { Serra }\end{array}$ & 11.878 & 27-May-14 & http://www.mirantedaserra.ro.gov.br/transparencia/ \\
\hline 110160 & $\mathrm{RO}$ & Theobroma & 10.649 & $22-$ Oct-14 & http://187.6.245.123:8080/portaltransparencia/ \\
\hline 140015 & RR & Bonfim & 10.943 & 28-May-14 & http://www.bonfim.rr.gov.br/ \\
\hline 140030 & RR & Mucajaí & 14.792 & 28-May-14 & [Não possui] \\
\hline 430040 & RS & Alegrete & 77.653 & $20-$-Oct-14 & http://www.alegrete.rs.gov.br/ecidade_transparencia/ \\
\hline 430110 & RS & $\begin{array}{l}\text { Arrio dos } \\
\text { Ratos }\end{array}$ & 31.606 & 27-May-14 & $\begin{array}{l}\text { http://e- } \\
\text { gov.betha.com.br/transparencia/recursos.faces?mun=pW ItcToFu } \\
\text { 9p_NC1ULUXY97zffHqOotIT }\end{array}$ \\
\hline 430620 & RS & $\begin{array}{l}\text { Cruzeiro do } \\
\text { Sul } \\
\end{array}$ & 12.320 & 20-Oct-14 & http://24horas.cruzeiro.rs.gov.br:8080/sistemas/transparencia/ \\
\hline 430650 & RS & $\begin{array}{l}\text { Dom } \\
\text { Feliciano }\end{array}$ & 14.380 & 27-May-14 & http://187.4.19.162/ecidade_transparencia/ \\
\hline 430676 & RS & $\begin{array}{l}\text { Eldorado } \\
\text { do Sul }\end{array}$ & 34.343 & 21-Oct-14 & http://186.216.241.46:8081/pronimtb/index.asp \\
\hline 430700 & RS & Erechim & 96.087 & 21-Oct-14 & http://www.pmerechim.rs.gov.br/pagina/203/portal-transparencia \\
\hline 430750 & RS & Espumoso & 15.240 & 20-Oct-14 & https://sim.digifred.net.br/espumoso/ \\
\hline 430940 & RS & Guaporé & 22.814 & $20-$ Oct-14 & http://www.guapore.rs.gov.br/?p=pref_transparente \\
\hline 431020 & RS & ljuí & 78.915 & 21-Oct-14 & http://servertb.ijui.rs.gov.br:81/pronimtb/index.asp \\
\hline 431140 & RS & Lajeado & 71.445 & $15-O c t-14$ & $\begin{array}{l}\text { http://www.lajeado.rs.gov.br/home/pagina.asp?titulo=Portal\%20d } \\
\text { a\%20Transpar\%EAncia\&categoria=Portal\%20da\%20Transpar\% } \\
\text { EAncia\&codigoCategoria=972\&imagemCategoria=portal_transpar } \\
\text { encia.jpg\&INC=pagina.asp?\&conteudo=972 }\end{array}$ \\
\hline 431320 & RS & \begin{tabular}{|l|} 
Nova \\
Petrópolis
\end{tabular} & 19.054 & 15-Oct-14 & http://www.novapetropolis.rs.gov.br/informacoes.php \\
\hline 431330 & RS & Nova Prata & 22.830 & 20-Oct-14 & http://189.14.233.75:7070/sistemas/transparencia/ \\
\hline 431337 & RS & $\begin{array}{l}\text { Nova Santa } \\
\text { Rita }\end{array}$ & 22.716 & 21-Oct-14 & http://tb.novasantarita.rs.gov.br/pronimtb/index.asp \\
\hline 431370 & RS & \begin{tabular}{|l|} 
Palmeira \\
das \\
Missões \\
\end{tabular} & 34.328 & 20-Oct-14 & [Não possui] \\
\hline 431410 & RS & $\begin{array}{l}\text { Passo } \\
\text { Fundo }\end{array}$ & 184.826 & 16-Oct-14 & http://www.pmpf.rs.gov.br/transparencia/ \\
\hline 431470 & RS & Planalto & 10.524 & $20-$ Oct-14 & http://www.planalto.rs.gov.br/portal_da_transparencia \\
\hline 431480 & RS & Portão & 30.920 & $20-$ Oct-14 & http://201.41.58.250:82/sistemas/transparencia/ \\
\hline 431540 & RS & Redentora & 10.222 & $21-$ Oct-14 & http://transparencia. abase.com.br/Home.aspx?cod=15 \\
\hline 431645 & RS & $\begin{array}{l}\text { Salto do } \\
\text { Jacuí }\end{array}$ & 11.880 & $21-$ Oct-14 & http://www.saltodojacui.rs.gov.br/transparencia/ \\
\hline 431690 & RS & $\begin{array}{l}\text { Santa } \\
\text { Maria }\end{array}$ & 261.031 & 21-Oct-14 & http://www.santamaria.rs.gov.br/transparencia/ \\
\hline 431750 & RS & $\begin{array}{l}\text { Santo } \\
\text { Ângelo }\end{array}$ & 76.275 & 16-Oct-14 & http://177.85.24.245/portaltransparencia/Home.aspx?cod=6 \\
\hline 431850 & RS & $\begin{array}{l}\text { São José } \\
\text { do Norte }\end{array}$ & 25.503 & 20-Oct-14 & http://www.saojosedonorte.rs.gov.br/?p=transparencia \\
\hline 431940 & RS & $\begin{array}{l}\text { São Pedro } \\
\text { do Sul }\end{array}$ & 16.368 & 21-Oct-14 & $\begin{array}{l}\text { http://e- } \\
\text { gov.betha.com.br/transparencia/con_despesasempenhadas.faces } \\
\text { ?mun=NQpf3BLLgRc= }\end{array}$ \\
\hline 432010 & RS & Sarandi & 21.285 & 21-Oct-14 & http://www.sarandi.rs.gov.br/transparencia/contas-online.html \\
\hline
\end{tabular}




\begin{tabular}{|c|c|c|c|c|c|}
\hline 432080 & RS & Soledade & 30.044 & 16-Oct-14 & http://177.101.230.30/pronimtb/index.asp \\
\hline 432090 & RS & Tapejara & 19.250 & 21-Oct-14 & $\begin{array}{l}\text { http://www.tapejara.rs.gov.br/site/paginas/14/Portal- } \\
\text { Transparencia }\end{array}$ \\
\hline 432166 & RS & $\begin{array}{l}\text { Três } \\
\text { Cachoeiras }\end{array}$ & 10.217 & 21-Oct-14 & $\begin{array}{l}\text { http://www.trescachoeiras.rs.gov.br/index.php/portal- } \\
\text { transparencia }\end{array}$ \\
\hline 432170 & RS & $\begin{array}{l}\text { Três } \\
\text { Coroas }\end{array}$ & 23.848 & 27-May-14 & http://transparenciabrasil.trescoroas.rs.gov.br/pronimtb/index.asp \\
\hline 432260 & RS & $\begin{array}{l}\text { Venâncio } \\
\text { Aires } \\
\end{array}$ & 65.946 & $20-$ - ct- 14 & http://www.venancioaires.rs.gov.br/site/home/pagina/id/138 \\
\hline 432300 & RS & Viamão & 239.384 & $16-$-Oct-14 & $\begin{array}{l}\text { http://200.203.89.54/transparencia/gestaoAdministrativa/fontes/P } \\
\text { HP/framework/instancias/index/index2.php?PHPSESSID =c4eb86 } \\
\text { 854da7ac883dfa8010a519502d\&tamanho=0\&transparencia=1 }\end{array}$ \\
\hline 420130 & SC & Araquari & 24.810 & $24-O c t-14$ & http://www.araquari.sc.gov.br/c/portal-da-transparencia \\
\hline 420210 & SC & Barra Velha & 22.386 & $27-$ Oct-14 & https://barravelha.atende.net/?pg=transparencia\#!/ \\
\hline 420240 & SC & Blumenau & 309.011 & 28-May-14 & http://www.blumenau.sc.gov.br/transparencia \\
\hline 420370 & SC & Canelinha & 10.603 & 22-Oct-14 & $\begin{array}{l}\text { http://e- } \\
\text { gov.betha.com.br/transparencia/recursos.faces?mun=tMQoJcv5w } \\
\text { meXGK-Wm5jTdg== }\end{array}$ \\
\hline 420380 & SC & Canoinhas & 52.765 & 23-Oct-14 & $\begin{array}{l}\text { http://e- } \\
\text { gov.betha.com.br/transparencia/recursos.faces?mun=721yBGlsO } \\
\text { Oc= }\end{array}$ \\
\hline 420425 & SC & $\begin{array}{l}\text { Cocal do } \\
\text { Sul }\end{array}$ & 15.159 & $27-$ Oct- 14 & $\begin{array}{l}\text { http://e- } \\
\text { gov.betha.com.br/transparencia/recursos.faces?mun=2Bwpmndp } \\
\text { PAg= }\end{array}$ \\
\hline 420450 & SC & Corupá & 13.852 & 27-Oct-14 & $\begin{array}{l}\text { http://www.corupa.sc.gov.br/transparencia/index/codMapaltem/20 } \\
\text { 940\#.VE6vZfnF92E }\end{array}$ \\
\hline 420540 & SC & $\begin{array}{l}\text { Florianópoli } \\
\text { s }\end{array}$ & 421.240 & 22-Oct-14 & http://www.pmf.sc.gov.br/sites/transparencia/ \\
\hline 420570 & SC & Garopaba & 18.138 & 27-Oct-14 & $\begin{array}{l}\text { http://e- } \\
\text { gov.betha.com.br/transparencia/recursos.faces?mun=I2Ky4oqCVt } \\
\mathrm{E}=\end{array}$ \\
\hline 420670 & SC & $\begin{array}{l}\text { Herval } \\
\text { D'Oeste }\end{array}$ & 21.239 & 28-May-14 & $\begin{array}{l}\text { http://e- } \\
\text { gov.betha.com.br/transparencia/recursos.faces?mun=VSaZgfdKN } \\
\text { WA= }\end{array}$ \\
\hline 420850 & SC & Ituporanga & 22.250 & $2-$ Oct-14 & https://ituporanga.atende.net/?pg=transparencia\#!/ \\
\hline 420880 & SC & Jaguaruna & 17.290 & 28-May-14 & om.br/transparencia/recur \\
\hline 420890 & SC & $\begin{array}{l}\text { Jaraguá do } \\
\text { Sul }\end{array}$ & 143.123 & 24-Oct-14 & http://www.jaraguadosul.sc.gov.br/portal-da-transparencia \\
\hline 421120 & SC & $\begin{array}{l}\text { Morro da } \\
\text { Fumaça }\end{array}$ & 16.126 & 23-Oct-14 & $\begin{array}{l}\text { http://e- } \\
\text { gov.betha.com.br/transparencia/recursos.faces?mun=KAqcqgtqo } \\
38=\end{array}$ \\
\hline 421150 & SC & $\begin{array}{l}\text { Nova } \\
\text { Trento }\end{array}$ & 12.190 & 27-Oct-14 & $\begin{array}{l}\text { http://e- } \\
\text { gov.betha.com.br/transparencia/recursos.faces?mun=h6rzXKD6y } \\
\text { vE= }\end{array}$ \\
\hline 421190 & SC & Palhoça & 137.334 & $24-60 t-14$ & [Não possui] \\
\hline 421500 & SC & \begin{tabular}{|l|} 
Rio \\
Negrinho \\
\end{tabular} & 39.846 & 27-Oct-14 & http://www.rionegrinho.sc.gov.br/?pagina=portal_transparencia \\
\hline 421690 & SC & \begin{tabular}{|l|} 
São \\
Lourenço \\
do Oeste \\
\end{tabular} & 21.792 & $27-$ Oct-14 & $\begin{array}{l}\text { http://e- } \\
\text { gov.betha.com.br/transparencia/recursos.faces?mun=B4zsLcelE } \\
\text { I= }\end{array}$ \\
\hline 421740 & SC & Schroeder & 15.316 & 24-Oct-14 & $\begin{array}{l}\text { http://gpm.fecam.org.br/schroeder/transparencia/index/codMapalt } \\
\text { em/17409\#.VEqgd_nlYnB }\end{array}$ \\
\hline 421760 & SC & Siderópolis & 12.998 & 23-Oct-14 & $\begin{array}{l}\text { http://e- } \\
\text { gov.betha.com.br/transparencia/recursos.faces?mun=3ZNNYZdQ } \\
\text { sKM= }\end{array}$ \\
\hline 421880 & SC & Turvo & 11.854 & 23-Oct-14 & $\begin{array}{l}\text { http://e- } \\
\text { gov.betha.com.br/transparencia/recursos.faces?mun=E1_KVwBi } \\
\text { Bls= }\end{array}$ \\
\hline 421900 & SC & Urus & 20.223 & 24-Oct-14 & http://lai.fecam.org.br/urussanga \\
\hline 280040 & SE & Arauá & 10.878 & 18-Nov-14 & $\begin{array}{l}\text { http://www.municipalnet.com.br/fornecedorweb/recDesp.php?cod } \\
=\text { =dHJhbnNwd2ViX2FyYXVh }\end{array}$ \\
\hline 280100 & SE & $\begin{array}{l}\text { Campo do } \\
\text { Brito }\end{array}$ & 16.749 & 29-May-14 & $\begin{array}{l}\text { http://www.municipalnet.com.br/fornecedorweb/recDesp.php?cod } \\
=\text { dHJhbnNwd2ViX2NhbXBvZG9icmlObw }\end{array}$ \\
\hline 280140 & SE & Carira & 20.007 & 19-Nov-14 & $\begin{array}{l}\text { http://www.municipalnet.com.br/fornecedorweb/recDesp.php?cod } \\
=\text { dHJhbnNwd2ViX2NhcmlyYQ== }\end{array}$ \\
\hline 280210 & SE & Estância & 64.409 & 18-Nov-14 & $\begin{array}{l}\text { http://www.estancia.se.gov.br/portal/definido.wsp?tmp.tipo=transp } \\
\text { arencia }\end{array}$ \\
\hline 280300 & SE & Itabaianinh & 38.910 & 29-May-14 & http://www.transparencia.net.br/1237 \\
\hline
\end{tabular}




\begin{tabular}{|c|c|c|c|c|c|}
\hline & & a & & & \\
\hline 280340 & SE & Japoatã & 12.938 & 18-Nov-14 & http://www.japoata.se.gov.br/transparencia \\
\hline 280350 & SE & Lagarto & 94.861 & 18-Nov-14 & 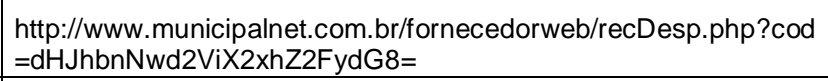 \\
\hline 280540 & SE & \begin{tabular}{|l|} 
Poço \\
Redondo
\end{tabular} & 30.880 & 29-May-14 & http://www.transparencia.net.br/16 \\
\hline 280740 & SE & \begin{tabular}{|l|} 
Tobias \\
Barreto \\
\end{tabular} & 48.040 & 19-Nov-14 & http://www.tobiasbarreto.se.gov.br/index.php \\
\hline 350190 & SP & Amparo & 65.829 & 29-Oct-14 & $\begin{array}{l}\text { http://www.amparo.sp.gov.br/content/transpar\%C3\%AAncia- } \\
\text { governamental }\end{array}$ \\
\hline 350380 & SP & \begin{tabular}{|l|} 
Artur \\
Nogueira
\end{tabular} & 44.177 & 03-Nov-14 & http://187.103.145.151/ATN/ \\
\hline 350420 & SP & Auriflama & 14.202 & 14-Nov-14 & http://www.auriflama.sp.gov.br/transparencias \\
\hline 350490 & SP & Bananal & 10.223 & 13-Nov-14 & $\begin{array}{l}\text { http://179.111.214.215:8081/pmbananal/websis/portal_transparen } \\
\text { cia/financeiro/contas_publicas/index.php }\end{array}$ \\
\hline 350610 & SP & Bebedouro & 75.035 & 29-Oct-14 & $\begin{array}{l}\text { http://bebedouro.prefeitura.sp.etransparencia.com.br/portal/transp } \\
\text { arencia.aspx }\end{array}$ \\
\hline 350790 & SP & Brotas & 21.580 & 11-Nov-14 & $\begin{array}{l}\text { http://brotas.prefeitura.sp.etransparencia.com.br/portal/transparen } \\
\text { cia.aspx }\end{array}$ \\
\hline 350840 & SP & Cabreúva & 41.604 & 18-Nov-14 & $\begin{array}{l}\text { http://leideacesso.etransparencia.com.br/cabreuva.prefeitura.sp/P } \\
\text { ortal/desktop.html }\end{array}$ \\
\hline 350850 & SP & Caçapava & 84.752 & 17-Nov-14 & $\begin{array}{l}\text { http://cacapava.prefeitura.sp.etransparencia.com.br/portal/transpa } \\
\text { rencia.aspx }\end{array}$ \\
\hline 350940 & SP & Cajuru & 23.371 & 13-Nov-14 & $\begin{array}{l}\text { http://leideacesso.etransparencia.com.br/cajuru.prefeitura.sp/Port } \\
\text { al/desktop.html?325 }\end{array}$ \\
\hline 351020 & SP & $\begin{array}{l}\text { Capão } \\
\text { Bonito }\end{array}$ & 46.178 & 06-Nov-14 & http://transparencia.capaobonito.sp.gov.br/ \\
\hline 351060 & SP & $\begin{array}{l}\text { Carapicuíb } \\
\text { a }\end{array}$ & 369.584 & 13-Nov-14 & http://www.transparencia.carapicuiba.sp.gov.br/ \\
\hline 351080 & SP & $\begin{array}{l}\text { Casa } \\
\text { Branca }\end{array}$ & 28.307 & 28-May-14 & $\begin{array}{l}\text { http://www.casabranca.sp.gov.br/index1 } . \text { asp?nm=Municipal\&nip= } \\
\text { PZ3_\&qm=s\&ed=0\&C=283\&ter=apn76 }\end{array}$ \\
\hline 351200 & SP & Colina & 17.371 & 04-Nov-14 & http://200.144.17.186/pronimtb/ \\
\hline 351230 & SP & Conchas & 16.288 & 03-Nov-14 & $\begin{array}{l}\text { http://www.transparencia.conchas.sp.gov.br/Portal/Transparencia } \\
\text { DosMunicipios.aspx }\end{array}$ \\
\hline 351340 & SP & Cruzeiro & 77.039 & 17-Nov-14 & $\begin{array}{l}\text { http://pmccruzeiro.no- } \\
\text { ip.org:8184/pmcruzeiro/websis/siapegov/portal/index.php }\end{array}$ \\
\hline 351390 & SP & $\begin{array}{l}\text { Divinolândi } \\
\text { a }\end{array}$ & 11.208 & 07-Nov-14 & http://ptdivinolandia.outcenter.com.br:8081/pronimtb/index.asp \\
\hline 351450 & SP & Duartina & 12.251 & 06-Nov-14 & http://186.224.0.62:5656/scpiweb/ \\
\hline 355730 & SP & $\begin{array}{l}\text { Estiva } \\
\text { Gerbi } \\
\end{array}$ & 10.044 & 17-Nov-14 & [Não possui] \\
\hline 351550 & SP & $\begin{array}{l}\text { Fernandóp } \\
\text { olis }\end{array}$ & 64.696 & 25-Nov-14 & http://servicos.fernandopolis.sp.gov.br:5656/scpiweb \\
\hline 351570 & SP & $\begin{array}{l}\text { Ferraz de } \\
\text { Vasconcelo } \\
\text { s }\end{array}$ & 168.306 & 10-Nov-14 & $\begin{array}{l}\text { http://ferrazdevasconcelos.prefeitura.sp.etransparencia.com.br/po } \\
\text { rtal/transparencia.aspx }\end{array}$ \\
\hline 351905 & SP & Holambra & 11.299 & 05-Nov-14 & http://www.holambra.sp.gov.br/transparencia/ \\
\hline 351970 & SP & Ibiúna & 71.217 & 14-Nov-14 & [Não possui] \\
\hline 352030 & SP & Iguape & 28.841 & 04-Nov-14 & $\begin{array}{l}\text { http://www.transparencia.iguape.sp.gov.br/Portal/TransparenciaD } \\
\text { osMunicipios.aspx }\end{array}$ \\
\hline 352040 & SP & Ilhabela & 28.196 & 11-Nov-14 & $\begin{array}{l}\text { http://www.transparencia.ilhabela.sp.gov.br/Portal/Transparencia } \\
\text { DosMunicipios.aspx }\end{array}$ \\
\hline 352130 & SP & Ipuã & 14.148 & 17-Nov-14 & http://www.ipua.sp.gov.br/index.php?escolha $=5$ \\
\hline 352170 & SP & Itaberá & 17.858 & 03-Nov-14 & $\begin{array}{l}\text { http://itabera.prefeitura.sp.etransparencia.com.br/portal/transpare } \\
\text { ncia.aspx }\end{array}$ \\
\hline 352240 & SP & Itapeva & 87.753 & 13-Nov-14 & $\begin{array}{l}\text { http://itapeva.prefeitura.sp.etransparencia.com.br/portal/transpare } \\
\text { ncia.aspx }\end{array}$ \\
\hline 352250 & SP & Itapevi & 200.769 & 10-Nov-14 & http://www.itapevi.sp.gov.br/portaltransparencia/home/index.php \\
\hline 352270 & SP & Itápolis & 40.051 & 07-Nov-14 & $\begin{array}{l}\text { http://201.63.46.4:8080/dadosweb/loginWeb.jsp?execobj=XXPW2 } \\
0200\end{array}$ \\
\hline
\end{tabular}




\begin{tabular}{|c|c|c|c|c|c|}
\hline 352340 & SP & Itatiba & 101.471 & 18-Nov-14 & $\begin{array}{l}\text { http://www.itatiba.sp.gov.br/Financas/gestao-transparente- } \\
\text { itatiba.html }\end{array}$ \\
\hline 352350 & SP & Itatinga & 18.052 & 17-Nov-14 & http://www.itatinga.sp.gov.br/portal/transparencia.asp \\
\hline 352390 & $\mathrm{SP}$ & Itu & 154.147 & 14-Nov-14 & http://www.itu.sp.gov.br/?area $=558$ \\
\hline 352480 & SP & Jales & 47.012 & 14-Nov-14 & http://www.transparencia.jales.sp.gov.br/ \\
\hline 352530 & SP & Jaú & 131.040 & 07-Nov-14 & $\begin{array}{l}\text { http://jau.prefeitura.sp.etransparencia.com.br/portal/transparencia } \\
\text {.aspx }\end{array}$ \\
\hline 352570 & SP & \begin{tabular}{|l|} 
José \\
Bonifácio \\
\end{tabular} & 32.763 & 07-Nov-14 & $\begin{array}{l}\text { http://www.josebonifacio.sp.gov.br/prefeitura/financas-e-gestao- } \\
\text { publica/cat:26/subcat:141 }\end{array}$ \\
\hline 352590 & $\mathrm{SP}$ & Jundiaí & 370.126 & 03-Nov-14 & $\begin{array}{l}\text { http://deolhonodinheiropublico.jundiai.sp.gov.br/sitetranspV2/port } \\
\text { al.nsf/V03.02/index?OpenDocument }\end{array}$ \\
\hline 352920 & SP & $\begin{array}{l}\text { Martinópoli } \\
\text { s }\end{array}$ & 24.219 & 18-Nov-14 & http://online.martinopolis.sp.gov.br:5656/transparenciaweb/ \\
\hline 353190 & SP & \begin{tabular}{|l|} 
Morro \\
Agudo \\
\end{tabular} & 29.116 & 07-Nov-14 & http://e-gov.betha.com.br/transparencia/recursos.faces \\
\hline 353300 & $\mathrm{SP}$ & $\begin{array}{l}\text { Nova } \\
\text { Granada }\end{array}$ & 19.180 & 13-Nov-14 & $\begin{array}{l}\text { http://www.transparencia.novagranada.sp.gov.br/Portal/Transpare } \\
\text { nciaDosMunicipios.aspx \| } \\
\text { http://187.103.80.130/transparencia/ }\end{array}$ \\
\hline 353490 & SP & Pacaembu & 13.226 & 03-Nov-14 & $\begin{array}{l}\text { http://portaltransparencia.sistemas } 4 \text { r.com.br/wpportaltransparenci } \\
\text { a.aspx?hTW9MmeuAys15jeLianZFQ== }\end{array}$ \\
\hline 353620 & SP & $\begin{array}{l}\text { Pariquera- } \\
\text { Açu }\end{array}$ & 18.446 & 05-Nov-14 & $\begin{array}{l}\text { http://www.transparencia.pariqueraacu.sp.gov.br/Portal/Transpare } \\
\text { nciaDosMunicipios.aspx }\end{array}$ \\
\hline 353700 & SP & Pedregulho & 15.700 & 13-Nov-14 & http://www.pedregulho.sp.gov.br/governo-transparente \\
\hline 353820 & SP & Pinhalzinho & 13.105 & $25-$ Nov-14 & http://177.107.66.152/pronimtb/ \\
\hline 353860 & SP & Piracaia & 25.116 & 29-Oct-14 & $\begin{array}{l}\text { http://www.probidadebrasil.com.br/(S(0cyzsbizczl3aidlxbiodwin))/ } \\
\text { Web ARRECADACAO.aspx?id=1 }\end{array}$ \\
\hline 353870 & SP & Piracicaba & 364.571 & 03-Nov-14 & http://transparencia.piracicaba.sp.gov.br/ \\
\hline 353950 & SP & $\begin{array}{l}\text { Pitangueira } \\
\mathrm{s}\end{array}$ & 35.307 & $25-$ Nov-14 & http://www.pitangueiras.sp.gov.br/transparencia-publica.htm \\
\hline 354000 & SP & Pompéia & 19.964 & 29-Oct-14 & $\begin{array}{l}\text { http://www.mmrsistemas.com.br/transparencia/principal.jsf?idEnti } \\
\text { dade=6901001 }\end{array}$ \\
\hline 354070 & SP & $\begin{array}{l}\text { Porto } \\
\text { Ferreira }\end{array}$ & 51.400 & 28-May-14 & $\begin{array}{l}\text { http://portoferreira.prefeitura.sp.etransparencia.com.br/portal/tran } \\
\text { sparencia.aspx }\end{array}$ \\
\hline 354075 & SP & Potim & 19.397 & 06-Nov-14 & $\begin{array}{l}\text { http://186.237.6.53/pmpotim/websis/portal_transparencia/financeir } \\
\text { o/contas_publicas/ }\end{array}$ \\
\hline 354090 & SP & Pradópolis & 17.377 & 17-Nov-14 & http://189.19.193.201:5656/transparencia/ \\
\hline 354390 & SP & Rio Claro & 186.253 & 05-Nov-14 & $\begin{array}{l}\text { http://rioclaro.prefeitura.sp.etransparencia.com.br/portal/transpare } \\
\text { ncia.aspx }\end{array}$ \\
\hline 354490 & SP & \begin{tabular}{|l|} 
Sales \\
Oliveira \\
\end{tabular} & 10.568 & 13-Nov-14 & http://189.112.90.177/portaltransparencia \\
\hline 354750 & SP & \begin{tabular}{|l|} 
Santa Rita \\
do Passa \\
Quatro \\
\end{tabular} & 26.478 & 18-Nov-14 & http://200.204.245.148:5656/transparencia/ \\
\hline 354770 & SP & $\begin{array}{l}\text { Santo } \\
\text { Anastácio }\end{array}$ & 20.475 & 06-Nov-14 & $\begin{array}{l}\text { http://www.transparencia.santoanastacio.sp.gov.br/Portal/Transpa } \\
\text { renciaDosMunicipios.aspx }\end{array}$ \\
\hline 354970 & SP & \begin{tabular}{|l|} 
São José \\
do Rio \\
Pardo \\
\end{tabular} & 51.900 & 04-Nov-14 & http://www.saojosedoriopardo.sp.gov.br/portal-da-transparencia \\
\hline 354990 & SP & $\begin{array}{l}\text { São José } \\
\text { dos } \\
\text { Campos } \\
\end{array}$ & 629.921 & 29-Oct-14 & http://www.sjc.sp.gov.br/servicos/portal_da_transparencia.aspx \\
\hline 355070 & SP & $\begin{array}{l}\text { São } \\
\text { Sebastião }\end{array}$ & 73.942 & 17-Nov-14 & [Acesso indisponível] \\
\hline 355340 & SP & Tanabi & 24.055 & 04-Nov-14 & http://201.28.69.131/transparencia/ \\
\hline 355360 & SP & Tapiratiba & 12.737 & 18-Nov-14 & http://www.tapiratiba.sp.gov.br/novo_site/portaltransparencia/ \\
\hline 355410 & SP & Taubaté & 278.686 & 10-Nov-14 & $\begin{array}{l}\text { http://leideacesso.etransparencia.com.br/taubate.prefeitura.sp/Po } \\
\text { rtal/desktop.html?325 }\end{array}$ \\
\hline 355450 & $\mathrm{SP}$ & Tietê & 36.835 & 13-Nov-14 & http://www.tiete.sp.gov.br/portal-transparencia-municiapl.php \\
\hline 355630 & SP & Valparaíso & 22.576 & 10-Nov-14 & $\begin{array}{l}\text { http://valparaiso.prefeitura.sp.etransparencia.com.br/portal/transp } \\
\text { arencia.aspx }\end{array}$ \\
\hline 355645 & SP & Vargem & 42.997 & 18-Nov-14 & http://200.168.9.56:8080/portalcidadao \\
\hline
\end{tabular}




\begin{tabular}{|c|c|c|c|c|c|}
\hline & & $\begin{array}{l}\text { Grande } \\
\text { Paulista }\end{array}$ & & & \\
\hline 355660 & SP & Vera Cruz & 10.769 & $07-N o v-14$ & http://189.79.167.155:5656/Transparencia/ \\
\hline 355670 & SP & Vinhedo & 63.611 & 17-Nov-14 & http://simtransparencia.vinhedo.sp.gov.br/ \\
\hline 355710 & SP & $\begin{array}{l}\text { Votuporang } \\
\text { a }\end{array}$ & 84.692 & 18-Nov-14 & http://web.votuporanga.sp.gov.br:5656/transparencia/ \\
\hline 170930 & TO & Guaraí & 23.200 & 24-Nov-14 & http://guarai.to.gov.br/portal/transparencia/ \\
\hline 170950 & TO & Guripi & 76.755 & 29-May-14 & $\begin{array}{l}\text { http://gurupi.megasofttransparencia.com.br/gurupi- } \\
\text { transparencia/index.jsf }\end{array}$ \\
\hline 171488 & TO & $\begin{array}{l}\text { Nova } \\
\text { Olinda }\end{array}$ & 10.686 & 29-May-14 & $\begin{array}{l}\text { http://contaspublicas.dattasystem.com.br/transparencia.asp?id_e } \\
\text { ntidade }=9\end{array}$ \\
\hline 172120 & TO & $\begin{array}{l}\text { Tocantinóp } \\
\text { olis }\end{array}$ & 22.619 & 29-May-14 & http://www.tocantinopolis.to.gov.br/transparencia/ \\
\hline 172210 & TO & Xambioá & 11.484 & $24-N o v-14$ & [Acesso indisponível] \\
\hline
\end{tabular}




\section{APÊNDICE B - Disponibilidade dos dados do levantamento amplo}

Este apêndice disponibiliza todos os dados coletados do levantamento amplo com 561 municípios. Todos os dados coletados durante a avaliação e utilizados para realizar este trabalho são fornecidos como dados abertos para serem consumidos por qualquer pessoa. $O$ repositório completo pode ser acessado e baixado em https://datahub.io/dataset/opennessbrazil2014. Há três arquivos CSV, como explicado a seguir.

- municipalities.csv - contém todos os dados pesquisados relacionados com cada município avaliado. A Tabela 6 detalha sua estrutura de dados.

- required_items.csv - contém todos os dados pesquisados relacionados com a avalição dos itens mínimos necessários e o respectivo formato utilizado para divulgação. A Tabela 7 detalha sua estrutura de dados.

- technical_requirements.csv - contém todos os dados pesquisados para avaliar os requisitos técnicos. A Tabela 8 detalha sua estrutura de dados.

Além disso, as visitas geraram evidências de visitação aos websites e reuniu documentos com os principais achados que testemunham o processo de avaliação. Esses arquivos podem ser acessados em https://datahub.io/dataset/opennessbrazil2014. Há uma estrutura de pastas com o código e nome do município identificando cada grupo de arquivos.

\begin{tabular}{|l|l|l|}
\hline Campo & Descrição & Exemplo \\
\hline Ibge_code & Código que identifica unicamente o município & 120080 \\
\hline State & Acrônimo da unidade de federação & AC \\
\hline municipality & Nome por extenso do município & Porto Acre \\
\hline population & Número de habitantes & 14880 \\
\hline assess_date & $\begin{array}{l}\text { Data de quando o website foi avaliado (dd-MMM- } \\
\text { yyyy) }\end{array}$ & 25-Apr-14 \\
\hline transp_url & Principal endereço do website & http://www.portoacre.ac... \\
\hline
\end{tabular}




\begin{tabular}{|l|l|l|}
\hline Campo & Descrição & Exemplo \\
\hline Ibge_code & Código que identifica unicamente o município & 120080 \\
\hline ri_x & $\begin{array}{l}\text { Resultado da avaliação dos itens mínimos de } \\
\text { divulgação, onde } x \text { representa as letras de "a" a "f" } \\
\text { para referenciar a cada item (veja Tabela 4). Os } \\
\text { critérios possíveis de avaliação são "Y" para sim, } \\
\text { "N" para não e "P" para parcial }\end{array}$ & Y \\
\hline ri_x_format & $\begin{array}{l}\text { Formatos dos dados/arquivos identificados para } \\
\text { cada item requerido, onde } x \text { representa as letras } \\
\text { de "a" a "f" para referenciar o item (veja Tabela 4). } \\
\text { Havendo mais de um formato, há a separação por } \\
\text { barra }\end{array}$ & HTML/CSV \\
\hline
\end{tabular}

\begin{tabular}{|l|l|l|}
\hline Campo & Descrição & Exemplo \\
\hline Ibge_code & Código que identifica unicamente o município & 120080 \\
\hline tr_x & $\begin{array}{l}\text { Resultado da avaliação dos requisitos técnicos, } \\
\text { onde } x \text { representa os números romanos de "I" a } \\
\text { "VIII" (exceto "V") para referenciar cada item (veja } \\
\end{array}$ & Tabela 5). Os critérios possíveis de avaliação dos \\
& $\begin{array}{l}\text { requisitos de "I" a "VII" são "Y" para sim e "N" para } \\
\text { não; para o requisito "VIII" o critério varia de um a } \\
10 \text { (veja Tabela 6) }\end{array}$ & \\
\hline
\end{tabular}




\section{APÊNDICE C - Fichas de análise arquitetural geradas no processo de validação}

Este apêndice fornece as cópias digitalizadas das fichas de análise arquitetural geradas pelo time de validadores durante o processo de validação. Cada validador teve acesso a um total de oito fichas, sendo que cada ficha era referente à um cenário selecionado da arquitetura. No total foram oito cenários avaliados. Três pessoas participaram do processo de validação.

A seguir são apresentadas as fichas referentes ao Validador 1.

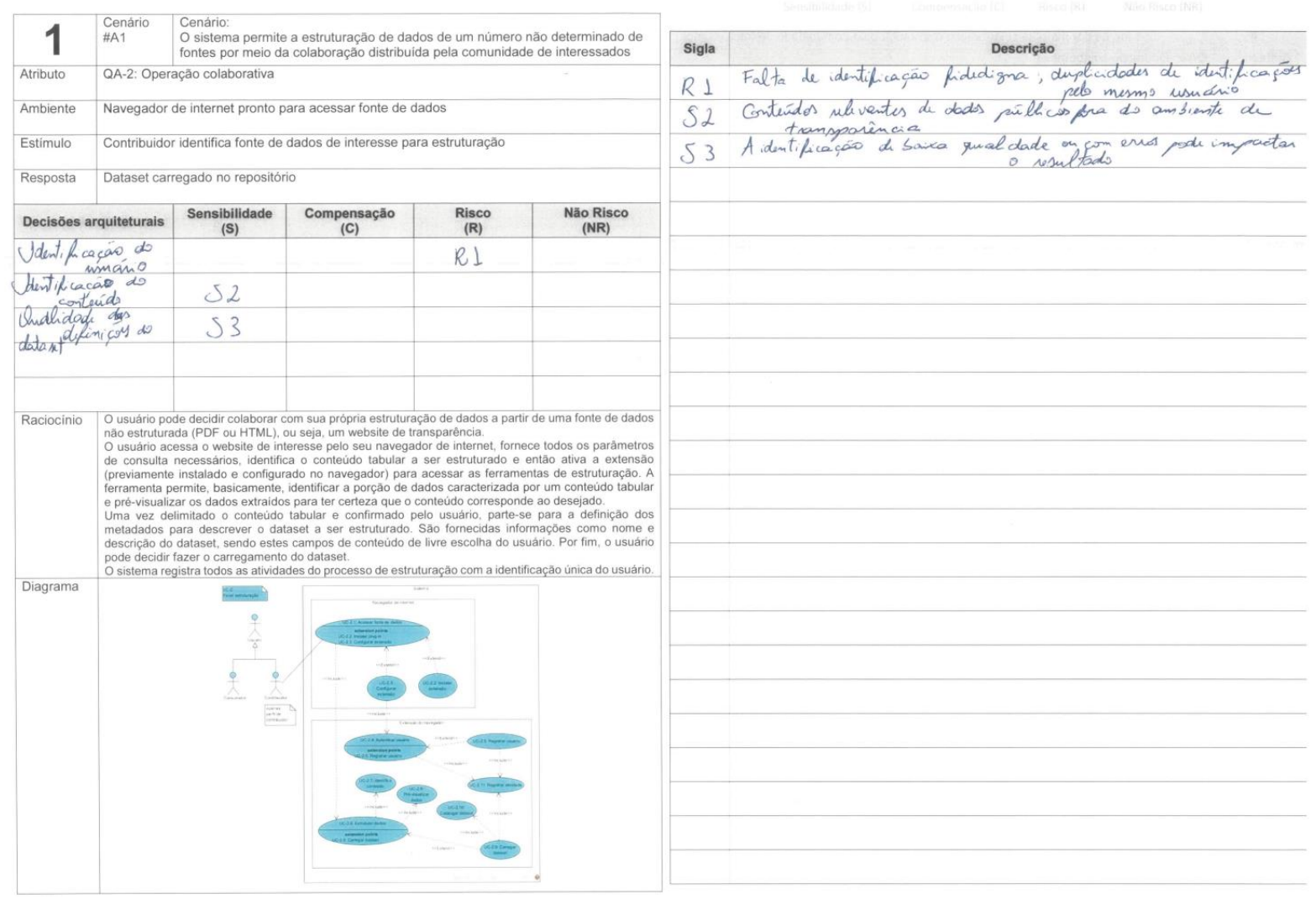




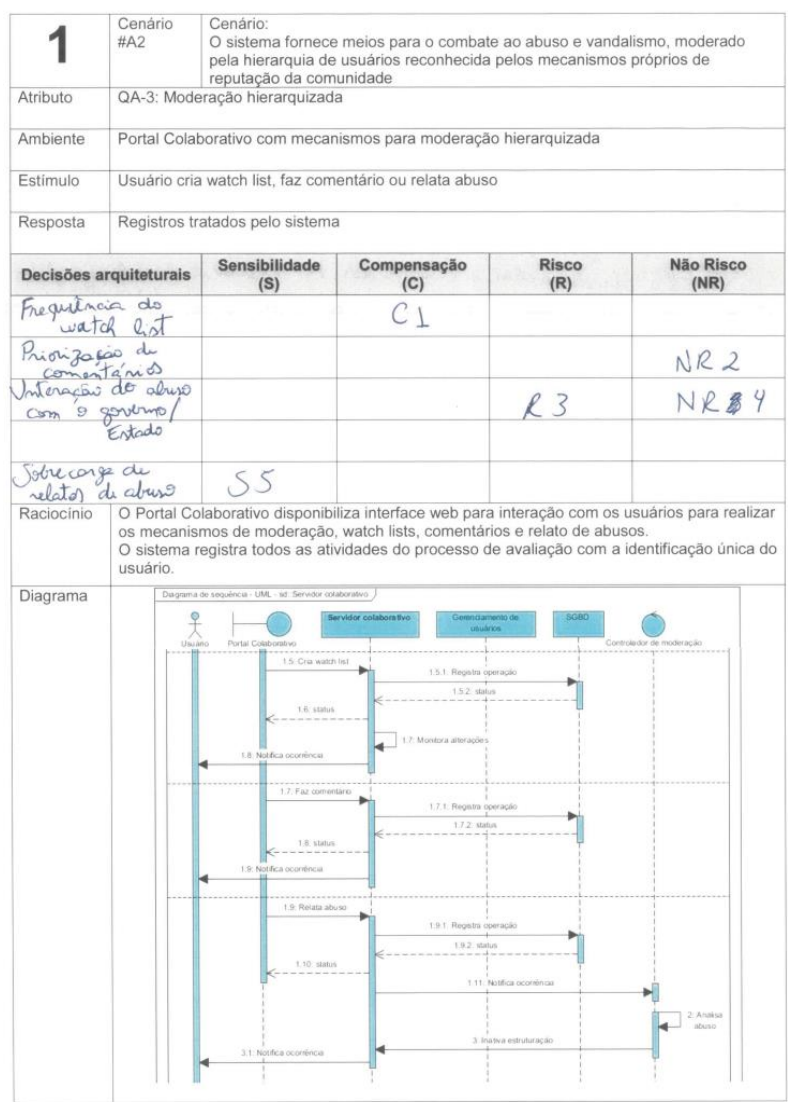

Sigla A possifilidede de moderecea do wate list pode trazer main NR2 Prionzer comentários traz mais vala ass comentániss gue säs, R3 A cracéo de intere cä́s de ferramente cum o govermo en cass de

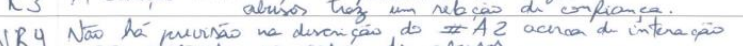

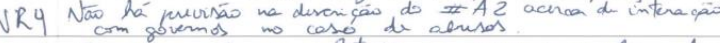
$\$ 5$ Os abusos podom in relatados an exceser e macular a fer-

\begin{tabular}{|l|}
\hline \\
\hline \\
\hline \\
\hline \\
\hline \\
\hline \\
\hline \\
\hline
\end{tabular}

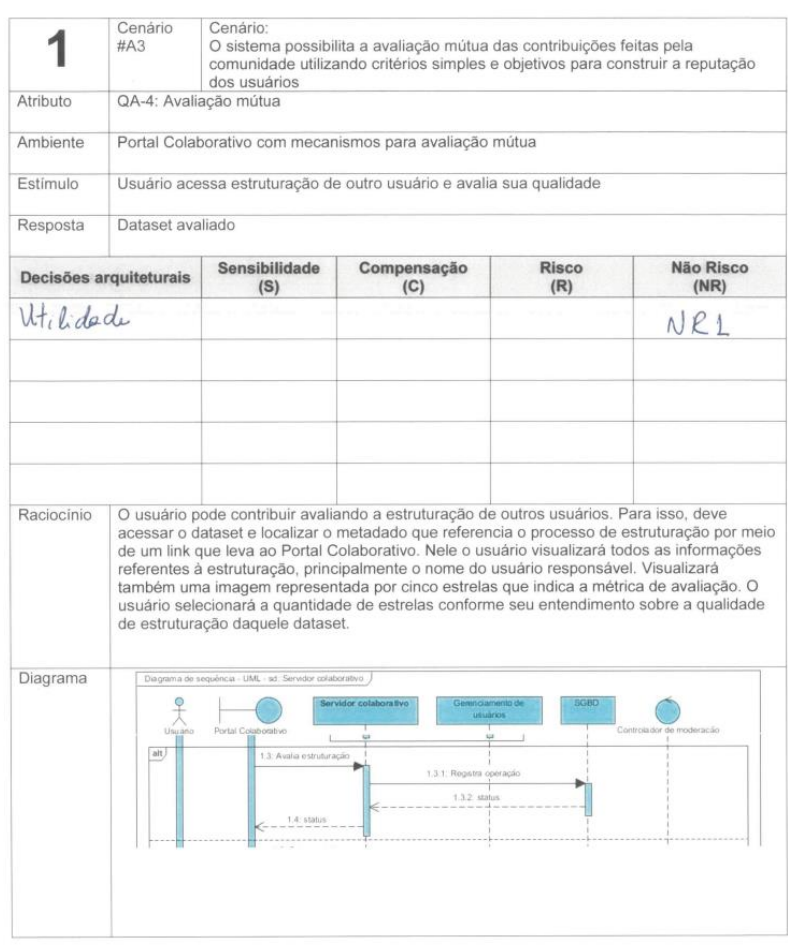

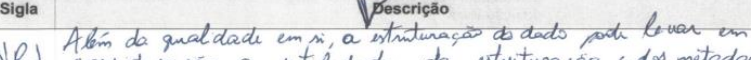
VRI considere céso a util dede da estrutura,éo c dos metada 


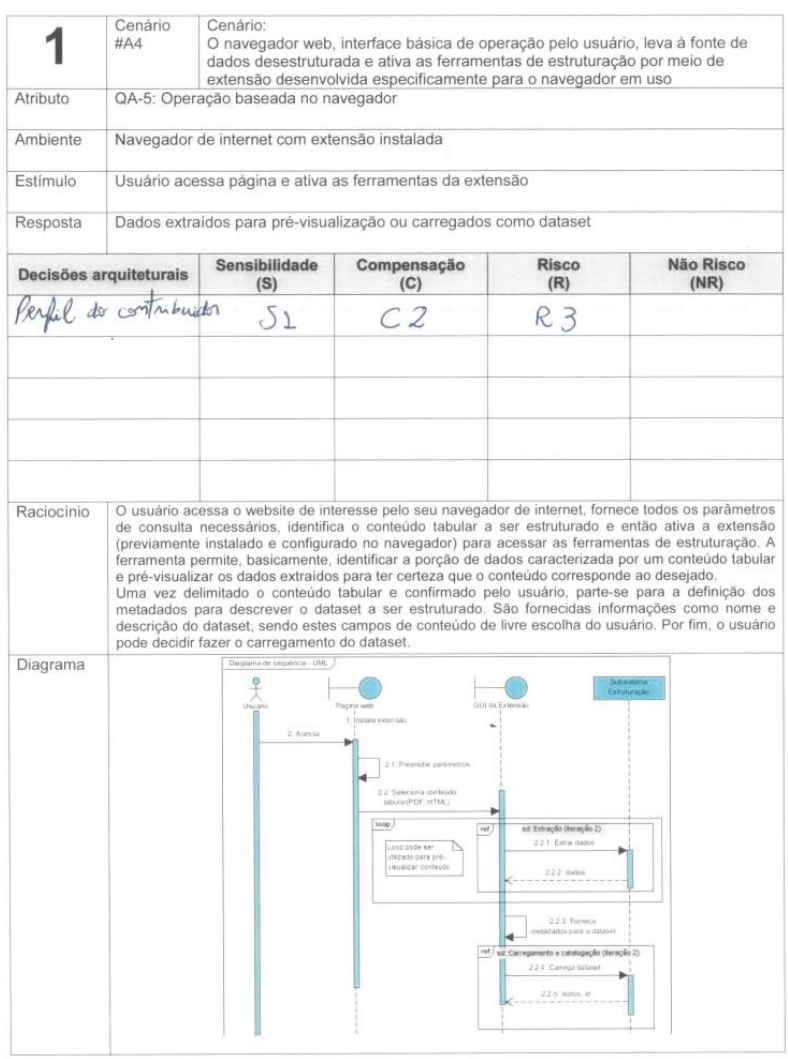

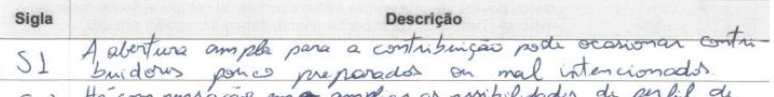

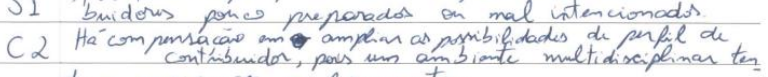
de a enriguecer a ferramenta.

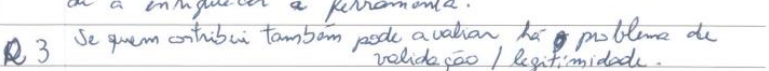
cere

\begin{tabular}{|l}
\hline \\
\hline \\
\hline \\
\hline \\
\hline \\
\hline \\
\hline \\
\hline \\
\hline
\end{tabular}

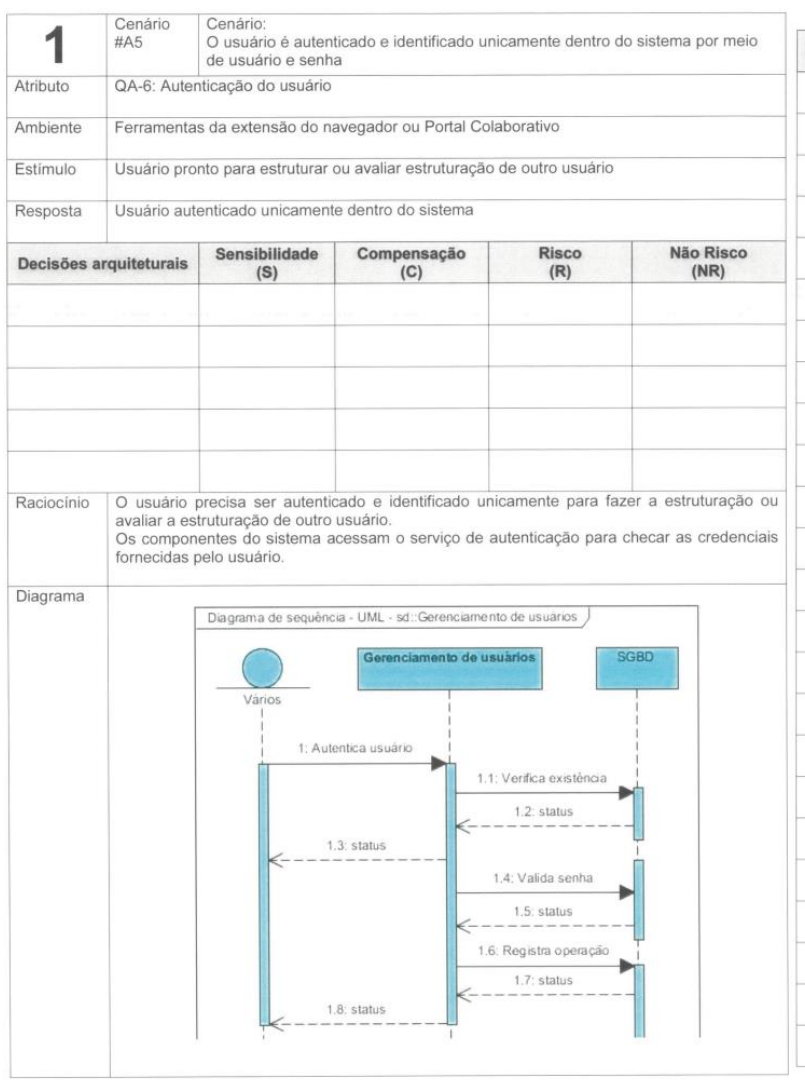




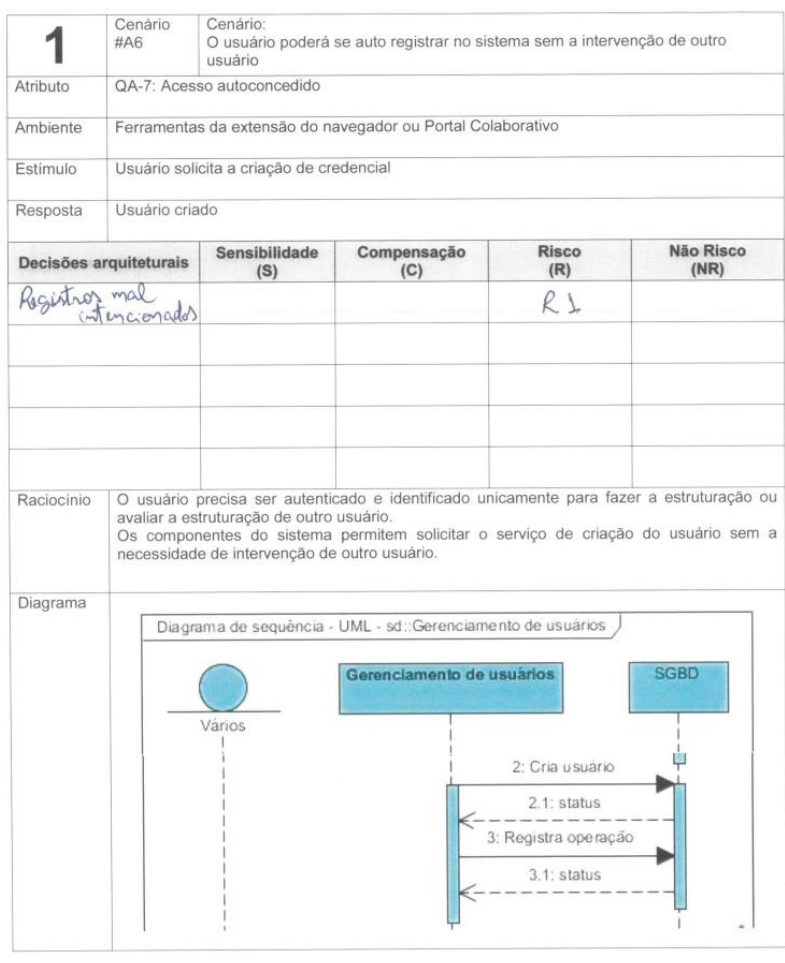

\begin{tabular}{|c|c|}
\hline Sigla & 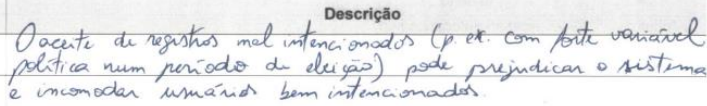 \\
\hline & \\
\hline & \\
\hline & \\
\hline & \\
\hline & \\
\hline & \\
\hline & \\
\hline & \\
\hline & \\
\hline & \\
\hline & \\
\hline & \\
\hline & \\
\hline & \\
\hline & \\
\hline & \\
\hline & \\
\hline & \\
\hline & \\
\hline
\end{tabular}

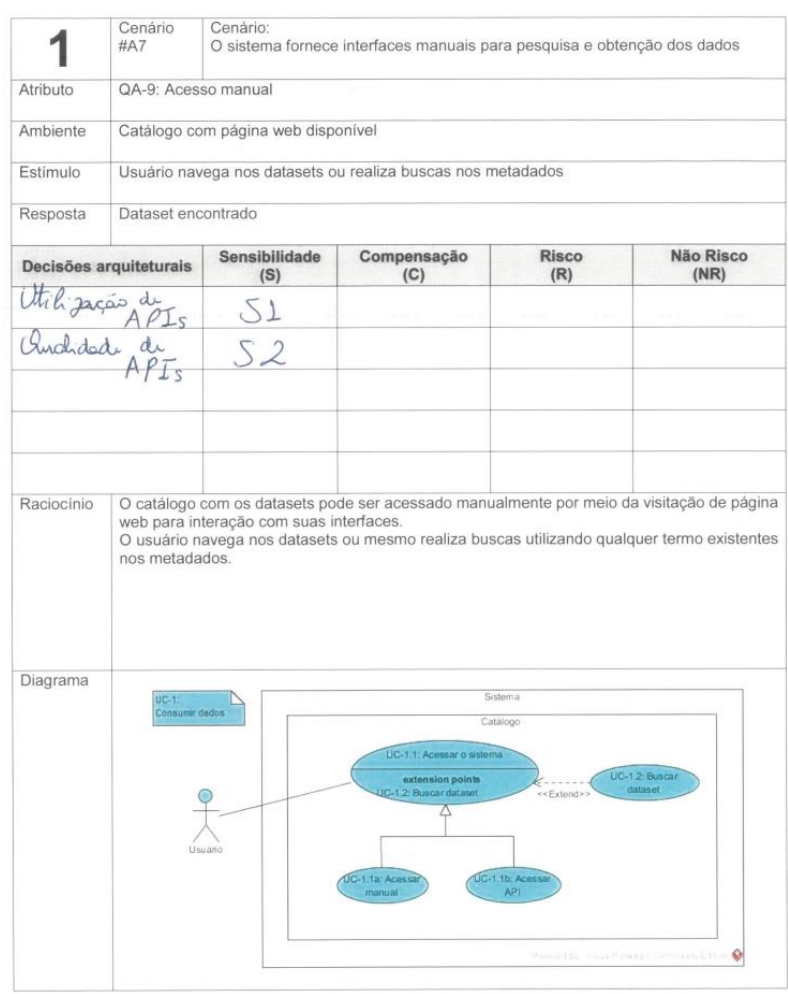

Sigla

S1 A utilizecaio de APIs mal estriturados por un usucénio pode S2 As APIs com qualidade devemser a mito de toda a ferramenta. 


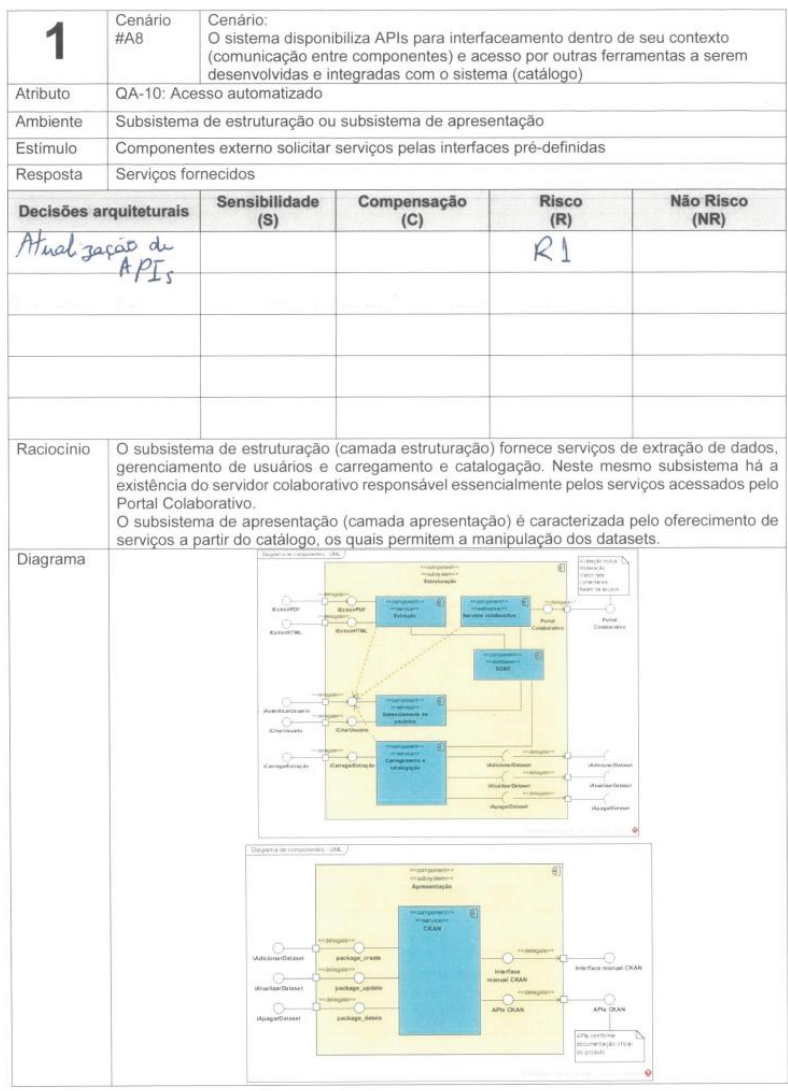

\begin{tabular}{|c|c|}
\hline Sigla & \\
\hline RI & 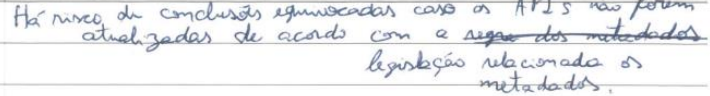 \\
\hline & \\
\hline & \\
\hline & \\
\hline & \\
\hline & \\
\hline & \\
\hline & \\
\hline & \\
\hline & \\
\hline & \\
\hline & \\
\hline & \\
\hline & \\
\hline & \\
\hline & \\
\hline & \\
\hline
\end{tabular}

A seguir são apresentadas as fichas referentes ao Validador 2.
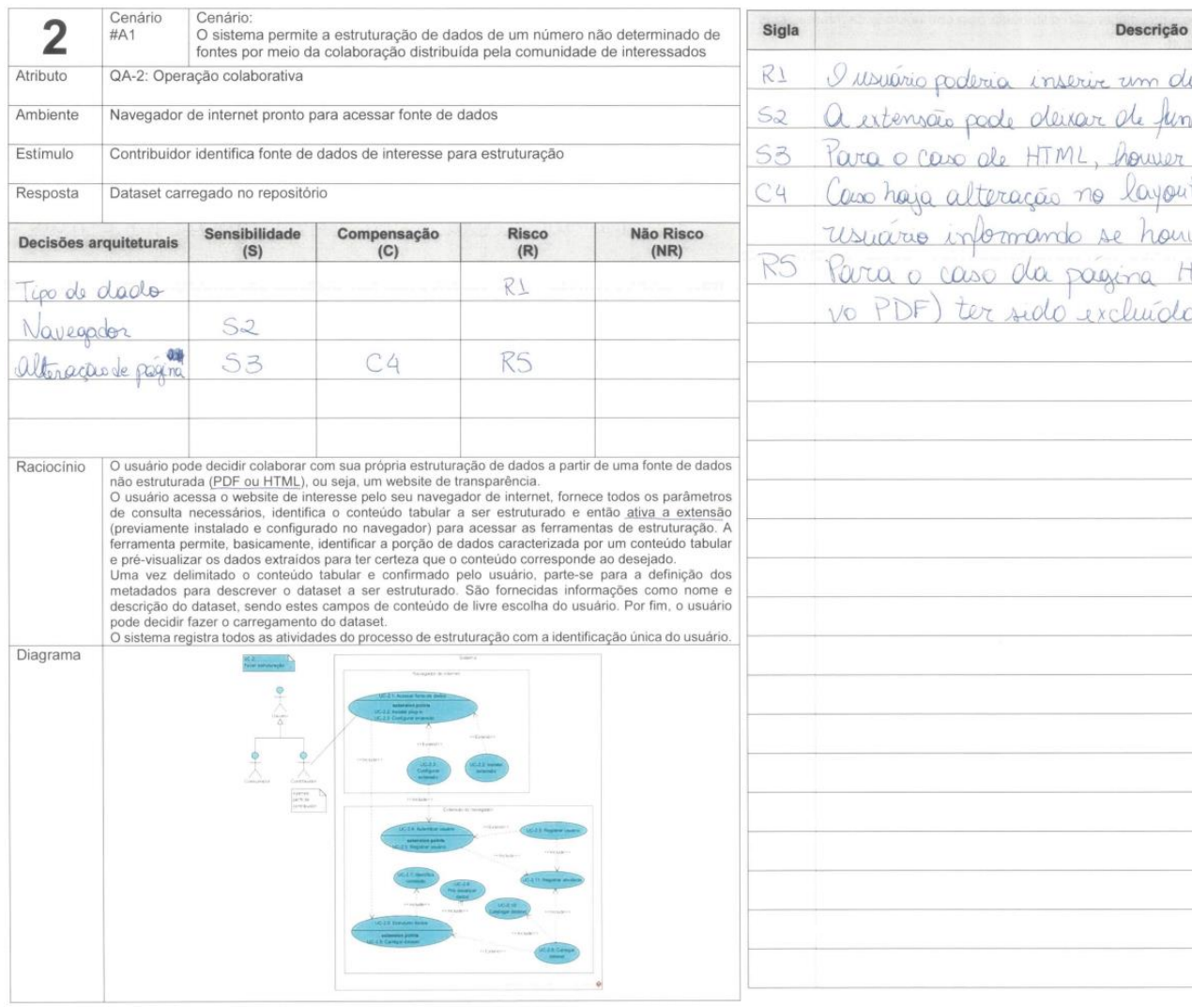

R1 Unsuário poderia inserie um dado de um tipo diferente. S2 A extensaio pade dexar de funcionar c/ nova versaio

53 Para o caso de HTML, houver mudancas no lavout

C4 Caso haja alteraçás no layout mandar um e-mail as usuário informando se houve alteracaio

R5 Para o caso da página HTML (ou mesmo o arqu vo PDF) ter sudo excluído (o erro 404)

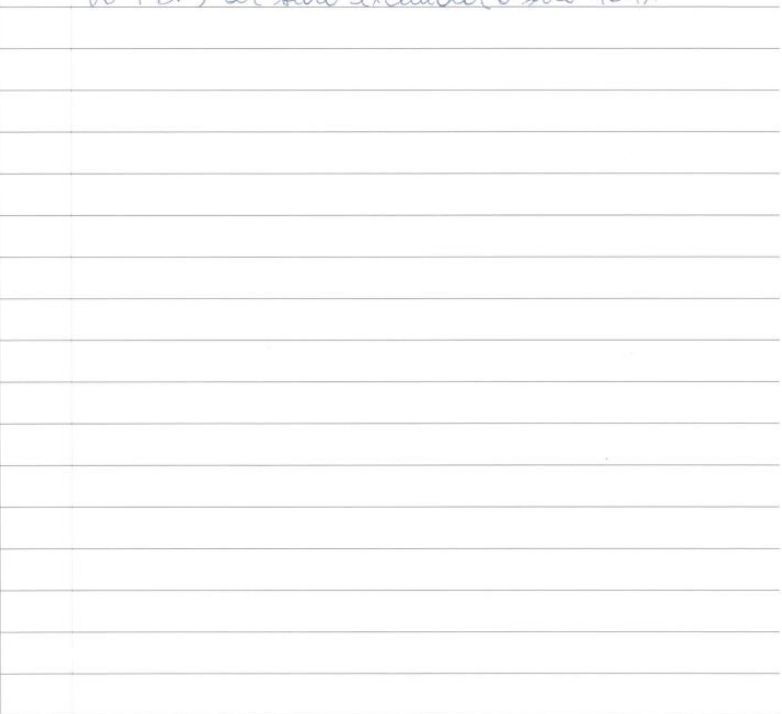




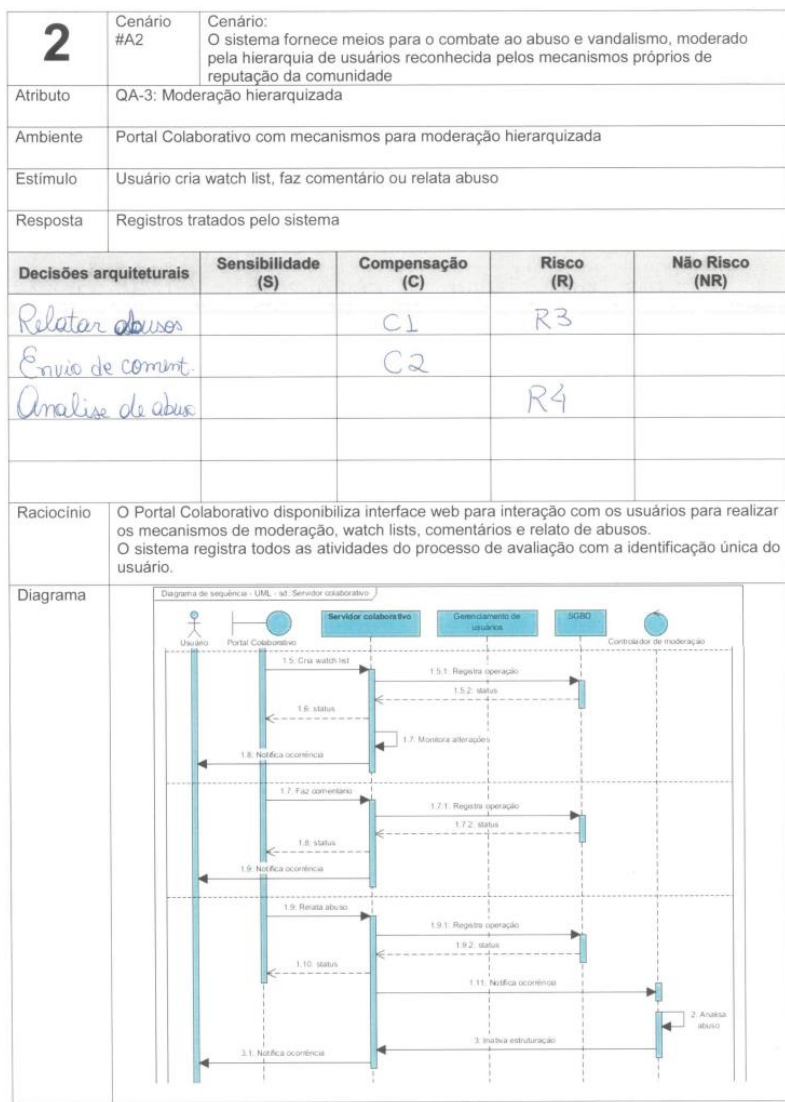

Sigla

Cl Um usuário (ou um orcupo de usuários) pode "abusar" d. levramenta de revatar a busos Ou combinarem de relatar coletivamente determinado conteúdo

C2 Usuarios podem usar essa ferramenta para en viar comentários el palaviós e outras pala. vras de baino caláa

R3 Omesmo usuario (cl contas diferentes) pode abusar do zeso dessa fercamento

R4 Guem garante que a análise de abuso sera imparia

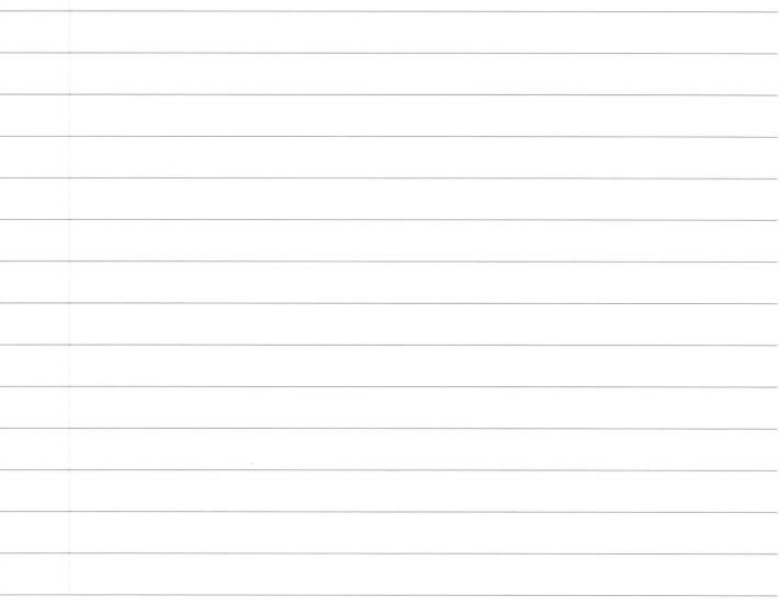

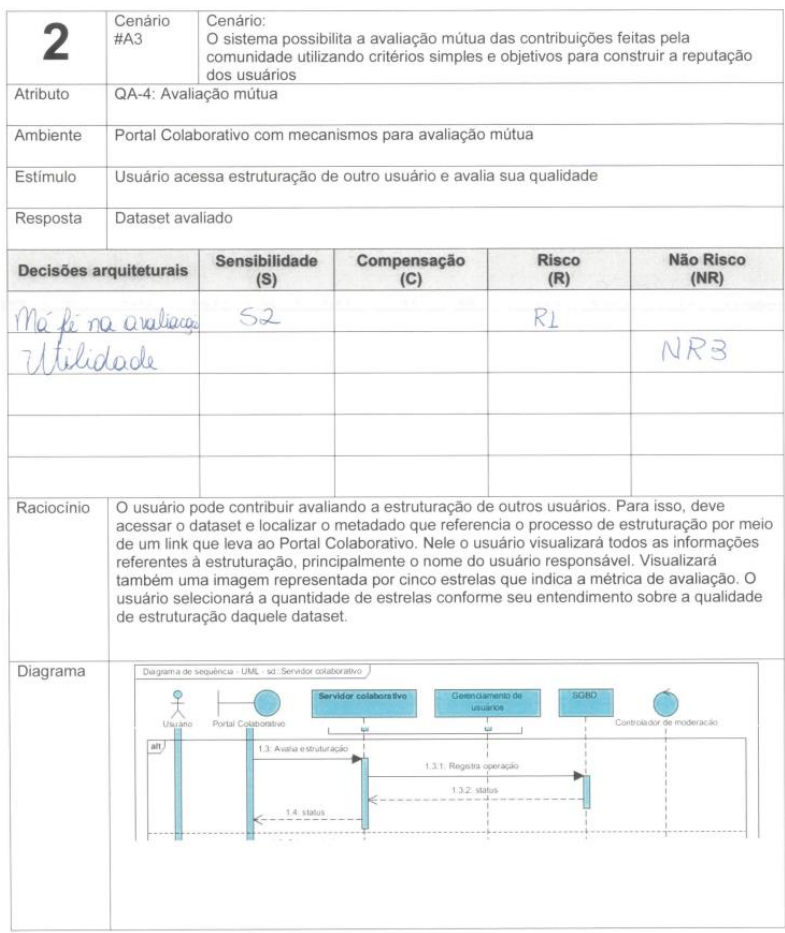

Sigla

\section{Descriçăo}

R1 Um usuário pode, por má fé, avaliar negativamente ou tro usuario

S2 Como o sistema trotará as avaliacos (e os avaliadas) que receberam muitas avaliacos negortwas inaduertide mente

NR3 Oque ocorrera d as baxas avaliacoes? 


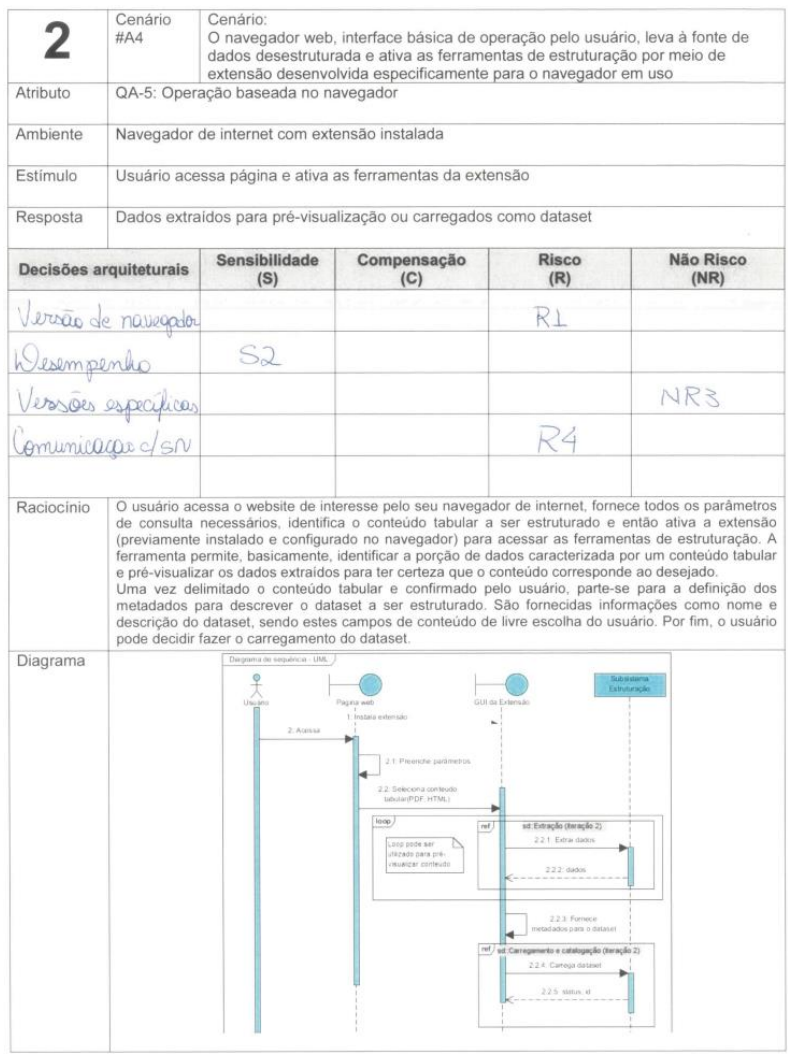

Sigla

Descriçăo

R1 Caso o navegodor seja atralizado e a ex tensaí deixe de fimsion S2 A extensás pode acauritar numa perda de desempenk p/ o naveapdor (como maror consumo de memoria) VR3 Talvez haja necessidade de versoes p/ cado navegado R4 A extensāo pode se comunicar como servidor pore - servidor pode estar fora do ar

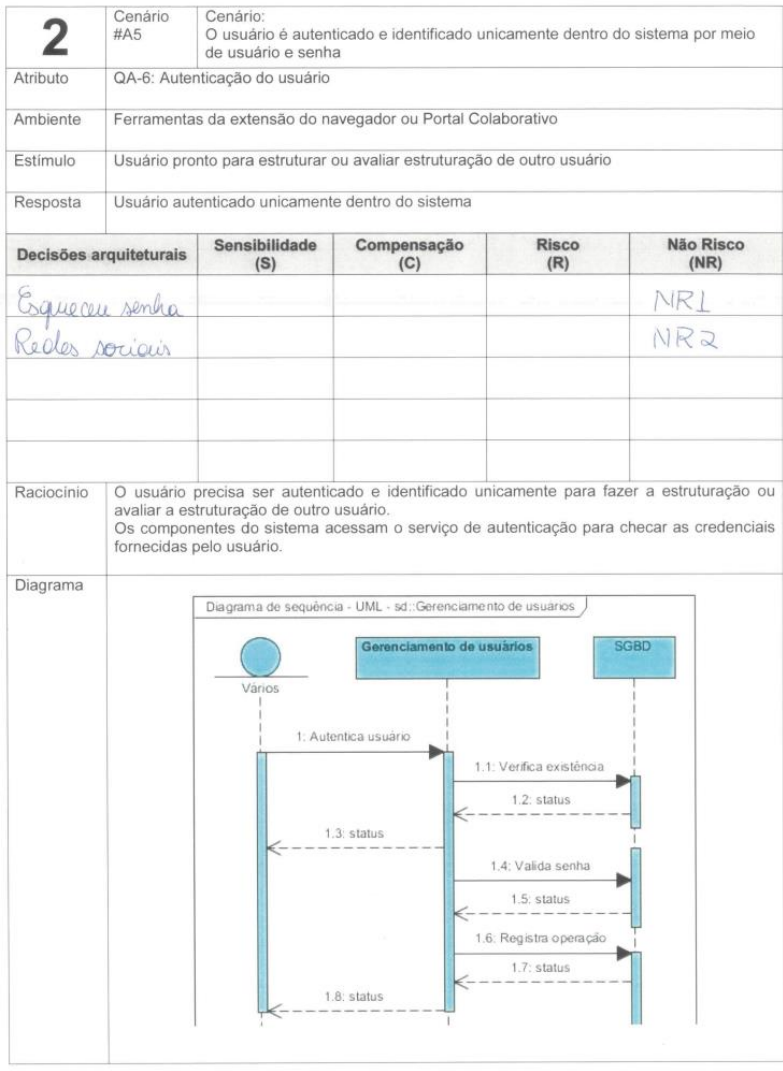

Sigla

Descriçăo

NR1 Ussuário pode ter esquecido a sentra dele Doú pode. ria ser envriada uma nova senha a ele por e-mail NR2 Poder logar-se c/ contas de redes sociais (6+, Faa book. turitter, etc.) 


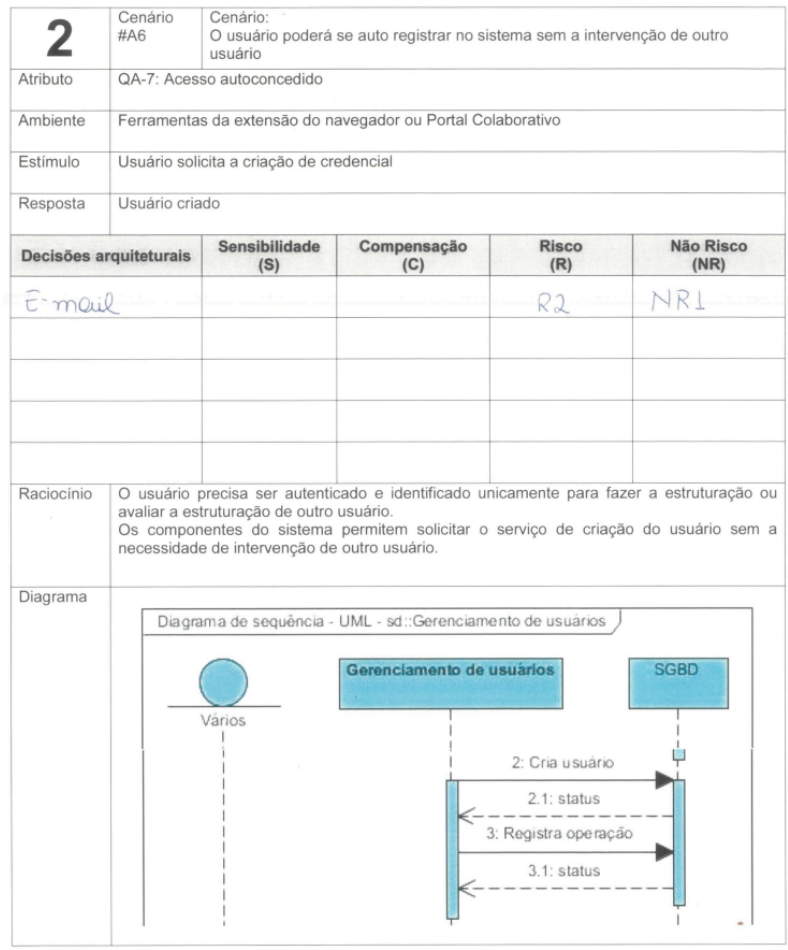

\begin{tabular}{|c|c|}
\hline Sigl & Descricăo \\
\hline
\end{tabular}

NR1 Caso o usuairio use um e-maul que noì existe R2 I usuário pode se registrar d um e-mail já existant

\begin{tabular}{|l|}
\hline \\
\hline \\
\hline \\
\hline \\
\hline \\
\hline \\
\hline \\
\hline 5 \\
\hline
\end{tabular}

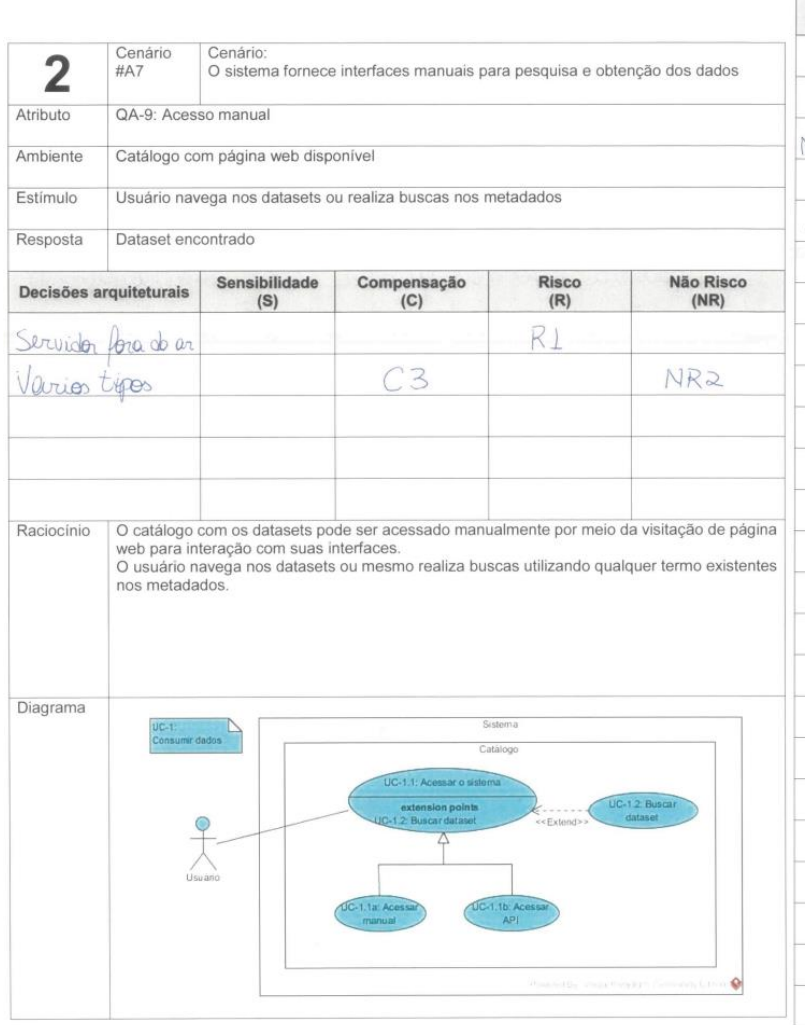

\section{Descriçăo}

R1 Oacesso a API pode ser futo quando o servidor estiver fora do ar

NR2 Ulm mesmo dataset pode ter vários tipos Daí a API poderia informar qual o tipo a ser consumido

C3 U tipo a ser consumido pode naĩ exister mais, ou estar corrompido 


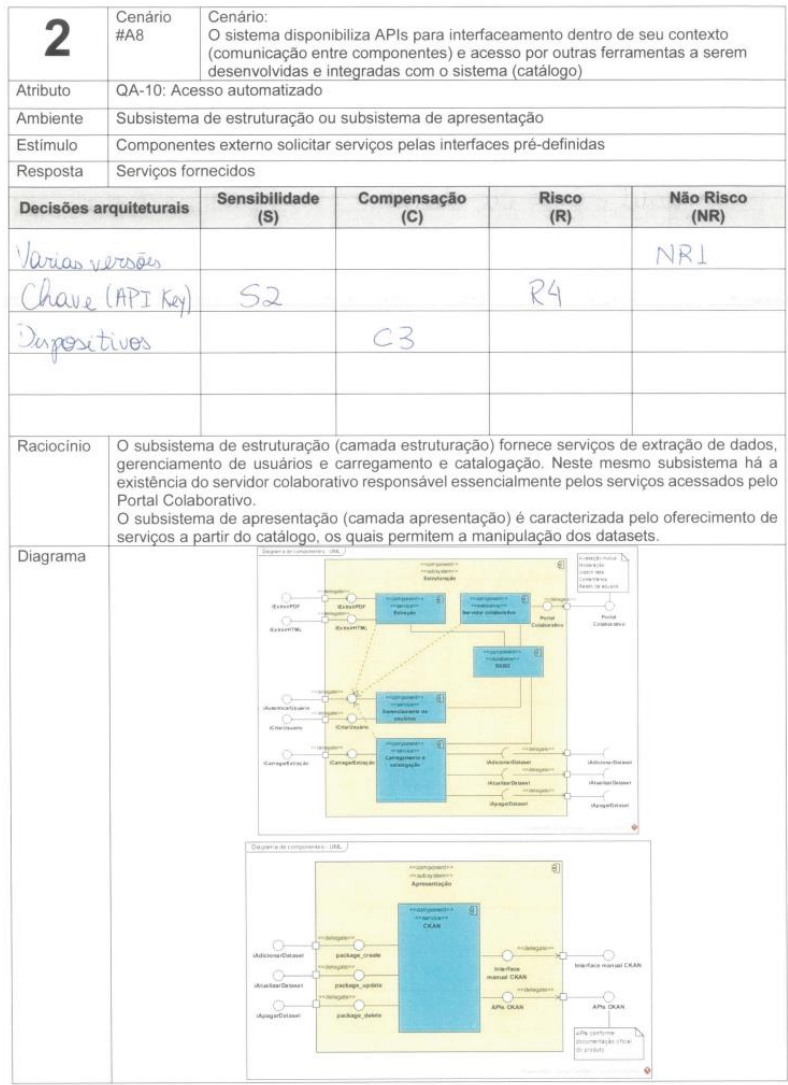

\begin{tabular}{|c|c|}
\hline Sigla & Descriçăo \\
\hline$N R \perp$ & $\begin{array}{l}\text { Odataset pode ter diversos tipos de dados distintos } \\
\text { Ficaria a cargo de mais um parámetro di zendo } \\
\text { qual o tipo de dado. }\end{array}$ \\
\hline S2 & $\begin{array}{l}\text { Para evitar abuso no uso da API, opereece ou- } \\
\text { so de rema chave (API Key) }\end{array}$ \\
\hline$c 3$ & $\begin{array}{l}\text { A API deve ser simples de ser usado pelos mais } \\
\text { diveros dispositivos existentes. }\end{array}$ \\
\hline Ru & Evitar com que haja vazamento dessas chaves. \\
\hline & \\
\hline & \\
\hline & \\
\hline & \\
\hline & \\
\hline & \\
\hline & \\
\hline & \\
\hline & \\
\hline & \\
\hline
\end{tabular}

\section{A seguir são apresentadas as fichas referentes ao Validador 3.}

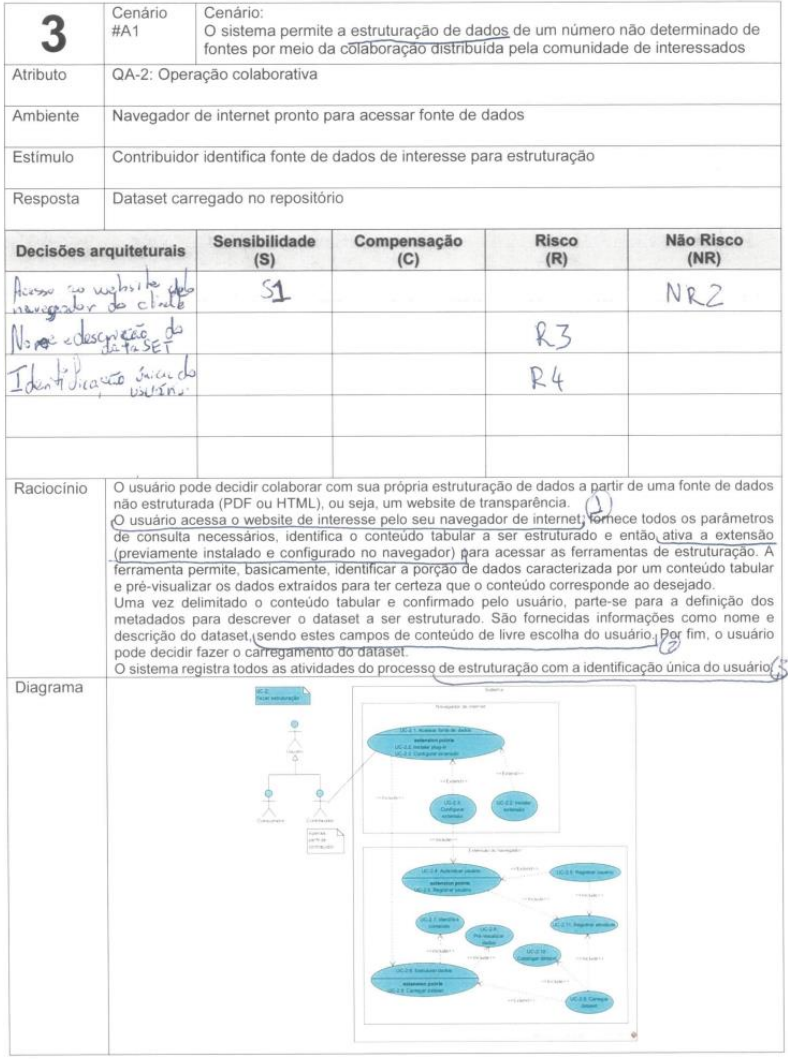




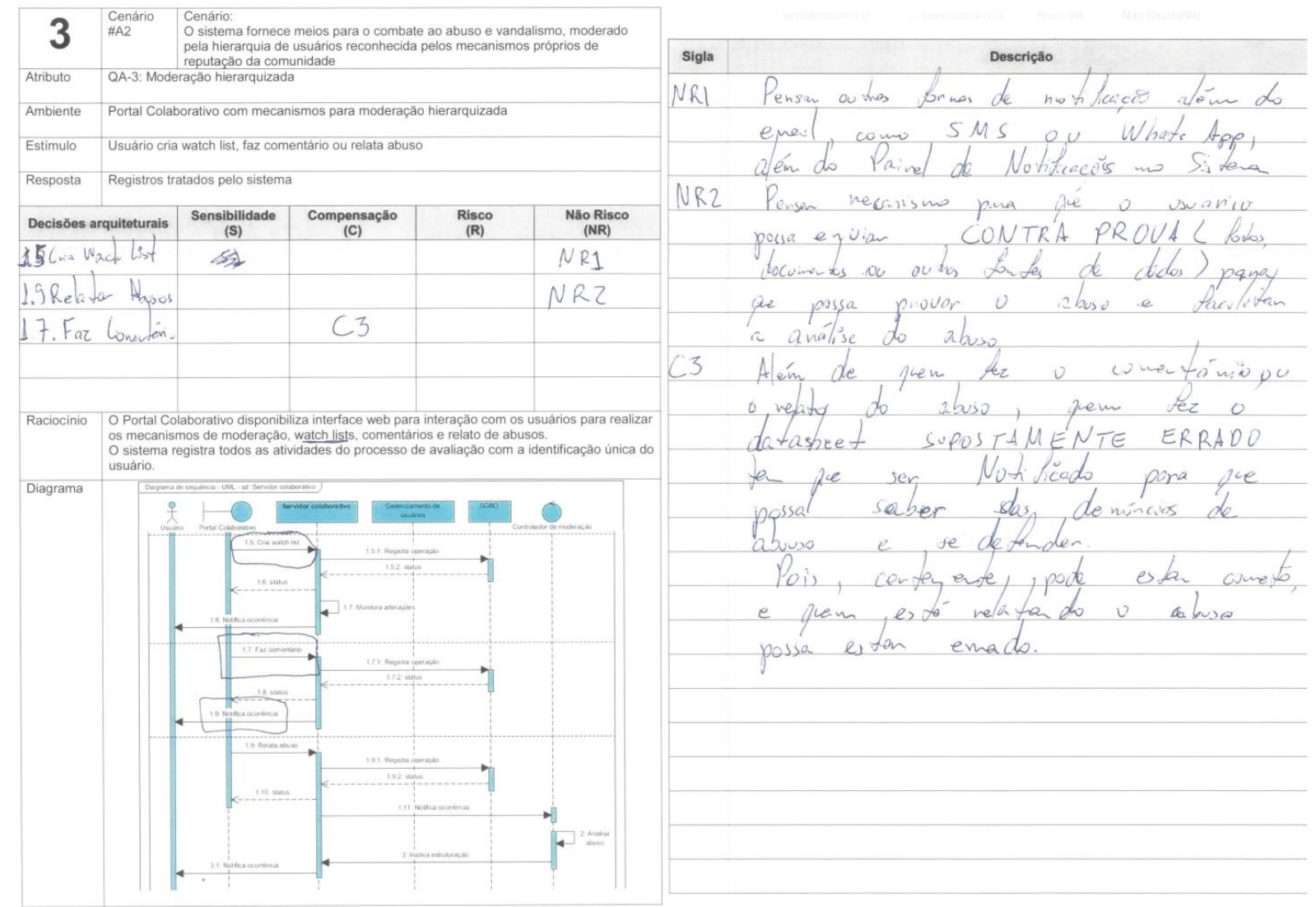

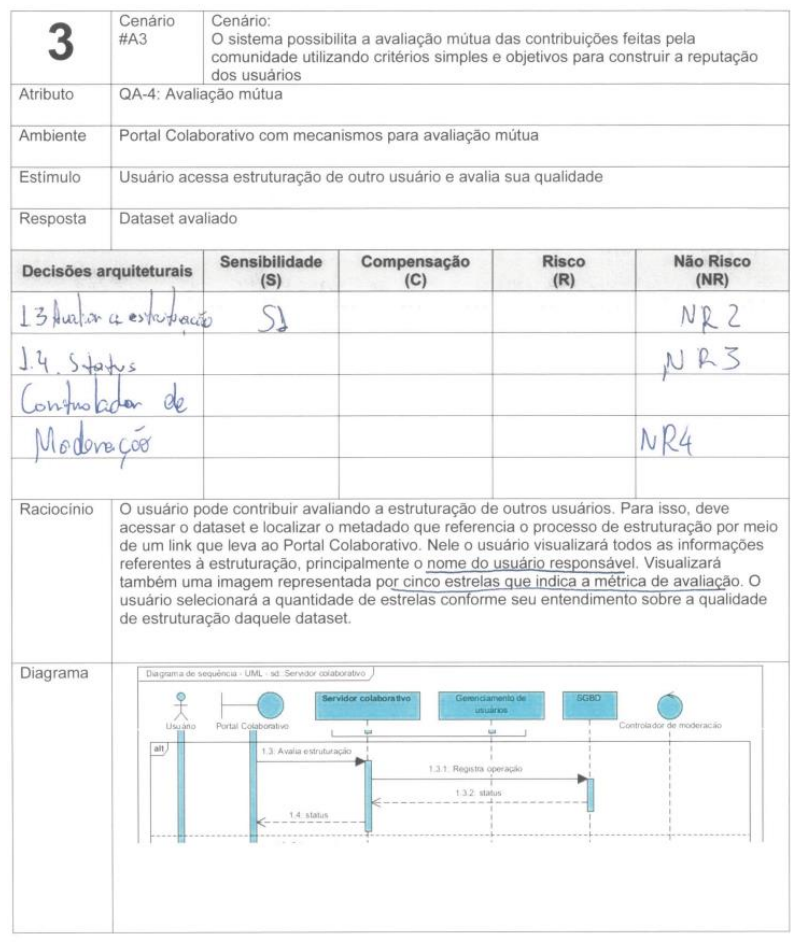

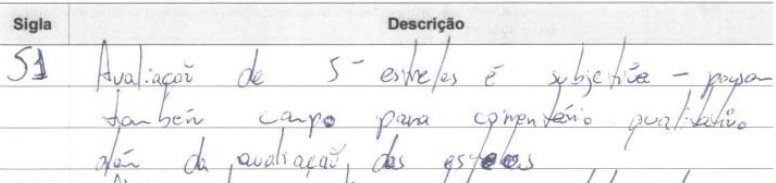
NR2 Aléra de visualizar todos, os dados d. estrutu racé, mostruar o dedo de origim, ov iejo, o liuk lá ua pópiria

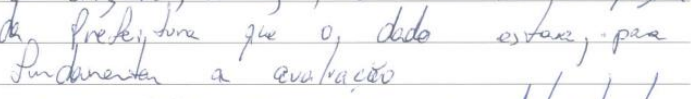
NRS 0 uzuáno qu gerou o data sheet que está sencto avaliado taubém deve ser notificado, para ten bèm ser

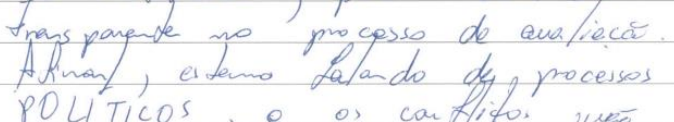

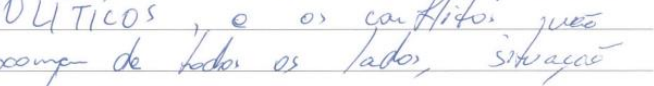
quarto oposica.

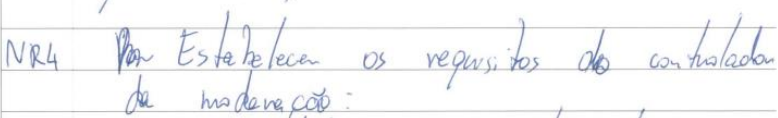
- quem vai deterinar se es E-cento ov

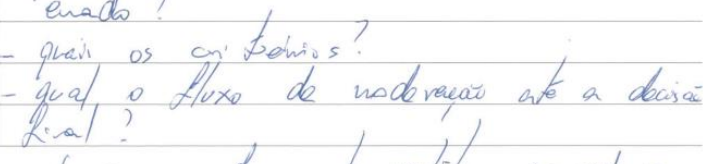

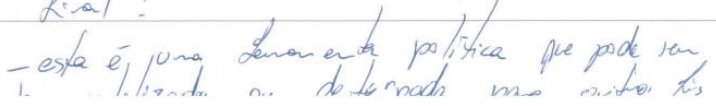




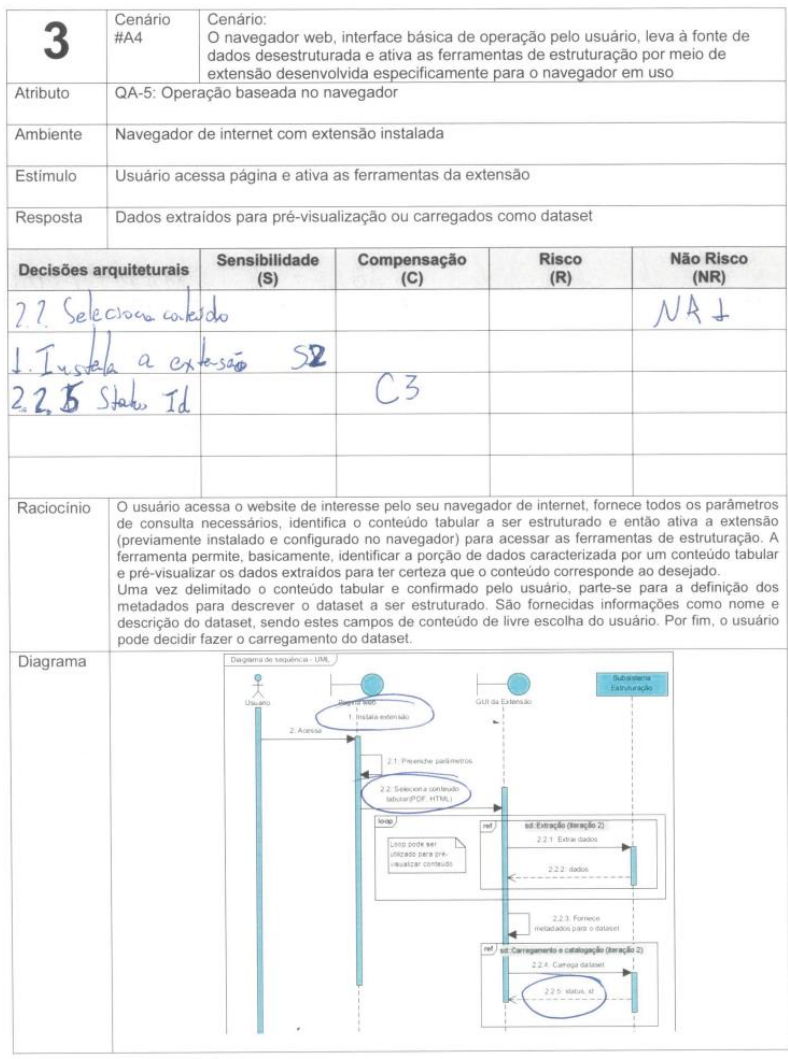

Descricăa
NRI Incluin outar bonts de dades ano Exce/, Doc ete.

S2 Exis bu, pé requisitos, ou sejp, Incoone

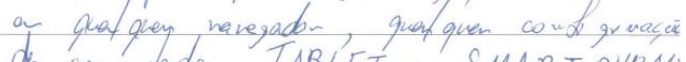
de com putada, TABLET ou SMART PHDNS C3 Alew de none e ID, pengurtar para - usvánio se ele guer sequin equeles dodos (Wacht list) e as derixar, par depoir

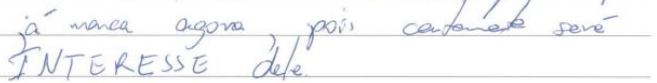

INTERESSE dele.

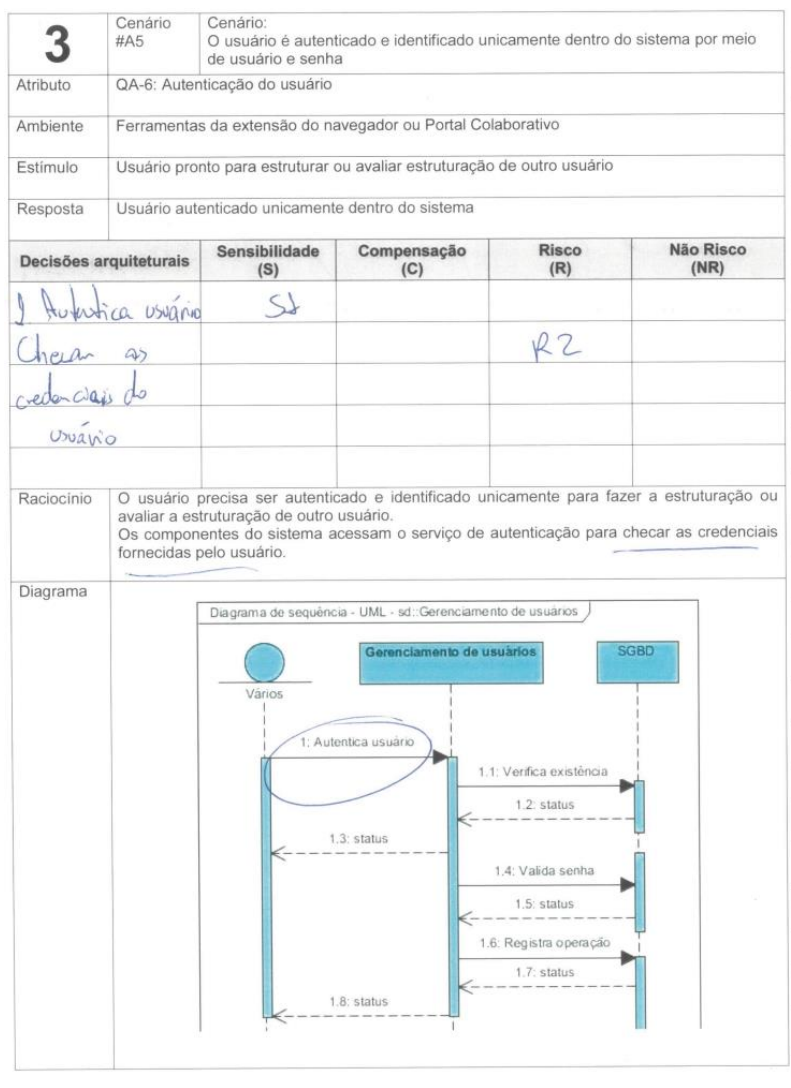

Sigia Incluin outhos Lames de autaticeaca de Usuánio cono Face, $G+$, alui do Whals app neste mido politico, os "ROSTOS"

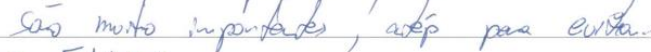
D FAKES

R2 Como o sistema vai identifica que way tor robà's ou cougúnis Lakes.?

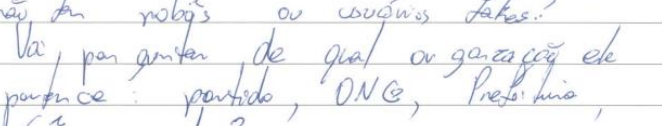
parfuce : partido
Canara ete? 


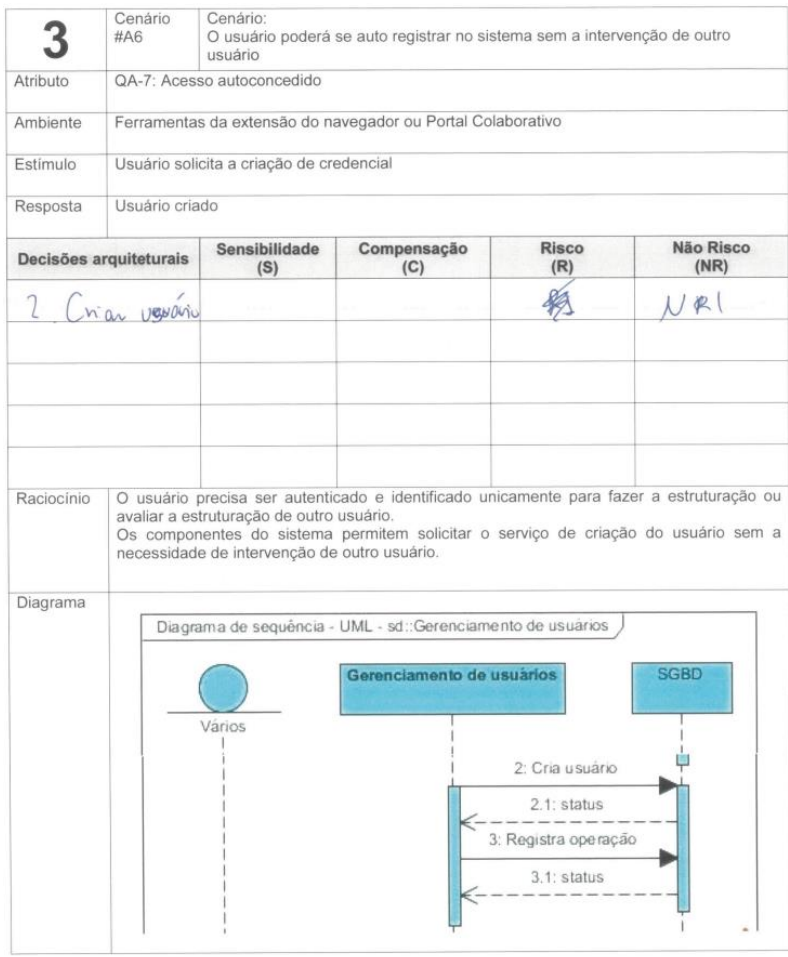

\begin{tabular}{|l|l|}
\hline Sigla & Descriça \\
\hline NRI & Face, Gt e whats app \\
\hline & \\
\hline & \\
\hline & \\
\hline & \\
\hline & \\
\hline
\end{tabular}

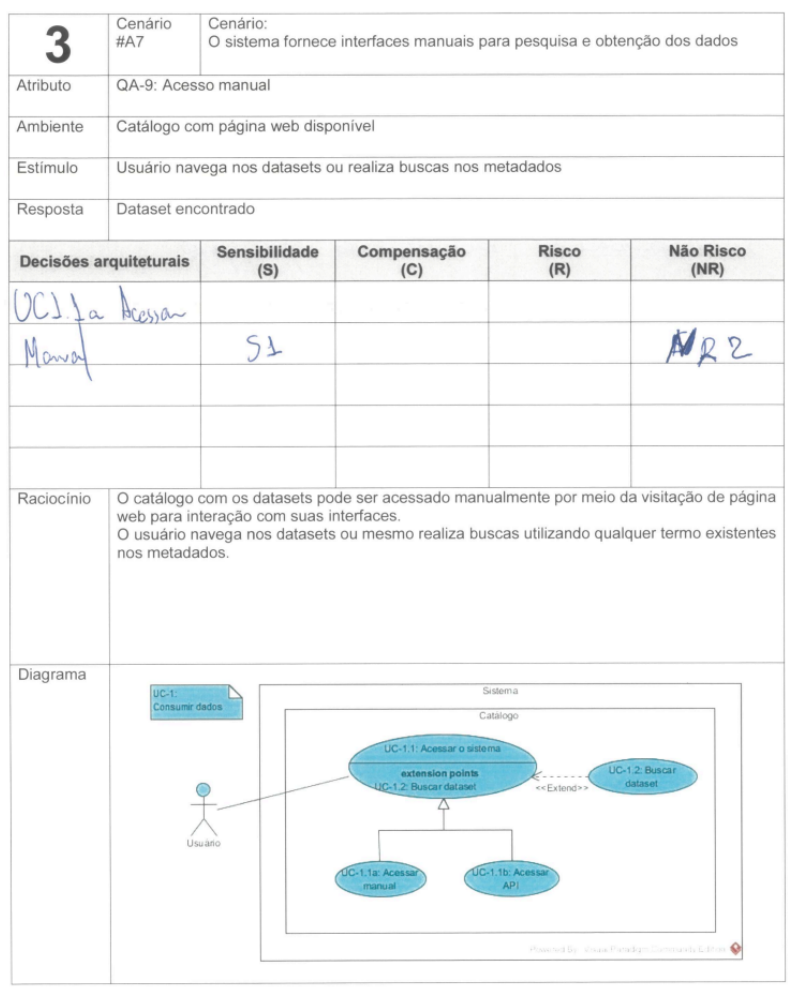




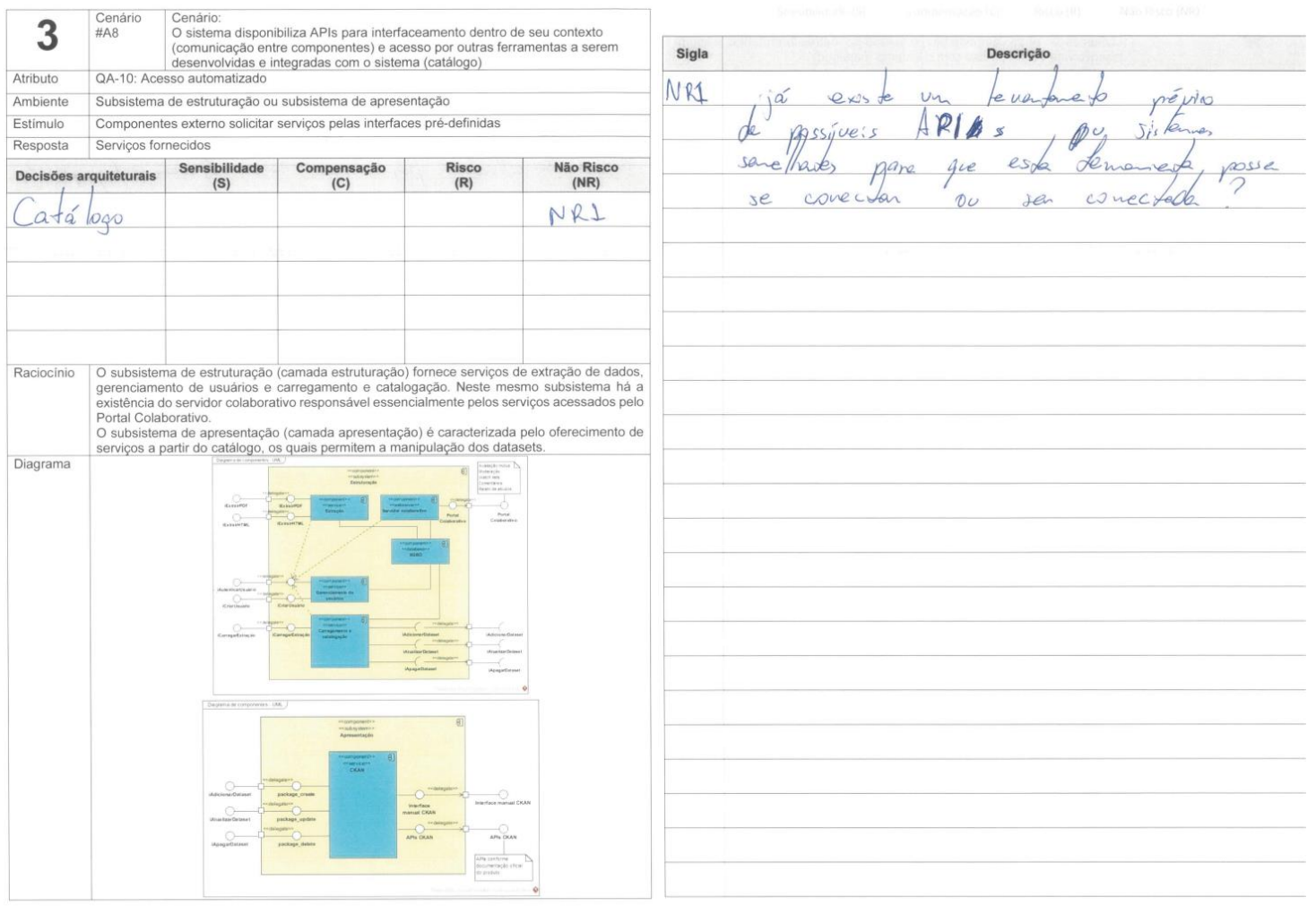


APÊNDICE D - Quadro comparativo de serviços, ferramentas e bibliotecas para extração de dados tabulares

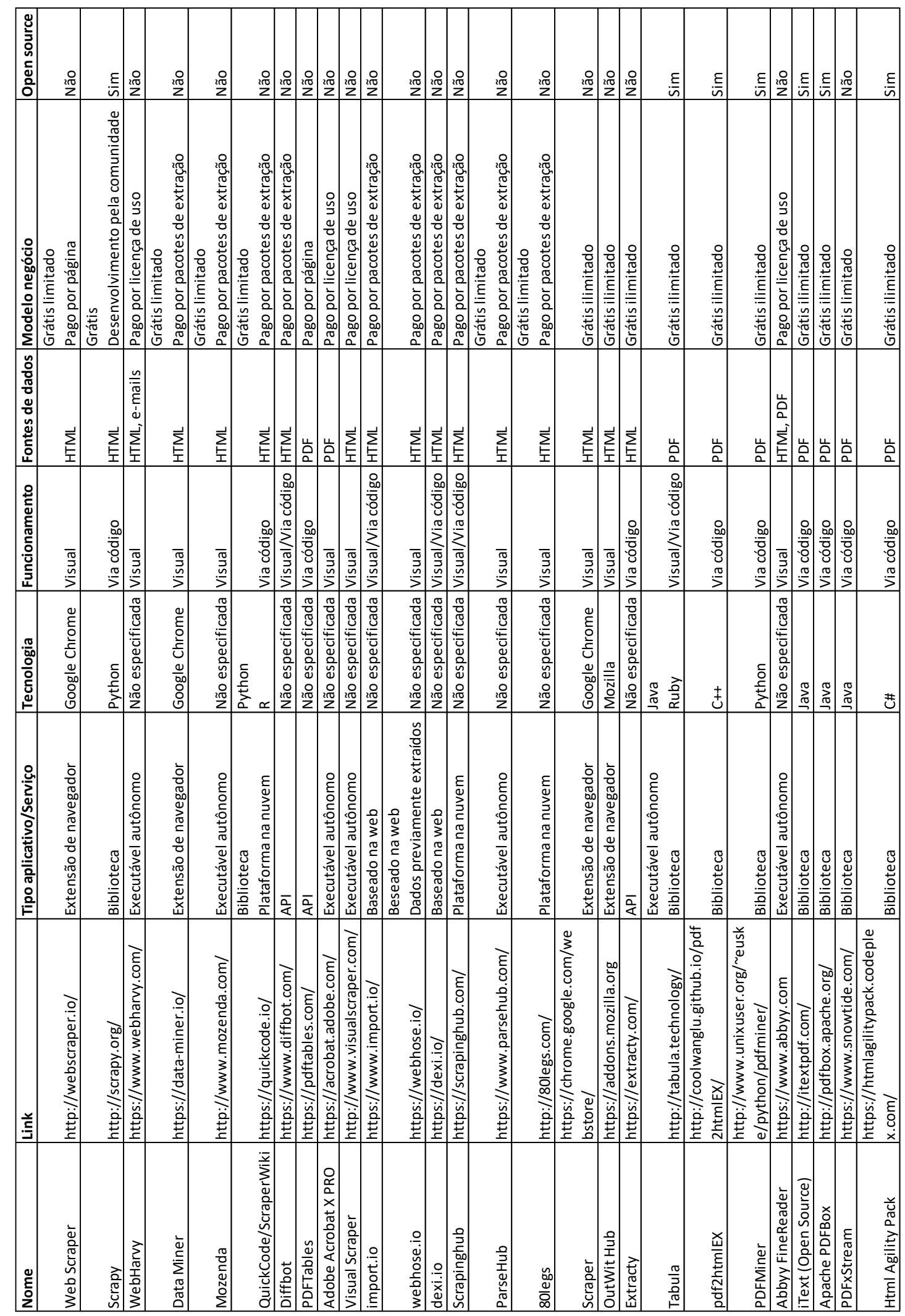

